\title{
PRODUTIVIDADE DO TRABALHO E DA TERRA \\ NA AGROPECUÁRIA PARANAENSE
}

\author{
EZIQUIEL GUERREIRO \\ Economista
}

Orientador: Prof. Dr. Rodolfo Hoffmann

\begin{abstract}
Dissertação apresentada à Escola Superior de Agricultura "Luiz de Queiroz", da Universidade de São Paulo, para obtenção do título de Mestre em Agronomia, Área de Concentração: Economia Agrária.
\end{abstract}

PIRACICABA

Estado de São Paulo - Brasil

Julho - 1995 
CATALOGAÇÃO NA PUBLICAÇÃO

DIVISÃO DE BIBLIOTECA E DOCUMENTAÇÃO - CAMPUS "LUIZ DE QUEIROZ"/USP

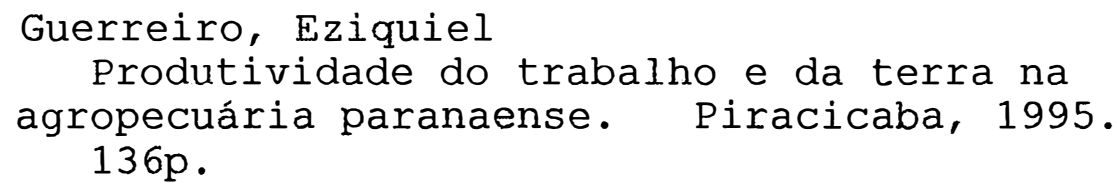

Diss. (Mestre) - ESALQ

Bibliografia.

1. Agropecuária - Produtividade - Paraná 2. Trabalho rural - Produtividade - Paraná I. Escola Superior de Agricultura Luiz de Queiroz, Piracicaba, SP. 


\title{
PRODUTIVIDADE DO TRABALHO E DA TERRA NA AGROPECUÁRIA PARANAENSE
}

\author{
EZIQUIEL GUERREIRO
}

Aprovada em: 04.09.1995

Comissão Julgadora:

Prof. Dr. Rodolfo Hoffmann

ESALQ/USP

Prof. Dr. José Vicente Caixeta Filho

ESALQ/USP

Prof. Dr. Shigeo Shiki

ESALQ/USP

Pof. Dr. Rodoltb Hoffmann

Orientador 
Aos meus pais, em reconhecimento ao sacrifício de me proporcionarem as oportunidades que não tiveram.

$$
\begin{array}{r}
\grave{\mathrm{A}} \\
\text { Juraci, } \\
\text { Leandro } \\
\text { e Francine } \\
\text { dedico. }
\end{array}
$$


AGRADECIMENTOS

Ao Prof. Rodolfo Hoffmann, pela orientação dada na realização deste trabalho.

Aos professores do curso de mestrado em Economia Agrária da ESALQ/USP, que contribuíram com a minha formação acadêmica.

Aos técnicos Inês Fumiko Ubukata Yada e José Gomes, pelas contribuições técnicas e orientação na utilização do software SAS.

A todos os colegas do curso de mestrado com os quais tive a oportunidade de conviver e trocar idéias.

Aos colegas de trabalho Roger de Souza Milléo, José Laskosk Neto, Nilcéa Macedo dos Santos e Sandra Cristina Araújo Vuitik, pela ajuda no processamento dos dados, arte gráfica e datilografia.

Aos funcionários do DESR/ESALQ, pelo auxílio que me forneceram durante esse período de mestrado.

Ao Instituto Agronômico do Paraná-IAPAR e à CAPES, pelo incentivo e apoio financeiro recebido.

A todas as pessoas e Instituições, cuja contribuição permitiu a realização desse trabalho. 


\section{SUMÁRIO}

Página

LISTA DE TABELAS ................... vi vi

LISTA DE FIGURAS....................

RESUMO......................... xi

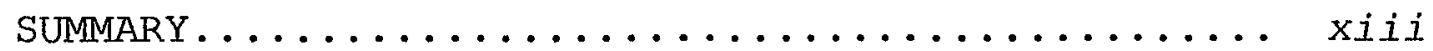

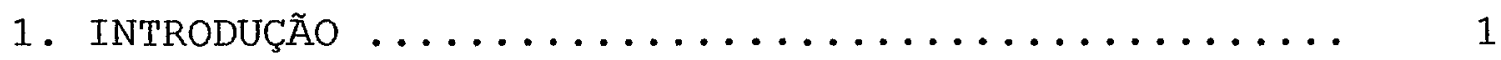

1.1 . Objetivos $\ldots \ldots \ldots \ldots \ldots \ldots \ldots \ldots \ldots \ldots \ldots \ldots$

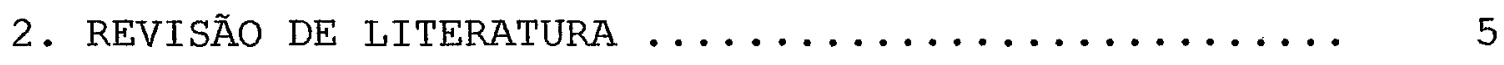

2.1. O interesse geral pela produtividade ....... 10

2.2. Aspectos metodológicos de cálculos da produ-

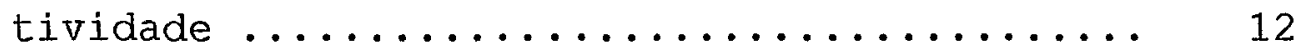

2.2.1. Produtividade do trabalho .......... 14

2.2.2. Produtividade da terra .......... 16

2.2.3. Modelos utilizados na análise da produtividade................... 17

2.3. Produção e produtividade da agropecuária bra-

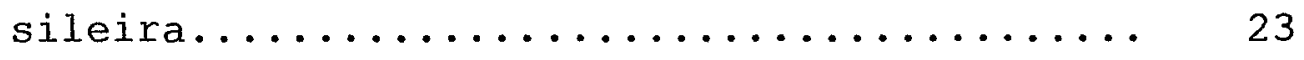

2.4. Produção e produtividade da agropecuária paranaense $\ldots \ldots \ldots \ldots \ldots \ldots \ldots \ldots \ldots \ldots \ldots \ldots \ldots$

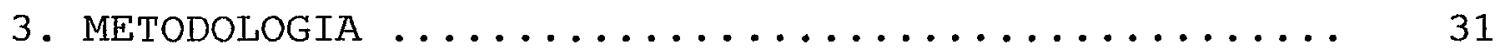

3.1. Valor agregado .................... 36

3.1.1. Valor bruto da produção .......... 36 
3.1.2. Consumo intermediário $\ldots \ldots \ldots \ldots \ldots .38$

3.1.3. Depreciação ................ 39

3.2. Pessoal ocupado na agricultura .......... 40

3.2.1. Empregados temporários para serviços eventuais ................... 40

3.2.2. Serviço de empreitada ........... 41

3.2.3. Força de trabalho em equivalentes -homem-ano.................. 41

3.3. Análise dos fatores que afetam as produtividades do trabalho e da terra ........... 43

3.3.1. Seleção das variáveis .......... 46

3.3.1.1. Relação dos fatores de produção utilizados na determinação das variáveis independentes.. 46

4. ANÁLISE dos RESULtados $\ldots \ldots \ldots \ldots \ldots \ldots \ldots \ldots \ldots \ldots \ldots \ldots \ldots$

4.1. Produtividade do trabalho e da terra por microrregião homogênea (MRH) e Estado do

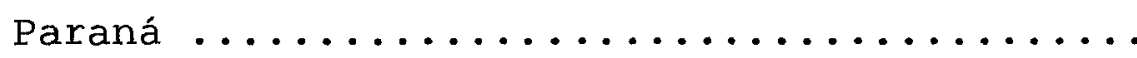

4.2. Produtividade do trabalho e da terra por conglomerado e Estado do Paraná............ 58

4.2.1. Análise de regressão............ 63

4.2.1.1. Análise das variáveis 70

4.2.1.2. Análise das unidades de estudo 73

4.2.1.2.1. Estado do Paraná.. 73

4.2.1.2.2. Conglomerado C01.. 75 
4.2.1.3.3. Conglomerado C02.. 77

4.2.1.3.4. Conglomerado C03.. 78

4.2.1.3.5. Conglomerado C04.. 79

4.2.1.3.6. Conglomerado C05.. 80

4.2.1.3.7. Conglomerado C06.. 81

4.2.1.3.8. Conglomerado C07.. . 83

4.2.1.3.9. Conglomerado C08.. 84

4.2.1.3.10. Conglomerado C09.. 85

4.2.1.3.11. Conglomerado C10.. 87

4.2.1.3.12. Conglomerado C11.. 88

4.2.1.3.13. Conglomerado C12.. 89

4.2.1.3.14. Conglomerado C13.. 90

4.2.1.3.15. Conglomerado C14.. 92

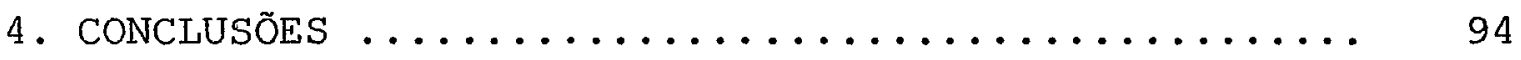

5. BIBLIOGRAFIA ........................ 98

Apêndice 1. Dados utilizados na determinação das produtividades do trabalho e da terra por município, $1985 \ldots \ldots \ldots \ldots \ldots \ldots \ldots$

Apêndice 2. Dados utilizados na determinação das produtividades do trabalho e da terra, por conglomerado e Estado do Paraná, 1985..... 116

Apêndice 3. Valores dos indicadores, não disponíveis no Censo Agropecuário, utilizados no cálculo das variáveis, por município e conglomerado, $1985 \ldots \ldots \ldots \ldots \ldots \ldots \ldots \ldots$ 
Apêndice 4. Resultados das regressões sobre as produtividades do trabalho e da terra, por Conglomerado e Estado do Paraná, 1985..... 131

Apêndice 5. Coeficientes de correlação de Pearson entre as variáveis utilizadas no modelo de $4.3 \ldots \ldots \ldots \ldots \ldots \ldots \ldots \ldots \ldots \ldots \ldots \ldots$ 
LISTA DE TABELAS

Pág.

Tabela 2.1. Taxas anuais de crescimento da produção agrícola, da produtividade da terra, da relação área/homem e da mão-de-obra, por Região e Brasil,

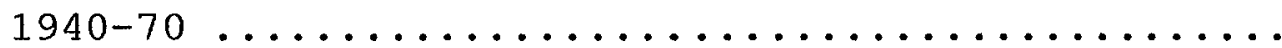

Tabela 2.2. Produtividade do trabalho e da terra (VA/EH e VA/AE), vem 1975 e 1980, por microrregião homogênea do Estado do Paraná ............... 3

Tabela 3.1. Principais características de cada conglomerado, Paraná, 1985................. 33

Tabela 4.1. Produtividade do trabalho e da terra, por microrregião homogênea e Estado do Paraná, 1975,1980 e $1985 \ldots \ldots \ldots \ldots \ldots \ldots \ldots \ldots \ldots \ldots \ldots \ldots$

Tabela 4.2 Produtividade do trabalho e da terra e outros indicadores sócio-econômicos, por conglomerado e Estado do Paraná, 1985 ................ 59

Tabela 4.3. Grau de homogeneidade da função de produÇão Cobb-Douglas, por conglomerado e Estado Paraná, 1985; e teste da hipótese de que os rendimentos de escala são constantes ............... 63

Tabela 4.4. Observações discrepantes, por conclomerado e Estado do Paraná, $1985 \ldots \ldots \ldots \ldots \ldots \ldots \ldots \ldots$ 
Tabela 4.5. Resultados das regressões do valor agregado (modelo 4.3), por conglomerado e Estado do

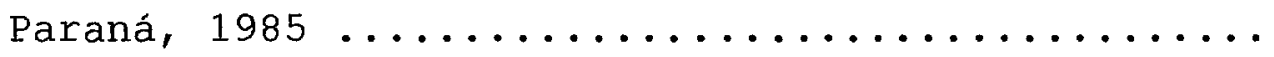

Tabela 4.6. Resultados das regressões do valor bruto de produção (modelo 4.4), por conglomerado e Estado do Paraná, $1985 \ldots \ldots \ldots \ldots \ldots \ldots \ldots \ldots \ldots$ 
LISTA DE EIGURAS

Pág.

Figura 3.1. Conglomerados do Estado do Paraná, 1985.. 32

Figura 4.1. Localização geográfica das microrregiões homogêneas do Estado do Paraná, 1985 ........... 52

Figura 4.2. Produtividade do trabalho (VA/EH), por microrregião homogênea e Estado do Paraná, 1985... 53 Figura 4.3. Variação da produtividade do trabalho (VA/EH), por microrregião homogênea e Estado

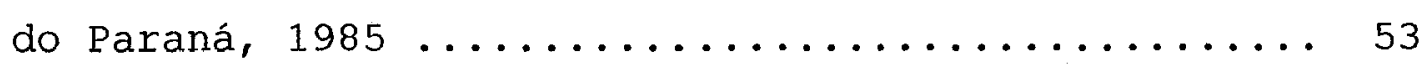

Figura 4.4. Produtividade da terra (VA/AE), por microrregião homogênea e Estado do Paraná, 1985... 55

Figura 4.5. Variação da produtividade da terra (VA/AE), por microrregião homogênea e Estado

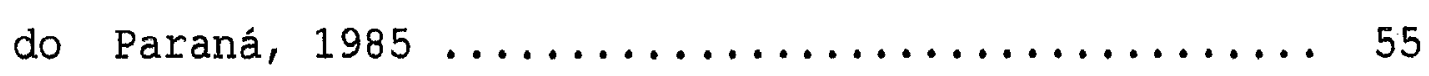

Figura 4.6. Produtividade do trabalho (VA/EH), por Conglomerado e Estado do Paraná, $1985 \ldots . . \ldots . . . .60$ Figura 4.7. Produtividade da terra (VA/AE), por Conglomerado e Estado do Paraná, $1985 \ldots . . \ldots \ldots$..... 60 Figura 4.8. Aptidão agrícola das terras do Estado

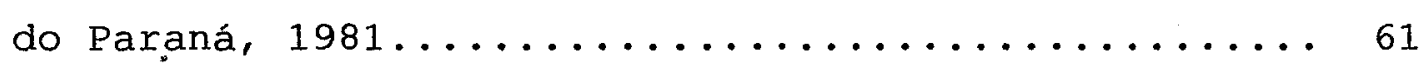


PRODUTIVIDADE DO TRABALHO E DA TERRA

NA AGROPECUÁRIA PARANAENSE

Autor: EZIQUIEL GUERREIRO

Orientador: Rodolfo Hoffmann

\section{RESUMO}

Com base nos dados do Censo Agropecuário de 1985, foram calculadas as produtividades médias do trabalho e da terra para o Estado do Paraná, nos seus 310 municípios, nas 24 microrregiões homogêneas (MRH) e nos 14 conglomerados estabelecidos pelo IAPAR. Através de modelos de regressão linear múltipla analisou-se a influência de "fatores de produção" no valor agregado (VA) e nas produtividades do trabalho (PL) e da terra (PT). Considerando o valor da PL em cada uma das 24 MRH do Estado em 1975, 1980 e 1985, verificou-se que nos dois quiinqüênios, a PL cresceu em quatro $\mathrm{MRH}$, embora tenha diminuido em quatro $M R H$ e no Estado como um todo. Contudo no último qüinquiênio essa produtividade decresceu em 15 MRH e no Estado. Naquele decênio a PT cresceu em três MRH, embora tenha diminuido em três MRH e no Estado. De 1980 a 
1985 a mesma cresceu no Estado e decresceu em treze MRH. As produtividades do trabalho e da terra variaram significativamente entre os conglomerados. Nos conglomerados com solos de melhor aptidão agrícola (C01 a C08) essas produtividades foram, em média, 1,54 e 2,79 vezes maiores do que as produtividades dos conglomerados com solos de menor aptidão agrícola (C09 a C14), respectivamente. Em termos monetários, não houve diferença da influência de cada "fator de produção" para o VA e para as produtividades. Entretanto, o efeito de cada "fator de produção" dependeu das características edafoclimáticas e sócio-econômicas de cada conglomerado. Um fator pode estar associado positivamente com $O$ VA ou as produtividades num conglomerado, negativamente em outro e vice-versa. Força de trabalho, qualidade da terra e área explorada foram os "fatores de produção" que mais influenciaram o VA e consequientemente as produtividades do trabalho e da terra. 
LABOR AND LAND PRODUCTIVITY IN THE

AGRICULTURE OF PARANÁ STATE, BRAZIL.

Author: EZIQUIEL GUERREIRO

Adviser: Prof. Rodolfo Hoffmann

SUMMARY

Average labor and land productivities were determined using data from the 1985 Agricultural Census, for the state of Paraná, in its 310 counties, in the 24 homogeneous microregions (MRH), and for the 14 counties conglomerates defined by IAPAR. Multiple linear regression models were applied to study the effect of the "production factors" on the aggregate value, as well as on the labor (PL) and land (PT) productivities. Concerning the PI value for each of the $24 \mathrm{MRH}$ in 1975, 1980 and 1985, it can be noticed that the PL increased in four MRH, although it has decreased in another four MRH and in the state as a whole. But for the last five years period, the PL decreased in fifteen $M R H$ and in the state it self. During that 10 years period the PT increased in three MRH, although it has decreased in another three MRH and in the whole state. 
From 1980 to 1985, it increased in the state and decreased in thirteen MRH. Land and labor productivities varied significantly among the conglomerates. In those conglomerates with the best soil aptness (C01 and C08) these productivities were, on average, 1.54 and 2.79 times higher than in the conglomerates with lower soil aptness (C09 a C14), respectively. There was no difference on the influence of each "production factor" on the aggregate value and productivities. However, the effect of each "production factor" depended on soil, climate and socioeconomic characteristics of each conglomerate. A factor may be positively associated with the aggregate value or the productivities in one conglomerate, negatively in another and vice-versa. Labor, land quality and area in use were the "production factors" that most affected the aggregate value and consequently both productivities. 


\section{INTRODUÇÃO}

Terra e trabalho são os recursos básicos da agricultura. A produtividade ${ }^{1}$ desses é fundamental para o desenvolvimento econômico dos estabelecimentos agrícolas e consequientemente dos municípios, estados e países. 0 incremento da produtividade do trabalho e da terra é um dos meios para se aumentar a produção do setor rural e possibilitar um padrão de vida melhor para a sua população.

A produtividade sempre fez parte das preocupą̧ões básicas de qualquer sociedade. Desde o surgimento das Ciências Econômicas no século XVIII, a mesma tem sido tema central das teorias econômicas.

O crescimento da produtividade no setor agrícola contribui para a expansão dos demais setores da economia, principalmente através da transferência de recursos produtivos (capital e mão-de-obra), da criação de mercado interno e da produção de matérias primas e alimentos para o setor industrial.

Quanto menos desenvolvida é uma nação, maior é a necessidade de se elevar a produtividade dos seus fatores de produção na agricultura. E essa é uma condição fundamental para o desenvolvimento. Kuznets, com base em

${ }^{1}$ Referimo-nos à produtividade de mais de um fator de produção; quando for tratada a produtividade parcial mencionaremos of fator a que se refere. 
estudos comparativos de desenvolvimento econômico, concluiu: "uma revolução agrícola - uma elevação marcante da produtividade por trabalhador na agricultura - é uma précondição da revolução industrial em qualquer parte do mundo" (NICHOLS, 1975, p.4).

A importância da produtividade dos fatores de produção será cada vez maior dentro da ciência econômica, pressionada pelo esgotamento dos recursos não renováveis, internacionalização dos mercados e formação de blocos econômicos em busca de um desenvolvimento mais rápido e maior competitividade externa. Como exemplo, a implementação do Mercado Comum do sul (Mercosul), formado inicialmente pelo Brasil, Argentina, Uruguai e Paraguai, traz preocupações ao setor rural do sul do Brasil, pois a competitividade também ocorre intra bloco e a agropecuária da 'Argentina tem sido mais competitiva na produção de leite, soja, trigo, milho, arroz, alho, cebola, maçã e pêssego (STULP, 1992 e LOPES, 1992).

Se o aumento da produtividade dos fatores de produção implica no desenvolvimento dos países, sua mensuração é necessária para se ter parâmetros de eficiência ou não do sistema analisado. Quanto mais eficiente for um sistema de produção, maior será a produtividade dos seus fatores.

Os índices de produtividade do trabalho e da terra servirão de base às análises do processo de desenvolvimento do setor rural. 
Para o Estado do Paraná, é importante estudar a produtividade dos fatores produtivos no setor rural, pois quase $50 \%$ da renda gerada no Estado provém de atividades direta e indiretamente ligadas à agropecuária (VOLACO, 1991). Também as características regionais ${ }^{2}$ quanto à qualidade do solo, clima, relevo, tamanho de estabelecimentos, combinação de explorações e tecnologia utilizada fazem desse um Estado com produtividades diferenciadas entre regiões.

Este trabalho subsidiará as organizações governamentais (OGS) e as não governamentais (ONGS), com dois indicadores fundamentais à discussão do processo de desenvolvimento da agropecuária paranaense. Cabe salientar seu caráter inédito, por determinar a produtividade da terra e do trabalho para todos os municípios paranaenses, com dados do Censo Agropecuário de 1985.

\subsection{Objetivos:}

o objetivo geral do trabalho diz respeito à mensuração da produtividade do trabalho e da terra no Estado do Paraná, nos seus 310 municipios, nas 24 microrregiões homogêneas (MRH) e nos 14 conglomerados estabelecidos pelo Instituto Agronômico do Paraná - IAPAR, com base em trabalho de regionalização da agricultura, no ano de $1985^{3}$.

Em termos mais específicos, pretende-se também:

${ }^{2}$ Descrição das caracteristicas regionais do Paraná é encontrada em : FUENTES LLANILLO (1984) e FUENTES LLANILLO at alii (1993).

${ }^{3}$ FUENTES LLANILLO et alii (1993). 
a) determinar as variáveis que influenciam a produtividade do trabalho e da terra, por município, conglomerado e Estado, no ano de 1985;

b) avaliar a influência de algumas variáveis sobre as produtividades do trabalho e da terra, no Estado do Paraná e nos 14 conglomerados, no ano de 1985;

C) explicar as variações das produtividades do trabalho e da terra entre os conglomerados; e

d) determinar as variações dessas produtividades no Estado e nas vinte e quatro $\mathrm{MRH}$, nos periodos 1975 a 1980 e 1980 a 1985 . 


\section{REVISÃO DE LITERATURA}

A teoria de crescimento econômico desenvolvida por Adam Smith fundamentou-se na divisão do trabalho, considerada como a base do aumento da produtividade do trabalho. SMITH (1776, ed. em português de 1985) dedicou o primeiro capítulo de "A Riqueza das Nações" para discutir como a divisão do trabalho permite aumentar sua produtividade.

Para Smith, o grande aumento de produtividade do trabalho proporcionado pela divisão do trabalho é devido à três circunstâncias distintas:

a) maior destreza do trabalhador;

b) eliminação da perda de tempo na alternância de atividades; e

c) invenção de máquinas que facilitam e abreviam o trabalho.

Smith também percebeu que havia diferenciação de produtividade entre países ricos e pobres e entre setores da economia, e que as possibilidades de crescimento da produtividade na agricultura eram distintas das do setor industrial, pois a agricultura é mais vulnerável aos fenômenos edafoclimáticos.

RICARDO (1817, ed. em português de 1982, pp.71-72) considerou dois tipos de melhoramentos na 
agricultura: os que aumentam a produtividade da terra (inovações químico-biológicas) e os que proporcionam maior produtividade do trabalho (inovações mecânicas). "As melhorias que aumentam a capacidade produtiva da terra são, por exemplo, a rotação mais eficiente das culturas ou a escolha mais cuidadosa dos fertilizantes. Tais melhoramentos permitem obter a mesma produção de uma extensão de terra menor... Existem, porém, aperfeiçoamentos que podem reduzir - valor relativo do produto sem reduzir a renda em trigo, embora diminuam a renda da terra em termos monetários. Tais aperfeiçoamentos não aumentam a capacidade produtiva da terra, mas permitem obter seu produto com menos trabalho. Estão mais relacionados com a formação do capital aplicado à terra do que ao cultivo propriamente dito. São dessa espécie os aperfeiçoamentos nos implementos agrícolas, tais como o arado e a debulhadora, a economia no uso de animais empregados na lavoura e um melhor conhecimento da arte veterinária".

MARX (1867, ed. em português de 1968), em continuidade aos trabalhos iniciados pelos clássicos sobre a teoria do valor-trabalho de uma mercadoria, analisou a influência da produtividade do trabalho sobre a produção, o valor, o valor da força de trabalho, a mais valia e a acumulação de capital. Discutiu também os métodos para aumentá-la, tais como: aperfeiçoamento das ferramentas e das máquinas e a jornada de trabalho coletiva. Em resumo, Marx analisou a produtividade do trabalho, abordando seus 
aspectos sócio-politicos e econômicos, tecnológicos e a influência dos fenômenos naturais, pois para ele "a produtividade do trabalho é determinada pelas mais diversas circunstâncias, entre elas a destreza média dos trabalhadores, o grau de desenvolvimento da ciência e sua aplicação tecnológica, a organização social do processo de trabalho, o volume e a eficácia dos meios de produção, e as condições naturais" (MARX, 1968, pp. 46-47).

Para Marx, à medida que a produtividade do trabalho aumenta, o tempo necessário à produção ide uma mercadoria diminui e consequientemente diminui o seu valor por unidade. Então, se ocorrer aumento de produtividade nos ramos industriais cujos produtos pertencem ao conjunto dos meios de subsistência dos trabalhadores, o valor da força de trabalho decresce. Se a jornada de trabalho não diminuir, a mais valia do capitalista aumenta, pois o tempo de trabalho excedente aumentou. Enquanto o valor das mercadorias e o da força de trabalho varia na razão inversa, a mais valia relativa varia na razão direta da produtividade do trabalho. Com isso o capitalista moderno se apropria de mais trabalho excedente que o capitalista tradicional. (MARX, 1968, p. 367) . Marx entendia que a elevação da produtividade do trabalho só era possível pelas transformações técnicas e sociais do processo de trabalho (inovações mecânicas, divisão do trabalho, jornada de trabalho coletiva, virtuosidade do trabalhador $e$ menos ociosidade das instalações), permitindo com o mesmo tempo de 
trabalho. social produzir maior valor de uso (MARX, 1968, pp. 378, 391-392, 442).

Marx não tinha dúvidas de que a produtividade do trabalho na indústria moderna se elevaria extraordinariamente, em função da incorporação das forças naturais e da ciência no processo de produção. O que não estava claro, era se essa produtividade não seria obtida às custas de maior dispêndio do trabalho, já que capital é trabalho acumulado no passado e não gera valor, mas transfere seu valor para o produto final. O uso de maquinaria seria viável desde que a quantidade de trabalho utilizada na sua produção fosse menor que a quantidade que ela poderia substituir. (MARX, 1968, pp. 441, 447).

Marx considerou a maquinaria o meio mais poderoso para aumentar a produtividade do trabalho, e o mais potente para prolongar a jornada de trabalho. "De poderoso meio de substituir trabalho e trabalhadores, a maquinaria transformou-se imediatamente em meio de aumentar o número de assalariados, colocando todos os membros da família do trabalhador, sem distinção de sexo, sob o domínio direto do capital" (MARX, 1968, pp. 450, 459).

"Quanto mais cresce a produtividade do trabalho, tanto mais pode reduzir-se a jornada de trabalho, e quanto mais se reduz a jornada, tanto mais pode aumentar a intensidade do trabalho... Dadas a intensidade e a produtividade, o tempo que a sociedade tem de empregar na produção material será tanto menor, e, em consequiência, tanto maior o tempo conquistado para a atividade livre, 
espiritual e social dos indivíduos". O aumento da produtividade do trabalho implica em mudança na composição técnica do capital; enquanto o capital constante varia na razão direta da produtividade do trabalho, o capital variável varia na razão inversa. (MARX, 1968, pp. 606-607, 723-725) .

HAYAMI e RUTTAN (1971, ed. em português de 1988) também fizeram uma discussão detalhada sobre tecnologia e produtividade agrícola. Enquanto, a produtividade do trabalho é determinada por inovações mecânicas, a produtividade da terra é determinada predominantemente por inovações químico-biológicas. Aquelas envolvem a substituição de mão-de-obra por terra, porque a produtividade mais elevada do trabalho, através da mecanização, exige, geralmente, o cultivo de uma área de terra maior por trabalhador, e estas facilitam a substituição de terra por mão-de-obra e/ou insumos industriais, devido às novas exigências de manejo e conservação de solo e às novas práticas culturais. Não obstante, há tecnologias químico-biológicas que proporcionam maior produtividade do trabalho e tecnologias mecânicas que elevam a produtividade da terra. O uso de herbicidas, por exemplo, substitui a capina manual no controle de ervas daninhas, com maior rendimento da mão-de-obra por unidade de tempo; analogamente, o uso de semeadoras eleva o rendimento por unidade de área pelo espaçamento uniforme que proporciona entre as plantas.

HAYAMI e RUTTAN (1975), analisando a produtividade agrícola no Japão e nos Estados Unidos, 
confirmaram a hipótese de que o crescimento rápido da produtividade e da produção agrícola depende de uma grande adaptação da tecnologia agrícola às contrastantes proporções dos fatores nos dois países. Verificaram que no Japão, onde - fator terra era mais escasso, a produtividade da terra aumenta mais rapidamente, e nos Estados Unidos, onde esse fator era mais abundante, a produtividade do trabalho cresce com maior rapidez. Enquanto no Japão $\circ$ incremento da produtividade proporcionado por inovações químico-biológicas data de 1880, nos Estados Unidos o crescimento da produtividade se deu a partir de 1930, com o uso de inovações mecânicas e inovações químico-biológicas. Até então, nos Estados Unidos, o uso de inovações mecânicas não tinha sido eficiente para elevar a produtividade, devido ao elevado estágio de degradação dos solos. Concluíram que os preços relativos, decorrentes da escassez ou abundância de fatores, determinam a geração das soluções (pesquisas para economizar o fator escasso).

Kuznets, citado por HAYAMI e RUTTAN (1988), considera que o crescimento contínuo da produtividade e da renda per capita advém da aplicação sistemática do conhecimento científico à atividade econômica.

\subsection{O interesse geral pela produtividade}

Apesar de Adam Smith ter discutido a produtividade do trabalho na produção de alfinetes em 1776, dos vários exemplos desse tipo de produtividade citados por 
Marx em 1867, e da agência do governo norte americano, Bureau of Labor (hoje Bureau of Labor statistics) ter iniciado trabalhos com medidas de produtividade em 1899, o interesse mais geral pela produtividade só ocorreu após a Segunda Guerra Mundial, em função da necessidade de se reconstruir os países destruídos pela Guerra. Foi no final da década de quarenta e início da década de cinquienta que surgiram instituições em prol da produtividade na GrãBretanha, França, Holanda, Bélgica, Áustria, Itália e Brasil. E foi nas décadas de cinqüenta e sessenta que apareceram novos avanços teóricos para cálculos da produtividade, através do conceito neoclássico de função de produção (FONTES, 1966 e MOREIRA, 1990).

Com os elevados ganhos de produtividade no Japão e na Alemanha Ocidental e o crescimento mais lento da produtividade americana, aumenta extraordinariamente o interesse pela produtividade.

Em 1952, instalou-se provisoriamente no Brasil um escritório técnico de produtividade, pois o Brasil tinha assinado um acordo de cooperação técnica com os Estados Unidos, com a finalidade de elevar a produtividade do setor industrial. Como a execução desse acordo dependia da aprovação do Congresso Nacional, o que por motivos políticos não aconteceu, o escritório foi fechado em 1953. O Governo Brasileiro reconsiderou o assunto em 1956 e instalou no Ministério do Trabalho uma Comissão Nacional de Produtividade, mas não se fez nada. Desde então, a questão da produtividade passou a ser considerada principalmente 
pela Federação das Indústrias do Estado de São Paulo, o Instituto de Organização Racional do Trabalho (IDORT) e o Instituto de Ciências Sociais da Universidade do Brasil (MACHADO, 1964) e os trabalhos acadêmicos. Em novembro de 1990, o governo brasileiro retomou a discussão sobre a produtividade e lançou o Programa Brasileiro da Qualidade e Produtividade ( $\mathrm{PBQP}$ ), com o objetivo de apoiar o esforço brasileiro de modernização através da promoção da qualidade e da produtividade, visando aumentar a competitividade de bens e serviços produzidos no país.

\subsection{Aspectos metodológicos de cálculos da produtividade}

Conforme FORASTIÉ (1961, p. 58), a Organização Européia de Cooperação Econômica (OECE) publicou em 1950 a seguinte definição de produtividade: "a produtividade é o quociente de uma produção por um dos fatores de produção". Essa é uma definição técnica ou física de produtividade, a única aceita pela OECE naquela época, porque considerava essa noção de produtividade suficientemente rica e porque medidas cujo numerador era expresso em valor monetário conduziam a confusões graves, conforme as descritas na obra The Conditions of Economic Progress.

As medidas de produtividade passaram a ser discutidas com maior profundidade a partir da conferência sobre renda e riqueza, promovida pelo National Bureau of Economics Research, em 1961. Nessa conferência, a produtividade foi definida como a razão entre a produção e 
as despesas com os recursos utilizados no processo produtivo, em termos reais (KENDRICK, 1961 p. 4).

o conceito de produtividade média já era utilizado pelo Serviço de Pesquisa Econômica do Departamento de Agricultura dos Estados Unidos (ERS-USDA), que o definia como medida de eficiência na qual as despesas com recursos produtivos são convertidas em bens e serviços. Semelhantemente ao resultado da conferência, a produtividade (produção média por unidade de recurso) resulta da divisão da produção total pelo total de recursos usados (BARRANDA, 1970) .

O mais adequado seria medir produtividade em termos físicos, isto é, a quantidade produzida por unidade de recurso utilizado. Mas devido ao caráter heterogêneo da produção agropecuária, mensurar a produtividade dessa forma é complexo. Usa-se, então, uma medida comum de valor real, calculando o valor monetário da produção.

Como a produtividade está associada à eficiência de um processo produtivo, ela serve para comparar diferentes sistemas produtivos em um dado instante de tempo (estudos cross-section) e analisar a dinâmica evolutiva de um mesmo sistema ao longo do tempo (estudos de séries temporais). Mas pouco significa qualquer medida isolada de produtividade, fora de um quadro comparativo (Kendrick e Fabricant, citados por MOREIRA, 1990, p. 32).

A produtividade pode ser mensurada de duas formas: produtividade marginal e produtividade média do 
fator, e em qualquer nível de agregação da economia lao nível de país, estado, município, setor, sub-setor, empresa e atividade) e dimensão dos fatores (global ou múltipla e parcial). Diz-se produtividade parcial quando a produção é referida a um fator de produção e produtividade total ou múltipla quando se considera mais de um fator de produção.

\subsubsection{Produtividade do trabalho}

A OECE, em 1950, definiu produtividade do trabalho em termos físicos como o quociente da produção pelo tempo de trabalho empregado na produção. FORASTIÉ (1961, p. 62), alèm da produtividade em termos físicos, considerou também a medida de produtividade do trabalho em termos monetários, chamada por ele de produtividade líquida do trabalho e definida como a relação entre o produto líquido (valor bruto da produção menos as despesas com os demais fatores de produção) e a quantidade de trabalho visível dispendida no ciclo de produção. Essa definição não satisfaz, mas procura contornar o que Marx discutiu no século passado sobre a produtividade do trabalho. Para Marx "o valor de uma mercadoria não é determinado apenas pela quantidade de trabalho que the dá a última forma, mas também pela quantidade de trabalho contida em seus meios de produção. O valor de uma bota por exemplo, não é determinado apenas pelo trabalho do sapateiro, mas também pelo valor do couro, da cera, dos fios, etc" (MARX, 1968 pp. 46 e 363). O valor de uma mercadoria é relacionado inversamente à produtividade do trabalho. Para determinar essa 
produtividade seria necessário, portanto, considerar o trabalho incorporado em todo o processo de produção, conforme demonstrado por Piero sraffa através do método de "redução a quantidades de trabalho datadas" (SRAFFA, 1960, ed. em português de 1983, p. 203).

HOFFMANN e JAMAS (1990) reconhecem que além do trabalho diretamente empregado no processo de produção de certa mercadoria deve-se também considerar o trabalho empregado na produção dos insumos e instrumentos utilizados, e também o trabalho necessário à produção dos insumos utilizados na produção dos insumos, e assim por diante ${ }^{2}$. Mas dada a dificuldade para se determinar a quantidade de trabalho indireto necessário à produção de uma mercadoria, recorreram ao conceito de valor agregado, subtraindo do valor bruto da produção o valor de todos os insumos utilizados e a depreciação das instalações e equipamentos utilizados no processo de produção. Assim, uma medida de produtividade do trabalho que pode ser utilizada é a razão entre o valor agregado e a quantidade de trabalho diretamente empregado na produção.

o valor agregado está sujeito às influências de fatores climáticos, econômicos e políticos. Então a produtividade do trabalho pode ser elevada simplesmente

\footnotetext{
I"Redução a quantidades de trabalho datadas" é "uma operação mediante a qual, na equação de uma mercadoria, os diferentes meios de produção utilizados são substituídos por uma série de quantidades de trabalho, cada uma das quais com sua "data" adequada" (SRAFFA, 1983 p. 203).

${ }^{2}$ Ver SRAFFA (1983) e HOFFMAN e JAMAS (1990) para melhor entendimento sobre o trabalho direto e indiretamente empregado na produção.
} 
ampliando o diferencial entre preços e custos (poder de mercado), indicando uma variação nos lucros e não necessariamente variação na produtividade física do trabalho (KAGEYAMA, 1986), ou pela elevação do preço de certo produto nacional causada pela quebra de safra do mesmo tipo de produto no exterior, ou ainda por medidas de política econômica que proporcionem maior demanda seguida de elevação nos preços de venda, como ocorreu no Plano Cruzado, sem alterar custos. Mesmo assim, o valor agregado por equivalente-homem (EH) parece ser a melhor medida de produtividade do trabalho que pode ser obtida com os dados usualmente disponíveis (HOFFMANN e JAMAS, 1990).

\subsubsection{Produtividade da terra}

A produtividade da terra determinada pela relação entre o valor bruto da produção (VBP) e a área explorada não é uma boa medida de produtividade, pois um aumento do VBP igual ao acréscimo nos custos dos insumos, corresponde a aumentar a produtividade bruta da terra, mas não há crescimento da produtividade em termos de valor agregado (HOFFMANN e JAMAS, 1990). É importante trabalhar em termos de valor agregado, visto que a partir dos anos sessenta o uso de insumos agrícolas se elevou bastante e o maior ou menor custo destes pode dar uma idéia distorcida de variações na produtividade. Se acréscimos no uso de insumos tiverem custos superiores às variações positivas no VBP, o valor agregado diminuirá e conseqüentemente a produtividade também. 


\subsubsection{Modelos utilizados na análise da produtividade}

BARRANDA (1970) considerou a produtividade média do trabalho - PML (VBP/EH $\left.{ }^{3}\right)$ como função das variáveis mão-de-obra, total do ativo (terra, construções, criações e máquinas e equipamentos), despesas operacionais, idade, escolaridade, nível tecnológico, localização geográfica, valor do rebanho por equivalente-homem (EH), máquinas e equipamentos por $\mathrm{EH}$ e área cultivada por $\mathrm{EH}$, e a produtividade média da terra - PMT (VBP/área cultivada) como função das variáveis mão-de-obra total, área total, idade, escolaridade, nível tecnológico, localização geográfica, EH por hectare, máquinas e equipamentos por hectare e despesas operacionais por hectare.

Através do teste $t$ dos coeficientes de regressão do modelo estatístico (2.1), usado para a análise da PML e PMT, BARRANDA (1970) identificou os fatores que estavam significativamente associados com as variações dessas produtividades.

$$
Y=\alpha+\beta_{1} X_{1}+\beta_{2} X_{2}+\ldots+\beta_{n} X_{n}+U_{t}
$$

DELFIM NETO, PASTORE e CARVALHO (1965); BARROS, PASTORE, RIZZIERE (1977) e ARAÚJO et alii (1986) utilizaram a técnica de decomposição da taxa anual de

\footnotetext{
${ }^{3} \mathrm{Na}$ tranformação do número de pessoas ocupadas em equivalente-homem, Barranda utilizou o seguinte critério: $1 \mathrm{EH}=300$ dias de
} trabalho produtivo; 1 mulher $=0,5 \mathrm{EH}$ e cri an ça s = várias frações de $1 \mathrm{EH}$ dependendo da idade. 
crescimento da produção física em três componentes: as taxas de crescimento da produtividade física da terra, da área cultivada por homem e da mão-de-obra rural, através do modelo matemático:

$$
Y=(Y / A) \times(A / N) \times N
$$

onde:

$\mathrm{Y}=$ produção agrícola;

$\mathrm{Y} / \mathrm{A}=$ pródutividade da terra;

$\mathrm{A} / \mathrm{N}=$ relação área cultivada por homem;

$\mathrm{N}$ = quantidade de trabalho ocupada na produção agrícola.

Tomando-se o logaritmo neperiano da equação

(2.2), e derivando a expressão resultante em relação ao tempo, tem-se a seguinte equação, válida para variações infinitesimais:

$(\Delta \mathrm{Y}) / \mathrm{Y}=[\Delta(\mathrm{Y} / \mathrm{A})] /(\mathrm{Y} / \mathrm{A})+[\Delta(\mathrm{A} / \mathrm{N})] /(\mathrm{A} / \mathrm{N})+(\Delta \mathrm{N}) / \mathrm{N}$

Através da equação (2.3) é possível decompor - crescimento da produção agrícola $[(\Delta Y) / Y]$ em três componentes básicos: taxa de variação da produtividade da terra $[\Delta(\mathrm{Y} / \mathrm{A})] /(\mathrm{Y} / \mathrm{A})$, taxa de variação da relação área/homem $\{[\Delta(A / N)] /(A / N)\}$ e taxa de variação da mão-de-obra empregada na agropecuária $[(\Delta \mathrm{N}) / \mathrm{N}]$.

Outra forma de analisar a equação (2.2) é a de transferir o fator trabalho (N) para o primeiro membro da equação, como segue: 


$$
Y / N=(Y / A) \times(A / N)
$$

obtendo assim, as fontes de variação da produtividade do trabalho $(\mathrm{Y} / \mathrm{N})$. Ou seja, a soma das taxas de variação da produtividade da terra e da relação área/homem fornece a taxa de variação da produtividade do trabalho:

$$
[\Delta(\mathrm{Y} / \mathrm{N})] /(\mathrm{Y} / \mathrm{N})=[\Delta(\mathrm{Y} / \mathrm{A})] /(\mathrm{Y} / \mathrm{A})+[\Delta(\mathrm{A} / \mathrm{N})] /(\mathrm{A} / \mathrm{N})
$$

BARROS, PASTORE e RIZZIERE (1977) analisaram - comportamento do crescimento da produção e da produtividade agrícola, em três níveis de agregação (grupos de produtos, regiões e para o País), ampliando para o período 1940-70 o estudo já realizado por DELFIM NETO; PASTORE; CARVALHO (1965). Construíram índices de produção, com dados do FIBGE e IEA, pelo critério de Laspeyres com base móvel e encadeados, para capturar corretamente a introdução de novos produtos na evolução da quantidade produzida.

$$
\text { - trabalho de ARAÚJO et alii }
$$

determinou as taxas anuais de crescimento da produção agrícola, da produtividade da terra, da relação área/homem e do fator trabalho, por região e para o Brasil, no período 1970 a 1980. O fator trabalho foi estimado com os dados da PEA agrícola (pessoas economicamente ativas no setor agropecuário) e a produção pelo índice de valor da produção (IVP) : 


$$
I V P=\frac{\sum_{j} q_{i j} \times p_{i j}}{\sum_{j} q_{o j} \times p_{o j}}
$$

onde:

- $j=1,2,3, \ldots, 15$, representa os 15 produtos mais importantes em termos de valor da produção agrícola (VPA);

- $q_{o j}$ e $q_{i j}=$ produções do bem $j$ no ano base (1970) e no ano i (1980), respectivamente;

- $p_{o j}$ e $p_{i j}=$ preços reais ao nível de 1980 (deflacionados pelo IGP-DI), do produto $j$ no ano base e no ano $i$, respectivamente.

- valor da produção agrícola (VPA) foi decomposto de acordo com o modelo: $\mathrm{VPA}=\mathrm{P} \times \mathrm{Y}=(\mathrm{P} \times \mathrm{Y}) / \mathrm{A} \times \mathrm{A} / \mathrm{N}$ $\times \mathrm{N}$, em que: $\mathrm{Y}=$ produção agrícola; $\mathrm{P}=$ preço; $\mathrm{A}=$ área; $\mathrm{e} N$ = quantidade de homens no campo. Estes autores ressaltam que "uma vez determinadas as taxas de crescimento do valor da produção, do valor da produtividade parcial da terra, da relação área/homem e da quantidade de homens, há que se adicionar/subtrair a influência do efeito-preço nas taxas de crescimento do valor da produção e do valor da produtividade da terra para estimar as taxas de crescimento físico dessas variáveis".

$$
\text { AGUIRRE e BACHA (1989) decompuseram o }
$$

produto pela seguinte identidade: 


$$
V=P \times(Q / N) \times(N / A) \times A
$$

onde:

$\mathrm{V}=\mathrm{valor}$ do produto agropecuário $(\mathrm{V}=\mathrm{P} \times \mathrm{Q})$;

$\mathrm{P}=$ preço;

$Q$ = quantidade física do produto agropecuário;

$A=$ área;

$\mathrm{N}=$ quantidade de mão-de-obra;

Tomando o logaritmo neperiano da expressão (2.7) e derivando a expressão resultante em relação ao tempo, tem-se a seguinte expressão válida para variações infinitesimais:

$(\Delta \mathrm{V}) / \mathrm{V}=(\Delta \mathrm{P}) / \mathrm{P}+[\Delta(\mathrm{Q} / \mathrm{N})] /(\mathrm{Q} / \mathrm{N})+[\Delta(\mathrm{N} / \mathrm{A})] /(\mathrm{N} / \mathrm{A})+(\Delta \mathrm{A}) / \mathrm{A}$

Para aplicar a expressão (2.8) na agropecuária brasileira, os autores definiram as variáveis como sendo:

$\mathrm{V}=$ produto interno bruto da agropecuária a custo de fatores, deflacionado pelo deflator implícito do produto nacional (base $1977=100$ );

$\mathrm{P}=$ indice de preços recebidos pela agropecuária, deflacionado conforme item anterior;

$Q=$ produto físico da agropecuária;

$\mathrm{N}=$ total de mão-de-obra ocupada na agropecuária segundo os Censos Agropecuários; 
$A=$ área total explorada, definida como a soma da área utilizada com lavouras (permanentes, temporárias e em descanso para a lavoura), com pastagens (naturais e plantadas) e com matas e florestas plantadas.

VICENTE (1989), com dados dos Censos Agropecuários, Fundação Getúlio Vargas, Instituto de Economia Agrícola e outras fontes, ajustou modelos por mínimos quadrados ordinários para verificar a influência da educação, pesquisa e assistência técnica na produtividade da agricultura brasileira, por região fisiográfica e para o Brasil, no período de 1970-80. As produtividades totais e parciais da terra e do trabalho foram obtidas pelo quociente de índices Fisher encadeados de produção por índices Fisher encadeados do uso dos fatores terra, trabalho, fertilizantes, máquinas e investimentos em culturas perenes. Considerou como variáveis explicativas o número de produtores assistidos pelos serviços de extensão rural, número de artigos científicos publicados referentes à tecnologia agrícola, uma medida de aptidão das terras e, como variáveis representativas de adversidades climáticas, deficiência hídrica e geada.

A maioria dos modelos acima procurou analisar a evolução da produção agrícola em função do aumento ou da diminuição dos indices de produtividade parcial dos fatores terra e mão-de-obra (fatores determinantes do crescimento do produto) 


\subsection{Produção e produtividade da agropecuária brasileira}

o estudo sobre crescimento da produção agrícola brasileira, para o período 1950-60, realizado por DELFIM NETO; PASTORE e CARVALHO (1965), pelo método da decomposição da produção, evidenciou que a variação anual da produtividade da terra $(1,41 \%)$ foi função da incorporação de áreas mais nobres, da aplicação de técnicas mais refinadas e da aplicação de pesquisas genéticas à produção. A variação da produtividade do trabalho $(0,34 \%)$ estava mais relacionada com a mecanização da agricultura.

BARRANDA (1970) mediu o nível de produtividade da terra e do trabalho em seis municípios do sul do Brasil e verificou que o mesmo varia bastante entre os tipos de estabelecimentos e é influenciado pelos fatores tamanho da área, intensidade de uso dos recursos, nível tecnológico e localização geográfica. Com exceção das variáveis área total, da mão-de-obra e do ativo, os demais fatores estatisticamente significativos (despesas operacionais, nível tecnológico, máquinas e equipamentos por $\mathrm{EH}$, valor do rebanho por $\mathrm{EH}$ e a área cultivada por $\mathrm{EH}$ ) estavam associados positivamente às produtividades do trabalho e da terra. Escolaridade e idade foram inconclusivas.

Conforme BARROS; PASTORE e RIZZIERE (1977) e ARAÚJo et alii (1986), de 1955 em diante houve um incremento na contribuição da produção por unidade de área e do crescimento da relação área/homem (esta a partir de 1960). Apesar do aumento das produtividades da terra e do trabalho, 
estas permaneciam aquém das produtividades obtidas por países mais desenvolvidos.

Os resultados da Tabela 2.1 foram influenciados por fatores diversos de região para região:

a) no Nordeste as variações dos índices (produção por área, relação área por homem, mão-de-obra rural e produção) se deram de forma extensiva, influenciada pelo meio físico adverso, falta de novos conhecimentos, aumento do número de tratores após 1950 e diminuição da mãode-obra a partir de 1960;

b) no Centro-Sul, o crescimento da produção ocorreu de forma intensiva em função das variações nas produtividades do trabalho e da terra. Estas foram influenciadas pelas geadas do período de 1950-55, incorporação de terras mais férteis, ação da pesquisa, da extensão rural e da motomecanização;

c) em São Paulo a terra já se configurava como fator escasso de produção e o crescimento da produção esteve mais em função do uso de tecnologias poupadoras de terra e de mão-de-obra;

d) para o conjunto do pais, constataram taxas anuais de crescimento da produção de $3,11 \%$ na década de 40 e entre 5\% e 6\% nas décadas de 50, 60 e 70, sendo que - desenvolvimento do subconjunto de produtos industrializáveis e de alimentos foi maior que o dos produtos exportáveis. É a partir de 1955 que se verifica um 
Tabela 2.1. Taxas anuais de crescimento da produção agrícola, da produtividade da terra, da relação área/homem e da mão-de-obra, por Região e Brasil, 1940-70

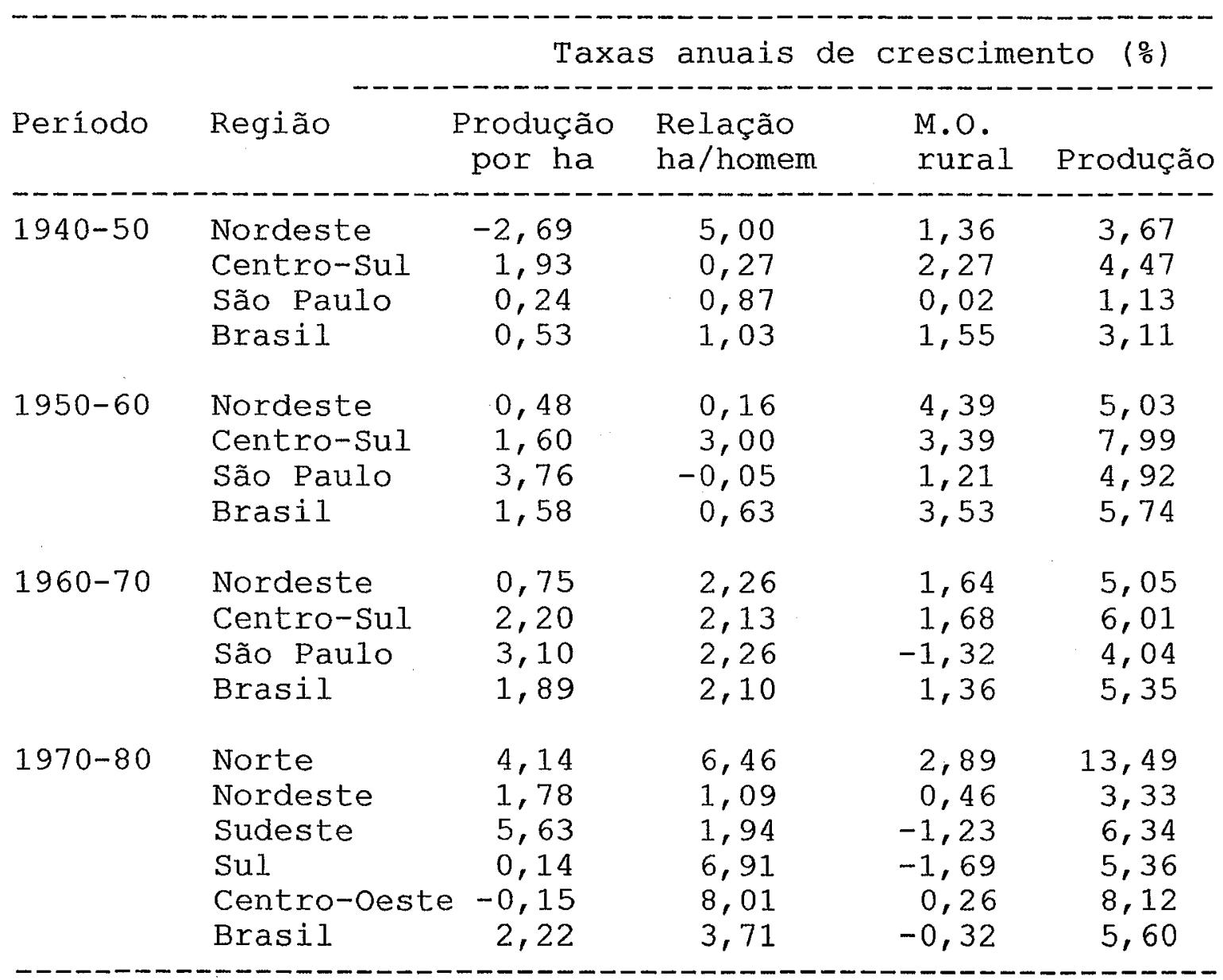

Fonte: BARROS et alii (1977) e ARAÚJO et alii (1986)

Nota: Centro-Sul - Mato Grosso, Goiás e Minas Gerais

Sudeste - Minas Gerais, Espirito Santo, Rio de Janeiro e São Paulo

incremento maior da produtividade na produção agrícola. A produção por unidade de área teve uma crescimento médio anual de $0,53 \%, 1,58 \%, 1,89 \%$ e 2,22\% e a relação área/homem $1,03 \%, 0,63 \%, 2,10 \%$ e 3,71\%, nas décadas de 40, 50, 60, 70, respectivamente. 
Concluíram que 0 aumento da produtividade se deu em função do crescimento industrial e modificações alocativas (insumos e produtos) no setor rural.

SILVA (1982), em estudo sobre a evolução e determinantes da produtividade agrícola, analisou o caso da pesquisa e da extensão rural no estado de são Paulo e constatou que os ganhos de produtividade estão diretamente relacionados aos investimentos públicos em pesquisa, mas o efeito da extensão rural não pode ser captado.

Após a década de 70, mesmo com um processo de modernização menos intensivo no uso de insumos e maquinaria e com menor expansão de área (devido à crise econômica e ao esgotamento da fronteira agrícola), a produção agrícola continuou crescendo.

Para AGUIRRE E BACHA (1989) as causas da elevação da produtividade do trabalho, a taxas geométricas anuais médias decrescentes $(3,52 \%$ de 1970 a $75,1,05 \%$ de 1975 a 80 e 1,06\% de 1980 a 85), na década de 70, estiveram relacionadas à melhoria nos meios de transporte, incorporação de terras virgens e maior uso de insumos modernos e máquinas, e na década de 80 essas taxas estiveram associadas às mudanças nas características dos bens de capital e maior eficiência no uso dos fatores de produção.

VICENTE (1989) analisou o comportamento das produtividades parciais da terra, do trabalho, dos fertilizantes, das máquinas e das culturaśs perenes, para o 
Brasil e por região fisiográfica, no período 1970-80. Nesse período, mesmo com uma redução de $33 \%$ e $54 \%$ na produtividade dos fertilizantes e das máquinas, respectivamente, a produtividade total dos fatores da agricultura brasileira cresceu 31\%, a produtividade da terra 25\%, a produtividade do trabalho 55\%, e a produtividade do capital em culturas perenes 20\%, proporcionando um crescimento de $60 \%$ na produção ${ }^{4}$. Maior dinamismo das produtividades total, da terra e do trabalho foi verificado nas regiões Sul, CentroOeste e Sudeste. Apesar das produtividades dos fertilizantes e das máquinas decrescerem em todas as regiões, no sul e Sudeste as reduções foram menores, e em São Paulo e Paraná, particularmente, a produtividade dos fertilizantes cresceu. Aquele trabalho e o de THOMPSON (1974) evidenciaram que, além da expansão de área cultivada e da utilização de mãode-obra, as diferenças regionais de produtividade também são explicadas pelos investimentos em educação, pesquisa e extensão rural. Vicente mostrou, pelo cálculo dos retornos marginais, que os investimentos em pesquisa foram mais rentáveis, seguidos dos investimentos em assistência técnica e por último, em escolaridade da população rural.

HOFEMANN e JAMAS (1990) discutiram questões conceituais e metodológicas e calcularam a produtividade da terra e do trabalho na agricultura de 332 microrregiões homogêneas das regiões Nordeste, Sudeste, sul e Centro-Oeste

\footnotetext{
4 Tanto terra como trabalho são considerados fatores primários. $O$ excedente econômico, produto líquido ou mais-valia se destina a remunerar trabalho e os proprietários da terra e ser distribuído como luero/juros. Isso tudo dá cetta base teórica para analisar a produtividade do trabalho e também a da terra. Mas falar da produtividade dos fertilizantes es estranho. No minimo é algo muito secundário, quase sem sentido. Seria necessário definir o "produto liquido dos fertilizantes". A queda da produtividade (bruta) dos fertilizantes é uma consequêencia do crescimento relativamente rápido de un insumo cuja importância relativa no total da produçăo agropecuária ainda era pequena.
} 
do Brasil, para os anos de 1975 e 1980. Das vinte unidades da federação analisadas, o estado do Paraná foi a única unidade com decréscimos nas produtividades do trabalho $(-0,5 \%)$ e da terra $(-17,5 \%)$. As maiores produtividades do trabalho foram verificadas nos estados. de São Paulo e Mato Grosso do Sul, em 1975 e 1980, respectivamente. Os autores também constataram que a produtividade da terra medida pelas relações valor agregado por área explorada e valor bruto da produção por área explorada estavam altamente correlacionadas entre si e que havia correlações positivas entre as medidas de produtividade da terra e a produtividade do trabalho.

CARVALHO (1993) analisou a evolução da produtividade do trabalho na agricultura brasileira e constatou que a produtividade média anual cresceu a taxas decrescentes nos períodos 1970-75 (10,44\%), 1975-80 (2,65\%) e 1980-85 (1,04\%), porém a produtividade marginal do fator trabalho foi positiva. Dos estados analisados, o Ceará foi o único com diminuição da produtividade média do trabalho.

\subsection{Produção e produtividade da agropecuária paranaense.}

São poucos os estudos sobre a produtividade da agropecuária paranaense.

MENDES e DOSSA (1982), pela análise dos 15 principais produtos, estimaram a contribuição da produtividade e da expansão de área no crescimento da produção agrícola do Paraná, na década de 70. o crescimento 
na produção de $4,2 \%$ ao ano foi exclusivamente devido à incorporação de novas áreas no processo produtivo associado às elevadas taxas de crescimento da produção de soja, pois o efeito da produtividade da terra foi negativo, principalmente pela incorporação de áreas menos férteis à produção, e pela inadequada conservação dos solos.

HOFFMANN e JAMAS (1990) determinaram a produtividade do trabalho e da terra da agropecuária paranaense, ao nível de microrregiões homogêneas e Estado, no período 1975-80 (Tabela 2.2). Para o Estado, nesse período, a produtividade da terra e a produtividade do trabalho diminuíram $17,5 \%$ e 0,50, respectivamente. Das vinte e quatro microrregiões homogêneas (MRH), nove apresentaram decréscimos na produtividade do trabalho e onze na produtividade da terra. 
Tabela 2.2. Produtividade do trabalho e da terra (VA/EH e VA/AE), por microrregião homogênea e Estado do Paraná,1975 e 1980.

(em mil cruzeiros de 1980)

\begin{tabular}{|c|c|c|c|c|c|c|}
\hline \multirow{4}{*}{ MICRORREGIÕES E ESTADO } & \multicolumn{3}{|c|}{$\begin{array}{c}\text { PRODUTIVIDADE DO } \\
\text { TRABALHO }\end{array}$} & \multicolumn{3}{|c|}{$\begin{array}{c}\text { PRODUTIVIDADE DA } \\
\text { TERRA }\end{array}$} \\
\hline & & & & & & \\
\hline & (VA/EH) & (VA/EH) & VAR. & $(\mathrm{VA} / \mathrm{AE})$ & $(\mathrm{VA} / \mathrm{AE})$ & VAR. \\
\hline & 1975 & 1980 & $\left(\frac{8}{8}\right)$ & 1975 & 1980 & $(8)$ \\
\hline & & $:===-=$ & $===$ & $====$ & $======$ & $======$ \\
\hline 1 CURITIBA & 62,48 & 56,29 & $-9,9$ & 9,56 & 7,26 & $-24,0$ \\
\hline 2 LITORAL PARANAENSE & 31,81 & 85,48 & 168,7 & 1,22 & 3,62 & 197,0 \\
\hline 3 ALTO RIBEIRA & 29,51 & 27,69 & $-6,2$ & 4,15 & 2,55 & $-38,6$ \\
\hline 4 A.R. NEGRO PARANAENSE & 41,37 & 45,52 & 2,8 & 6,91 & 7,44 & 7,6 \\
\hline 5 CAMPOS DA LAAPA & 62,68 & 92,33 & 47,3 & 4,51 & 6,43 & 42,7 \\
\hline 6 CAMPOS DE PONTA GROSSA & 104,21 & 90,78 & $-12,9$ & 3,70 & 4,48 & 21,2 \\
\hline 7 CAMPOS DE JAGUARIAIVA & 63,04 & 76,89 & 22,0 & 2,57 & 3,78 & 47,3 \\
\hline 8 SÃO MATEUS DO SUL & 42,23 & 101,78 & 141,0 & 5,47 & 13,42 & 145,4 \\
\hline 9 COLONIAL DO IRATI & 54,41 & 62,34 & 14,6 & 6,93 & 7,41 & 6,9 \\
\hline 10 NORTE V. WENC. BRAZ & 52,53 & 79,50 & 51,3 & 7,67 & 10,96 & 42,9 \\
\hline 11 MÉDIO IGUAÇU & 79,70 & 127,47 & 59,9 & 3,84 & 5,27 & 37,2 \\
\hline 12 ALTO IVAf & 45,39 & 49,77 & 9,7 & 5,97 & 5,87 & $-1,7$ \\
\hline 13 CAMPO MOURÃO & 69,54 & 86,73 & 24,7 & 11,83 & 11,95 & 1,0 \\
\hline 14 PITANGA & 42,58 & 50,69 & 19,0 & 6,30 & 6,47 & 2,7 \\
\hline 15 EXTREMO O. PARANAENSE & 71,78 & 99,01 & 37,9 & 14,72 & 14,27 & $-3,1$ \\
\hline 16 SUDOESTE PARANAENSE & 63,19 & 89,07 & 41,0 & 13,14 & 15,82 & 20,4 \\
\hline 17 CAMPO DE GUARAPUAVA & 350,03 & 101,17 & $-71,1$ & 18,47 & 5,82 & $-68,5$ \\
\hline 18 NORTE V. JACAREZINHO & 88,14 & 92,24 & 4,6 & 12,76 & 11,12 & $-12,9$ \\
\hline 19 ALGODOEIRA DE ASSAI & 61,12 & 73,69 & 20,6 & 10,90 & 11,90 & 9,2 \\
\hline 20 NORTE NOVO DE LONDRINA & 99,66 & 88,69 & $-11,0$ & 16,67 & 10,69 & $-35,9$ \\
\hline 21 NORTE NOVO DE MARINGÁ & 114,68 & 98,69 & $-13,9$ & 22,13 & 13,99 & $-36,8$ \\
\hline 22 NORTE N. DE PARANAVAI & 150,77 & 101,11 & $-32,9$ & 12,31 & 7,46 & $-39,4$ \\
\hline 23 NORTE NOVO APUCARANA & 70,52 & 68,27 & $-3,2$ & 15,38 & 12,57 & $-18,2$ \\
\hline 24 NORTE N. DE UMUARAMA & 94,90 & 79,56 & $-16,2$ & 14,23 & 9,41 & $-33,8$ \\
\hline TOTAL DO ESTADO & 85,08 & 84,62 & $-0,5$ & 11,65 & 9,61 & $-17,5$ \\
\hline
\end{tabular}

Fonte: HOFFMANN e JAMAS (1990) 


\section{ME TODOLOGIA}

A metodologia utilizada neste trabalho para calcular a produtividade do trabalho e da terra é semelhante àquela empregada nos trabalhos de KAGEYAMA (1986); HOFEMANN, JAMAS e KASSOUF (1990); HOFEMANN e JAMAS (1990) e CARVALHO (1993). A diferença é que estes autores não consideraram a depreciação na determinação do valor agregado.

Mesmo sabendo da dificuldade em determinar-se a depreciação com as informações disponíveis, e que essa não é utilizada no cálculo das Contas Nacionais, a sua estimativa, nesse trabalho, evita que as áreas mais capitalizadas sejam privilegiadas.

As produtividades médias do trabalho e da terra terão como unidade de análise o Estado (310 municípios) e os 14 conglomerados determinados pelo IAPAR, no ano de 1985 (F'igura 3.1 e Tabela 3.1). Essas produtividades são calculadas pelas expressões (3.1) e (3.2), respectivamente.

$$
\begin{aligned}
& \mathrm{PL}=\frac{\mathrm{VA}}{\mathrm{EH}} \\
& \mathrm{PT}=\frac{\mathrm{VA}}{\mathrm{AE}}
\end{aligned}
$$


sendo:

$\mathrm{PL}=$ produtividade média do trabalho;

$\mathrm{VA}=$ valor agregado;

$\mathrm{EH}=$ número de equivalentes-homem;

$\mathrm{PT}=$ produtividade média da terra;

$\mathrm{AE}=$ área total explorada, definida como a soma das áreas utilizadas com lavouras (temporárias, permanentes e em descanso para lavouras), pastagens (plantadas e naturais) e matas (plantadas e naturais).

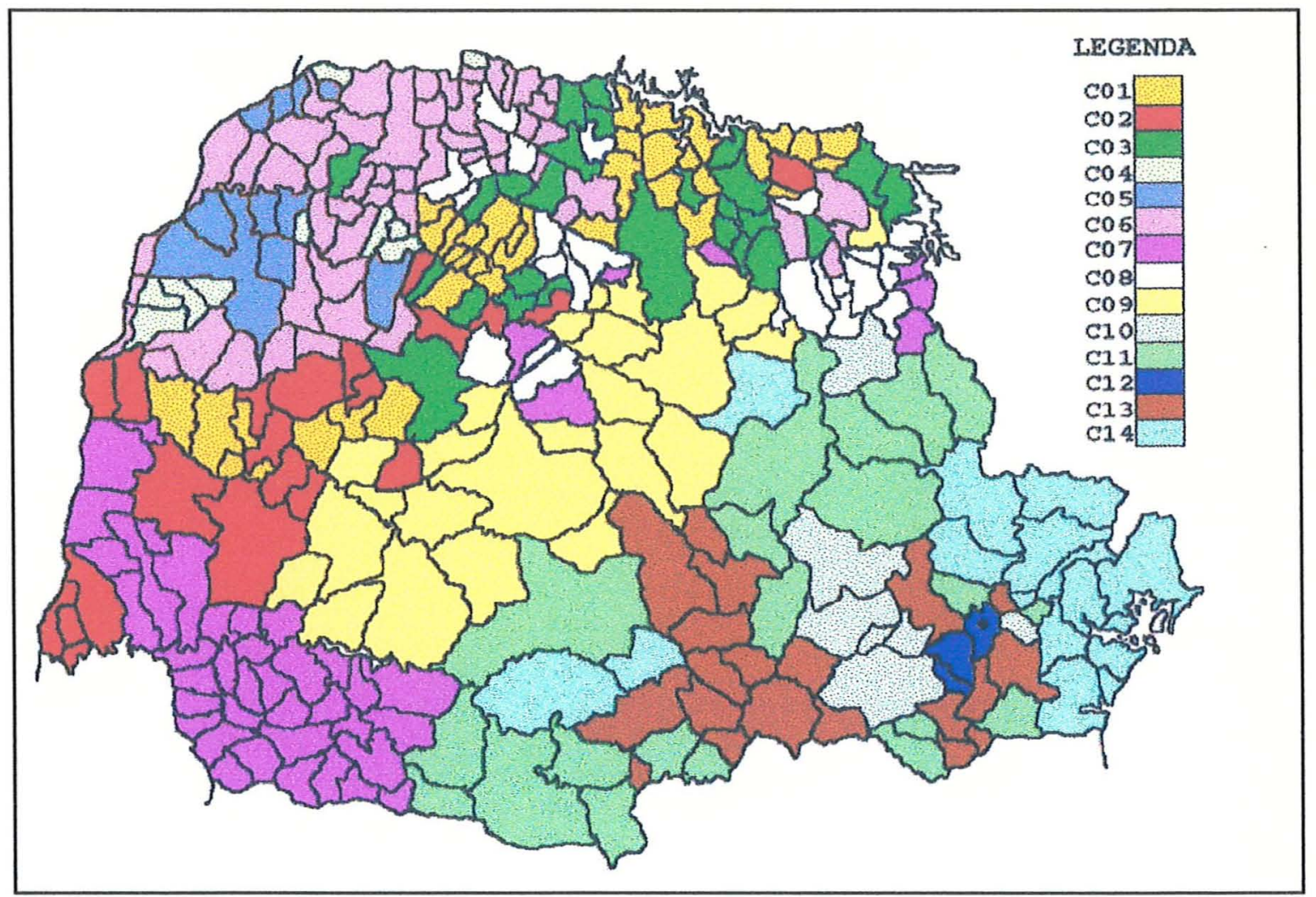

Fonte: elaborado a partir de dados do ASE/IAPAR

Figura 3.1. Conglomerados do Estado do Paraná, 1985. 
Tabela 3.1. Principais características de cada conglomerado, Paraná, $1985^{1}$.

Cong. Principais características Alta participação das lavouras de soja e trigo, e
secundariamente, milho, algodão e café, baixa desigualdade no acesso à terra, associada a um elevado uso de insumos agroindustriais e da motomecanização (37) .

C02 Alta participação de lavouras temporárias, principalmente a soja, algodão e milho, baixa desigualdade no acesso à terra, associada à grande p̉articipação no uso de insumos agroindustriais e motomecanìzação (20).

C03 Alta participação de lavouras temporárias e pastagens, média desigualdade no acesso à terra, significativa importância da pecuária de leite, associada à menor utilização de insumos agroindustriais e motomecanização (26) •

C04 Alta participação da cultura do café, de utilização de força de trabalho familiar e de parceiros, com pequena participação de lavouras temporárias e pecuariação, igualdade no acesso à terra associada ao menor uso de insumos agroindustriais (10).

C05 Alta participação da cultura de café, milho e algodão, de pecuária de corte, de pastagens plantadas, de uso de força de trabalho familiar, associada à pequena utilização de insumos agroindustriais e motomecanização (10) .

C06 Alta participação da pecuária de corte, de pastagens plantadas, de culturas de milho, mandioca e algodão, grande desigualdade no acesso à terra, associadas à pequena utilização de insumos agroindustriais e motomecanização (50) •

C07 Alta participação de culturas temporárias, principalmente milho e feijão, baixíssima desigualdade no acesso à terra, uso de tração animal e de força de trabalho familiar, associada à uma baixa utilização de insumos agroindustriais e motomecanização (44) .

\footnotetext{
${ }^{1}$ Os números entre parênteses indicam o total de municipios por conglomerado.
} 
Tabela 3.1. Continuação

Cong.

Principais caracteristicas

C08 Alta participação de culturas de milho, soja, feijão e café, pastagens com pecuária de leite, uso de força de trabalho familiar e de tração animal, associada à pequena utilização de insumos agroindustriais e motomecanização (23).

C09 Alta participação de lavouras temporárias, principalmente milho e feijão, de uso de força de trabalho familiar, de tração animal e igualdade no acesso à terra, associada à pequena utilização de insumos agroindustriais e motomecanização nas culturas de subsistência (25).

C10 Alta participação da pecuária de leite em pastagens naturais e grande desigualdade no acesso à terra, associada à pequena utilização de insumos agroindustriais e motomecanização nas culturas temporárias de subsistência (7).

C11 Alta densidade de pastagens e matas naturais, de reflorestamentos, de áreas em pousio, alta desigualdade no acesso à terra, uso de força de trabalho contratada permanente e significativa participação da pecuáría de leite, associada à utilização de insumos agroindustriais e de motomecanização (20).

C12 Grande participação da pecuária de leite tecnificada, de produtos da hortifruticultura, de milho e feijão e baixa desigualdade no acesso à terra, associada à utilização de insumos agroindustriais e de motomecanização (3) .

C13 Alta participação de culturas temporárias, principalmente milho, feijão e fumo, alto uso de força de trabalho familiar, de tração animal, de pastagens e matas naturais, de reflorestamento, de áreas em pousio, associadas à baixíssima utilização de insumos agroindustriais e motomecanização nas culturas de subsistência, principalmente milho e feijão (21).

C14 Altíssima desigualdade no acesso à terra, grande participação de matas naturais, de reflorestamentos e de áreas em pousio, associadas à baixíssima utilização de insumos agroindustriais e motomecanização nas culturas de subsistência, principalmente milho e feijão (14). 
A influência de cada variável nas produtividades do trabalho e da terra, no Estado e por conglomerado, é determinada por mínimos quadrados ordinários, conforme modelo econométrico descrito na p.45 (expressão $3 \cdot 10)$.

Os conglomerados foram determinados pelo IAPAR, através da Análise de Conglomerados (Cluster Analysis), no trabalho sobre regionalização da agropecuária paranaense. Essa análise é usada para construir classes ou grupos, de maneira que as diferenças entre os elementos de um conglomerado sejam mínimas, e as diferenças entre conglomerados sejam máximas.

- Para o cálculo dessas produtividades e determinação das variáveis que as influenciam, é necessário usar dados publicados e não publicados do Censo Agropecuário do Paraná. Aqueles são obtidos no CENSO AGROPECUÁRIO-85 (1991) e estes estão disponíveis em fita magnética elaborada pelo Instituto Brasileiro de Geografia e Estatística - IBGE (Apêndices 1, 2 e 3).

Como o ciclo agrícola não obedece ao ano civil, o valor agregado (VA) determinado a partir das informações do Censo Agropecuário (CA) não reproduz com exatidão o VA em um ciclo de produção, pois o período de referência do CA (ano civil) não coincide com o período da safra agrícola. Por exemplo: a maior parte do valor bruto da produção dos cereais de verão, colhidos em 1985, referese ao plantio de 1984. Nas despesas com insumos, no ano de 1985 está incluída parte das despesas da safra 1984/85 e 
parte da's despesas da safra 1985/86. Dada a ausência de informações dos estabelecimentos agrícolas, por município, para o mesmo período da safra agrícola, é impossivel determinar o VA referente a um ciclo de produção (ano agrícola).

As informações do CA de 1985 sobre área, valor dos bens e efetivos da pecuária referem-se a 31 de dezembro e os dados sobre despesas, receitas e produção dizem respeito ao ano de 1985 .

Ressalte-se que 1984 foi um ano normal e 1985 foi um ano atípico, com seca prolongada no segundo semestre.

\subsection{Valor Agregado (VA)}

o valor agregado (VA) é definido como a diferença entre o valor bruto da produção (VBP) e a soma dos valores do consumo intermediário (CI) e da depreciação (Dep) :

$$
\mathrm{VA}=\mathrm{VBP}-\mathrm{CI}-\mathrm{Dep}
$$

\subsubsection{Valor bruto da produção (VBP)}

Ao VBP agropecuária que aparece no Censo acrescenta-se uma parcela referente à variação do estoque, representada apenas pela variação dos rebanhos (bovino, bubalino, suíno, ovino, caprino e cunícola), dada a impossibilidade de se obter a variação do valor das culturas permanentes e matas. No VBP publicado no Censo 
Agropecuário, o valor da produção animal refere-se ao valor de animais abatidos e vendidos, não levando em. conta a variação do estoque animal.

o valor da variação do rebanho é determinado pela variação do número de animais (nascidos + comprados vitimados - vendidos - abatidos) multiplicada pelo preço médio estadual de compra $\left(\mathrm{PMeC}^{2}\right)$, em cruzados, calculado conforme metodologia usada pela Fundação Getúlio Vargas para as Contas Nacionais: "Como não são disponíveis informações sobre preço médio dos animais nascidos e vitimados, optou-se pela utilização de preços médios de compra, ao invés de preços médios de venda, para valorar a variação de rebanhos. Esta escolha fundamenta-se em que os preços médios de venda, em princípio, incluem também preços médios de animais adultos e prontos para abate, sendo superiores aos preços médios de compra, e que o número de animais nascidos no ano é parcela muito significativa da variação do rebanho" (EUNDAÇÃo GETÚLIO VARGAS, 1984 p.4).

Dessa forma o VBP é determinado pela expressão:

$\mathrm{VBP}=\mathrm{VBP}_{\text {(censo p.503) }}+$ valor da variação do estoque animal

\footnotetext{
${ }^{2} \mathrm{PMeC}$ do rebanho bovino (Cz\$ 950,00), bubalino (Cz\$ 1551,73), suíno (Cz\$ 183,30), ovinos (Cz\$ 227,76), caprino (Cz\$ 132,64) e cunicola (Cz\$29,47).
} 


\subsubsection{Consumo Intermediário (CI)}

o valor do consumo intermediário é determinado a partir dos dados de despesas dos estabelecimentos com adubos e corretivos; sementes e mudas; defensivos agrícolas; medicamentos para animais; alimentação e trato dos animais (sal, rações industriais e outros alimentos); aluguel de máquinas, equipamentos e reprodutores; transporte da produção; sacaria e outras embalagens; combustíveis e lubrificantes; energia elétrica; impostos e taxas; ovos fertilizados e pintos de um dia; compra de sêmen e outras despesas. A esses gastos acrescentou-se as despesas com compra de animais (bovinos, bubalinos, suínos, caprinos, coelhos; ovinos e galinhas ${ }^{3}$ e outras aves) dado que no Censo o VBP animal se refere ao valor das vendas e abates, sem descontar o valor das compras efetuadas dentro do próprio setor. Essas compras e vendas inter-setoriais são transferências, portanto, não representam acréscimo de valor. Do valor das despesas que aparece no Censo foi deduzido o valor referente aos gastos com salários; quota-parte da produção entregue a parceiros; arrendamento e parceria de terras; empreitada; juros e despesas bancárias, por não fazerem parte do consumo intermediário. Como estes gastos não estão disponíveis, por municipio, no $\mathrm{CA}$, os mesmos foram determinados a partir da fita magnética do CA com os dados por estabelecimento.

$3_{\text {Inclui galinhas, galos, frangas e frangos . }}$ 


\subsubsection{Depreciação}

A depreciação é calculada pelo método linear:

$$
D_{t}=(B-F) / N
$$

onde:

$\mathrm{D}_{\mathrm{t}}=$ depreciação no ano $\mathrm{t}$;

$B$ = valor-base, é o valor em 31 de dezembro de 1985, dos bens (instalações e outras benfeitorias, veículos e outros meios de transporte, máquinas e instrumentos agrários, animais de trabalho ${ }^{4}$ e culturas permanentes), extraídos da fita magnética do Censo Agropecuário;

$F=$ valor de sucata, foi arbitrado em 15\% do valor-base das máquinas, equipamentos e veículos, instalações e outras benfeitorias5;

$\mathrm{N}=$ vida útil em anos, adotando-se dez anos para máquinas e equipamentos, veículos e animais de tração; vinte e cinco anos para instalações e outras benfeitorias; e vinte anos para as culturas permanentes ${ }^{6}$.

O valor de sucata e a vida útil foram estimados com base em HOFFMANN et alii (1984, pp. 16-17) e OCEPAR (1989, p.35). No caso da vida útil das culturas permanentes

\footnotetext{
${ }^{4} \mathrm{O}$ valor dos animais de tração foi estimado com base no efetivo de muares e equảinos vezes o preço médio de venda: eqüinos $=\mathrm{CZ \$}$ 1965,66 e muares $=$ Cz\$ $\$ 1642,94$.

5 Não há um percentual determinado empiricamente, a OCEPAR, 1989 p. 35 considerou como valor de sucata os seguintes porcentuais do valor novo: implementos (5\%), trator, carreta e carreta graneleira (15\%), colheitadeira (20\%), camioneta (40\%) e construçöes (10\%). ${ }^{6}$ Como o valor -base utilizado não é o valor novo, no cálculo da depreciação deveria ser considerada a vida útil restante dos bens., mas isso não foi possivel porque o Censo Agropecuário não traz informações sobre tempo de uso dos bens.
} 
obteve-se informações com pesquisadores do IAPAR (contato pessoal).

\subsection{Pessoal ocupado na agricultura}

O CENSO AGROPECUÁRIO-1985 (1991) traz informações sobre pessoas ocupadas nos estabelecimentos agrícolas, em 31 de dezembro, conforme sexo e idade (de 14 anos e mais e de menos de 14 anos), classificadas em cinco categorias: responsável e membros nãó remunerados da família (RF), empregados permanentes (EP), empregados temporários (ET), parceiros (P) e outra condição (OC) . Para a categoria OC os dados não estão classificados por idade. Neste caso, o número de menores de 14 anos é determinado subtraindo do total de menores de 14 anos dado pelo Censo (obtido pela diferença entre o total de pessoas ocupadas e o total de homens e mulheres maiores de 14 anos) os menores de 14 anos das demais categorias (RF, EP, ET e P).

O Censo Agropecuário (CA) também informa o número máximo mensal de empregados temporários contratados para a execução de serviços eventuais ou de curta duração (ETSE) e o gasto dos estabelecimentos com serviços de empreitada (SE).

\subsubsection{Empregados temporários para serviços eventuais (ETSE)}

Obteve-se a estimativa do número de ETSE pela média aritmética mensal do número máximo de trabalhadores temporários. Para posterior conversão em equivalentes-homem, 
a divisão em adultos e crianças é obtida aplicando-se a mesma proporção de adultos e crianças da categoria ET.

\subsubsection{Serviço de empreitada (SE)}

O número de equivalentes-homem envolvidos em trabalhos de empreitada é determinado pela relação do número total de diárias pagas/300 dias. O total de diárias pagas é estimado pela relação entre o montante gasto com serviços de empreita, em cruzados, registrado no Censo (fita magnética) e o valor médio da diária no ano de 1985 (Cz\$ 14,74) (DERAL, 1985).

\subsubsection{Força de trabalho em equivalentes-homem ano}

A transformação do número de pessoas

ocupadas em equivalentes-homem (expressão 3.6.) é necessária para se obter unidades aproximadamente homogêneas de força de trabalho. Um equivalente-homem (EH) corresponde a 300 dias de trabalho de um adulto. Para converter o número de pessoas ocupadas em equivalenteshomem foi adotado o seguinte critério:

a) responsável e membros não remunerados da família:

1 mulher $=0,6$ EH e 1 criança $=0,4 \mathrm{EH}$;

b) empregados permanentes e temporários 1 mulher $=1,0$ EH e 1 criança $=0,5 \mathrm{EH}$;

c) parceiros e outra condição

1 mulher $=0,66 \mathrm{EH}$ e 1 criança $=0,5 \mathrm{EH}$. 
Os cálculos feitos para chegar ao total de equivalentes-homem (EHT) estão indicados nas expressões a seguir:

$\mathrm{EHT}=\mathrm{RFEH}+\mathrm{EPEH}+\mathrm{ETEH}+\mathrm{PEH}+\mathrm{OCEH}+\mathrm{ETSEEH}+\mathrm{SEEH}$

onde:

RFEH = responsáveis e membros não remunerados da família; em equivalentes-homem (EH);

$\mathrm{EPEH}=$ empregados permanentes em EH;

$\mathrm{ETEH}=$ empregados temporários em EH;

$\mathrm{PEH}=$ parceiros em EH;

OCEH = outra condição em EH;

ETSEEH = empregados temporários para serviços esporádicos em EH; e SEEH = serviços de empreitada em EH [ $\sum$ valor das diárias com empreita/Cz\$14,74)/300 dias];

Nas siglas, que aparecem do lado direito das fórmulas a seguir, RFH, REM, EPH, EPM, ETH, ETM, PH, PM, OCH, OCM, ETSEH e ETSEM, as letras iniciais, em negrito, referem-se às categorias $e$ as letras finais $H$ ou $M$ correspondem à homem e mulher, respectivamente.

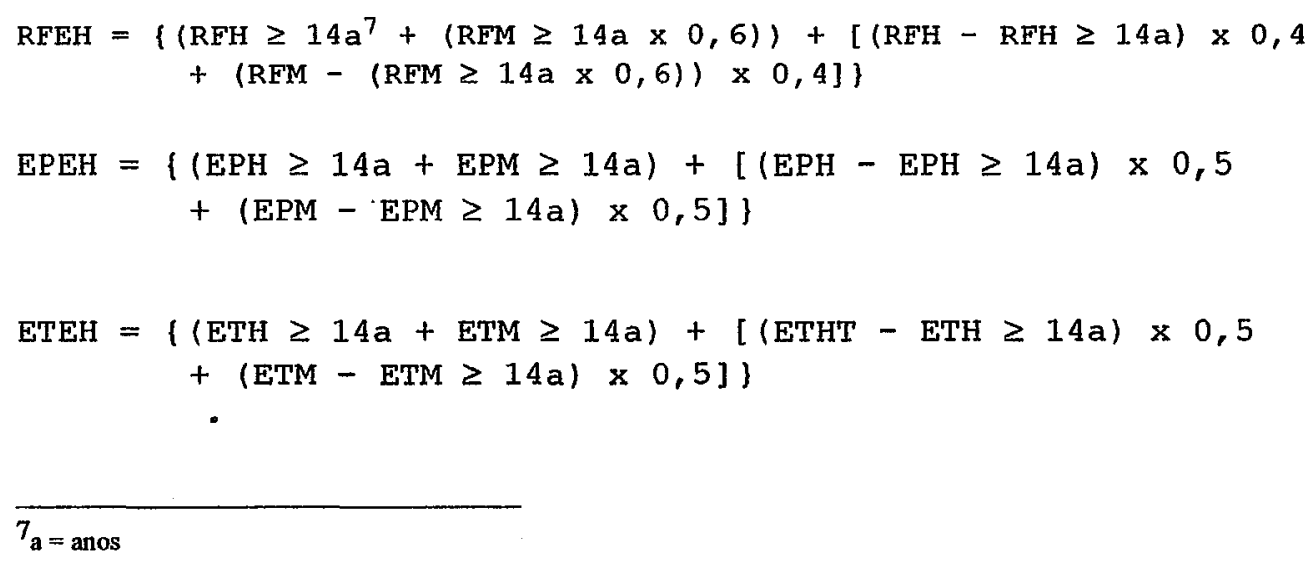




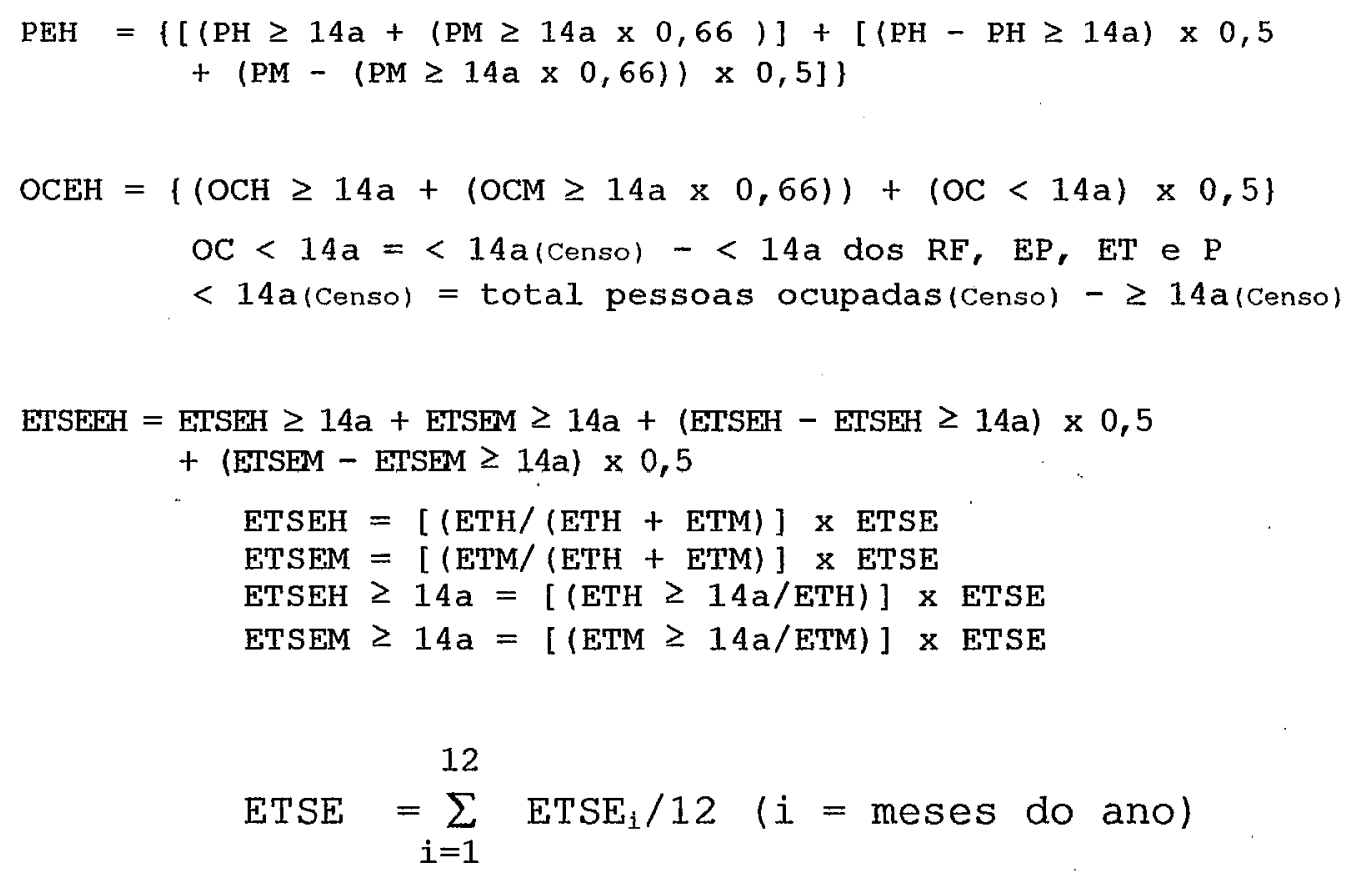

\subsection{Análise dos fatores que afetam as produtividades do} trabalho e da terra

A eficiência de cada fator de produção pode ser mensurada através da sua produtividade média ou da sua produtividade marginal. Essas produtividades pressupõem a existência de funções de produção ${ }^{B}$. A produtividade média de um fator de produção é determinada pela relação entre a quantidade total produzida e a quantidade empregada desse fator. A produtividade marginal representa o aumento na produção total decorrente do acréscimo de uma unidade de um fator produtivo, mantendo-se constantes os demais.

"A função de produção é uma relação técnica que associa a cada dotação de fatores de produção a máxima

\footnotetext{
8 Sobre Funç̃es de Produção ver HEADY e DILLON (1961); ENGLER (1978); CHIANG (1982); VARIAN (1984); BARBOSA (1985) e HOFFMANN, JAMAS E KASSOUF (1990).
} 
quantidade de produto obtida a partir da utilização desses fatores" (BARBOSA, 1985).

Para uma dada tecnologia e um determinado período de tempo, a função de produção pode ser expressa da seguinte forma:

$$
Y=f\left(X_{1}, X_{2}, \ldots, X_{k}\right)
$$

onde se supõe que (3.7) é uma função contínua, unívoca e derivável, sendo que $Y$ representa o produto físico total e os $\mathrm{X}_{\mathrm{i}}$ as quantidades dos $\mathrm{k}$ fatores empregados na produção.

Consideramos uma função de produção do tipo Cobb-Douglas com retornos constantes de escala (função homogênea de grau 1), isto é, $\Sigma \beta_{i}=1$, conforme evidenciado na página 63, definida por:

$$
\mathrm{Y}=\alpha \prod_{i=1}^{k} \mathrm{X}_{\mathrm{i}}^{\mathrm{i}}
$$

onde $\alpha$ e $\beta_{i}$ são constantes.

Na função (3.8), o produto médio de um fator de produção $\left(Y / X_{h}\right)$ é dado por:

$$
Y / X_{h}=\alpha \prod_{i \neq h}\left(X_{i} / X_{h}\right)^{n_{i}}
$$

A análise dos fatores capazes de influenciar as produtividades médias do trabalho e da terra na agricultura, num determinado momento (análise estática), pode ser realizada através do modelo de regressão linear 
múltipla com k-1 variáveis independentes e k parâmetros. Como uma função de produção do tipo Cobb-Douglas é uma função linear nos logaritmos das variáveis, o modelo econométrico ${ }^{9}$ para a análise das produtividades médias fica:

$$
\ln \left(Y / X_{h}\right)=\ln \alpha+\sum_{i \neq h} \beta_{i} \ln \left(X_{i} / X_{h}\right)+u
$$

onde: :

- In $\left(\mathrm{Y} / \mathrm{X}_{\mathrm{h}}\right)$ é o logaritmo do índice de produtividade média do fator $\mathrm{x}_{\mathrm{h}}$;

- os $\ln \left(\mathrm{X}_{\mathrm{i}} / \mathrm{X}_{\mathrm{h}}\right)$ representam as variáveis independentes;

- $\alpha$ é o termo constante e $\beta_{i}$ é o coeficiente de regressão do i-ésimo fator; e

- u é o erro aleatório com as pressuposições usuais.

Ao ajustar um modelo de regressão múltipla o técnico se depara com dois problemas básicos: por um lado, existe a possibilidade de não incluir todas as variáveis relevantes e gerar estimativas viesadas dos coeficientes das variáveis incluídas no modelo. Por outro lado, a inclusão de muitas variáveis no modelo tende a aumentar o problema de multicolinearidade, gerando estimativas menos precisas dos parâmetros (HOFEMANN e VIEIRA, 1987 pp. 153-156 e HOFFMANN; JAMAS e KASSOUF, 1990 p.85). A multicolinearidade pode ser atenuada através de agregação das variáveis independentes correlacionadas.

\footnotetext{
${ }^{9}$ Todos os procedimentos econométricos foram realizados através do software SAS ( SAS INSTITUTE INC., 1985).
} 


\subsubsection{Seleção das variáveis}

A teoria econômica preconiza que a produtividade do trabalho é determinada principalmente por tecnologias mecânicas e a produtividade da terra por tecnologias químico-biológicas. Mas aquelas tecnologias também elevam a produtividade da terra e estas proporcionam maior produtividade do trabalho. Com base nessa teoria selecionou-se os mesmos fatores como influenciadores dessas produtividades, a partir do Censo Agropecuário de $1985^{10}$.

Na determinação das variáveis independentes relacionadas às produtividades do trabalho e da terra só se altera o denominador. Para a produtividade do trabalho (definida pela relação entre valor agregado e o total de equivalentes-homem) o denominador das variáveis independentes é o total de equivalentes-homem. Na produtividade da terra (definida pelo quociente entre o valor agregado e a área explorada) o denominador é a área explorada.

3.3.1.1. Relação dos "fatores de produção" utilizados na determinação das variáveis independentes

a) $\mathrm{BE}=$ valor das instalações $e$ outras benfeitorias, em mil cruzados. É o valor total das instalações e benfeitorias existentes nos estabelecimentos

\footnotetext{
${ }^{10} \mathrm{~A}$ maioria das variáveis não agregadas estão definidas no manual do recenseador.
} 
e utilizadas nas atividades agropecuárias: silos, depósitos, galpões, paióis, galinheiros, pocilgas ou chiqueiros, estábulos, cocheiras, apriscos, apiários, estrumeiras, banheiros (carrapaticidas ou sarnífugos), canais de irrigação e drenagem, açudes, casas de força, casas de farinha, redes de eletrificação, casas de máquina, e outros;

b) $\mathrm{ME}=$ valor das máquinas e instrumentos agrários, veículos e outros meios de transporte, combustíveis e lubrificantes, energia elétrica, embalagens e transporte da produção, em mil cruzados. Refere-se ao valor das máquinas agrícolas, instrumentos agrários e motores existentes no estabelecimento, incluindo o valor dos que se encontram em reforma ou reparo fora do estabelecimento e o de acessórios e de peças para reposição mantidas em estoque, valor total dos veículos (caminhões, camionetas, jipes, carros de bois, carroças, charretes, etc.) e outros meios de transporte existentes, incluindo o valor de acessórios e de peças para reposição (pneus, correias, amortecedores, etc.) mantidos em estoque. Não foi considerado o valor de veículos utilizados pelo produtor exclusivamente para passeio ou viagens recreativas. Considerou-se como máquinas e instrumentos agrários: tratores, colheitadeiras, trilhadeiras, ceifadeiras, picadeiras, arados, grades, pulverizadores, moto-serras, geradores, motores a explosão, motores elétricos, moinhos, 
moendas, e outros. É incluído valor das despesas com fretes e carretos para o transporte da produção do estabelecimento e o total gasto com embalagens (sacos caixas, caixotes, cestos, etc);

c) $\mathrm{CP}=$ valor das culturas permanentes e das matas plantadas, em mil cruzados. É o valor total das plantações de produtos considerados como lavoura permanente (banana, café, laranja, etc.) e o valor total das plantações de espécies ou essências florestais (pinus, eucalipto, quiri, etc.) existentes no estabelecimento, excluindo-se o valor da terra;

d) $\mathrm{RE}=$ valor do rebanho, em mil cruzados. Refere-se ao valor total dos animais de reprodução, criação, recriação, engorda e de trabalho (sela e tração), aves e dos pequenos animais;

e) $\mathrm{IA}=$ valor dos insumos utilizados na agropecuária (IA $=I L+I C+O D)$, em mil cruzados, sendo:

- IL as despesas com insumos para culturas (sementes e mudas, adubos, corretivos e defensivos agrícolas). Inclui o valor total dos adubos (químicos ou orgânicos), corretivos do solo (calcário), sementes e/ou mudas e dos defensivos agrícolas (inseticidas, fungicidas, herbicidas, etc.) e dos produtos químicos destinados a prepará-los (talcos, óleos emulsionáveis, solventes, dispersantes, espalhante adesivo, e outros); 
- IC as despesas com insumos para criações (medicamentos, sal e rações, ovos fertilizados e pintos de um dia, e sêmen), em mil cruzados. Compõe-se do valor dos medicamentos para tratamento dos animais (vacinas, antibióticos, carrapaticidas, etc.), sal comum e mineral, rações balanceadas, concentradas, outros alimentos cereais (milho, sorgo, etc.), alfafa, capim colonião, palma forrageira, uréia, cama aviária, farelos, tortas (de soja, amendoim e outras), compra de sêmen, valor total da despesa realizada com a utilização de reprodutores pertencentes a terceiros, na cobertura ou monta de fêmea do estabelecimento, total gasto na compra de ovos fertilizados para produção de pintos (incubação) e o valor da compra de pintos de 1 dia; e

- OD as outras despesas com compra de ovos do bicho-da-seda, enxame de abelhas, alevinos, girinos, visita de veterinários, etc.

f) $\mathrm{AE}=$ área total explorada, definida como a soma das áreas utilizadas com lavouras (temporárias, permanentes e em descanso para lavouras), pastagens (plantadas e naturais) e matas (plantadas e naturais).

g) $\mathrm{EH}=$ quantidade de trabalho empregada na agropecuária, em equivalente-homem, conforme definido nas pp. $42-46$.

h) $\mathrm{QT}=$ qualidade da terra. Determinada pela relação entre o preço da terra nua e o total da área 
explorada, em mil cruzados. Como não há uma variável especifica de qualidade da terra que inclua qualidade do solo, proximidade e qualidade dos mercados para produtos e insumos, disponibilidade de assistência técnica e outras caracteristicas, espera-se que esses condicionantes da produção agropecuária estejam representados nessa variável. 


\section{ANÁLISE DOS RESULTADOS}

4.1. Produtividade média do trabalho e da terra por microrregião homogênea (MRH) e Estado do Paraná.

Como HOFFMANN, JAMAS e KASSOUF (1990) calcularam a produtividade do trabalho (PL) e a produtividade da terra (PT), por MRH e para o Estado do Paraná nos anos de 1975 e 1980, pela atualização dos dados desses autores foi possível mostrar a evolução dessas produtividades de 1975 à 1985.

A localização geográfica e o nome das MRH estão evidenciados na Figura 4.1 .

Nessa análise utilizou-se da mesma metodologia empregada por HOFFMANN, JAMAS e KASSOUF (1990), isto é, $\mathrm{PL}=\mathrm{VA} / \mathrm{EH}$ e $\mathrm{PT}=\mathrm{VA} / \mathrm{AE}, \cdot$ sem considerar a depreciação no cálculo do VA.

A PL no Estado do Paraná decresceu $0,54 \%$ de 1975 a 1980 e $6,45 \circ$ de 1980 a 1985, acumulando uma queda de $6,95 \%$ no período de 1975 a 1985. Pode-se dizer que a agropecuária paranaense era mais eficiente em 1975, quando gerou, em valores de 1980, Cr\$ 85.080,00 (21,17 salários mínimos - SM) por EH ocupado, que em 1985 onde o retorno por $\mathrm{EH}$ foi de Cr\$ $79.170,00(19,71 \mathrm{SM})$ (Figura 4.2 e $4.3 \mathrm{e}$ Tabela 4.1). 


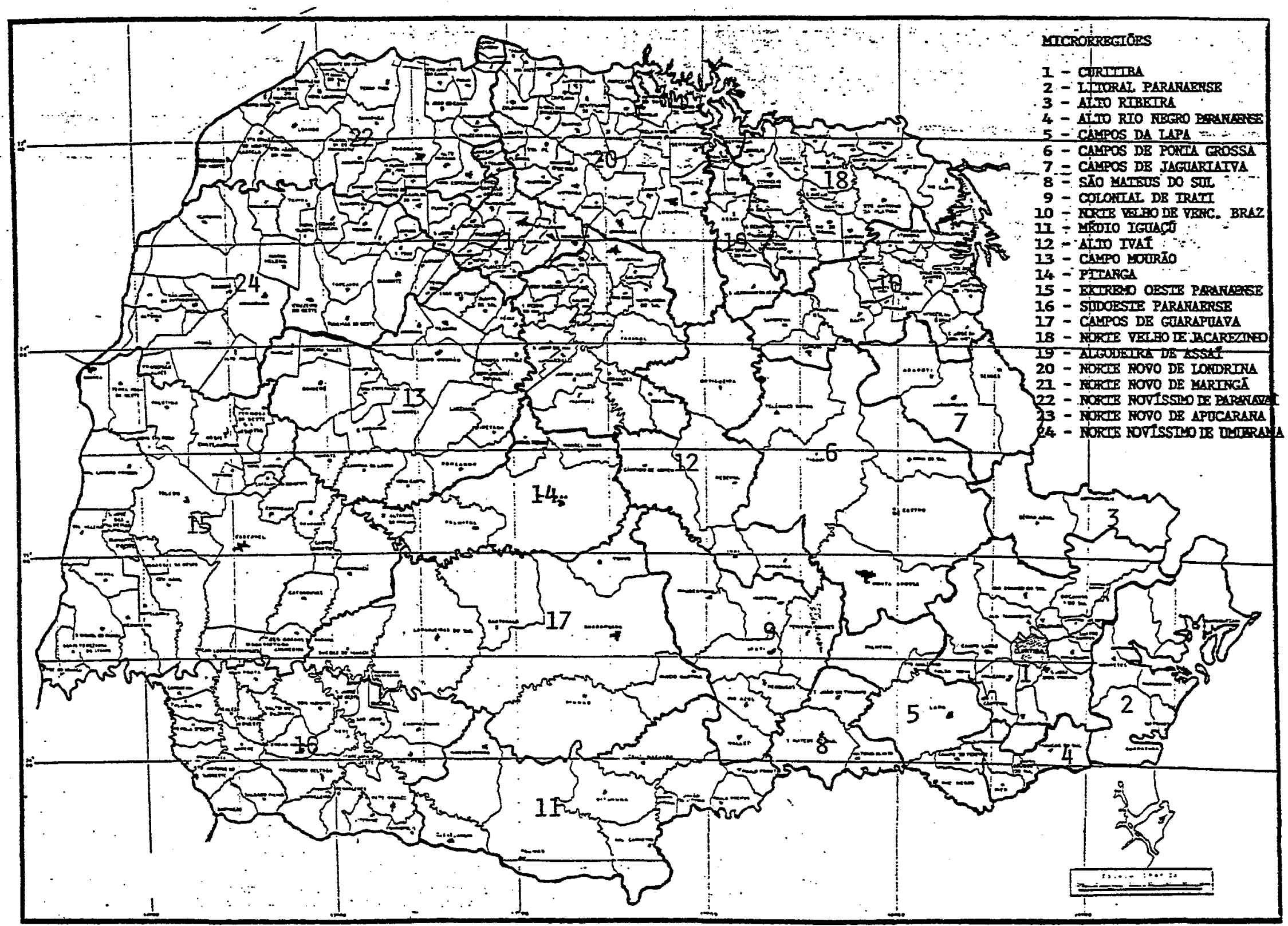

Figura 4.1. Localização geográfica das microrregiōes homogéneas do Estado do Paraná, 1985. 


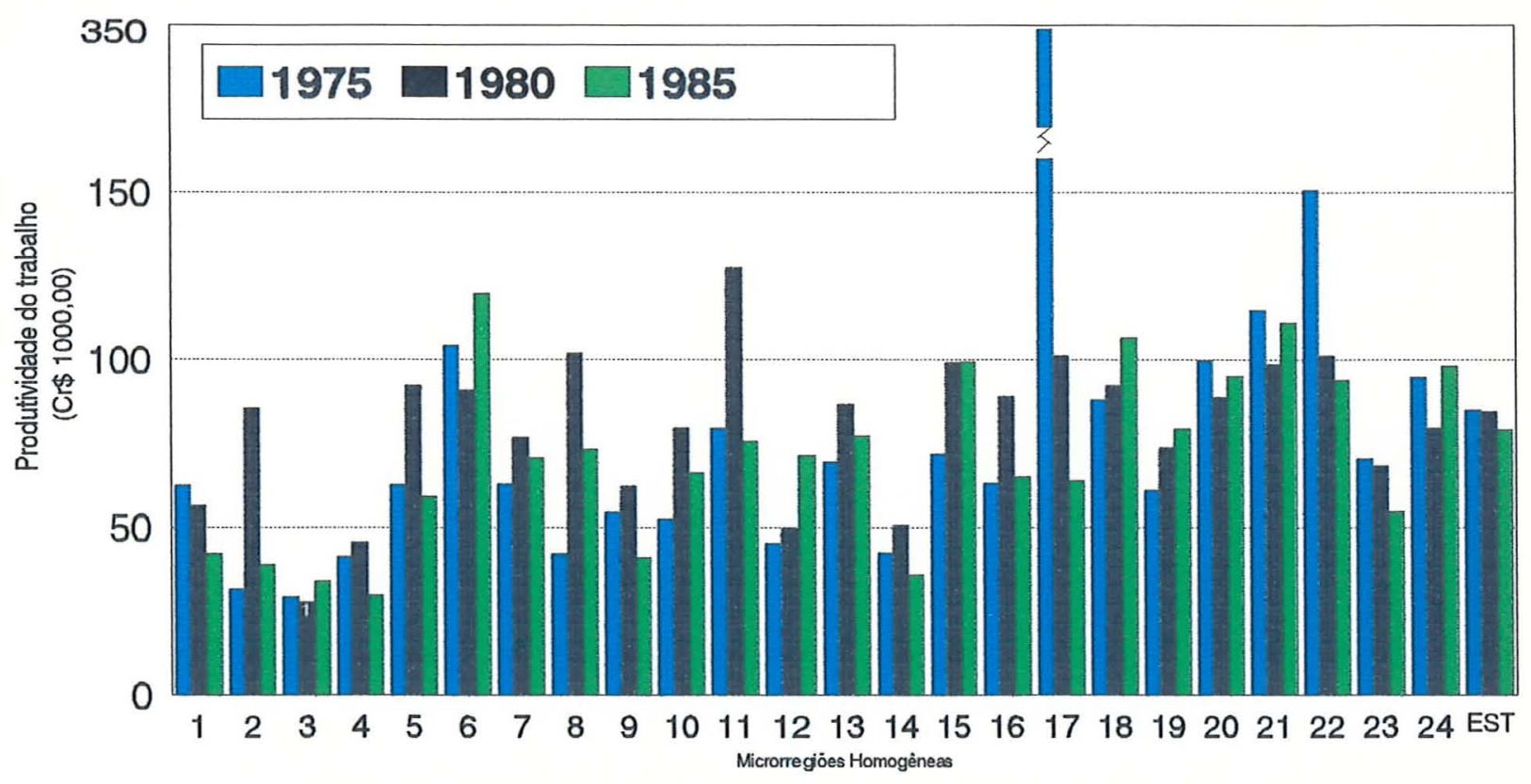

Figura 4.2. Produtividade do trabalho (VA/EH), por microrregião homogênea e Estado do Paraná, 1985.

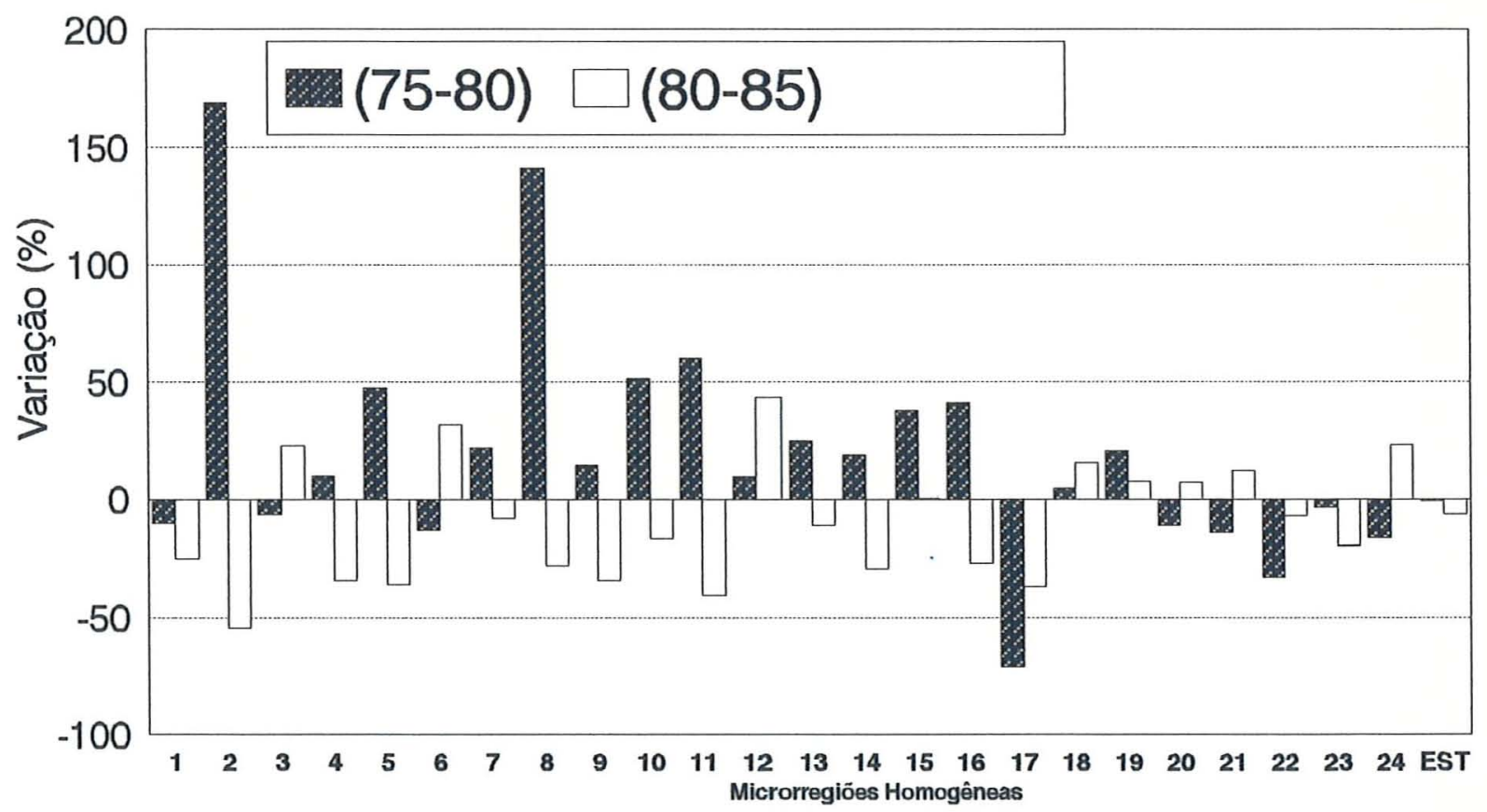

Figura 4.3. Variação da produtividade do trabalho (VA/EH), por microrregião homogênea e Estado do Paraná, 1985

Fonte: Dados da pesquisa e HOFFMANN e JAMAS (1990) 
Tabela 4.1. Produti vidade do trabalho e da terra, por microrregião homogênea e Estado do Paraná, 1975, 1980 e 1985.

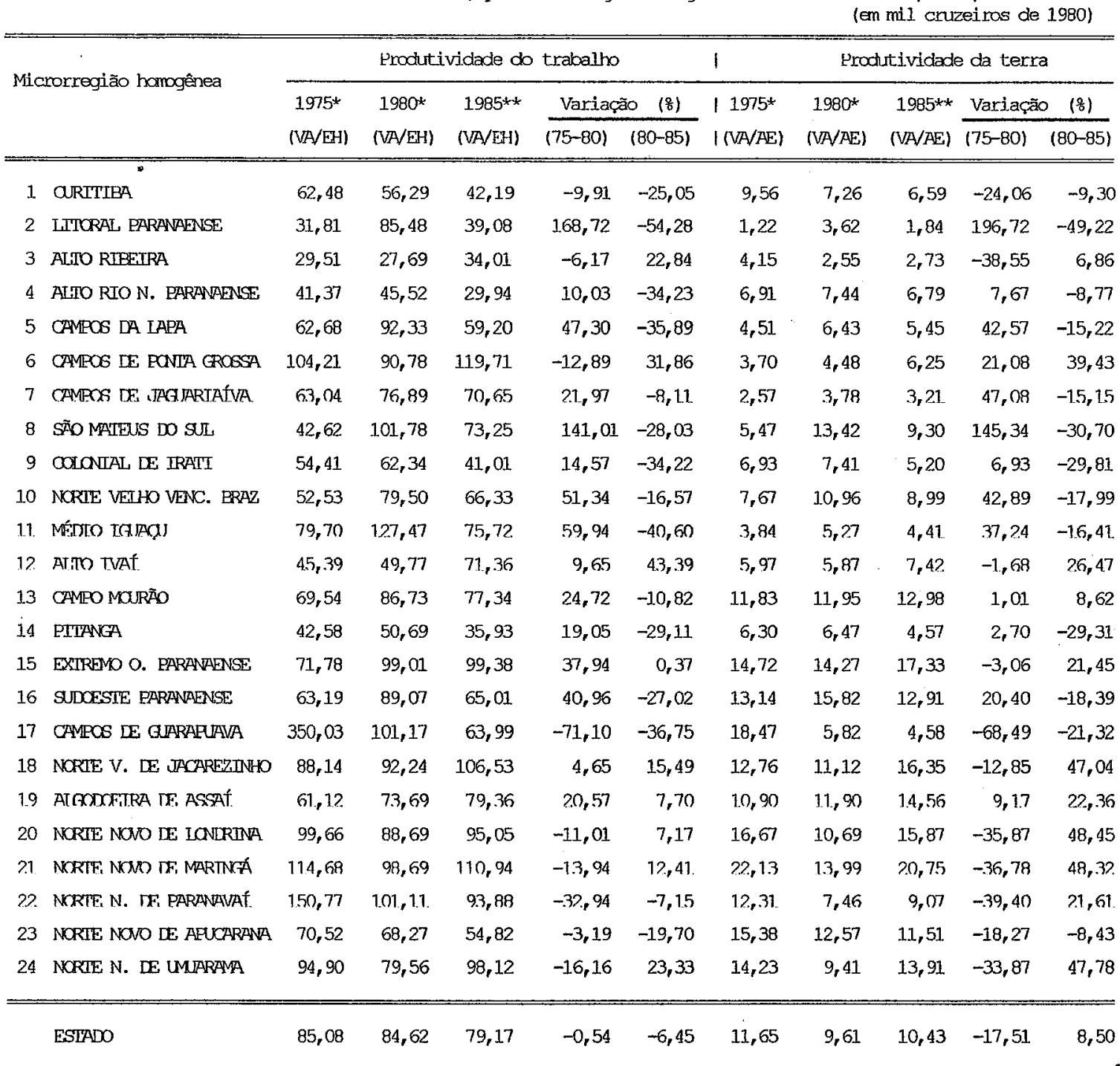

Fonte: **Dados da pesquisa; *HOFFMANN e JAMAS (1990)

Dados em cruzeiros de 1980, deflacionados pelo IGP-DI, $1977=100$

Valores de 1985 multiplicados por $(427,5 / 46,587,50)$ e transformados em cruzeiros

Valores de 1975 multiplicados por $(427,5 / 49,6333)$

Dólar oficial, média ponderada $1980=$ Cr\$ $52,69:$ US\$ 1,00 (Conj. Econ. v.40, ñ. 3)

Salário minimo (Centro-Sul), média ponderada de $1980=\operatorname{Cr} \$ 4017,20$ (Conj. Econ. v.40, n. 2)

A PT Estadual de 1980 foi 17,5\% menor que a de 1975, mas a de 1985 superou em 8,5\% a de 1980, mesmo assim, ficou 10,47\% aquém da PT verificada em 1975, um decréscimo de Cr\$ $1.220,00 \quad(0,30$ SM) por hectare de AE (Tabela 4.1 e Figuras 4.4 e $4.5)$. 


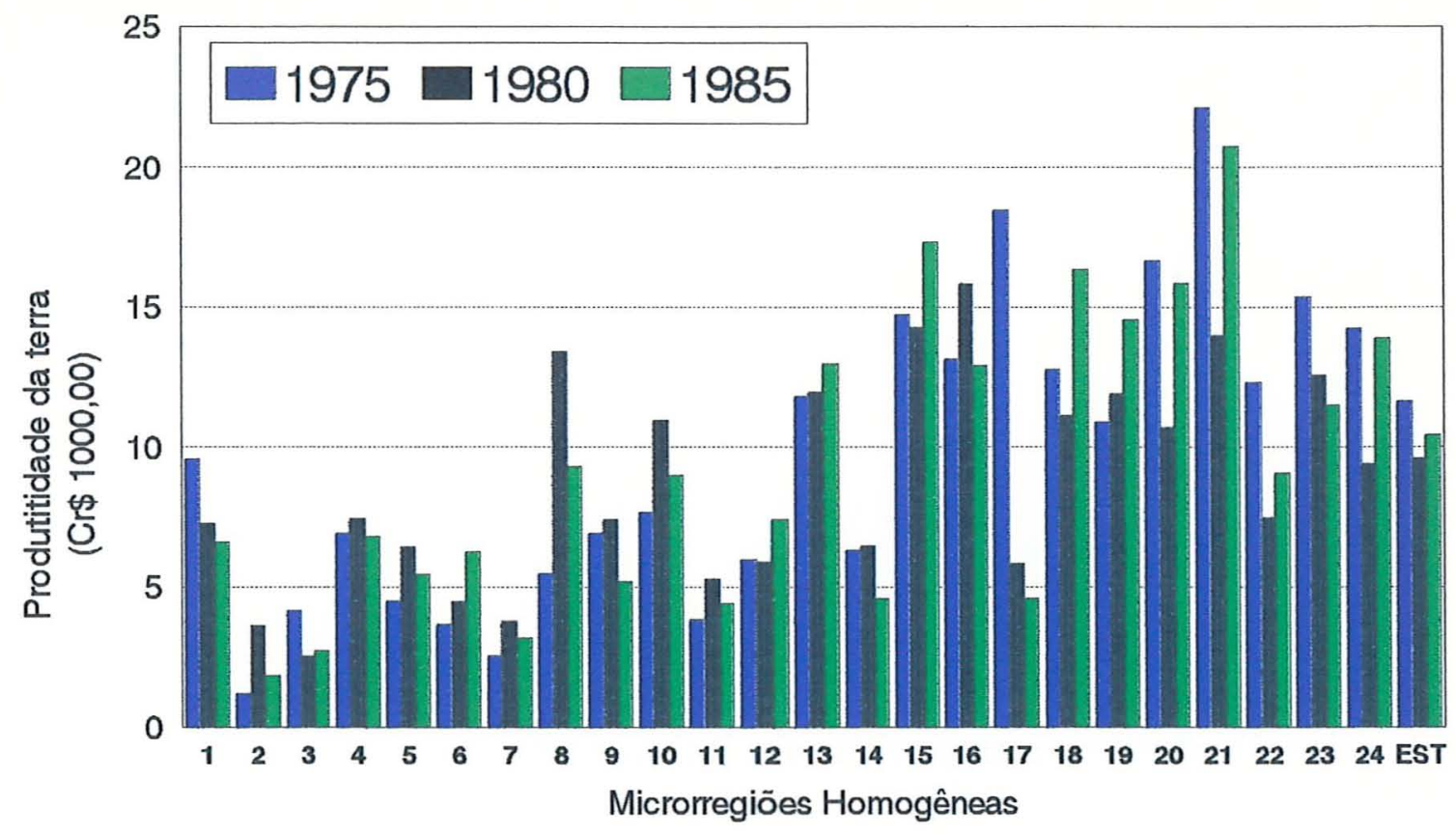

Figura 4.4. Produtividade da terra (VA/AE), por microrregião homogênea e Estado do Paraná, 1985.

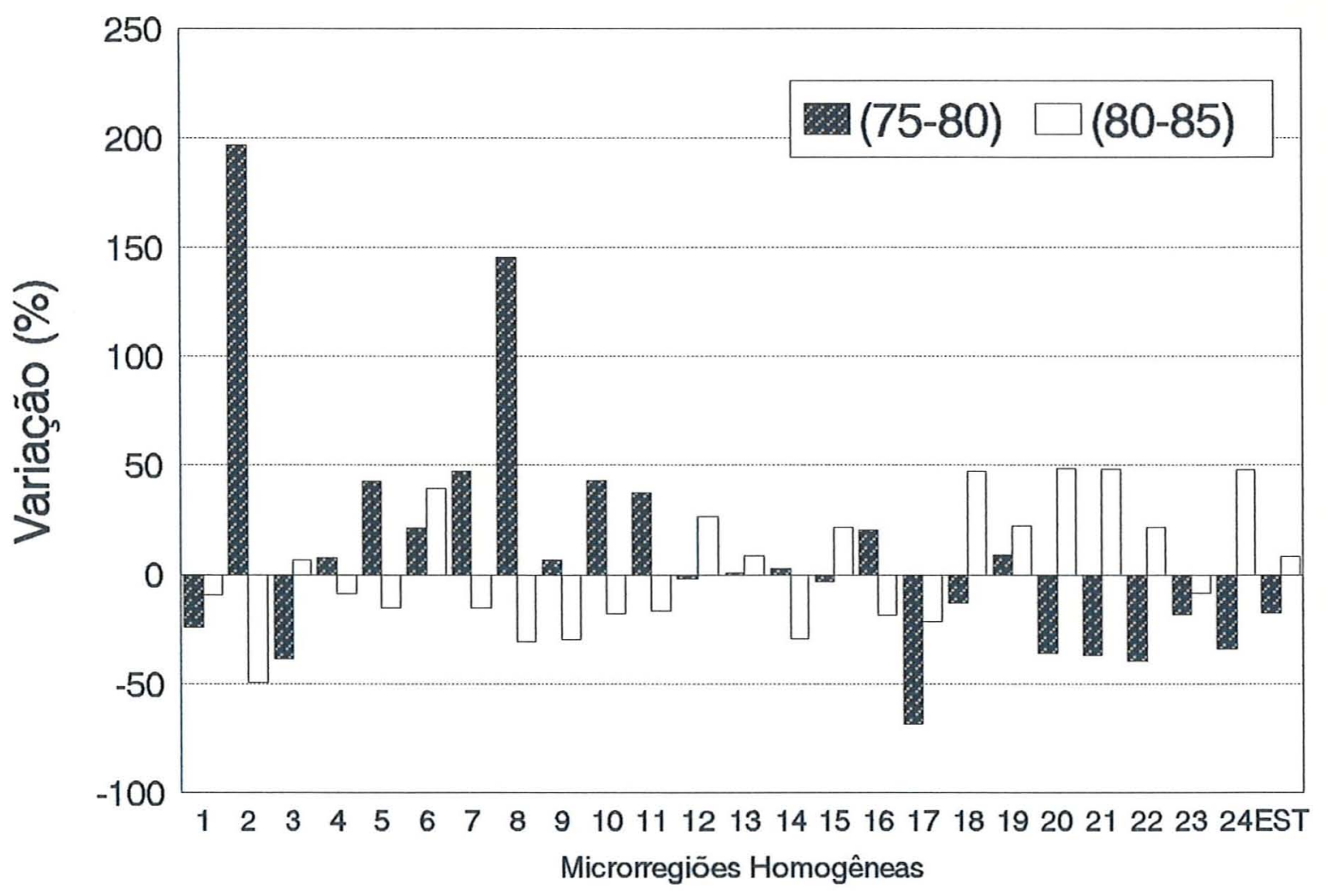

Figura 4.5. Variação da produtividade da terra (VA/AE), por microrregião homogênea e Estado do Paraná, 1985. 
Nas vinte e quatro $\mathrm{MRH}$, considerando os valores observados em 1975, 1980 e 1985, as variações nas produtividades do trabalho e da terra se deram de forma acentuada, mas sem tendência clara, isto é, sem manter os sinais das variações nos dois quiinquiênios, na maioria delas. As seguintes tendências foram observadas:

a) as MRH 1-Curitiba, 17-Campos de Guarapuava e 23-Norte Novo de Apucarana apresentaram tendência decrescente na PL e na PT;

b) a MRH 19-Algodoeira de Assai foi a única com tendência crecente nas duas produtividades; e

c) as MRH 12-Alto do Ivaí, 15-Extremo oeste Paranaense) e 18-Norte Velho de Jacarezinho tiveram tendência crescente na PL. Nas MRH 6-Campos de Ponta Grossa e 13-Campo Mourão também se verificou essa tendência para a PT.

No período 1975-80 a PL decresceu em nove MRH, numa média de $19,70 \%$, e teve um crescimento médio de $44,83 \%$ em quinze MRH. No período mais recente a PL apresentou variações negativas em quinze MRH, com decréscimo médio de $27,17 \%$ e variações positivas com acréscimo médio de $18,28 \%$ em nove MRH (Figura 4.3) .

A PT, no período de 1975 a 1980, decresceu em média $28,44 \%$ em onze MRH, e teve um crescimento médio de 44,68\% em treze MRH. De 1980 a 1985 a PT diminuiu em treze MRH e aumentou em onze MRH, com variações médias de $-20,77 \%$ e 30,69\%, respectivamente (Tabela 4.1 e Figura 4.5). 
É sabido que no período de 1975 a 1985 houve um dos maiores surtos de êxodo rural no Paraná, onde 10,78\% do pessoal ocupado (224.111 pessoas, equivalente a 56.028 familias de 4 pessoas) deixaram de residir e/ou exercer atividades no campo), consequêencia da decadência da cafeicultura que se inicia após a forte geada de 1975 e a motomecanização da agricultura com a expansão do binômio soja-trigo. Mesmo com essa diminuição de mão-de-obra no campo a PL apresentou tendência decrescente, no período de 1975 a 1985.

$\mathrm{Na}$ verdade a diminuição da força de trabalho em EH ocorreu no período de 1975 a 1980, na ordem de 9,96\% (180.145 EH). No período de 1975 a 1985, considerando que o número de $\mathrm{EH}$ ocupados em serviços por empreita ${ }^{1}$ teve uma variação de $-53,02 \%$ e que o número de EH contratados para serviços eventuais temporários aumentou de $98,39 \%$, a força de trabalho ocupada na agricultura aumentou 2,53\% $\quad$ (50.279 $\mathrm{EH})$.

A tendência decrescente da PL, no Estado, teve como principal causa a variação mais que proporcional do consumo intermediário ${ }^{2}(39,66 \%)$ em relação à variação do valor bruto de produção ${ }^{3}(14,22 \%)$, no mesmo período.

Não se discutirão as causas dessas variações nas produtividades, por MRH. Esse tópico teve por objetivo acrescentar ao trabalho informações disponíveis sobre PL e

${ }^{2} \mathrm{Em} 1975$ e 1985 os EH ocupados por empreita foram determinados pela fórmula: (valor dos gastos com empreita/valor da diária)/300 dias, sendo o valor da diária = salário mínimo do Centro-Sul (média ponderada) dividido por 22 dias. SM de 1975 = Cr $\$ 393,00$ e de $1985=\mathrm{Cz} \$ 322,00$ (Conj. Econ. v.39, $\mathrm{n}^{\circ} .2$ e v.40, $\mathrm{n}^{\mathrm{D}} .2$ ).

${ }^{2}$ Consumo intermediário $=$ despesa total menos os valores das despesas com salários, quota-parte, parceria, empreitada e juros.

${ }^{3}$ No ano de 1975 a variação de estoque refere-se a variação dos rebanhos bovino e suíno. 
PT, determinadas com dados do Censo Agropecuário de 1975 e 1980. Na seqüência se fará a análise por Conglomerado e Estado com os dados do Censo Agropecuário de 1985, conforme metodologia descrita no capitulo 3.

4.2. Produtividade do trabalho $e$ da terra por conglomerado e Estado.

Os valores dos indicadores utilizados na determinação do VA e da $\mathrm{AE}$ e o número de equivalentes-homem ocupados, por município, conglomerado e Estado estão nos Apêndices 1 e 2 .

Antes de entrar na análise propriamente dita, chama-se a atenção do leitor para as diferenças metodológicas na análise das produtividades nos conglomerados e nas MRH. Enquanto naqueles empregou-se a metodologia discutida nos item 3.1, nestas seguiu-se os mesmos procedimentos utilizados por HOFFMANN; JAMAS e KASSOUF (1990). Nos conglomerados obteve-se um valor agregado $14,64 \%$ menor, por considerar no seu cálculo o valor da depreciação. Com isso se evita que as regiões mais capitalizadas sejam privilegiadas.

Analisando as produtividades do trabalho e da terra (Tabela 4.2 e Figuras 4.6 e 4.7), com a localização geográfica dos conglomerados no Estado (Figura $3.1, p .32$ ) e o mapa de aptidão agrícola do solo (Figura 4.8), constatou-se uma relação direta dessas produtividades com a qualidade do recurso natural (aptidão agrícola do solo), principalmente para a PT. 
Tabela 4.2. Produtividades do trabalho e da terra e outros indicadores sócio-econômicos, por conglomerado e Estado, 1985.

\begin{tabular}{|c|c|c|c|c|c|c|c|c|c|c|c|c|c|c|c|c|}
\hline \multirow{2}{*}{$\begin{array}{l}\text { Indi- } \\
\text { cado- } \\
\text { res }\end{array}$} & \multirow{2}{*}{ Unid. } & \multirow{2}{*}{ Est. } & \multicolumn{14}{|c|}{ Conglomerados } \\
\hline & & & $\mathrm{CO1}$ & $\mathrm{CO} 2$ & $\mathrm{CO} 3$ &. $\mathrm{CO} 4$ & $\mathrm{CO5}$ & $\mathrm{C} 06$ & $\mathrm{CO}$ & $\mathrm{COB}$ & $\mathrm{COg}$ & C10 & $\mathrm{C} 11$ & $\mathrm{C} 12$ & $\mathrm{C} 13$ & $\mathrm{C} 14$ \\
\hline $\mathrm{CA}$ & S 1000EH & 7,36 & 11,68 & 9,03 & 8,82 & 11,90 & 9,90 & 6,85 & 6,19 & 6,65 & 4,09 & 6,50 & 8,49 & 6,20 & 4,07 & 6,86 \\
\hline \multirow[t]{2}{*}{$\mathrm{PT}$} & \multirow[t]{2}{*}{$\mathrm{C} \$ 1000 \mathrm{ha}$} & 0,97 & 2,39 & 1,59 & 1,15 & 2,55 & 1,07 & 0,85 & 1,27 & 1,27 & 0,49 & 0,48 & 0,48 & 1,59 & 0,63 & 0,39 \\
\hline & & & & & . & & & & & & & & & & & \\
\hline \multicolumn{2}{|c|}{$\mathrm{VBP} / \mathrm{AE} \mathrm{CXS} 1000 \mathrm{ha}$} & 1,66 & 4,10 & 2,89 & 2,11 & 3,31 & 1,67 & 1,56 & 2,20 & 1,97 & 0,80 & 1,07 & 0,87 & 3,48 & 0,98 & 0,50 \\
\hline $\mathrm{CI} / \mathrm{AE}$ & CS\$1000/ha & 0,53 & 1,30 & 1,05 & 0,73 & 0,58 & 0,42 & 0,51 & 0,74 & 0,48 & 0,23 & 0,46 & 0,30 & 1,47 & 0,23 & 0,08 \\
\hline $\mathrm{K} / \mathrm{AE}$ & $\mathrm{CA} \$ 1000 \mathrm{ha}$ & 18,00 & 41,29 & 926,03 & 27,48 & 35,00 & $0 \quad 21,42$ & 22,36 & $\begin{array}{ll}6 & 18,21\end{array}$ & 123,50 & 10,05 & 11,49 & 9,33 & 26,60 & 7,18 & 6,30 \\
\hline $\mathrm{EH} / \mathrm{AE}$ & EHha & 0,13 & 0,20 & 0,18 & 0,13 & 0,21 & 0,11 & 0,12 & 0,20 & 0,19 & 0,12 & 0,07 & 0,06 & 0,26 & 0,15 & 0,06 \\
\hline $\mathrm{AE} / \mathrm{EH}$ & haEH & 7,59 & 4,89 & 5,67 & 7,69 & 4,67 & 9,22 & 8,10 & 4,88 & 5,23 & 8,40 & 13,46 & 17,54 & 3,90 & 6,47 & 17,60 \\
\hline $\mathrm{AC} / \mathrm{EH}$ & haEH & 5,78 & 4,53 & 4,83 & 6,96 & 4,66 & 8,05 & 7,32 & 3,85 & 4,63 & 5,93 & 9,70 & 11,30 & 2,82 & 3,40 & 8,61 \\
\hline ALP/AE & $\%$ & 4,05 & 4,83 & 1,94 & 5,79 & 20,32 & 211,51 & 6,73 & 1,33 & 11,28 & 0,98 & 0,45 & 0,54 & 1,14 & 0,83 & 7,41 \\
\hline ALT/AE & $\%$ & 35,07 & 72,60 & 62,61 & 38,72 & 8,95 & 8,64 & 18,69 & 60,81 & 28,74 & 32,97 & 27,77 & 22,16 & 60,39 & 36,33 & 8,85 \\
\hline ALTD/AE & $\%$ & 3,89 & 0,56 & 1,41 & 0,65 & 0,34 & 0,58 & 0,50 & 2,78 & 1,24 & 7,61 & 4,89 & 4,08 & 5,61 & 16,10 & 5,77 \\
\hline APN/AE & $\%$ & 9,18 & 2,16 & 2,71 & 8,29 & 0,28 & 1,66 & 1,77 & 4,12 & 9,23 & 8,50 & 23,20 & 22,81 & 16,00 & 14,26 & 12,47 \\
\hline APP/AE & $\%$ & 29,53 & 16,01 & 22,72 & 39,15 & 58,34 & 71,55 & 68,44 & 22,66 & 43,43 & 33,09 & 14,55 & 12,29 & 3,79 & 3,43 & 6,92 \\
\hline$A M N / A E$ & $\%$ & 12,99 & 2,98 & 6,77 & 6,00 & 2,19 & 5,40 & 3,17 & 6,85 & 4,74 & 13,36 & 15,60 & 24,61 & 11,57 & 23,95 & 38,95 \\
\hline $\mathrm{AMP} / \mathrm{AE}$ & $\%$ & 5,29 & 0,86 & 1,82 & 1,41 & 0,59 & 0,66 & 0,70 & 1,45 & 1,33 & 3,49 & 13,55 & 13,53 & 1,49 & 5,10 & 19,62 \\
\hline$A C / A E$ & $\%$ & 83,12 & 96,45 & 91,81 & 93,35 & 97,46 & 94,01 & 96,33 & 90,37 & 94,02 & 79,04 & 79,52 & 71,31 & 82,82 & 59,95 & 55,28 \\
\hline AE/TRAT & ha & 153 & 52 & 82 & 111 & 268 & 369 & 204 & 109 & 152 & 298 & 180 & 328 & 37 & 191 & 904 \\
\hline AC/TRAT & ha & 127 & 50 & 75 & 104 & 261 & 347 & 196 & 99 & 143 & 236 & 143 & 234 & 31 & 115 & 500 \\
\hline $\mathrm{AE} / \mathrm{COLH}$ & ha & 737 & 227 & 351 & 629 & 3546 & 5087 & 1933 & 395 & 946 & 1774 & 751 & 1217 & 153 & 1260 & 6061 \\
\hline AC/COLH & tha & 613 & 219 & 322 & 587 & 3456 & 4783 & 1862 & 357 & 889 & 1402 & 597 & 868 & 127 & 755 & 3350 \\
\hline $\mathrm{AE} / \mathrm{AT}$ & ha & 25 & 38 & 33 & 26 & 17 & 23 & 22 & 31 & 16 & 21 & 25 & 37 & 9 & 11 & 46 \\
\hline $\mathrm{AC} / \mathrm{AT}$ & ha & 21 & 37 & 30 & 24 & 17 & 22 & 21 & 28 & 15 & 17 & 20 & 26 & 7 & 7 & 25 \\
\hline
\end{tabular}

Fonte: dados da pesquisa

Nota: $\mathrm{K}=$ capital total, $\mathrm{AC}=$ área cultivada $(\mathrm{AE}-\mathrm{AMN}-\mathrm{ALTD}), \mathrm{ALP}=$ área de lavoura permanente, $\mathrm{ALT}=$ área de lavoura temporária, $\mathrm{ALTD}=$ área de lavoura temporária em descanso, $\mathrm{APN}=$ área de pastagem natural, $\mathrm{APP}=$ área de pastagem plantada, $\mathrm{AMN}=$ área de mata natural, $\mathrm{AMP}=$ área de mata plantada, $\mathrm{TRAT}=$ trator, $\mathrm{COLH}=$ colhcitadeira, $\mathrm{AT}=$ animais de tração

Salário mínimo (média ponderada) de $1985=\mathrm{Cz} \$ 322,08$ 


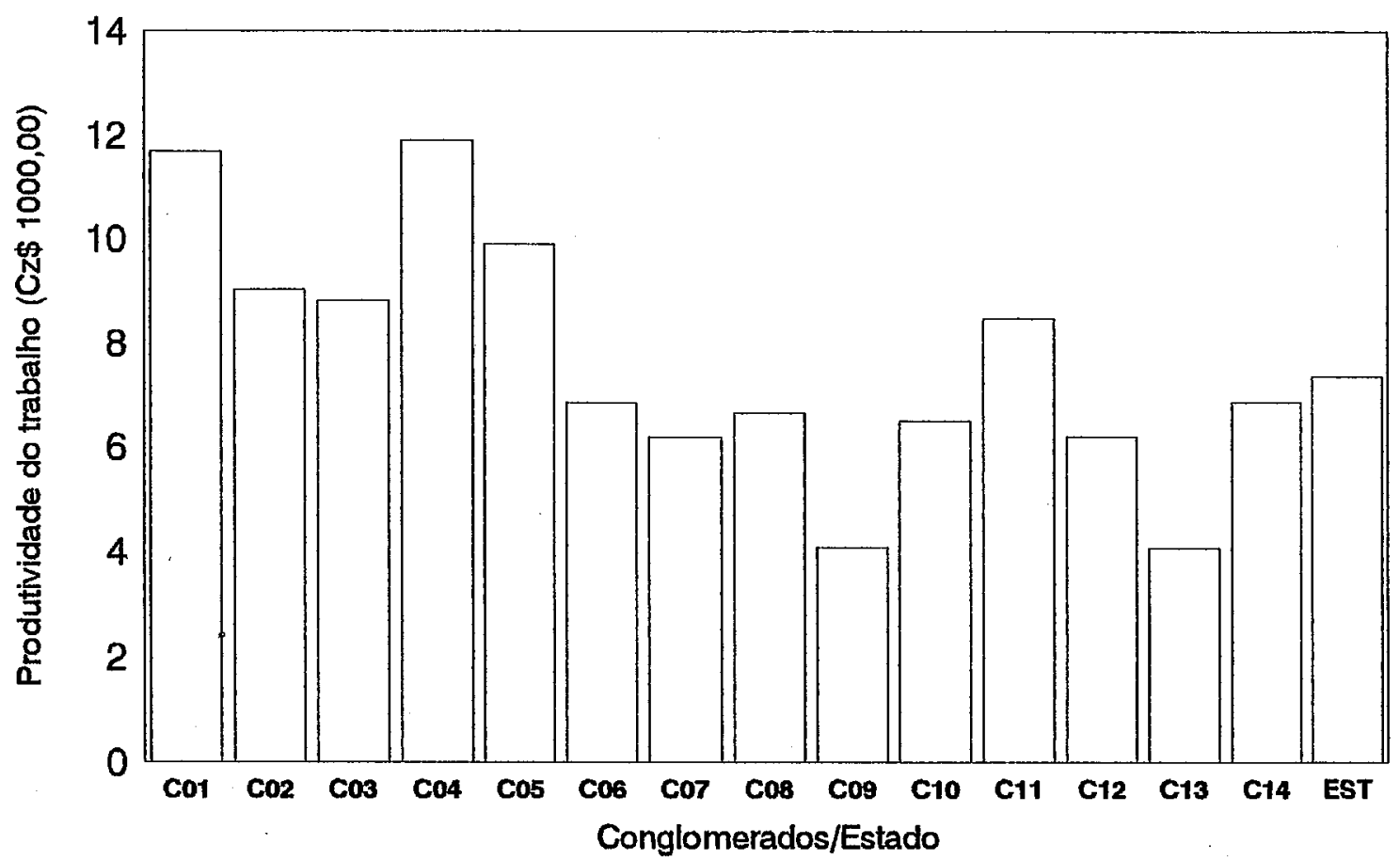

Figura 4.6. Produtividade do trabalho (VA/EH), por conglomerado e Estado do Paraná, 1985.

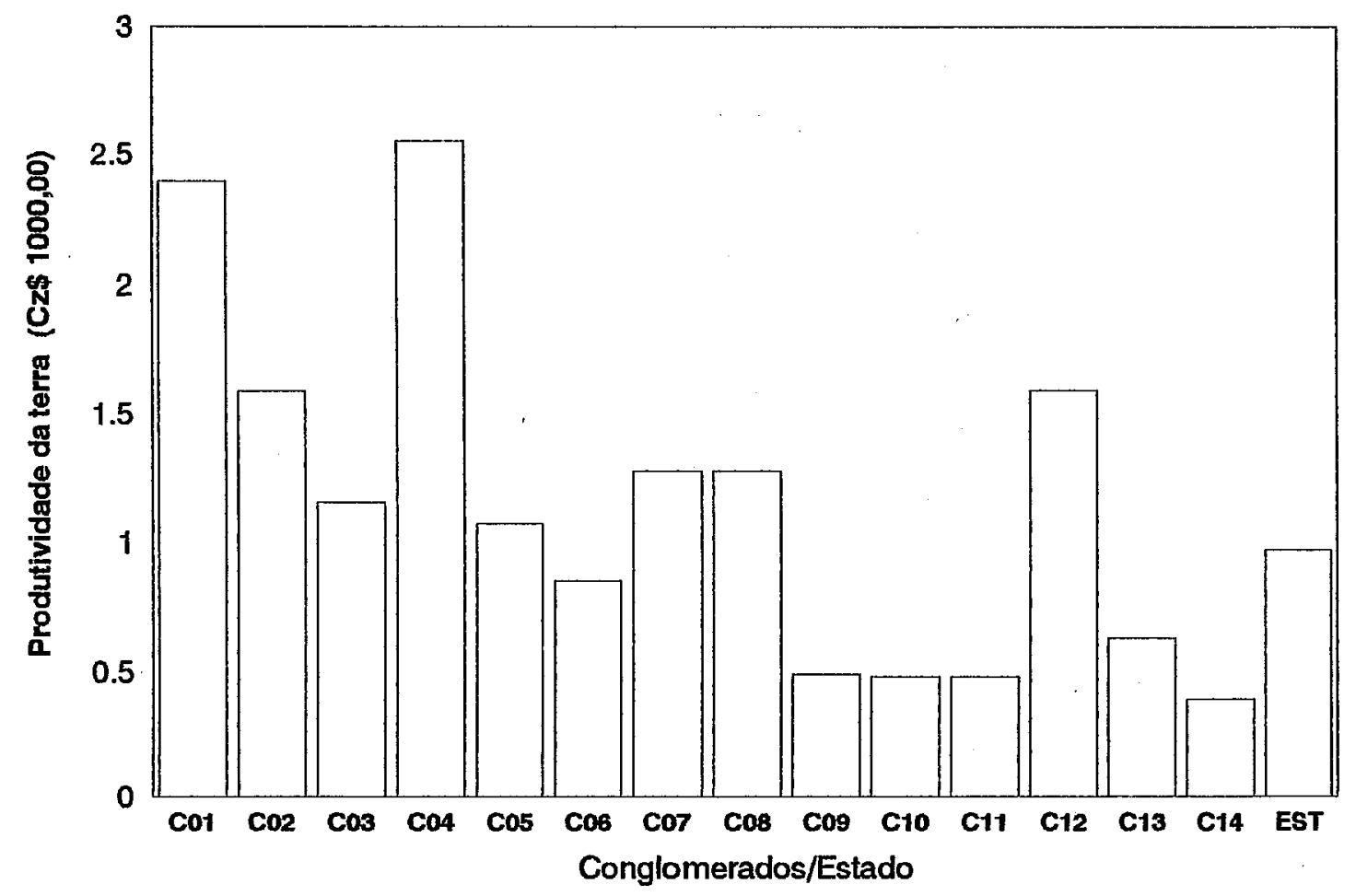

Figura 4.7. Produtividade da terra (VA/AE), por conglomerado e Estado do Paraná, 1985. 


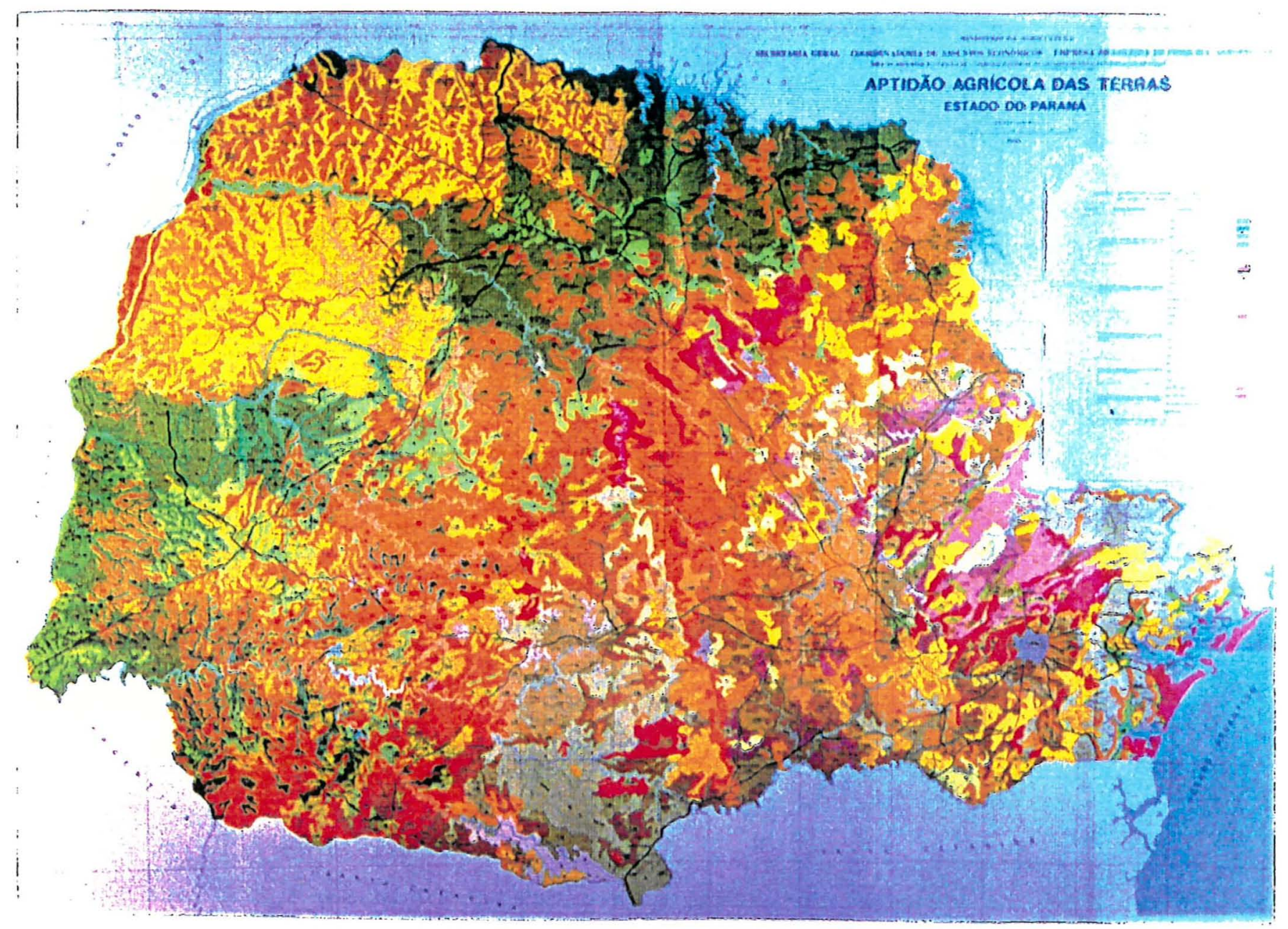

I. genda

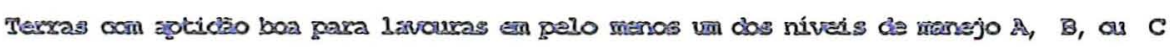

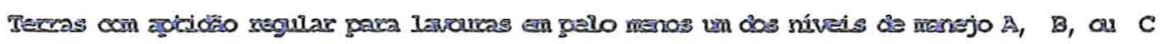

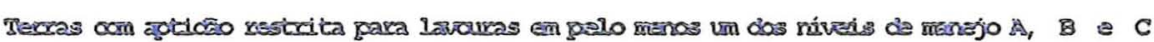

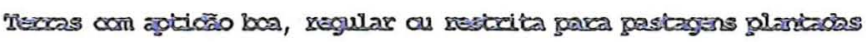

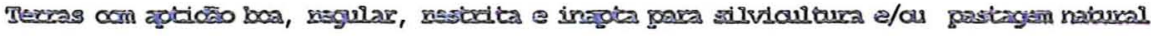
Tercas sen apiozo para uso agricola

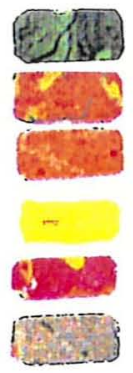

Figura 4.8. Aptidão agrícola das terras do Estado do Paraná, 1981 (adaptado de Brasil, 1981). 
Enquanto a produtividade da terra foi em média $^{4} 2,79$ vezes maior nos conglomerados de melhor aptidão agrícola (C01 a C08), comparada aos conglomerados de menor aptidão agrícola (C09 a C14), a PL foi 1,54 vezes maior naqueles conglomerados. Isso evidencia que os solos de baixa aptidão são mais limitativos à $\mathrm{PT}$ que à $\mathrm{PL}$. No entanto, a PT, proporcionada mais por tecnologias químicobiológicas, pode ser potencializada em solos de baixa aptidão. Por exemplo, a PT do conglomerado $\mathrm{C}_{12}{ }^{7}$ foi $16,06 \%$ maior que a média da PT dos conglomerados C01 a C08 (solos de alta aptidão), e 224,49\% maior que a média da PT dos conglomerados C09 a C14 (solos de baixa aptidão). Já a produtividade do trabalho, proporcionada principalmente por tecnologias mecânicas, nos atuais sistemas de produção, tem seu desenvolvimento limitado nos solos de baixa aptidão por serem declivosos, pouco profundos, suscetíveis à erosão e de baixa fertilidade. Isso limita o desenvolvimento de sistemas de produção mecanizados mais rentáveis. Neste caso a média da PL dos conglomerados C09 a C14 foi 54,27\% menor que a média da $\mathrm{PL}$ dos conglomerados $\mathrm{C} 01$ a $\mathrm{C} 08$, mas a $\mathrm{PL}$ do conglomerado $\mathrm{C} 12$ foi $15,24 \%$ maior que a média da.PL daqueles conglomerados.

\footnotetext{
${ }_{5}^{4}$ média ponderada.

${ }^{5}$ São solos de alta aptidăo aqueles sem limitações significativas para a produção sustentada de um determinado tipo de utilização, observando-se as condições de manejo considerado. As restriç̧̋es existentes não reduzem a produtividade física e não aumentam o uso de insumos acima de um nivel aceitável (BRASIL, 1981). Eståo localizados basicamente no terceiro planalto, e a maior parte delés é de origem basáltica.

${ }^{6}$ São solos de baixa aptidão aqueles com limitações significativas à produção sustentada de um determinado tipo de utilização, observando-se as condiçőes de manejo considerado. As restriçöes existentes reduzem a produtividade fisica e requerem grande quantidade de insumos (BRASIL, 1981). Esses solos se situam principalmente no prịmeiro e segundo planaltos, e são de origem granitica e sedimentar, respectivamente.

7 As atividades principais desse conglomerado são: pecuária de leite e hortifrutícultura, associados à utilização de insumos agroindustriais.
} 


\subsubsection{Análise de regressão}

Os conglomerados sem a análise estatística não satisfazem a condição de que o número de parâmetros estimados, que é igual ao número de variáveis independentes mais um, tem que ser menor que o número de observações.

A função de produção Cobb-Douglas apresentou rendimentos constantes à escala, para os conglomerados e Estado (Tabela 4.3).

Tabela 4.3. Grau de homogeneidade da função de produção Cobb-Douglas, por conglomerado e Estado do Paraná, 1985; e teste da hipótese de que os rendimentos de escala são constantes ${ }^{8}$.

\begin{tabular}{ccccc}
\hline Est/Cong & $\mathrm{N}$ & $\Sigma \boldsymbol{\beta}_{\mathrm{i}}{ }^{*}$ & Teste $\mathrm{F}$ & $\mathrm{P}$ \\
\hline Estado & 307 & 1,00 & 0,10 & 0,75 \\
C01 & 37 & 1,00 & 0,32 & 0,58 \\
C02 & 20 & 1,00 & 0,05 & 0,82 \\
C03 & 26 & 1,00 & 2,07 & 0,17 \\
C04 & 10 & 1,00 & 0,71 & 0,49 \\
C05 & 10 & 1,00 & 0,83 & 0,46 \\
C06 & 50 & 1,00 & 0,00 & 0,98 \\
C07 & 43 & 1,00 & 0,08 & 0,78 \\
C08 & 23 & 1,00 & 0,25 & 0,62 \\
C09 & 25 & 1,00 & 0,12 & 0,73 \\
C10 & - & - & - & - \\
C11 & 19 & 1,00 & 0,53 & 0,48 \\
C12 & - & - & - & - \\
C13 & 20 & 1,00 & 0,07 & 0,80 \\
C14 & 14 & 1,00 & 0,00 & 0,97 \\
\hline
\end{tabular}

Fonte: Dados da pesquisa

$\mathrm{P}=$ Probabilidade de $\mathrm{o}$ valor de $\mathrm{F}$, sob $\mathrm{H}_{0:} \Sigma \beta_{\mathrm{i}}=1$, ser maior que o valor obtido.

*considerando apenas os coeficientes dos insumos fisicos que são $\mathrm{BE}, \mathrm{ME}, \mathrm{CP}, \mathrm{RE}, \mathrm{IA}, \mathrm{AE}$ e EH.

Quando se fez a análise estatística por
conglomerado e Estado, para determinar a influência dos

${ }^{8}$ Rendimentos em escala descrevem a variação na quantidade produzida, resultante de um acréscimo proporcional em todos os insumos. Os rendimentos em escala são constantes quando a quantidade produzida aumenta na mesma proporção que os insumos (WEBER, 1977). 
"fatores de produção" nas produtividades (modelos 4.1 e 4.2), tudo em logaritmo natural, verificou-se que os parâmetros estimados não eram afetados pelo denominador das variáveis desses modelos, variando apenas o valor do teste $F$ e do $R^{2}$ (Apêndice 4).

$\mathrm{PL}=\mathrm{F}(\mathrm{BEEH}, \mathrm{MEEH}, \mathrm{CPEH}, \mathrm{REEH}, \mathrm{IAEH}, \mathrm{AEEH}, \mathrm{QT})$

$\mathrm{PT}=\mathrm{f}(\mathrm{BEAE}, \mathrm{MEAE}, \mathrm{CPAE}, \mathrm{REAE}, \mathrm{IAAE}, \mathrm{EHAE}, \mathrm{QT})$

onde:

$\mathrm{PL}=$ produtividade do trabalho;

$\mathrm{PT}=$ produtividade da terra;

$\mathrm{BE}=$ do valor das instalações e outras benfeitorias;

$\mathrm{ME}=$ valor das máquinas e instrumentos agrários, veículos e outros meios de transporte, combustíveis e lubrificantes, energia elétrica, aluguel de máquinas e equipamentos e o valor do transporte e das embalagens;

$\mathrm{CP}=$ valor das culturas permanentes e das matas plantadas;

$\mathrm{RE}=$ valor do rebanho;

$I A=$ valor dos insumos agropecuários;

$\mathrm{EH}=$ número total de equivalentes-homem;

$\mathrm{QT}=$ qualidade da terra: valor da terra nua por $\mathrm{AE}$;

EH (equivalentes-homem) e AE (área explorada) são os denominadores dos fatores de produção referentes à PL e a $\mathrm{PT}$, respectivamente. 
Como essa análise evidenciou que a influência.dos fatores de produção nas produtividades e no valor agregado era igual, se utilizou como variável dependente o valor agregado e como variáveis explicativas os "fatores de produção" (modelo 4.3). Também foi analisado - efeito dos mesmos fatores no valor bruto de produção (modelo 4.4), para auxiliar na interpretação dos resultados daquele modelo.

$$
\begin{array}{r}
\mathrm{VA}=\mathrm{F}(\mathrm{BE}, \mathrm{ME}, \mathrm{CP}, \mathrm{RE}, \mathrm{IA}, \mathrm{AE}, \mathrm{EH}, \mathrm{QT}) \\
\mathrm{VBP}=\mathrm{G}(\mathrm{BE}, \mathrm{ME}, \mathrm{CP}, \mathrm{RE}, \mathrm{IA}, \mathrm{AE}, \mathrm{EH}, \mathrm{QT})
\end{array}
$$

As variáveis independentes foram agregadas para diminuir o problema de multicolinearidade. Mesmo assim, esse problema não foi superado totalmente nos conglomerados C01, C02, C03, C04, C05, C06, C11 e C14, conforme evidenciado pelas correlações entre essas variáveis (Apêndice 5).

Para se obter informações mais representativas dos municípios de cada unidade de análise, excluíramse as observações discrepantes ${ }^{9}$. Nos modelos 4.3 e 4.4 foram detectadas cinco e três observações discrepantes no Estado, e duas e três nos conglomerados, respectivamente (Tabela 4.4). 
Tabela 4.4. Observações discrepantes por conglomerado e Estado, 1985

Observação
discrepante

VA-Modelo 4.3

Estado | Conglom. Estado | Conglom.

VBP-Modelo 4.4

\begin{tabular}{lcccc} 
189-Santo A. Sudoeste & - & - & - & C07 \\
255-Campo do Tenente & $\mathrm{x}$ & - & $\mathrm{x}$ & - \\
260-Ipiranga & $\mathrm{x}$ & $\mathrm{C} 11$ & $\mathrm{x}$ & $\mathrm{C11}$ \\
272-União da Vitória & $\mathrm{x}$ & - & - & - \\
295-São Mateus do Sul & - & $\mathrm{C13}$ & - & $\mathrm{C13}$ \\
302-Guaraqueçaba & $\mathrm{x}$ & - & - & - \\
310-Telèmaco Borba & $\mathrm{x}$ & - & $\mathrm{x}$ & - \\
\hline
\end{tabular}

Fonte: dados da pesquisa

- número de observações, coeficiente de determinação e as equações estimadas para os modelos 4.3 e 4.4, nos conglomerados e no Estado dó Paraná, estão nas Tabelas 4.5 e 4.6 . Os valores do teste $F$ e do teste $t$ para a contribuição dos logaritmos das variáveis, para o VA e o VBP, assinalados com ${ }^{\mathbf{a}},{ }^{\mathbf{b}},{ }^{\mathbf{c}} \mathrm{e}^{\mathbf{d}}$ foram significativos a $1 \%$, $5 \%, 10 \%$ e $15 \%$, respectivamente

- coeficiente de cada "fator de produção" significa a influência (elasticidade ${ }^{10}$ ) deste na variável dependente, mantendo-se constantes os demais fatores.

${ }^{10}$ Porque as estimativas são em logaritmos. 
Tabela 4.5. Resultados das regressões do valor agregado (modelo 4.3), por conglomerado e Estado do Paraná, 1985.

\begin{tabular}{|c|c|c|c|c|c|c|c|c|c|c|c|c|}
\hline \multirow[b]{2}{*}{ C/EST. } & \multirow[b]{2}{*}{$\mathbf{N}$} & \multirow[b]{2}{*}{$\mathbf{R}^{2}$} & \multirow[b]{2}{*}{ Teste F } & \multicolumn{8}{|c|}{ Coeficientes estimados das variáveis independentes e respectivo teste $t$} & \multirow[b]{2}{*}{ QT } \\
\hline & & & & Intercep & $\mathrm{BE}$ & ME & $\mathbf{C P}$ & RE & IA & $\mathrm{AE}$ & EH & \\
\hline Est. & 305 & 0,857 & $253,450^{\wedge}$ & $\begin{array}{l}-0,170 \\
-1,098\end{array}$ & $\begin{array}{l}0,084 \\
2,035^{b}\end{array}$ & $\begin{array}{l}0,096 \\
1,879^{\mathrm{c}}\end{array}$ & $\begin{array}{l}0,032 \\
1,979^{b}\end{array}$ & $\begin{array}{l}-0,132 \\
-3,101^{2}\end{array}$ & $\begin{array}{l}0,090 \\
2,229^{\mathrm{b}}\end{array}$ & $\begin{array}{l}0,386 \\
5,878^{*}\end{array}$ & $\begin{array}{l}0,444 \\
9,800^{n}\end{array}$ & $\begin{array}{c}0,451 \\
10,134\end{array}$ \\
\hline $\mathrm{CO1}$ & 37 & 0,916 & $44,888^{\mathrm{a}}$ & $\begin{array}{l}-0,177 \\
-0,259\end{array}$ & $\begin{array}{l}0,033 \\
0,326\end{array}$ & $\begin{array}{l}-0,171 \\
-1,145\end{array}$ & $\begin{array}{l}-0,023 \\
-0,540\end{array}$ & $\begin{array}{l}-0,164 \\
-1,402\end{array}$ & $\begin{array}{l}0,209 \\
1,389\end{array}$ & $\begin{array}{l}0,831 \\
3,601^{2}\end{array}$ & $\begin{array}{l}0,285 \\
1,906^{c}\end{array}$ & $\begin{array}{l}0,485 \\
2,615\end{array}$ \\
\hline $\mathrm{C02}$ & 20 & 0,981 & $87,281^{\mathrm{a}}$ & $\begin{array}{l}-0,600 \\
-0,783\end{array}$ & $\begin{array}{l}-0,164 \\
-1,236\end{array}$ & $\begin{array}{l}0,372 \\
1,943 \text { c }\end{array}$ & $\begin{array}{l}-0,011 \\
-0,398\end{array}$ & $\begin{array}{l}-0,141 \\
-1,316\end{array}$ & $\begin{array}{l}0,358 \\
2,364^{b}\end{array}$ & $\begin{array}{l}0,097 \\
0,285\end{array}$ & $\begin{array}{l}0,489 \\
2,812^{b}\end{array}$ & $\begin{array}{l}0,555 \\
2,646^{\circ}\end{array}$ \\
\hline $\mathrm{C03}$ & 26 & 0,867 & $16,723^{\star}$ & $\begin{array}{l}1,061 \\
0,920\end{array}$ & $\begin{array}{l}0,231 \\
1,710^{c}\end{array}$ & $\begin{array}{l}-0,061 \\
-0,234\end{array}$ & $\begin{array}{l}0,106 \\
1,142\end{array}$ & $\begin{array}{l}-0,428 \\
-2,281\end{array}$ & $\begin{array}{l}0,297 \\
1,206\end{array}$ & $\begin{array}{l}0,461 \\
1,535^{d}\end{array}$ & $\begin{array}{l}0,393 \\
1,816^{\mathrm{c}}\end{array}$ & $\begin{array}{l}0,132 \\
0,530\end{array}$ \\
\hline $\mathrm{C} 04$ & 10 & 0,995 & $54,398^{b}$ & $\begin{array}{l}1,781 \\
1,317\end{array}$ & $\begin{array}{l}-0,884 \\
-3,221^{c}\end{array}$ & $\begin{array}{l}0,446 \\
1,674\end{array}$ & $\begin{array}{l}0,418 \\
3,812^{c}\end{array}$ & $\begin{array}{l}0,572 \\
2,653^{d}\end{array}$ & $\begin{array}{l}0,033 \\
0,093\end{array}$ & $\begin{array}{l}-0,272 \\
-1,257\end{array}$ & $\begin{array}{l}0,687 \\
2,180\end{array}$ & $\begin{array}{l}-0,179 \\
-0,437\end{array}$ \\
\hline $\cos$ & 10 & 0,997 & $82,961^{n}$ & $\begin{array}{l}-2,359 \\
-1,207\end{array}$ & $\begin{array}{l}0,297 \\
1,692\end{array}$ & $\begin{array}{l}-0,019 \\
-0,063\end{array}$ & $\begin{array}{l}-0,214 \\
-1,293\end{array}$ & $\begin{array}{l}-0,176 \\
-1,079\end{array}$ & $\begin{array}{l}0,406 \\
1,513\end{array}$ & $\begin{array}{l}0,587 \\
1,646\end{array}$ & $\begin{array}{l}0,120 \\
0,487\end{array}$ & $\begin{array}{l}1,392 \\
2,087\end{array}$ \\
\hline $\mathrm{C} 06$ & 50 & 0,877 & $42,705^{n}$ & $\begin{array}{l}-2,099 \\
-2,644^{a}\end{array}$ & $\begin{array}{l}-0,036 \\
-0,402\end{array}$ & $\begin{array}{l}0,129 \\
0,625\end{array}$ & $\begin{array}{l}0,059 \\
1,297\end{array}$ & $\begin{array}{l}-0,018 \\
-0,109\end{array}$ & $\begin{array}{l}0,025 \\
0,339\end{array}$ & $\begin{array}{l}0,625 \\
2,100^{\mathrm{b}}\end{array}$ & $\begin{array}{l}0,216 \\
1,475^{\circ}\end{array}$ & $\begin{array}{l}0,867 \\
3,218^{\mathrm{a}}\end{array}$ \\
\hline $\mathrm{C} 07$ & 44 & 0,945 & $88,226^{2}$ & $\begin{array}{l}1,144 \\
3,365^{*}\end{array}$ & $\begin{array}{l}-0,019 \\
-0,172\end{array}$ & $\begin{array}{l}0,427 \\
3,540^{2}\end{array}$ & $\begin{array}{l}0,055 \\
1,654^{d}\end{array}$ & $\begin{array}{l}0,215 \\
1,174\end{array}$ & $\begin{array}{l}0,100 \\
1,605^{d}\end{array}$ & $\begin{array}{l}-0,343 \\
-1,417\end{array}$ & $\begin{array}{l}0,565 \\
6,803^{n}\end{array}$ & $\begin{array}{l}-0,064 \\
-0,476\end{array}$ \\
\hline $\mathrm{C} 08$ & 23 & 0,863 & $13,440^{\mathrm{a}}$ & $\begin{array}{l}2,496 \\
1,152\end{array}$ & $\begin{array}{l}0,140 \\
0,555\end{array}$ & $\begin{array}{l}0,635 \\
1,807^{\circ}\end{array}$ & $\begin{array}{l}0,090 \\
0,645\end{array}$ & $\begin{array}{l}0,256 \\
1,408\end{array}$ & $\begin{array}{l}0,128 \\
0,570\end{array}$ & $\begin{array}{l}-0,409 \\
-0,681\end{array}$ & $\begin{array}{l}0,159 \\
0,517\end{array}$ & $\begin{array}{l}-0,687 \\
-1,065\end{array}$ \\
\hline C09 & 25 & 0,963 & $63,010^{\prime}$ & $\begin{array}{l}-0,839 \\
-1,053\end{array}$ & $\begin{array}{l}-0,085 \\
-1,159\end{array}$ & $\begin{array}{l}0,340 \\
2,997^{a}\end{array}$ & $\begin{array}{l}0,025 \\
1,069\end{array}$ & $\begin{array}{l}0,256 \\
1,894^{\mathrm{c}}\end{array}$ & $\begin{array}{l}-0,120 \\
-1,210\end{array}$ & $\begin{array}{l}0,322 \\
1,273\end{array}$ & $\begin{array}{l}0,261 \\
1,535 \mathrm{~d}\end{array}$ & $\begin{array}{l}0,286 \\
1,386\end{array}$ \\
\hline $\mathrm{Cl0}$ & - & - & - & - & - & - & - & $-\quad:$ & - & - & - & - \\
\hline C11 & 19 & 0,886 & $12,224^{a}$ & $\begin{array}{l}-0,748 \\
-0,991\end{array}$ & $\begin{array}{l}0,360 \\
1,105\end{array}$ & $\begin{array}{l}-0,118 \\
-0,346\end{array}$ & $\begin{array}{l}-0,166 \\
-1,306\end{array}$ & $\begin{array}{l}-0,471 \\
-1,256\end{array}$ & $\begin{array}{l}0,189 \\
0,680\end{array}$ & $\begin{array}{l}1,262 \\
3,432^{*}\end{array}$ & $\begin{array}{l}-0,056 \\
-0,179\end{array}$ & $\begin{array}{r}-0,071 \\
-0,224\end{array}$ \\
\hline $\mathrm{C} 12$ & - & - & - & - & - & - & - & - & - & - & - & - \\
\hline C13 & 20 & 0,911 & $17,541^{*}$ & $\begin{array}{l}0,633 \\
1,321\end{array}$ & $\begin{array}{l}0,260 \\
1,741^{d}\end{array}$ & $\begin{array}{l}0,141 \\
0,663\end{array}$ & $\begin{array}{l}-0,026 \\
-0,580\end{array}$ & $\begin{array}{l}0,172 \\
0,950\end{array}$ & $\begin{array}{l}0,176 \\
1,574^{d}\end{array}$ & $\begin{array}{l}0,016 \\
0,061\end{array}$ & $\begin{array}{l}0,261 \\
1,468\end{array}$ & $\begin{array}{l}-0,148 \\
-0,677\end{array}$ \\
\hline C14 & 14 & 0,971 & $28,243^{n}$ & $\begin{array}{l}-0,844 \\
-1,184\end{array}$ & $\begin{array}{l}-0,588 \\
-2,552^{b}\end{array}$ & $\begin{array}{l}0,428 \\
1,360\end{array}$ & $\begin{array}{l}0,564 \\
5,792\end{array}$ & $\begin{array}{l}-0,345 \\
-1,555\end{array}$ & $\begin{array}{l}0,332 \\
1,949^{\circ}\end{array}$ & $\begin{array}{l}0,155 \\
0,690\end{array}$ & $\begin{array}{l}0,455 \\
1,868^{\text {d }}\end{array}$ & $\begin{array}{l}0,936 \\
3,919^{n}\end{array}$ \\
\hline
\end{tabular}

Fonte: Dados da pesquisa

${ }^{a}=$ significativo a $1 \% ;{ }^{b}=$ significativo a $5 \% ;{ }^{c}=$ significativo a $10 \% ; e^{d}=$ significativo a $15 \%$. 
Tabela 4.6. Resultados das regressões do valor bruto de produção (modelo 4.4), por conglomerado e Estado do Paraná, 1985.

\begin{tabular}{|c|c|c|c|c|c|c|c|c|c|c|c|c|}
\hline \multirow[b]{2}{*}{ C/EST. } & \multirow[b]{2}{*}{$\mathrm{N}$} & \multirow[b]{2}{*}{$\mathrm{R}^{2}$} & \multirow[b]{2}{*}{ Teste $\mathbf{F}$} & \multicolumn{9}{|c|}{ Coeficientes estimados das variáveis independentes e respectivo teste t } \\
\hline & & & & Intercep & $\mathrm{BE}$ & ME & $\mathbf{C P}$ & RE & IA & $\mathrm{AE}$ & EH & QT \\
\hline Est. & 307 & 0,927 & $538,816^{n}$ & $\begin{array}{r}0,424 \\
3,843^{a}\end{array}$ & $\begin{array}{l}0,102 \\
3,465^{*}\end{array}$ & $\begin{array}{l}0,136 \\
3,728^{a}\end{array}$ & $\begin{array}{l}0,035 \\
3,094^{\mathrm{a}}\end{array}$ & $\begin{array}{l}-0,023 \\
-0,756\end{array}$ & $\begin{array}{l}0,229 \\
7,932^{\prime \prime}\end{array}$ & $\begin{array}{l}0,242 \\
5,292^{\prime \prime}\end{array}$ & $\begin{array}{l}0,278 \\
8,618^{a}\end{array}$ & $\begin{array}{r}0,364 \\
11,548^{\mathrm{a}}\end{array}$ \\
\hline $\mathrm{C} 01$ & 37 & 0,969 & $131,053^{\mathrm{a}}$ & $\begin{array}{l}0,616 \\
1,469^{d}\end{array}$ & $\begin{array}{l}0,049 \\
0,786\end{array}$ & $\begin{array}{l}0,036 \\
0,393\end{array}$ & $\begin{array}{l}-0,010 \\
-0,400\end{array}$ & $\begin{array}{l}-0,087 \\
-1,220\end{array}$ & $\begin{array}{l}0,322 \\
3,490^{\mathrm{a}}\end{array}$ & $\begin{array}{l}0,556 \\
3,928^{\prime \prime}\end{array}$ & $\begin{array}{l}0,135 \\
1,472^{d}\end{array}$ & $\begin{array}{l}0,281 \\
2,471^{b}\end{array}$ \\
\hline $\mathrm{C02}$ & 20 & 0,992 & $220,543^{\mathrm{a}}$ & $\begin{array}{l}-0,071 \\
-0,137\end{array}$ & $\begin{array}{l}-0,104 \\
-1,149\end{array}$ & $\begin{array}{l}0,278 \\
2,126^{b}\end{array}$ & $\begin{array}{l}0,011 \\
0,583\end{array}$ & $\begin{array}{l}-0,097 \\
-1,317\end{array}$ & $\begin{array}{l}0,435 \\
4,212^{\mathrm{a}}\end{array}$ & $\begin{array}{l}0,306 \\
1,315\end{array}$ & $\begin{array}{l}0,171 \\
1.438\end{array}$ & $\begin{array}{l}0,442 \\
3.085^{a}\end{array}$ \\
\hline $\mathrm{Co3}$ & 26 & 0,950 & $48,999^{*}$ & $\begin{array}{l}1,049 \\
1,516^{d}\end{array}$ & $\begin{array}{l}0,231 \\
2,851\end{array}$ & $\begin{array}{l}-0,047 \\
-0,305\end{array}$ & $\begin{array}{l}0,031 \\
0,554\end{array}$ & $\begin{array}{l}-0,340 \\
-3,029\end{array}$ & $\begin{array}{l}0,343 \\
2,320^{b}\end{array}$ & $\begin{array}{l}0,539 \\
2,999^{\text {a }}\end{array}$ & $\begin{array}{l}0,244 \\
1,875^{c}\end{array}$ & $\begin{array}{l}0,238 \\
1,597^{d}\end{array}$ \\
\hline $\mathrm{CO4}$ & 10 & 0,993 & $39,698^{b}$ & $\begin{array}{l}1,126 \\
0,796\end{array}$ & $\begin{array}{l}-0,826 \\
-2,874^{c}\end{array}$ & $\begin{array}{l}0,325 \\
1,165\end{array}$ & $\begin{array}{l}0,506 \\
4,416^{b}\end{array}$ & $\begin{array}{l}0,522 \\
2,314^{d}\end{array}$ & $\begin{array}{l}0,278 \\
0,741\end{array}$ & $\begin{array}{l}-0,033 \\
-0,147\end{array}$ & $\begin{array}{l}0,228 \\
0,690\end{array}$ & $\begin{array}{l}-0,043 \\
-0,100\end{array}$ \\
\hline $\mathrm{COS}$ & 10 & 0,998 & $126,992^{a}$ & $\begin{array}{l}1,585 \\
1,046\end{array}$ & $\begin{array}{l}0,257 \\
1,892\end{array}$ & $\begin{array}{l}-0,269 \\
-1,163\end{array}$ & $\begin{array}{l}-0,162 \\
-1,260\end{array}$ & $\begin{array}{l}-0,191 \\
-1,506\end{array}$ & $\begin{array}{l}0,680 \\
3,270^{c}\end{array}$ & $\begin{array}{l}0,887 \\
3,208^{\mathfrak{c}}\end{array}$ & $\begin{array}{l}-0,203 \\
-1,061\end{array}$ & $\begin{array}{l}-0,050 \\
-0,097\end{array}$ \\
\hline C06 & 50 & 0,950 & $112,884^{\mathrm{a}}$ & $\begin{array}{l}-0,577 \\
-1,210\end{array}$ & $\begin{array}{l}0,023 \\
0,420\end{array}$ & $\begin{array}{l}-0,004 \\
-0,031\end{array}$ & $\begin{array}{l}0,082 \\
2,995^{\mathrm{a}}\end{array}$ & $\begin{array}{l}0,082 \\
0,828\end{array}$ & $\begin{array}{l}0,193 \\
4,381^{a}\end{array}$ & $\begin{array}{l}0,375 \\
2,096^{b}\end{array}$ & $\begin{array}{l}0,250 \\
2,838^{n}\end{array}$ & $\begin{array}{l}0,624 \\
3,857^{\prime}\end{array}$ \\
\hline $\mathrm{C} 07$ & 43 & 0,985 & $323,025^{\AA}$ & $\begin{array}{l}1,384 \\
7,228^{a}\end{array}$ & $\begin{array}{l}-0,033 \\
-0,523\end{array}$ & $\begin{array}{l}0,379 \\
5,588^{\star}\end{array}$ & $\begin{array}{l}0,040^{\mathrm{b}} \\
2,124^{\mathrm{b}}\end{array}$ & $\begin{array}{l}0,237 \\
2,299^{b}\end{array}$ & $\begin{array}{l}0,307 \\
8,808^{n}\end{array}$ & $\begin{array}{l}-0,284 \\
-2,085^{b}\end{array}$ & $\begin{array}{l}\mathbf{0 , 3 5 3} \\
7,540^{n}\end{array}$ & $\begin{array}{l}-0,022 \\
-0,295\end{array}$ \\
\hline $\mathrm{C} 08$ & 23 & 0,927 & $27,374^{\mathrm{a}}$ & $\begin{array}{l}1,301 \\
0,840\end{array}$ & $\begin{array}{l}0,057 \\
0,313\end{array}$ & $\begin{array}{l}0,526 \\
2,095^{b}\end{array}$ & $\begin{array}{l}0,157 \\
1,573\end{array}$ & $\begin{array}{l}0,208 \\
1,600^{d}\end{array}$ & $\begin{array}{l}0,142 \\
0,883\end{array}$ & $\begin{array}{l}-0,060 \\
-0,141\end{array}$ & $\begin{array}{l}-0,030 \\
-0,137\end{array}$ & $\begin{array}{l}-0,226 \\
-0,490\end{array}$ \\
\hline $\mathrm{CO9}$ & 25 & 0,978 & $108,053^{\mathrm{a}}$ & $\begin{array}{l}1,013 \\
1,789^{c}\end{array}$ & $\begin{array}{r}-0,006 \\
-0,112\end{array}$ & $\begin{array}{l}0,127 \\
1,572^{d}\end{array}$ & $\begin{array}{l}0,028 \\
1,714^{c}\end{array}$ & $\begin{array}{l}0,188 \\
1,956^{\mathrm{c}}\end{array}$ & $\begin{array}{l}0,291 \\
4,139^{\mathrm{a}}\end{array}$ & $\begin{array}{l}0,045 \\
0,251\end{array}$ & $\begin{array}{l}0,327 \\
2,701^{b}\end{array}$ & $\begin{array}{l}0,088 \\
0,599\end{array}$ \\
\hline $\mathrm{C} 10$ & - & - & - & - & - & - & - & - & - & - & - & - \\
\hline C11 & 19 & 0,952 & $30,951^{*}$ & $\begin{array}{l}0,044 \\
0,091\end{array}$ & $\begin{array}{l}0,184 \\
0,883\end{array}$ & $\begin{array}{l}0,109 \\
0,499\end{array}$ & $\begin{array}{l}-0,107 \\
-1,317\end{array}$ & $\begin{array}{l}-0,141 \\
-0,590\end{array}$ & $\begin{array}{l}0,320 \\
1,806^{\mathfrak{c}}\end{array}$ & $\begin{array}{l}0,728 \\
3,096^{a}\end{array}$ & $\begin{array}{l}-0,093 \\
-0,463\end{array}$ & $\begin{array}{l}-0,016 \\
-0,081\end{array}$ \\
\hline $\mathrm{C} 12$ & - & - & - & - & - & - & - & - & - & - & - & - \\
\hline $\mathrm{C} 13$ & 20 & 0,958 & $38,780^{a}$ & $\begin{array}{l}0,915 \\
2,846^{a}\end{array}$ & $\begin{array}{l}0,163 \\
1,621^{d}\end{array}$ & $\begin{array}{l}0,331 \\
2,326^{b}\end{array}$ & $\begin{array}{l}-0,015 \\
-0,500\end{array}$ & $\begin{array}{l}0,129 \\
1,061\end{array}$ & $\begin{array}{l}0,191 \\
2,552^{b}\end{array}$ & $\begin{array}{l}-0,031 \\
-0,183\end{array}$ & $\begin{array}{l}0,232 \\
1,944^{c}\end{array}$ & $\begin{array}{l}-0,057 \\
-0,388\end{array}$ \\
\hline $\mathrm{C} 14$ & 14 & 0,977 & $36,395^{n}$ & $\begin{array}{l}-0,589 \\
-1,025\end{array}$ & $\begin{array}{l}-0,470 \\
-2,533^{b}\end{array}$ & $\begin{array}{l}0,503 \\
1,985^{\mathfrak{c}}\end{array}$ & $\begin{array}{l}0,410 \\
5,232^{*}\end{array}$ & $\begin{array}{l}-0,210 \\
-1,173\end{array}$ & $\begin{array}{l}0,220 \\
1,607\end{array}$ & $\begin{array}{l}0,268 \\
1,480\end{array}$ & $\begin{array}{l}0,278 \\
1,418\end{array}$ & $\begin{array}{l}0,767 \\
3,986^{\circ}\end{array}$ \\
\hline
\end{tabular}

Fonte: Dados da pesquisa

${ }^{a}=$ significativo a $1 \% ;{ }^{b}=$ significativo a $5 \% ;{ }^{c}=$ significativo a $10 \%$; $\mathrm{e}^{\mathrm{d}}=$ significativo a $15 \%$. 
O sinal positivo ou negativo do parâmetro indica escassez ou excesso do "fator de produção", respectivamente. A contribuição negativa de um determinado fator, para o valor agregado (VA), ocorre quando o retorno, em termos de valor bruto da produção (VBP), pelo emprego desse fator, é menos que proporcional ao seu custo. Isto é, - VA teria reduções pelo uso desse fator. Por exemplo, o uso de adubo químico sem corrigir a acidez do solo; a motomecanização dos solos de baixa aptidão agrícola sem manejá-los adequadamente; o super dimensionamento no uso de um fator, etc. Como a análise estatística foi realizada por conglomerado e Estado, já era esperado esse comportamento nas variáveis. Dependendo das características edafoclimáticas e sócio-econômicas dos conglomerados, uma variável pode estar associada positivamente com o VA ou as produtividades num conglomerado, negativamente em outro e vice-versa.

A análise estatística por conglomerado traz ganhos de qualidade na interpretação dos resultados e direciona com maior segurança e economia a aplicação de recursos ao setor rural. Por exemplo, se a análise do VA fosse realizada apenas para o Estado, pelos dados das equações estimadas (Tabela 4.5), concluir-se-ia que as variáveis $B E, M E, C P$ e IA tinham pouca importância, que a variável $R E$ contribuiu negativamente e que as variáveis $A E$, $\mathrm{EH}$ e QT foram as que mais influenciaram o VA. No entanto, as variáveis $\mathrm{BE}$ e $\mathrm{ME}$ foram as variáveis mais associadas com - incremento do VA nos conglomerados C13 e C09, 
respectivamente. A variável CP foi importante nos conglomerados $\mathrm{C} 04$ e C14, com coeficiente estatisticamente diferente de zero. As variáveis $Q T, A E$ e EH eram as mais importantes para o VA do Estado, mas estatisticamente a contribuição de QT e AE foi nula em oito dos conglomerados analisados. A variável rebanho mostrou-se importante para o VA dos conglomerados C04 e C09 e contribuiu negativamente para o mesmo no conglomerado $\mathrm{C03}$ e no Estado. Nas demais unidades de análise o seu parâmetro estimado foi estatisticamente nulo.

\subsubsection{Análise das variáveis}

os coeficientes de determinação das regressões, nos conglomerados e no Estado, apresentaram uma amplitude de 0,857 a 0,997 para modelo 4.3 e de 0,927 a 0,998 para o modelo 4.4, evidenciando um bom ajustamento dos mesmos (Tabela 4.5 e 4.6$)$.

A análise da influencia dos fatores no VA foi realizada com base no teste $t$. O teste $F$ foi significativo a 1\% em todas as unidades de análise, exceto no conglomerado $\mathrm{C} 04$. Os parâmetros estimados e o valor do teste $t$, por conglomerado e Estado (Tabelas 4.5 e 4.6), mostraram que:

a) BE (logaritmo do valor das instalações e outras benfeitorias). Apesar de contribuir pouco para o VA do Estado, isto é, para cada $1 \%$ de aumento no valor das instalações e benfeitorias, mantendo-se constante os demais fatores, o VA do Estado se eleva de 0,08\%, foi o fator mais 
importante no desenvolvimento do conglomerado $\mathrm{C} 13$ e apresentou a terceira maior contribuição no conglomerado C03. Sua influência no VA e no VBP dos conglomerados C04 e C14 foi negativa, mas estatisticamente nula nos demais conglomerados;

b) ME (logaritmo do valor das máquinas e instrumentos agrários). Seus parâmetros estimados para o VA foram estatisticamente diferentes de zero no Estado e nos conglomerados C02, C07, C08 e C09. A mecanização foi o fator que mais contribuiu para o VBP do conglomerado $\mathrm{C} 13$ e o segundo mais importante no conglomerado C14;

c) CP (logaritmo do valor das culturas permanentes e das matas plantadas). Sua contribuição para o VA só foi significativa nos conglomerados C04, C07 e C14 e no Estado, com coeficientes estimados de 0,418, 0,055, 0,564 e 0,032, respectivamente;

d) RE (logaritmo do valor do rebanho). o rebanho estava associado positivamente com o VA dos conglomerados $\mathrm{C04}$ e C09 e negativamente no Estado e no conglomerado $\mathrm{C03}$, mostrando que enquanto naqueles conglomerados a produção pecuária poderia ser incentivada, neste conglomerado havia excesso de rebanho. Nos outros conglomerados sua contribuição foi estatisticamente nula. Realmente, na última década ocorreu uma grande expansão da pecuária de corte nos conglomerados C04 e C09. Mesmo assim, ficou evidenciada a ineficiência do rebanho paranaense no incremento do VA da agropecuária, em 1985. Para o VBP sua 
contribuição foi positiva e estatisticamente diferente de zero nos conglomerados C04, C07, C08 e C09, negativa no conglomerado $\mathrm{C03}$ e nula nas demais unidades de análise.

e) IA (logaritmo das despesas com insumos para culturas e criações). O insumo usado na agropecuária teve grande influência no VBP da maioria dos conglomerados $\left(83,33 \frac{0}{6}\right)$ e do Estado, com parâmetros estimados estatisticamente significativos e positivos (Tabela 4.6), mas em termos de VA sua contribuição foi nula em $66,67 \%$ dos conglomerados. O uso de insumos só agregou valor na produção dos conglomerados C02, C07, C13 e C14 e no Estado. Isso revelou que uma maior eficiência no incremento do VA do Estado, via utilização de insumos, deveria ser buscada pela geração, adaptação e difusão de tecnologias químicobiológicas apropriadas para os sistemas de produção desses conglomerados.

f) $\mathrm{AE}$ (logaritmo da área explorada). A $\mathrm{AE}$ foi o terceiro fator mais associado com o VA do Estado, e o fator com maior contribuição para o aumento do VA nos conglomerados $\mathrm{C} 01, \mathrm{C} 03$ e $\mathrm{C} 11$, sendo o único fator não nulo deste conglomerado. Também foi o segundo fator em importância no conglomerado C06, mas estatisticamente não teve influência sobre o VA em $66,67 \%$ dos conglomerados;

g) EH (logaritmo do total de equivalenteshomem ocupados na agropecuária). A força de trabalho era o segundo fator de produção mais importante na geração do VA da agropecuária paranaense. Foi o fator mais associado ao 
VA dos conglomerados e o que mais agregou valor à produção agropecuária do conglomerado C07;

h) QT (logaritmo da qualidade da terra: valor da terra nua por AE). Essa variável mostrou-se importante em $37,5 \%$ dos conglomerados com solos de alta aptidão agrícola (C01 a C08) e em 25,0\% dos conglomerados de baixa aptidão agricola (C09 a C14). A qualidade da terra foi a variável que mais contribuiu para o valor agregado do Estado e dos conglomerados $\mathrm{C} 02$ e $\mathrm{C} 06$ e do conglomerado de menor aptidão agrícola do Estado (C14), que tinha sua AE ocupada com reflorestamentos (20\%), matas naturais (38\%), lavouras permanentes $(7 \%)$, pastagens (19\%) e lavouras temporárias (inclui a área em descanso) (150). Estes dados mostraram que o uso não conflitivo do solo com a sua classe de aptidão agrícola é fundamental para se agregar valor à produção.

\subsubsection{Análise das unidades de estudo}

\subsection{Estado do Paraná}

Em 1985, as produtividades do trabalho (PL) e da terra (PT) do Estado do Paraná foram iguais a $\mathrm{Cz}$ $7.360,00$ e Cz\$ 970,00, respectivamente. Isso eqüivalia a 22,85 salários mínimos $\left(\mathrm{SM}^{11}\right)$ por equivalente-homem ocupado na agropecuária e 3,01 SM por hectare de $\mathrm{AE}$

Os "fatores de produção" $\mathrm{AE}, \mathrm{EH}$ e QT foram os que mais agregaram valor à produção agropecuária do

\footnotetext{
11 valor do salário mínimo (média ponderada) de 1985, Cz\$322,08.
} 
Estado. Para cada 1\% de acréscimo na quantidade usada desses fatores $O$ VA se eleva de $0,39 \%, 0,44 \%$ e $0,45 \%$, respectivamente. Conseqüentemente as produtividades do trabalho (PL) e da terra (PT) se elevam na mesma proporção. os fatores de produção $\mathrm{CP}, \mathrm{BE}$ e $\mathrm{ME}$ contribuíram pouco para o VA. A influência do RE foi negativa para o VA e nula para o VBP. Pressupõe-se que esta influência foi devida à estiagem ocorrida naquele ano. Segundo DERAL (1985), esse fator climático foi responsável, no caso da pecuária, pela redução de 21000 toneladas na produção de carne, aumento no indice de mortalidade, diminuição na comercialização de reprodutores, bezerros e boi magro, aumento no índice de vacas abatidas e atraso na reforma de pastagens e capineiras.

O aumento do VA do Estado pode ser buscado pelo uso mais racional dos insumos, máquinas e benfeitorias; adequações na exploração da pecuária e das culturas permanentes; e incentivando o uso dos demais fatores.

A AE do Estado era composta pelas áreas com lavouras temporárias (39\%), áreas com lavouras permanentes (4\%), áreas com pastagens naturais (9\%), áreas com pastagens plantadas (30\%), áreas com matas naturais (13\%) e áreas com matas plantadas (5\%) (Tabela 4.2, p.59). 


\subsection{Conglomerado CO1}

O conglome-

rado C01 é composto pelos municípios: Alvorada do Sul, Andirá, Arapongas, Assaí, Assis Chauteaubriand, Barra do Jacaré, Bela Vista do Paraíso, Cafelândia, Cambará, Cambé, Doutor Camargo,

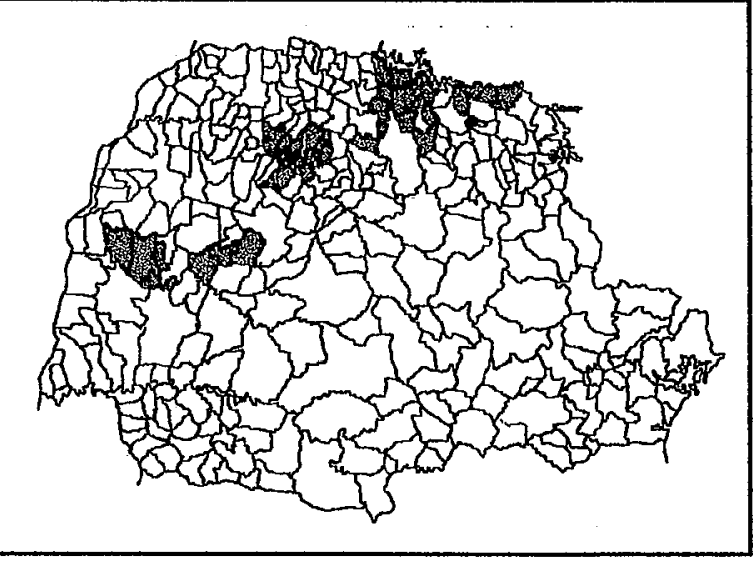

Engenheiro Beltrão, Floraí, Floresta, Ibiporã, Itambaracá, Itambé, Ivatuba, Jesuítas, Juranda, Mamborê, Marialva, Maringá, Ourizona, Paiçandu, Palotina, Primeiro de Maio, Rancho Alegre, Santa Amélia, Santa Mariana, São Jorge do Ivaí, Sarandi, Sertaneja, Sertanópolis, Tupassi, ubiratã e Uraí.

Esse conglomerado abrange as regiões Norte Velho, Norte Novo e Oeste do Paraná. Ocupa os solos de maior aptidão agrícola do Estado. Consequientemente ele alcançou a segunda maior produtividade do trabalho e da terra (Figuras 4.6 e $4.7, \mathrm{p} .60$ ).

Estava entre os conglomerados mais importantes do Paraná, em termos de produção agropecuária. Era o sexto em número de estabelecimentos agrícolas do Estado $(7,89 \%)$ com AE média de 30,58 ha. Ocupava o sétimo lugar em $\operatorname{AE}(7,23 \%)$ e empregava o terceiro maior contingente de mão-de-obra $(11,11 \%)$. Apresentou o maior VA $(17,80 \%)$ e $\mathrm{VBP} / \mathrm{AE}(\mathrm{Cz} \$ 4.100,00)$ e era o conglomerado mais tecnificado, ocupando o primeiro lugar no valor de máquinas 
e equipamentos $(23,64 \%)$. Em 1985, dispunha de um trator para cada 50 ha de área cultivada $(A C)$ e uma colheitadeira para cada 219 ha de $A C$, mudas e sementes $(30,10 \%)$, defensivos $(25,29 \%)$, aluguel de máquinas e equipamentos (24,90\%), transporte da produção $(28,80 \%)$ e impostos e taxas $(22,64 \%$ ) (Tabela 4.2, p.59 e Apêndices 3 e 4).

A sua AE era composta de lavouras temporárias (73\%), lavouras permanentes (5\%), pastagens naturais (2\%), pastagens plantadas (16\%), matas plantadas (1\%) e matas naturais (3\%) (Apêndice 2).

Mesmo sendo o conglomerado com a segunda maior PL do Paraná, tinha o terceiro maior número de $\mathrm{EH}$ ocupados na agropecuária, empregando 1 EH a cada 4,89 ha de AE .

- conglomerado $\mathrm{CO1}$ apresentou a segunda maior PL (Cz\$ 11.680,00) e PT (Cz\$ 2.390,00) do Estado, em função principalmente da $\mathrm{AE}$, da qualidade do seu recurso natural e da mão-de-obra.

Os resultados das regressões mostraram que o VA desse conglomerado ainda pode ser elevado pelo incremento da mão-de-obra, melhoria na qualidade do recurso natural e expansão da área de lavouras temporárias, pois o rebanho e as culturas permanentes não contribuíram para aumentar o VA.

Apesar do teste $F$ ser significativo a 1\%, indicando que os coeficientes estimados não são nulos, o teste $t$ foi não significativo até $15 \%$ para as variáveis $B E$, ME, CP, RE e IA. 
Uma agropecuária mais eficiente se dará com a expansão da AE com lavouras temporárias, melhorias no uso da terra e da mão-de-obra e adequação dos fatores sem contribuição. A restrição e a adoção de técnicas mais eficientes no uso destes fatores proporcionarão um VA ainda maior nesse conglomerado.

\subsection{Conglomerado $\mathrm{CO} 2$}

rado $\mathrm{C} 02$ localiza-se principalmente no Oeste do Estado. Seus municípios componentes são: Bandeirantes, Boa Esperança, Braganey, Cascavel, Corbé-

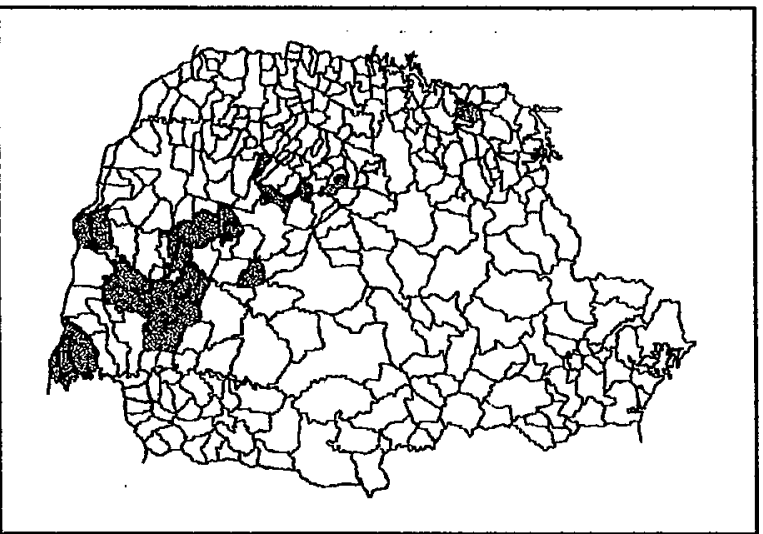
lia, Fênix, Formosa do Oeste, Foz do Iguaçu, Goioerê, Guaira, Janiópolis, Jussara, Kaloré, Nova Aurora, Nova Cantu, Peabiru, Santa Terezinha do Itaipu, São Miguel do Iguaçu, Terra Roxa e Toledo. Possui solos de alta aptidão agrícola, diferenciando do conglomerado C01 principalmente por ser menos intensivo no uso de máquinas e insumos (Tabela 4.7).

Estava entre os conglomerados mais importantes. Era $\circ$ quinto em número de estabelecimentos agrícolas $(8,35 \%)$, com $\mathrm{AE}$ média de 29,13 ha. Ocupava o sexto lugar em $\operatorname{AE}(7,28 \%)$, constituida principalmente pela área de lavouras temporárias $(64,02 \%)$, representando $11,17 \%$ das lavouras temporárias do Estado. Usava 9,75\% de mão-de- 
obra ocupada, era o segundo conglomerado que mais usava insumos por $\mathrm{AE}$ na produção animal $(16,78 \%)$, o terceiro no uso de máquinas e equipamentos $(15,52 \%)$ e no valor de aluguel de máquinas e equipamentos $(19,88 \%)$. Contribuiu com $15,93 \%$ dos impostos e taxas e ocupou o segundo lugar no consumo de combustíveis $(14,10 \%)$ e juros e despesas bancárias $(17,51 \%)$.

Nesse conglomerado o VA era afetado principalmente pelos fatores qualidade da terra, mão-deobra, insumos e mecanização. Os demais fatores, exceto $\mathrm{AE}$, apresentaram parâmetros negativos, mas estatisticamente nulos.

4.2.1.2.4. Conglomerado $\mathrm{CO} 3$

rado $\mathrm{C0} 3$ é formado por 26 municípios, localizados principalmente nas regiões Norte Velho e Norte Novo do Paraná: Amaporã, Astorga, Bom Sucesso, Campo Mourão, Centenário do Sul, Congonhinhas, Cornélio

Procópio, Florestópolis, Iguaraçu, Jacarezinho, Jaguapitã, Jataizinho, Jundiaí do Sul, Leópolis, Londrina, Mandaguaçu, Marumbi, Nova América da Colina, Nova Fátima, Porecatu, Quinta do Sol, Ribeirão Claro, Santo Antônio do Paraíso, São Pedro do Ivaí, São Sebastião da Amoreira e Terra Boa. A 
aptidão agrícola do solo era inferior à dos conglomerados C01 e C02, a área com pastagens representava 47,44\% da $\mathrm{AE}$ e a ALT 39,37\%. Ocupava o quarto lugar no uso de insumos para culturas por $\mathrm{AE}$ e valor de máquinas e equipamentos por EH. obteve a quinta maior $\mathrm{PL}$ e a sétima maior $\mathrm{PT}$.

$$
\text { Esse conglomerado tinha 4,21\% dos }
$$

estabelecimentos do Estado, com 56,91 ha de $A E$ por estabelecimento. Empregava 0,14 EH por hectare de área cultivada.

Os fatores $A E$, força de trabalho e benfeitorias contribuíram positivamente para o VA, indicando que o aumento desses fatores agrega valor à produção. O efeito da pecuária no VA foi negativo. Incremento no valor do rebanho de $1 \%$, sem alterar a composição dos demais fatores, faz o VA decrescer de 0,43\%.

A análise de regressão não permitiu constatar a influência da mecanização, do uso de insumos agropecuários, da qualidade da terra e do valor das culturas permanentes sobre o VA.

\subsection{Conglomerado $\mathrm{CO} 4$}

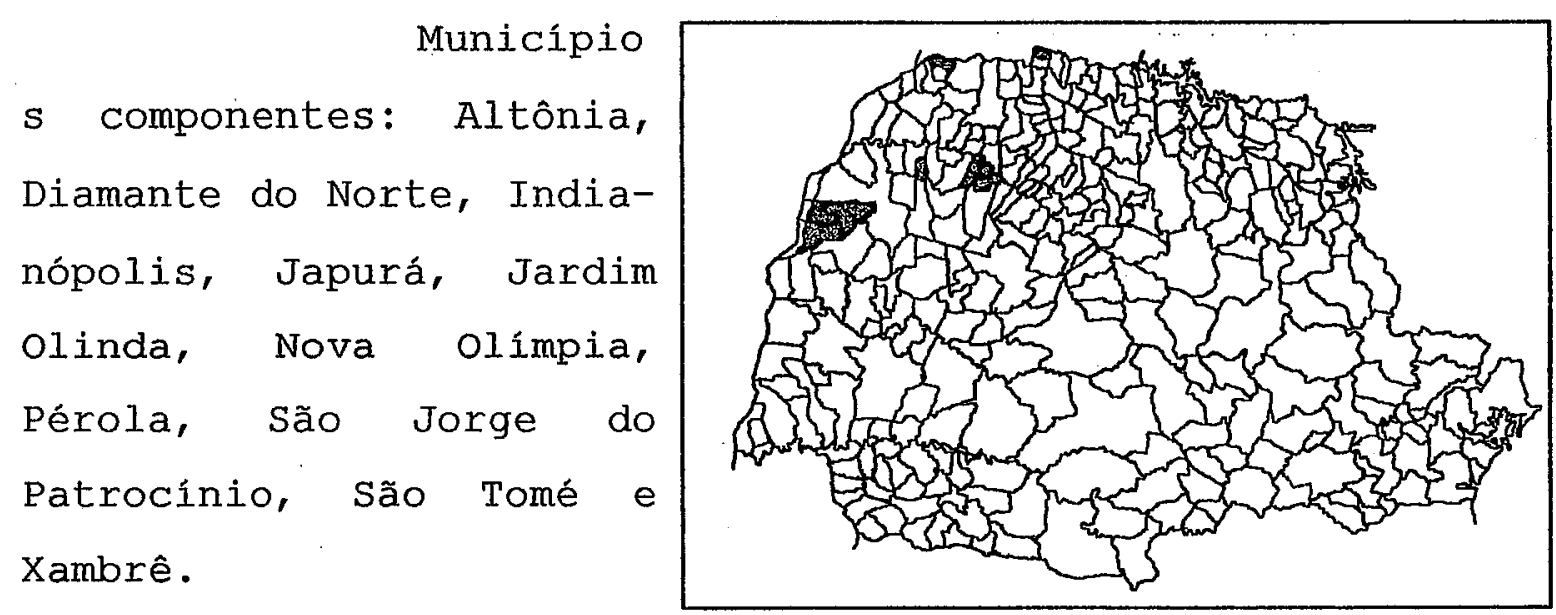


O conglomerado C04 está inserido no Noroeste do Estado, região do Arenito Caiuá. Era um reduto da cafeicultura, mas em processo de decadência iniciado no final da década de 70. Em substituição à cafeicultura inicia-se um processo de pecuariação. A área com lavouras permanentes (café) e a área com pastagens representavam $20,32 \%$ e $58,62 \%$ da $\mathrm{AE}$, respectivamente.

Cada estabelecimento tinha em média 20,34 ha de AE. Esse conglomerado ocupava o terceiro lugar no emprego de mão-de-obra por hectare de $\mathrm{AE}(0,21 \mathrm{EH})$, o mais baixo nível de mecanização ( $\mathrm{Cz}$ \$ 687,68 por ha) e o maior valor de cultura permanente por hectare de AE (Cz\$ 6560,00). O rebanho e as culturas permanentes foram os fatores que influenciaram positivamente $O$ VA, desse conglomerado, com parâmetros estimados iguais a 0,572 e 0,418 . $O$ valor das benfeitorias estava associado negativamente com $O$ VA. Estatisticamente não houve influência dos demais fatores no VA.

\subsection{Conglomerado C05}

o conglo-

merado C05 é constituído de 10 municípios: Cianorte, Douradina, Icaraíma, Itaúna do Sul, Maria Helena, Marilena, Porto Rico, São Pedro do Paraná, Tapira e Umuarama .

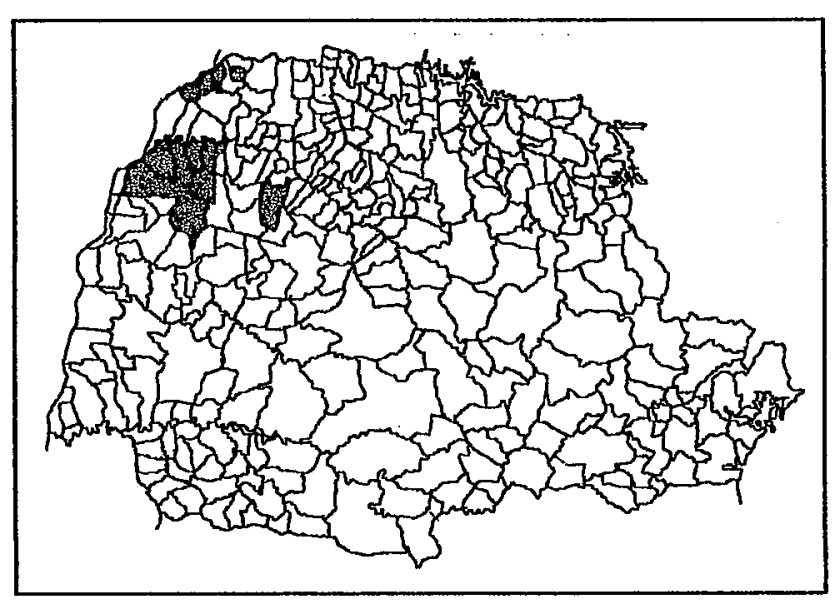


Localizado na região Noroeste do Estado, se diferenciava do conglomerado C04 por apresentar AE média dos estabelecimentos agrícolas bem maior (38,09 ha), utilizar 43 menos mão-de-obra por hectare de $A E(0,12 \mathrm{EH})$, estar num estágio de pecuariação mais elevado, com 73,21\% da $A E$ em pastagens e 11,51\% com lavouras permanentes (café), e ser menos intensivo no uso de máquinas e insumos.

Individualmente os "fatores de produção" não mostraram influência estatisticamente significativa no VA desse conglomerado, mas verificou-se influência dos insumos e da $A E$ no VBP. Neste caso os parâmetros estimados foram 0,68 e 0,89, respectivamente, significativos a $10 \%$ (teste t).

\subsection{Conglomerado $\mathrm{C06}$}

Situado basi-

camente no Noroeste do

Estado, é o maior conglomerado em número de municípios (50): Alto Paraná, Alto Piquiri, Araruna, Cafeara, Cidade Gaúcha,

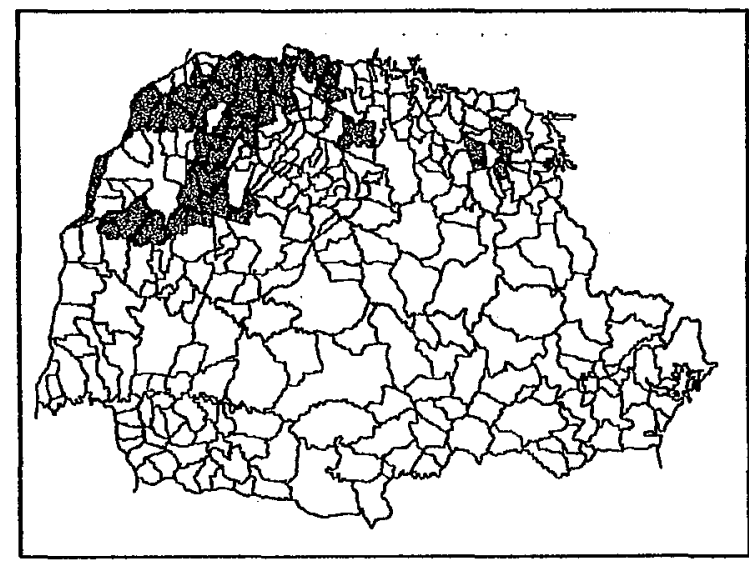

Conselheiro Mairinck, Cruzeiro do Oeste, Cruzeiro do Sul, Flórida, Francisco Alves, Guairacá, Guaporema, Guaraci, Ibaiti, Inajá, Iporã, Itaguagé, Loanda, Lobato, Lupionópolis, Mariluz, Mirador, Moreira Sales, Munhoz de Melo, Nossa Senhora das Graças, Nova Aliança do Ivaí, Nova 
Londrina, Paraíso do Norte, Paranacity, Paranapoema, Paranavaí, Planaltina do Paraná, Querência do Norte, Ribeirão do Pinhal, Rolândia, Rondon, Sabáudia, Santa Cruz do Monte Castelo, Santa Inês, Santa Izabel do Ivaí, Santo Antônio da Platina, Santo Antônio do Caiuá, Santo Inácio, São Carlos do Ivaí, São João do Caiuá, Tamboara, Tapejara, Terra Rica, Tuneiras do Deste e Uniflor.

Caracterizava-se pela forte pecuariação em substituição à cafeicultura. Era um dos conglomerados mais produtivos, pois gerava o quarto maior VA do Estado $(10,03 \%)$ e era o quínto maior empregador de mão-de-obra $(10,79 \%)$ e detinha a maior área de pastagens $(20,88 \%)$. A $\mathrm{AE}$ era composta de pastagens $(70,21 \%)$, lavouras permanentes $(6,73 \%), \cdot$ lavouras temporárias $(19,19 \%)$ e matas plantadas e naturais $(3,87 \%)$. A área média explorada por estabelecimento era de $45,74 \mathrm{ha}$.

Exceto as variáveis $\mathrm{QT}, \mathrm{AE}$, e $\mathrm{EH}$, estatisticamente as demais não contribuiram para o VA. Como 70,21\% da $\mathrm{AE}$ estava com pastagens, um VA maior teria que ser buscado, principalmente, via ajustes nos sistemas de produção do rebanho bovino. Além de melhorar a qualidade da terra, através do manejo adequado do solo; e elevar a quantidade de trabalho utilizada. 
4.2.1.2.8. Conglomerado $\mathrm{C07}$

O conglomerado $\mathrm{C07}$ situa-se principalmente no sudoeste e Oeste do Paraná e é composto de 44 municípios: Ampere, Barracão, Boa Vista da Aparecida, Califórnia, Capanema, Capitão (n) Leônidas Marques, Céu Azul, Chopinzinho, Coronel Vivida, Dois Vizinhos, Enéias Marques, Francisco Beltrão, Itapejara D'Oeste, Ivaiporã, Marechal Cândido Rondon, Mariópolis, Marmeleiro, Matelândia, Medianeira, Missal, Nova Prata do Iguaçu, Nova Santa Rosa, Pato Branco, Pérola D'Oeste, Planalto, Pranchita, Realéza, Renascença, Salgado Filho, Salto do Itararé, Salto do Lontra, Santa Cecilia do Pavão, Santa Helena, Santa Isabel do Oeste, Santana do Itararé, Santo Antônio do Sudoeste, São João, São João do Ivaí, São Jorge $D^{\prime}$ Oeste, São José da Boa Vista, Três Barras do Paraná, Vera Cruz do Oeste, Verê e Vitorino.

Era o conglomerado com maior número de estabelecimentos agrícolas (97.776), representando 21,07\% do total do Estado, e o que empregava mais mão-de-obra $(16,86 \%)$. Depois do conglomerado $\mathrm{C} 12$ foi o que apresentou a menor área explorada por estabelecimento $(17,18$ ha). Mesmo sendo o quarto conglomerado em $\mathrm{AE}(10,84 \%)$ foi 0 segundo em geração de VA $(14,16 \%)$ no Estado. É uma região de solos relativamente férteis, com limitações à 
motomecanização, mas dispondo de 1 trator para cada 109 ha e 1 colheitadeira e para cada 395 ha de AE. Também se destacava pela qualidade da força de tração animal ${ }^{12}$. Dispunha ainda de 1 animal de trabalho para cada 31 ha de AE (Tabela 4.2, p.59).

- conglomerado $\mathrm{C} 07$ se caracterizava como produtor de milho, feijão, fumo-de-corda e pequenos animais (suínos e aves). Ocupava o segundo lugar em despesa com insumos para criações por hectare de AE. Esta área era constituída por lavouras temporárias $(63,59 \%)$, pastagens $(26,78 \%)$, matas plantadas e naturais $(8,30 \%)$ e lavouras permanentes $(1,33 \%)$.

Os fatores mais associados com o VA desse conglomerado foram a mecanização e a força de trabalho. As culturas permanentes e os insumos também contribuíram para - VA. Os parâmetros estimados das variáveis $B E, R E, A E$ e $Q T$ não foram significativos a $15 \%$.

\subsection{Conglomerado C08}

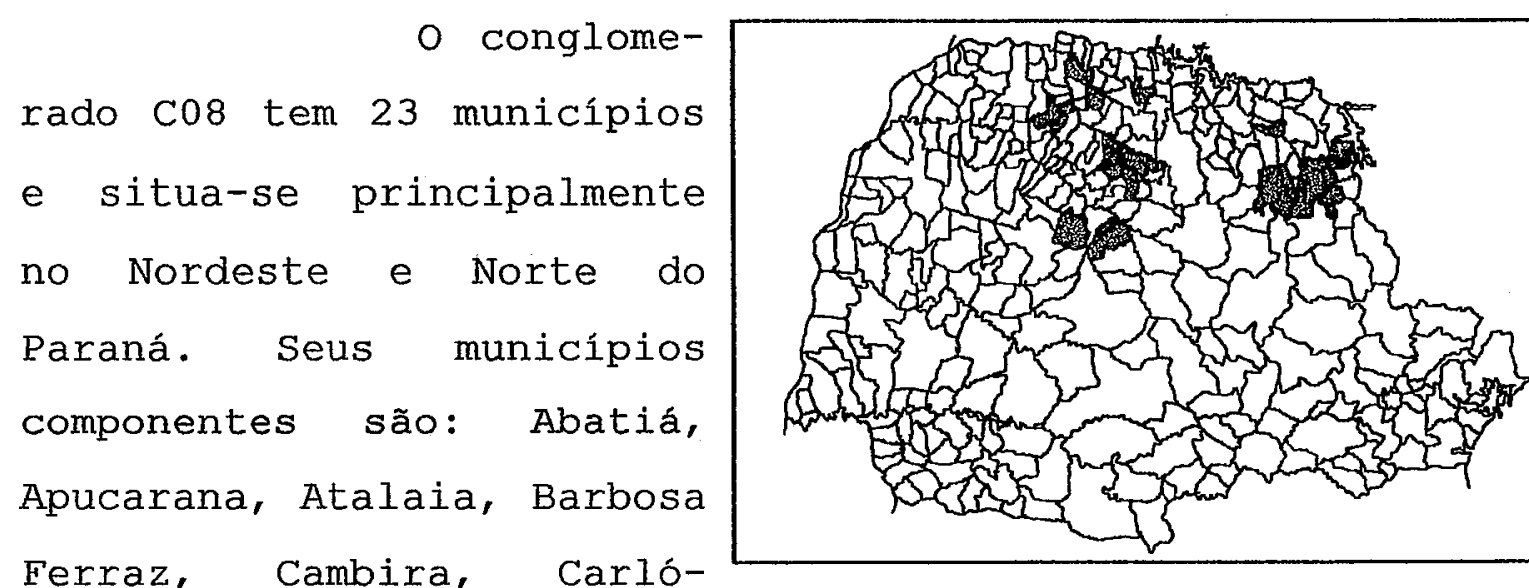

polis, Colorado, Figueira, Guapirama, Jaboti, Jandaia do

\footnotetext{
${ }^{12}$ Utilizava o boi como força de tração animal. Em 1985 existiam no Paraná 135.772 bois e garrotes para o trabalho.
} 
Sul, Japira, Jardim Alegre, Joaquim Távora, Lunardelli, Mandaguari, Miraselva, Nova Esperança, Presidente Castelo, Quatiguá, Santa Fé, Siqueira Campos e Tomazina.

Esse conglomerado se caracterizava como produtor de milho, café, feijão, algodão e leite. Com 5,54\% dos estabelecimentos agrícolas detinha 4,53\% da AE, 6,58\% da mão-de-obra ativa e gerava 5,94\% do VA do Estado.

Da AE, pastagens representavam 52,66\%, lavouras temporárias 29,98\%, lavouras permanentes 11,28\%, matas plantadas e naturais 6,07\%. Era pouco intensivo no uso de máquinas (AE/trator $=152$ ha e $A E /$ colheitadeira = 946 ha) e insumos.

Estatisticamente a mecanização foi o único fator significativamente associado com $O$ VA desse conglomerado. Já o VBP era influenciado pela mecanização, pelas culturas permanentes (café) e pelo rebanho.

4.2.1.2.10. Conglomerado C09

o conglome-

rado c09 conta com 25 municípios: Altamira do Paraná, Borrazópolis, Campina da Lagoa, Cândido de Abreu, Cantagalo, Catanduvas, Curiúva, Faxinal, Grandes Rios, Guaraniaçu, Iretama, Laranjeiras

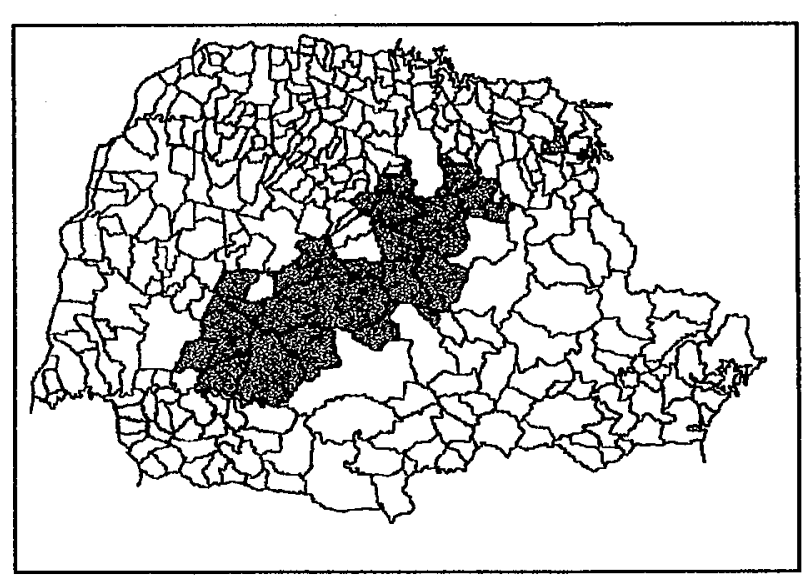


do Sul, Manoel Ribas, Marilândia do Sul, Ortigueira, Palmital, Pinhalão, Pitanga, Quedas do Iguaçu, Reserva, Rio Bom, Roncador, São Gerônimo da Serra, Sapopema e Turvo.

Localizado no Centro do Estado, é o maior conglomerado em extensão territorial, abrangendo a represa do Salto de Santiago, os Campos de Guarapuava e a região de Ortigueira.

Os solos são de baixa aptidão agrícola, com sérias limitações à motomecanização e à exploração de lavouras temporárias. São mais apropriados para as culturas permanentes, reflorestamentos e pecuária. No entanto, a falta de projetos para incentivar essas atividades tem sido uma constante. Mesmo assim, na última década o prócesso de pecuariação tem se acentuado nessa região. Em 1985, 41,63\%, $40,57 \%$ e $16,84 \%$ da $\mathrm{AE}$ estavam com pastagens, lavouras e matas (plantadas e naturais), respectivamente.

Era um conglomerado de grande importância sócio-econômica para o Estado. Possuía o segundo maior número de estabelecimentos agrícolas - $77.368(16,68 \%)$, com AE média de 30,17 ha e a maior $A E(15,07 \%)$. Detinha o segundo lugar em números de EH ocupados na agropecuária $(13,62 \%)$, área de lavouras $(14,55 \%)$, pastagens $(16,20 \%)$ e rebanho $(12,34 \%)$, e o maior valor em animais de trabalho $(17,78 \%)$.

Com exceção dos fatores rebanho, máquinas e equipamentos e força de trabalho, os demais não contribuíram para o VA. Já o VBP era afetado por aqueles fatores e também pelas culturas permanentes (erva-mate, 
fruticultura e silvicultura) e pelo uso de insumos para criações e lavouras.

A falta de infra-estrutura (saúde, educação, transporte, assistência técnica e serviços em geral) tem sido a grande limitação para o desenvolvimento rural desse conglomerado.

\subsection{Conglomerado C10}

o conglo-

merado ${ }^{\circ} 10$ situa-se no

Segundo Planalto, concentrando-se nas áreas dos Campos Gerais de Ponta Grossa e da Lapa e é composto por sete

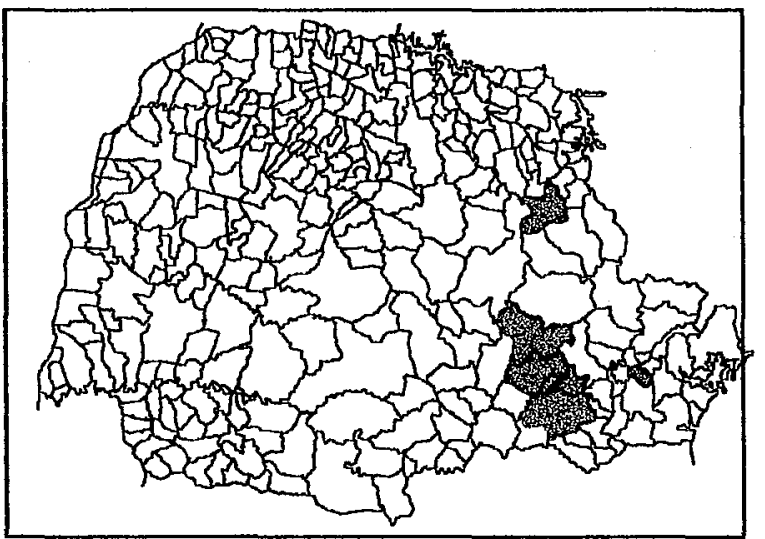

municípios: Arapoti, Balsa

Nova, Lapa, Palmeira, Piraquara, Ponta Grossa e Porto Amazonas. Esse conglomerado tinha 10.365 estabelecimentos $(2,23 \%)$, com $A E$ média de 56,50 ha, e um dos menores índices de mão-de-obra ocupada por hectare de $\mathrm{AE}$ $(0,07 \mathrm{EH})$. A $\mathrm{AE}$ era constituída de pastagens (37,75\%), lavouras temporárias $(32,66 \%)$ e matas $(29,15 \%)$. Apresentou a maior área de pastagem natural $(23,20 \%)$ e o quarto lugar em matas naturais $(15,60 \%)$. Produzia $6,91 \%$ do leite paranaense. Era uma região de contrastes tecnológicos: por um lado existia a agropecuária com tecnologia de ponta, desenvolvida principalmente por holandeses (Cooperativas Batavo, Castrolanda e CAPAL), alemães (Cooperativa 
Witmarsum) e sem etnia predominante (Bom Jesus e CLAC), e por outro lado a maioria dos produtores desenvolvia uma agropecuária tradicional com baixissimas produtividades físicas. Na média considera-se um conglomerado com concentração fundiária e pouco intensivo no uso de insumos, mas que detinha o terceiro lugar em valor de máquina e equipamentos por EH. Consequientemente teve a segunda menor $\mathrm{PT}$ e a quinta menor PL.

A análise de regressão não foi realizada devido ao baixo número de observações.

\subsection{Conglomerado C11}

o conglome-

rado C11 é composto por vinte municipios: Almirante Tamandaré, Bituruna, Campo do Tenente, Castro, Clevelândia, General Carneiro, Guarapuava, Ipiranga, Jaguariaiva, Mangueirinha, Palmas,

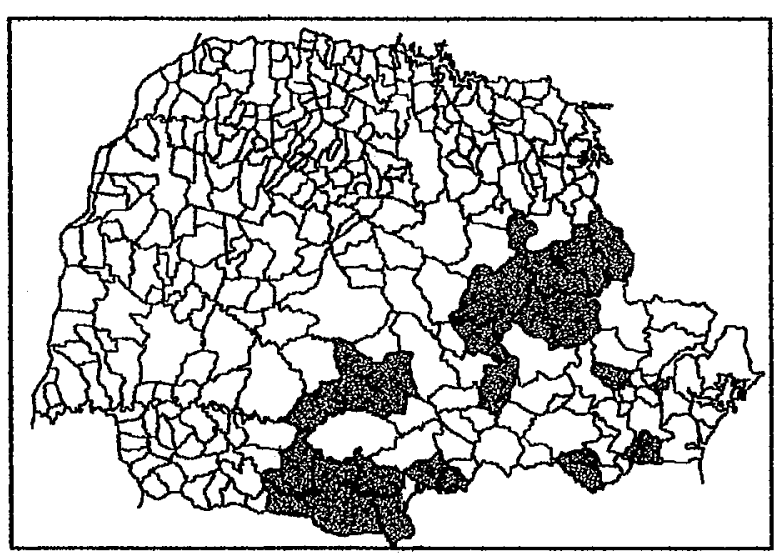

Paula Freitas, Pirai do Sul, Quatro Barras, Rio Negro, Sengés, Teixeira Soares, Tibagi, Tijucas do Sul e União da Vitória.

Se caracterizava como produtor de madeira, leite, soja, trigo, milho e feijão. Era o conglomerado com a maior área explorada por estabelecimento $(69,57$ ha) e a menor densidade de mão-de-obra rural $10,06 \mathrm{EH}$ por hectare de $A E)$. A sua participação no VA do Estado foi de $6,92 \%$. 
Teve o quinto melhor índice de máquinas e equipamentos por equivalente-homem (Cz\$ $12.150,00)$ e um dos menores indices de consumo intermediário por hectare de $\mathrm{AE}(\mathrm{Cz} \$ 300,00)$.

Apresentou a maior área de reflorestamento 290.675 ha $(35,47 \%)$ e mata nativa 528.815 ha $(24,61 \%)$ do Estado, representando $13,53 \%$ e $24,61 \%$ de sua $A E$, respectivamente. As áreas com pastagens e lavouras representavam $35,16 \%$ e $26,78 \%$ da $\mathrm{AE}$, respectivamente.

Apesar da $\mathrm{AE}$ e dos insumos contribuírem para o VBP, a AE foi o único fator significativamente associado com O VA.

Como a fronteira agrícola, em termos de AE, está esgotada, para se agregar mais valor à produção é necessário melhorar o uso da $\mathrm{AE}$ e racionalizar o uso dos demais fatores.

\subsection{Conglomerado $\mathrm{C} 12$}

O conglome-

rado $\mathrm{C} 12$, constituído pelos municípios de Araucária, Contenda e Curitiba, contava com 2761 estabelecimentos $(0,60 \%)$ e $0,25 \%$ da AE. Possuía a menor área explorada por estabele-

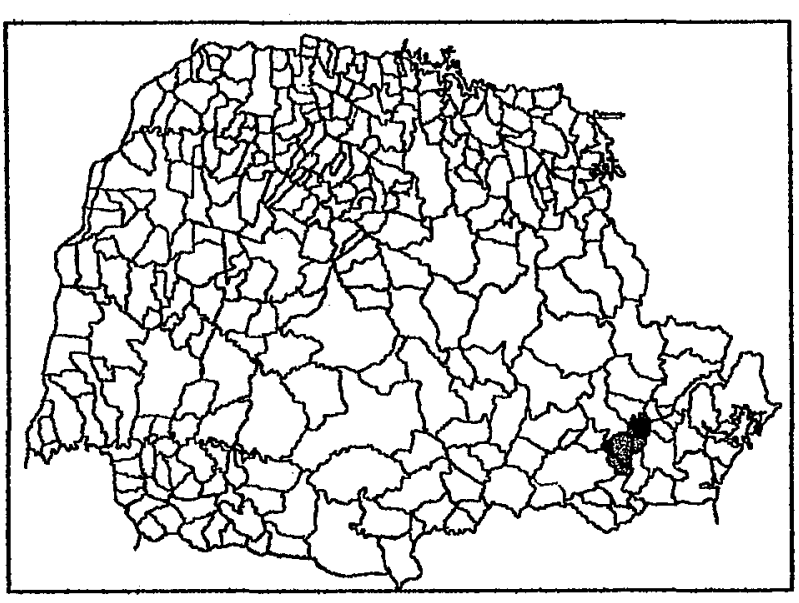
cimento $(13,94$ ha). Mesmo

localizado em solos de baixa aptidão agrícola, mas com a vantagem de estar junto ao maior centro consumidor do 
Paraná, obteve a maior PT do Sul do Estado (VA/AE $=\mathrm{Cz} \$$ $1.590,00)$ e uma razoável $\mathrm{PL}$ (VA/EH $=\mathrm{Cz} \$$ 6.200,00), evidenciando uma agropecuária eficiente. Essa eficiência foi conseguida pela exploração de atividades com maior densidade de renda como olericultura, fruticultura, avicultura e bovinocultura de leite.

Como o. número de observações desse conglomerado era menor que o número de variáveis independentes, não foi possível realizar a análise de regressão.

\subsection{Conglomerado C13}

O conglome-

rado $\mathrm{C} 13$ é composto por 21 municípios, concentrados nas regiões Centro-Sul e Sul do Estado: Agudos do Sul, Antônio Olinto, Campo Largo, Colombo, Cruz Machado, Imbituva, Irati,

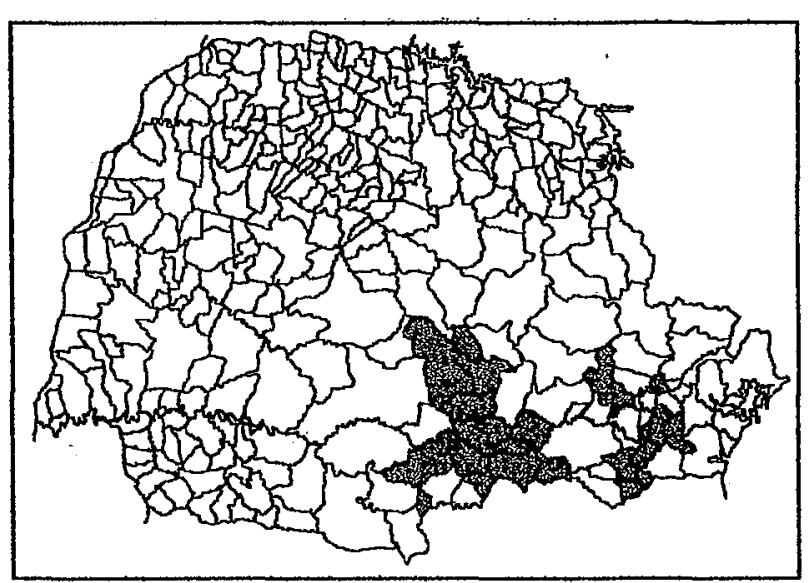
Ivaí, Mallet, Mandirituba, Paulo Frontin, Piên, Porto Vitória, Prudentópolis, Quitandinha, Rebouças, Rio Azul, São João. do Triunfo, São José dos Pinhais, São Mateus do Sul e Wenceslau Braz.

Esse conglomerado se caracterizava como a região da tração animal e produtora de fumo, milho e feijão em consórcio, cebola, batata e mel. Ocupava 5,7\% da AE e empregava $6,69 \%$ da mão-de-obra rural do Estado. 
A baixa aptidão agrícola do solo, aliada ao baixo nível tecnológico e de capitalização da agropecuária, proporcionaram-1he a mais baixa produtividade do trabalho e a quinta pior produtividade da terra.

O VA desse conglomerado era influenciado por dois fatores: benfeitorias e instalações e insumos agropecuários. Além desses fatores, a mecanização e a força de trabalho também contribuíram para o VBP, mas sem agregar valor à produção. Estatisticamente os outros fatores não contribuíram para a produção.

Nesse conglomerado predominava a fumicultura que usava bastante instalações e lenha para secagem do fumo. Só em Rio Azul havia mais de 1500 estufas de fumo consumindo em média $60 \mathrm{~m}^{3}$ de lenha/ano/estufa.

Seus solos apresentavam limitações sérias de fertilidade e de motomecanização. Como a maioria dos produtores eram descapitalizados, deixavam 16,10\% da $\mathrm{AE}$ em pousio como forma de recuperar a fertilidade do solo. Um grande incremento do VA pode ser conseguido pelo uso correto dos insumos, principalmente dos insumos para as lavouras, pois boa parte da pecuária ainda era utilizada como reserva de valor. Na segunda metade da década de 80, 0 rendimento de milho e feijão dos pequenos agricultores da região de Irati era de $966 \mathrm{~kg} / \mathrm{ha}$ e $747 \mathrm{~kg} / \mathrm{ha}$, respectivamente (GUERREIRO et alii, 1994). 


\subsection{Conglomerado C14}

o conglome-

rado C14 é composto por 14 municípios: Adrianópolis, Antonina, Bacaiúva do Sul, Campina Grande do Sul, Cerro Azul, Guaraqueçaba, Guaratuba, Inácio Martins, Matinhos, Morretes, Paranaguá,

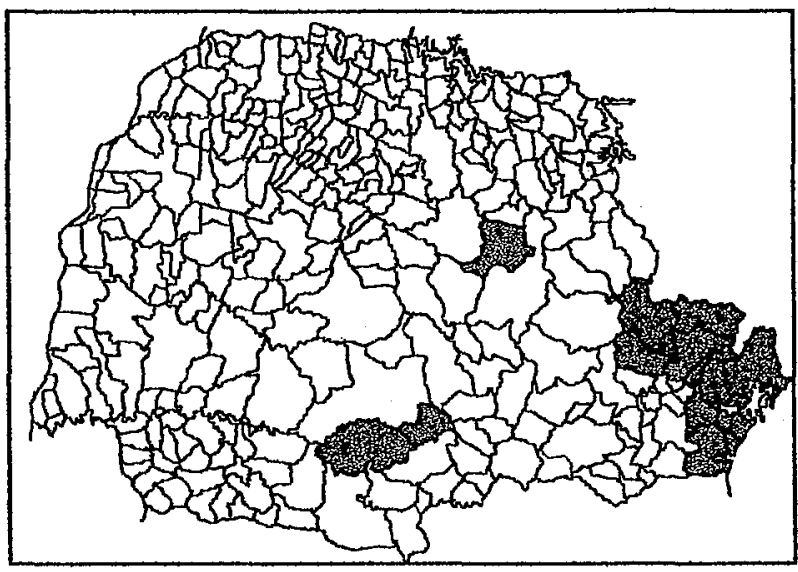
Pinhão, Rio Branco do Sul e Telêmaco Borba, situados no Litoral, Vale da Ribeira e Centro-Sul do Estado. Esse conglomerado possuía a menor densidade de pessoas ocupadas por hectare de $\mathrm{AE}(0,06 \mathrm{EH})$, juntamente com o conglomerado C11. A. AE era composta principalmente de mata natural $(38,95 \%)$, mata plantada $(19,62 \%)$ e pastagens $(19,39 \%)$.

É uma região de baixa aptidão agrícola e baixo nível de tecnificação. Tinha o menor índice de consumo intermediário por hectare de $\mathrm{AE}(\mathrm{Cz} \$ 80,00)$ e a maior proporção de área cultivada por trator (500 ha) (Tabela 4.2, p.59).

Em ordem decrescente de importância, os fatores que contribuíram para o incremento do VA desse conglomerado foram: qualidade da terra, culturas permanentes (inclui reflorestamento), força de trabalho e insumos. As benfeitorias e instalações estavam associadas negativamente com $O$ VA.

Esse conglomerado apresentou a menor PT $(\mathrm{VA} / \mathrm{AE})$ do Estado ( $\mathrm{Cz} \$ 390,00)$, conseqüência da baixa 
aptidão agrícola do solo. Foi o conglomerado com a menor relação entre área cultivada e $\mathrm{AE}(55,28 \%)$, e a maior relação entre área de matas naturais e AE (39\%). A área com culturas permanentes e matas plantadas representava $27,03 \%$ da AE. Parte dos municípios desse conglomerado se localiza no litoral e está na região de preservação ambiental da Serra do Mar.

Nesse conglomerado estão os solos de menor aptidão agrícola. No entanto, a qualidade da terra foi o fator mais associado com O VA. Como 85,37\% da sua AE estava ocupada com matas, reflorestamentos, culturas permanentes e pastagens, o solo estava sendo utilizado de acordo com a sua classe de aptidão agrícola. Então conclui-se que o uso não conflitivo do solo com a sua classe de aptidão agrícola é fundamental para se agregar valor à produção. 


\section{CONCLUSÕES}

A análise de regressão desenvolvida neste trabalho permitiu identificar variáveis que afetam o valor agregado e as produtividades da terra e do trabalho na agricultura paranaense e também por conglomerado (conforme regionalização do IAPAR) .

Em termos monetários, não houve diferença da influência de cada "fator de produção" para o valor agregado e para as produtividades do trabalho e da terra. Entretanto, o efeito de cada "fator de produção" para o valor agregado $e$ as produtividades dependeu das caracterı́sticas edafoclimáticas e sócio-econômicas de cada conglomerado. Um fator pode estar associado positivamente com o valor agregado e as produtividades num conglomerado e negativamente em outro e vice-versa. Portanto, recomendase que as ações de desenvolvimento rural considerem as peculiaridades de cada conglomerado.

As produtividades do trabalho e da terra variaram significativamente entre os conglomerados. Essa diferença se acentuou entre os conglomerados com predominância de solos com alta e baixa aptidão agrícola. As produtividades do trabalho e da terra daqueles 
conglomerados (C01 a C08) foram em média 1,54 e 2,79 vezes maiores que as produtividades destes conglomerados (C09 a C14), respectivamente.

A análise da influência da intensidade de uso de vários fatores de produção sobre o valor agregado e as produtividades, por conglomerado, tornou mais evidente que o agrupamento dos municípios com características edafoclimáticas e sócio-econômicas homogêneas é fundamental para que se possam fazer recomendações tecnológicas apropriadas a cada caso.

No Estado do Paraná, o valor agregado e as produtividades do trabalho e da terra foram influenciados principalmente pela qualidade da terra. Todavia esse fator não foi importante para $67 \%$ dos conglomerados analisados. A mão-de-obra e a área explorada ocuparam o segundo e o terceiro lugar em ordem de importância, respectivamente. Mas quando a análise foi realizada por conglomerado, verificou-se que em vários deles a intensidade do uso desses fatores não mostrou efeito positivo e estatisticamente significativo sobre o valor agregado $e$ as produtividades.

Nos qüinquiênios 1975 a 1980 e 1980 a 1985, a produtividade do trabalho cresceu em quatro microrregiões homogêneas (MRH), embora tenha diminuido em quatro MRH e no Estado como um todo. Contudo, no último quiinquiênio essa produtividade decresceu em $15 \mathrm{MRH}$ e no Estado. Naquele decênio a produtividade da terra cresceu em três MRH, embora tenha diminuido em três MRH e no Estado. De 1980 a 
1985 a mesma cresceu no Estado e decresceu em treze MRH. A tendência decrescente da produtividade do trabalho no Estado, de 1975 a 1985, teve como causa principal a variação mais que proporcional do consumo intermediário $(39,66 \%)$ em relação à variação do valor bruto da produção $(14,22 \%)$.

$\mathrm{Na}$ agropecuária, quando se trabalha com produtividade líquida do trabalho, não se pode generalizar que o aumento da mesma esteja associado com a diminuição do pessoal ocupado. Isso depende da atividade explorada e da tecnologia empregada. Por exemplo, o conglomerado C12, especializado na produção de frutas, olerícolas e leite, empregava 0,26 EH por hectare de área explorada e sua produtividade do trabalho era 1,52 vezes maior que a do conglomerado C13 que ocupava 0,15 EH por hectare de área explorada, mas explorava basicamente milho e feijão em consórcio, com baixo nível tecnológico.

O aumento do valor agregado e das produtividades do trabalho e da terra em cada unidade de análise deve ser buscado pelo incremento dos fatores associados positiva e significativamente com essas produtividades e/ou com a racionalização no uso dos fatores de contribuição negativa ou nula.

Para se agregar mais valor à produção agropecuária do Paraná e conseqüentemente melhorar os indices de produtividade do trabalho e da terra, os projetos de desenvolvimento rural do Estado devem ser elaborados com base em diagnóstico das restrições e 
oportunidades tecnológicas dos sistemas de produção de cada conglomerado, adequando o uso do solo com a sua classe de aptidão agrícola.

A agropecuária paranaense apresentou rendimentos constantes à escala, no Estado e nos conglomerados. 


\section{BIBLIOGRAFIA}

AGUIRRE, B.M.B.; BACHA, C.J.C. A especialização da mão-deobra rural no Brasil. In: CONGRESSO BRASILEIRO DE ECONOMIA E SOCIOLOGIA RURAL, 27, Piracicaba/SP, 1989. Anais. Brasilia, SOBER, 1989. v.1, pp.572-584. ARAÚJO, F.C.A. et alii. Mercado de trabalho na agricultura. Agricultura. FEALQ, Piracicaba, 1(2):1-7, 1986.

BARBOSA F.H. Microeconomia: teoria, modelos econométricos e aplicações à economia brasileira. Rio Janeiro. IPEA/INPES, 1985. pp. 219-231.

BARROS, J.R.M. de; PASTORE, A.C.; RIZZIERE, J.A.B. A evolução recente da agricultura brasileira. In: Estudos sobre a Modernização da Agricultura Brasileira. IPE, São Paulo, 1977.

BARRANDA, N.A. Analysis of factors associated with variations in land and labor productivity in Southern Brazil. The Ohio State University, 1970. 87p. (Thesis M. S.). BRASIL. Ministério da Agricultura. Secretaria Nacional de Planejamento Agrícola. Aptidão agrícola das terras do Paraná. Brasília, BINAGRI, 1981. 
CARVALHO, D. Mercado de trabalho na agricultura brasileira: década dos oitenta. Piracicaba, 1993. 160p. (Mestrado Escola Superior de Agricultura "Luiz de Queiroz"/USP). CENSO AGROPECUÁRIO-1985. Rio de Janeiro, FIBEG, Paraná. n.22, 1991. CENSO AGROPECUÁRIO-MANUAt DO RECENSEADOR-1985. Rio de Janeiro, FIBEG, Paraná.

CHIANG, A.C. Matemática para economistas. São Paulo, McGraw-Hill do Brasil, Ed. da Universidade de São Paulo, 1982. $683 \mathrm{p}$.

DRAPER, N.R.; SMITH, H. Applied Regression Analysis. John Wiley, New York, 407p.

DELFIM NETO, A.; PASTORE, A.C.; CARVALHO, E.P. Agricultura e desenvolvimento econômico no Brasil. 1965, pp.32-40. (Estudos ANPES n. 5).

DERAL. Acompanhamento da situação agropecuária do Paraná. Curitiba. $11(1-12)$. 1985.

ENGLER, J.J. de C. Análise da produtividade de recursos na agricultura. Piracicaba, 1968. 102p. (Doutorado Escola Superior de Agricultura "Luíz de Queiroz/USP"). FONTES, L.B. Princípios de produtividade. São Paulo, ATLAS, 1966. $130 \mathrm{p}$.

FOURASTIÉ, J. A produtividade. São Paulo, ATTAS, 1961. 120p. FUENTES LLANILLO, R. Caracterização da estrutura de produção agropecuária do Paraná. Piracicaba, 1984 . 
177p. (Mestrado - Escola Superior de Agricultura "Luíz de Queiroz"/USP).

EUENTES LLANILLO, R.; DEL GROSSI, M.E.; DORETTO, M.; VASCONCELOS, E. e UKUBATA, I.F. Regionalização da agropecuária paranaense. In: CONGRESSO BRASILEIRO DE ECONOMIA E SOCIOLOGIA RURAI, 31, Ilhéus/BA, 1993. Anais. Brasilia/DF, SOBER, 1993. v.1, pp.152-160. FUNDAÇÃO GETÚLIO VARGAS, IBRE, Centro de Contas Nacionais. Contas Nacionais do Brasil - Metodologia e Tabelas Estatísticas. Rio de Janeiro, pp. 9-10. GUERREIRO, E.; NEWMAIER, M.C.; ARAÚJO, A.C.; SOUZA, A.B.; MERTEN, G.H. Caracterização, tipologia e diagnóstico de sistemas de produção predominantes en uma comunidade rural: - caso de Cerro da Ponte Alta, Irati(PR). Londrina, IAPAR, 1994. 51p. (IAPAR, Boletim Técnico, 47).

HAYAMI Y. e RUTTAN V.W. Preços dos fatores e mudança técnica no desenvolvimento da agricultura: Estados Unidos e Japão, 1880 - 1960. In: ARAUJO, P.F.C. e SCHUH, G.E. Desenvolvimento da agricultura:educação, pesquisa e assistência técnica. São Paulo, Pioneira, 1975. v.2,.pp.53-75.

HAYAMI Y. e RUTTAN V.W. Desenvolvimento agrícola: teorias e experiências internacionais. Brasilia, EMBRAPA, 1988. 583p. HEADY, E.O. e DILLON, J.L. Agricultural production functions. Iowa state University Press, 1961. 
HOFFMANN, R.; SERRANO, O.; NEVES, E.M.; THAME A.C. e ENGLER J.J.C. Administração da empresa agrícola. 4. ed., São Paulo, Pioneira, 1984. 325p.

HOFFMANN, R.; CARVALHO, A.V.; KAGEYAMA, A. WIENDL, M.L.T. B. e QUEDA. A. Inovações tecnológicas e transformações recentes na agricultura brasileira. Relatório de pesquisa FINEP-FEALQ/ ESALQ/USP, 1985.

HOFFMANN, R. e VIEIRA, S. Análise de regressão: Uma introdução à econometria. 2.ed, São Paulo, HUCITEC, 1987. $379 \mathrm{p}$.

HOFEMANN, R.; JAMAS, A.L.; KASSOUF A.L. A modernização e a produtividade da agropecuária em 332 microrregiões homogêneas do Brasil em 1975 e 1980. Relatório de pesquisa CODEVASF-FEALQ/ESALQ/USP, 1990. $146 \mathrm{p}$.

HOFFMANN, R.; JAMAS, A.L. "A produtividade da terra e do trabalho na agricultura de 332 microrregiões do Brasil". In: CONGRESSO BRASILEIRO DE ECONOMIA E SOCIOLOGIA RURAL, 28, Florianópolis/SC, 1990. Anais. Brasilia, SOBER, 1990. v.2, pp. 21-40.

KAGEYAMA, A.A. Modernização, produtividade e emprego na agricultura - uma análise regional. Campinas, São Paulo. 389p. (uma versão modificada da tese de doutorado). KENDRICK, J.W. Productivity and national income accounting. Output, input, and productivity measurement: studies in income and wealth XXV, a Report of the National Bureau 
of Economic Research, Inc., Princeton University Press, Princeton, 1961. pp. 3-20.

LOPES, M.R. Prioridades para a integração das políticas agrícolas no MERCOSUL: uma avaliação brasileira para servir de referência nas discussões. In: A AGROPECUÁRIA BRASILEIRA E O MERCOSUL. Piracicaba, ESALQ/USP/MRE/MEFP /PNUD, 1992. 37p. (Projeto MERCOSUL).

MACHADO, A.C.M. Procutividade. São Paulo, ATLAS, 1964. 207p. MARX, K. O capital - Livro 1: o processo de produção capitalista. 2.ed., Rio de Janeiro, Civilização Brasileira, 1968. v.1., pp.41-533.

MARX, K. O capital - Livro 1: o processo de produção capitalista. 2.ed., Rio de Janeiro, Civilização Brasileira, 1968. v.2., pp.533-919.

MENDES, J.T. e DOSSA, D. A contribuição da área e da produtividade no crescimento agrícola paranaense. In: XX CONGRESSO BRASILEIRO DE ECONOMIA E SOCIOLOGIA RURAL, 28, Curitiba/PR, 1982. Anais. Brasilia, SOBER, 1982. v. 3, pp.73-77.

MOREIRA, D:A. Produtividade industrial brasileira. São Paulo, 1990. 257p. (Livre-docência - FEA/USP) NICHOLLS, W.H. "O excedente agrícola" como fator de desenvolvimento econômico. In: ARAUJO, P.F.C.; SCHUH, G.E. Desenvolvimento da agricultura; natureza do processo e modelos dualistas. São Paulo, Pioneira, 1975. v.1, pp.3-38. 
OCEPAR (ORGANIZAÇÃO DAS COOPERATIVAS DO ESTADO DO PARANÁ). Custos de produção, plantio direto: aveia, milho, soja, trigo. Curitiba, OCEPAR/FUNDAÇÃO ABC, 1989. 46p.

RICARDO, D. Princípios de economia política e tributação. São Paulo, Abril Cultural, 1982. (Coleção "Os Economistas").

SAS INSTITUTE INC. SAS/Estat Guide for Personal Computers. 6.ed., Cary, North Carolina. 1985, 378p.

SILVA, G.L.S.P. Evolução e determinantes da produtividade agrícola: o caso da pesquisa e da extensão rural em São Paulo. São Paulo, 1982. 234p. (Doutorado - "Faculdade de Economia e Administração"/USP) .

SMITH, A. A riqueza das nações - investigação sobre sua natureza e suas causas. São Paulo, Abril Cultural, 1985. (Coleção "Os Economistas").

SRAFFA, P. Produção de mercadoria por meio de mercadorias. São Paulo, Abril Cultural, 1983. p.203. (Coleção "Os Economistas)

STULP, V.J. Tecnologia, custos e competitividade no MERCOSUL: caso do trigo, soja, milho e arroz. In: A AGROPECUÁRIA BRASILEIRA E O MERCOSUL. Piracicaba, ESALQ/USP/MRE/MEFP/PNUD, 1992. 24p. (Projeto MERCOSUL). THOMPSON, R.L. The metaproduction funcion for Brazilian agricultural: an analysis of productivity and other aspects of agricultural growth. Purdue University, 1974 . 176p. (Tese de Ph.D). 
VARIAN, H.R. Microeconomic Analysis. $2^{\text {a }}$ ed., New York, $\mathrm{W}, \mathrm{W}$, Norton \& Company.

VICENTE, J.R. Influência de educação, pesquisa e assistência técnica na produtividade da agricultura brasileira na década de setenta. Piracicaba, 1989. 193p. (Mestrado - ESALQ/USP).

VOLACO, G. (Coordenador). Economia paranaense - desempenho recente e cenário de curto prazo. Análise Conjuntural. Curitiba, IPARDES, PR, 13(4):1-16, abril de 1991. WEBER, J.E. Matemática para Economia e Administração. São Paulo, HARBRA, 1977. pp.332-40. 


\section{APÊNDICE 1}

Dados utilizados na determinação das

produtividades do trabalho e da terra por municipio, 1985. 
Tabela 1A. Dados utilizados na determinação das produtividades do trabalho e da terra por municipio, 1985.

\begin{tabular}{|c|c|c|c|c|c|c|}
\hline MUNICIPIO & $\begin{array}{c}\text { VBP } \\
(\mathrm{Cz} \$ 1000)\end{array}$ & $\begin{array}{c}\mathrm{CI} \\
(\mathrm{Cz} \$ 1000)\end{array}$ & $\begin{array}{c}\text { DEP } \\
\langle\mathrm{Cz} \$ 1000)\end{array}$ & $\begin{array}{c}\text { VA } \\
(\mathrm{Cz} \$ 1000)\end{array}$ & EHH & $\begin{array}{l}\mathrm{AE} \\
\text { (ha) }\end{array}$ \\
\hline 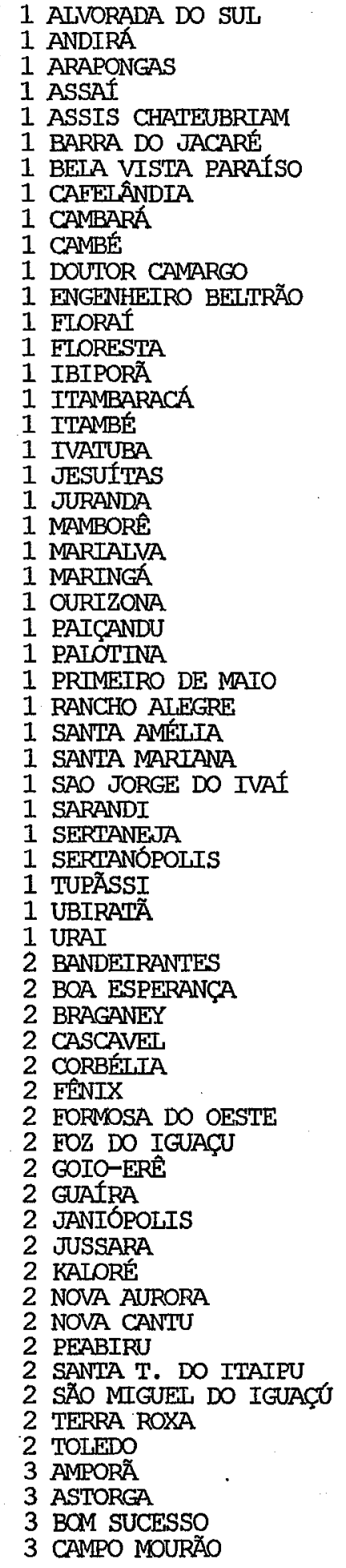 & $\begin{array}{r}135897 \\
83278 \\
125201 \\
113620 \\
475966 \\
36553 \\
95126 \\
110260 \\
135082 \\
148980 \\
34817 \\
142751 \\
56150 \\
54318 \\
109345 \\
60010 \\
81922 \\
40678 \\
91876 \\
92337 \\
169298 \\
170646 \\
135219 \\
52569 \\
49769 \\
467188 \\
157627 \\
63053 \\
24590 \\
178183 \\
130912 \\
36504 \\
150877 \\
167192 \\
124172 \\
218401 \\
75011 \\
118182 \\
93257 \\
60057 \\
407183 \\
173252 \\
70273 \\
107739 \\
41957 \\
291304 \\
114514 \\
72850 \\
331899 \\
175681 \\
51658 \\
82012 \\
8102123 \\
2329619 \\
99017 \\
62416\end{array}$ & $\begin{array}{r}38806.96 \\
26152.14 \\
55353.97 \\
38091.90 \\
147754.91 \\
8337.25 \\
26456.54 \\
41165.46 \\
33336.11 \\
57005.44 \\
7512.80 \\
36239.20 \\
14789.89 \\
18121.54 \\
26732.94 \\
21883.18 \\
35288.52 \\
15010.53 \\
25512.05 \\
30043.63 \\
79842.68 \\
55075.24 \\
38792.82 \\
13906.69 \\
14564.60 \\
137679.72 \\
45772.39 \\
19653.04 \\
5128.80 \\
43258.77 \\
40934.71 \\
11263.21 \\
67132.10 \\
45406.91 \\
38969.10 \\
731674.60 \\
1346.50 \\
20163.17\end{array}$ & $\begin{array}{r}10381.51 \\
6509.92 \\
15511.30 \\
13253.51 \\
34808.93 \\
3917.90 \\
10972.38 \\
8516.12 \\
14446.36 \\
18434.77 \\
3235.05 \\
13995.26 \\
4083.37 \\
4949.14 \\
9699.12 \\
6817.01 \\
6677.78 \\
5619.68 \\
9953.65 \\
6270.87 \\
17680.16 \\
16715.55 \\
47354.68 \\
4080.72 \\
4173.89 \\
45534.30 \\
13683.24 \\
4792.95 \\
2114.71 \\
21950.43 \\
11435.59 \\
5104.61 \\
15545.13 \\
17044.76 \\
7133.48 \\
16686.28 \\
6412.73 \\
10874.71 \\
8253.50 \\
5526.85 \\
38692.62 \\
17103.47 \\
6273.76 \\
8695.83 \\
2632.89 \\
19964.64 \\
11156.55 \\
6748.00 \\
7451.55 \\
3198.42 \\
13181.48 \\
4067.76 \\
8690.08 \\
6487.62 \\
11420.59 .62 \\
30659.50\end{array}$ & 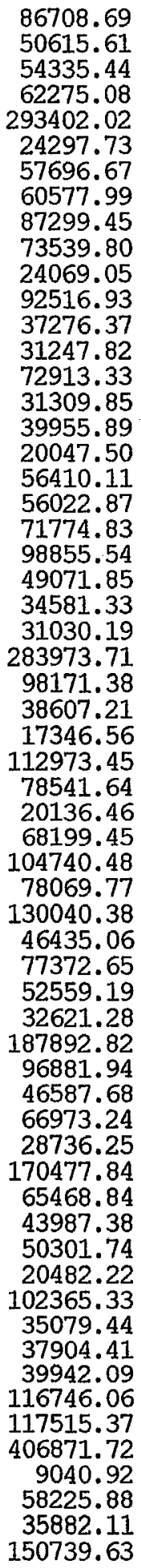 & 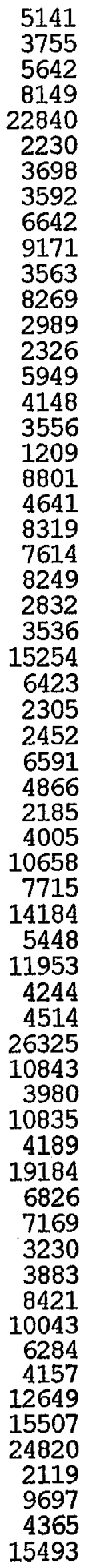 & 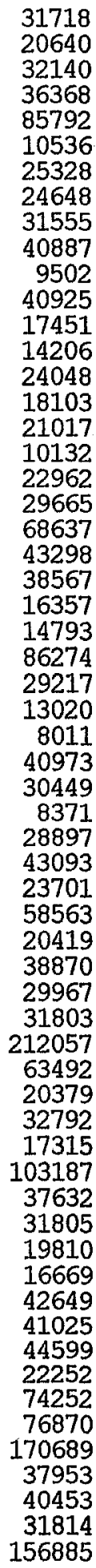 \\
\hline
\end{tabular}


Tabela 1A. Continução.

\begin{tabular}{|c|c|c|c|c|c|c|c|}
\hline 6 & MUNI & $\begin{array}{c}\text { VBP } \\
\mathrm{Cz} \$ 1000)\end{array}$ & $\begin{array}{c}C T \\
(\mathrm{Cz} \$ 1000)\end{array}$ & $\begin{array}{c}\text { DEP } \\
(\mathrm{Cz} \$ 1000)\end{array}$ & $\begin{array}{c}\text { VA } \\
(\mathrm{Cz} \$ 1000)\end{array}$ & EH & $\begin{array}{l}\mathrm{AE} \\
\text { (ha) }\end{array}$ \\
\hline & 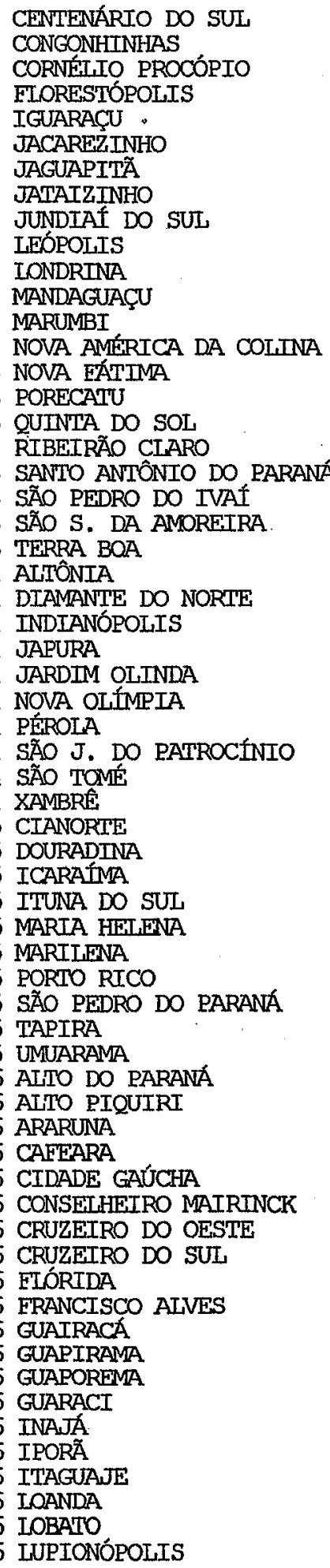 & $\begin{array}{r}72759 \\
37355 \\
155202 \\
63953 \\
63843 \\
159071 \\
76076 \\
40654 \\
35541 \\
89634 \\
345084 \\
77601 \\
28556 \\
38198 \\
38403 \\
50792 \\
78263 \\
68147 \\
23638 \\
102852 \\
56840 \\
132001 \\
111379 \\
68549 \\
64394 \\
90766 \\
5822 \\
37755 \\
129442 \\
103331 \\
78720 \\
60108 \\
164619 \\
71244 \\
97434 \\
30503 \\
66157 \\
62257 \\
28525 \\
37375 \\
57348 \\
398325 \\
54037 \\
171345 \\
55665 \\
37928 \\
42276 \\
28150 \\
117102 \\
55103 \\
10516 \\
49562 \\
81664 \\
40676 \\
22706 \\
30805 \\
21313 \\
422227 \\
14661\end{array}$ & 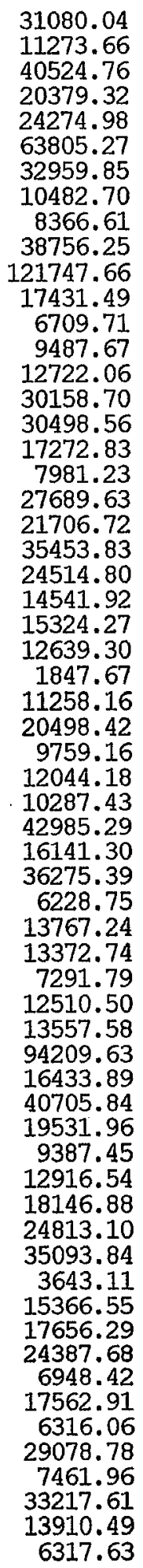 & $\begin{array}{r}4298.63 \\
3349.07 \\
14764.66 \\
4709.18 \\
5333.41 \\
14047.88 \\
8076.65 \\
5361.27 \\
3192.31 \\
7049.00 \\
50585.82 \\
10494.09 \\
4777.00 \\
3056.51 \\
6165.95 \\
2345.02 \\
8990.91 \\
8558.18 \\
2314.19 \\
7934.72 \\
5468.50 \\
12676.84 \\
30556.10 \\
6987.43 \\
7578.62 \\
11194.75 \\
461.12 \\
2472.60 \\
15636.28 \\
12025.53 \\
8792.23 \\
8418.43 \\
22202.92 \\
7868.53 \\
7821.38 \\
4602.95 \\
7590.31 \\
7127.30 \\
3733.50 \\
6964.34 \\
4971.09 \\
34466.58 \\
14770.35 \\
10867.65 \\
2056.83 \\
2093.65\end{array}$ & 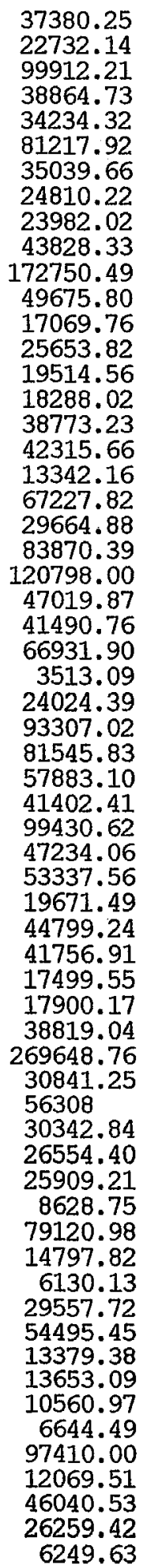 & $\begin{array}{r}6484 \\
7044 \\
5505 \\
2433 \\
3992 \\
7335 \\
5241 \\
2311 \\
1651 \\
4036 \\
25944 \\
5535 \\
2979 \\
2520 \\
2206 \\
2014 \\
3751 \\
3570 \\
2045 \\
4812 \\
4235 \\
7190 \\
12687 \\
3636 \\
4524 \\
5233 \\
278 \\
1413 \\
7525 \\
4994 \\
4041 \\
4223 \\
13623 \\
4423 \\
5620 \\
2012 \\
4598 \\
3695 \\
1781 \\
1798 \\
6128 \\
21990 \\
4842 \\
12868 \\
7710 \\
2267 \\
3255 \\
1189 \\
10531 \\
2655 \\
7777 \\
6445 \\
3031 \\
2322 \\
1700 \\
2464 \\
2053 \\
4962 \\
2776 \\
1833\end{array}$ & $\begin{array}{r}35278 \\
52531 \\
56214 \\
22945 \\
26048 \\
54215 \\
48042 \\
16068 \\
33013 \\
31251 \\
180305 \\
26749 \\
19021 \\
12127 \\
24327 \\
24462 \\
32438 \\
49289 \\
17350 \\
33544 \\
20110 \\
29364 \\
45932 \\
18364 \\
20450 \\
14695 \\
13376 \\
13353 \\
35684 \\
17087 \\
13605 \\
34410 \\
86752 \\
39793 \\
61375 \\
12832 \\
46531 \\
20185 \\
15467 \\
22461 \\
40996 \\
259009 \\
40853 \\
68188 \\
43416 \\
18743 \\
36973 \\
18842 \\
71090 \\
24747 \\
7173 \\
27284 \\
46673 \\
19474 \\
19073 \\
20748 \\
89341 \\
19407 \\
70010 \\
22707 \\
12425\end{array}$ \\
\hline
\end{tabular}


Tabela 1A. Continuação.

\begin{tabular}{|c|c|c|c|c|c|c|}
\hline MUNICfPIO & $\begin{array}{c}\text { VBP } \\
(\mathrm{Cz} \$ 1000)\end{array}$ & $\begin{array}{c}C I \\
(C z \$ 1000)\end{array}$ & $\begin{array}{c}\text { DEP } \\
(\mathrm{Cz} \$ 1000)\end{array}$ & $\begin{array}{c}\text { VA } \\
(\mathrm{Cz} \$ 1000)\end{array}$ & EH & $\begin{array}{l}\mathrm{AE} \\
\text { (ha) }\end{array}$ \\
\hline 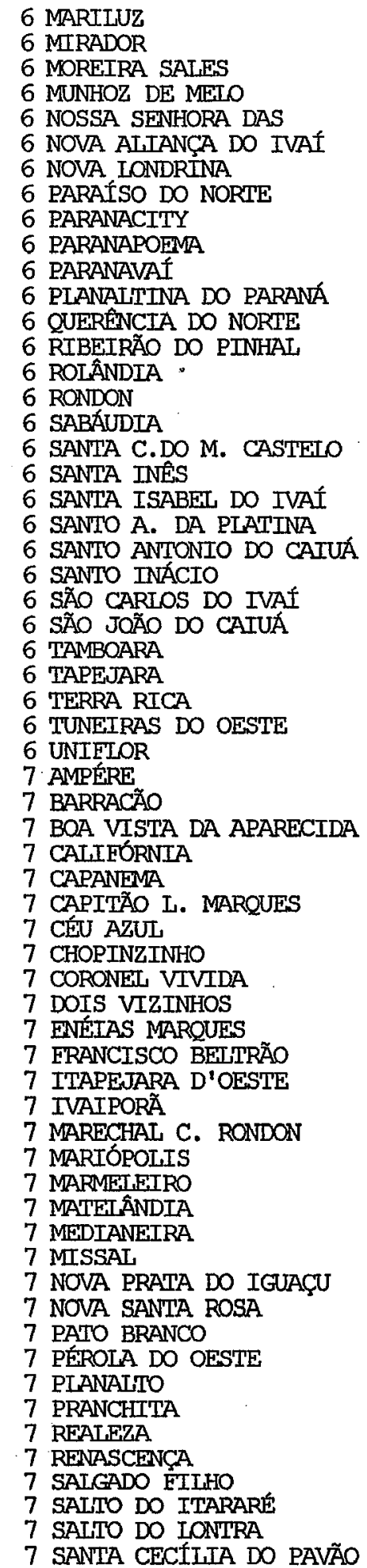 & $\begin{array}{r}61442 \\
21323 \\
78132 \\
31236 \\
28629 \\
9008 \\
48120 \\
30473 \\
45638 \\
19585 \\
119580 \\
29321 \\
82221 \\
73811 \\
212403 \\
71352 \\
43510 \\
54413 \\
15650 \\
79416 \\
112977 \\
17126 \\
36694 \\
34117 \\
25291 \\
25096 \\
87823 \\
96877 \\
46027 \\
19120 \\
69085 \\
37525 \\
34955 \\
21634 \\
113572 \\
68677 \\
73250 \\
150490 \\
91090 \\
196615 \\
58302 \\
139253 \\
46714 \\
130666 \\
340043 \\
37911 \\
61802 \\
117183 \\
151652 \\
64970 \\
73163 \\
87033 \\
76626 \\
711869 \\
68287 \\
59598 \\
29111\end{array}$ & $\begin{array}{r}20944.26 \\
6726.33 \\
29604.08 \\
8055.55 \\
9618.45 \\
2932.25 \\
15360.79 \\
9710.88 \\
26727.10 \\
6624.39 \\
38127.93 \\
10364.69 \\
39030.74 \\
19232.72 \\
62441.39 \\
20769.12 \\
18284.84 \\
16101.01 \\
5670.09 \\
24605.73 \\
29545.21 \\
7644.82 \\
13940.38 \\
14490.10 \\
10238.03 \\
7241.96 \\
28227.95 \\
25711.85 \\
17841.12 \\
4637.37 \\
15820.40 \\
8229.43 \\
7386.57 \\
5628.77 \\
23750.62 \\
16481.75 \\
29974.78 \\
61246.47 \\
27627.09 \\
101084.76 \\
23085.61 \\
60538.15 \\
20072.02 \\
28895.97 \\
119702.60 \\
13557.13 \\
18633.59 \\
39589.30 \\
62270.81 \\
22056.55 \\
20267.75 \\
33045.52 \\
48286.12 \\
19353.38 \\
17889.51 \\
14448.37 \\
18869.16 \\
27251.76 \\
16964.84 \\
2675\end{array}$ & $\begin{array}{r}5803.22 \\
1556.77 \\
8938.05 \\
3109.24 \\
2657.18 \\
1115.55 \\
4967.54 \\
2888.68 \\
4681.35 \\
1800.30 \\
19124.96 \\
4679.77 \\
8172.67 \\
7131.49 \\
23851.12 \\
7997.82 \\
4613.91 \\
5136.88 \\
1125.62 \\
11234.14 \\
15527.50 \\
2172.02 \\
3138.18 \\
4036.06 \\
3341.84 \\
1988.31 \\
7988.84 \\
16677.27 \\
6342.62 \\
1119.22 \\
4327.20 \\
3103.26 \\
2567.37 \\
2762.10 \\
10392.75 \\
5879.74 \\
7756.38 \\
9654.98 \\
9761.87 \\
11122.32 \\
3914.72 \\
10155.00 \\
4457.01 \\
10585.90 \\
36435.44 \\
4607.05 \\
5401.99 \\
12858.23 \\
14491.53 \\
7807.18 \\
6506.00 \\
7483.18 \\
14240.83 \\
6774.06 \\
6994.98 \\
5694.73 \\
7757.83 \\
7947.20 \\
3660.65 \\
1999.10 \\
4254.26 \\
3061.89\end{array}$ & $\begin{array}{r}34694.06 \\
13040.10 \\
39589.50 \\
20071.55 \\
16353.34 \\
4960.62 \\
27792.13 \\
17873.02 \\
14229.59 \\
11159.86 \\
62326.64 \\
14276.78 \\
35017.44 \\
47447.11 \\
126110.63 \\
42585.32 \\
20611.00 \\
33175.44 \\
8854.49 \\
43575.63 \\
67904.09 \\
7308.90 \\
19615.89 \\
15590.67 \\
11711.15 \\
15865.69 \\
51605.72 \\
54488.37 \\
21843.12 \\
13363.26 \\
48937.14 \\
26192.09 \\
25001.21 \\
13242.79 \\
79428.81 \\
46315.74 \\
35518.85 \\
79588.20 \\
53700.91 \\
84407.68 \\
31301.75 \\
68559.91 \\
22185.46 \\
91183.79 \\
183904.73 \\
19746.58 \\
37766.00 \\
64735.36 \\
74889.36 \\
35106.44 \\
46389.45 \\
46504.16 \\
66426.70 \\
50498.97 \\
34841.42 \\
44559.34 \\
33088.24 \\
37346.95 \\
13782.00 \\
17307.07\end{array}$ & $\begin{array}{r}4027 \\
1059 \\
10529 \\
2803 \\
2324 \\
554 \\
2533 \\
2854 \\
3641 \\
1920 \\
8480 \\
3228 \\
6006 \\
6755 \\
10337 \\
5567 \\
3373 \\
4135 \\
1187 \\
6827 \\
10000 \\
1926 \\
5369 \\
2900 \\
2234 \\
2334 \\
5749 \\
5088 \\
7767 \\
1094 \\
6055 \\
6645 \\
6721 \\
2410 \\
10837 \\
7838 \\
4245 \\
14564 \\
10689 \\
13443 \\
6435 \\
11128 \\
4464 \\
22513 \\
18422 \\
2606 \\
6020 \\
10166 \\
6933 \\
5100 \\
6794 \\
4864 \\
7928 \\
7733 \\
7834 \\
3075 \\
7986 \\
3348 \\
8585 \\
3152\end{array}$ & $\begin{array}{r}4164 \\
21144 \\
28235 \\
12626 \\
18971 \\
11816 \\
29254 \\
20067 \\
32650 \\
17131 \\
109896 \\
33229 \\
76092 \\
35930 \\
51021 \\
49781 \\
17597 \\
42395 \\
13147 \\
58069 \\
69066 \\
21500 \\
23823 \\
22019 \\
27522 \\
16486 \\
59375 \\
62876 \\
56310 \\
9429 \\
26548 \\
33379 \\
22208 \\
13373 \\
35010 \\
35685 \\
2306 \\
31591 \\
38167 \\
37092 \\
16990 \\
30734 \\
14050\end{array}$ \\
\hline
\end{tabular}


Tabela 1A. Continuação.

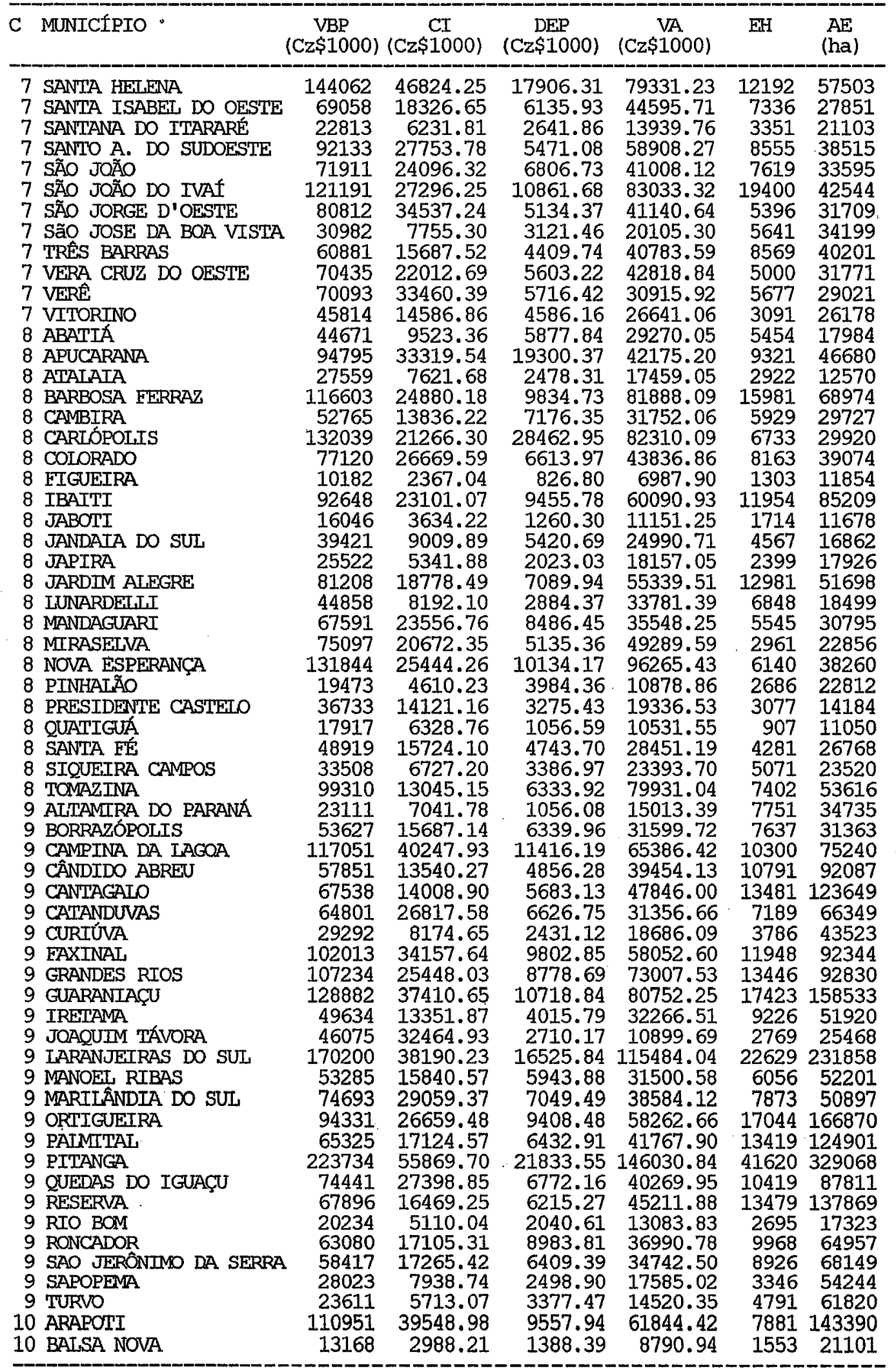


Tabela 1A. Continuação.

\begin{tabular}{|c|c|c|c|c|c|c|c|}
\hline $\mathrm{C}$ & & $\begin{array}{c}\text { VBP } \\
(\mathrm{Cz} \$ 1000)\end{array}$ & $\begin{array}{c}\text { CI } \\
\text { Cz\$1000) }\end{array}$ & $\begin{array}{c}\text { DEP } \\
\text { Cz\$1000) }\end{array}$ & $\begin{array}{c}\text { VA } \\
\mathrm{Cz} \$ 1000)\end{array}$ & EH & $\begin{array}{c}\mathrm{AE} \\
\text { (ha) }\end{array}$ \\
\hline $\begin{array}{l}1 \\
11 \\
11 \\
11 \\
11 \\
11 \\
11 \\
11 \\
11 \\
11 \\
11 \\
11 \\
11 \\
11 \\
11 \\
11 \\
11 \\
12 \\
12 \\
12 \\
13 \\
13 \\
13 \\
13 \\
13 \\
13 \\
13 \\
13 \\
13 \\
13 \\
13 \\
13 \\
13\end{array}$ & 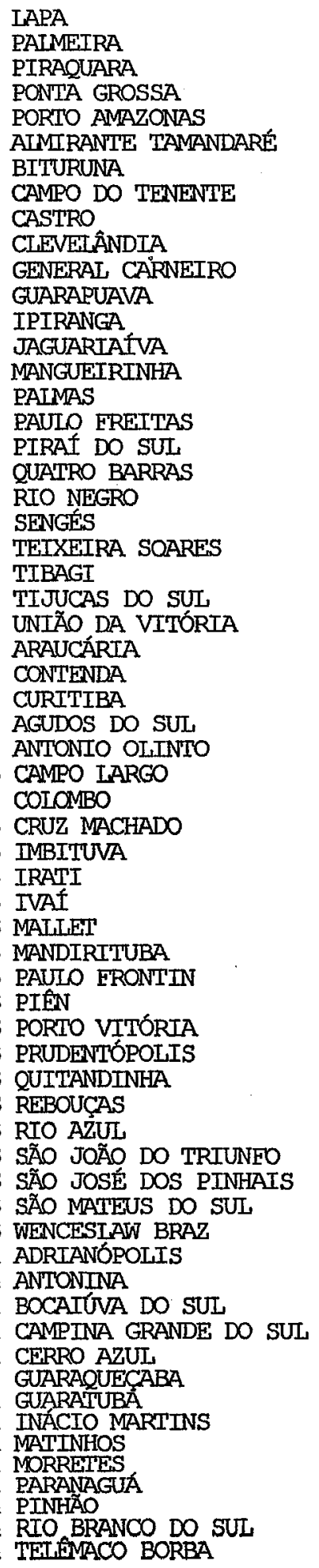 & 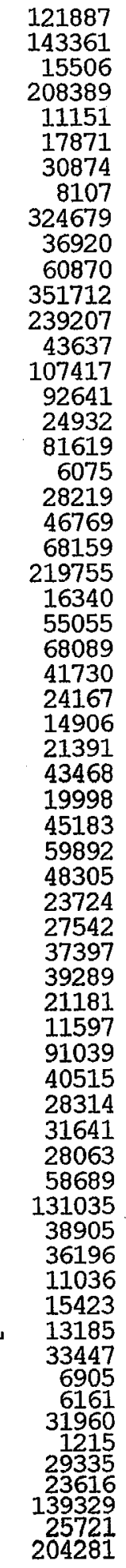 & $\begin{array}{r}48357.67 \\
50917.00 \\
5170.21 \\
118632.25 \\
3975.89 \\
7108.20 \\
4065.15 \\
3522.41 \\
189979.62 \\
15448.43 \\
5699.75 \\
116997.39 \\
17574.25 \\
17041.09 \\
46244.58 \\
31277.99 \\
6362.41 \\
33692.23 \\
2018.19 \\
8457.11 \\
9074.67 \\
28354.52 \\
85887.52 \\
7206.01 \\
5254.64 \\
33188.62 \\
10734.30 \\
12579.93 \\
2985.96 \\
4875.73 \\
13355.00 \\
8307.41 \\
7903.57 \\
18406.50 \\
12334.25 \\
6606.64 \\
7726.55 \\
13811.37 \\
9314.90 \\
3909.84 \\
2659.36 \\
14015.91 \\
11341.60 \\
49279.03 \\
9199.07\end{array}$ & $\begin{array}{r}16679.54 \\
16683.57 \\
3853.13 \\
22256.49 \\
1390.45 \\
1756.57 \\
3265.08 \\
1945.92 \\
32805.68 \\
5704.60 \\
3769.01 \\
38614.09 \\
5247.66 \\
3834.28 \\
13714.53 \\
7403.03 \\
3255.97 \\
5271.82 \\
769.62 \\
3252.91 \\
2828.12 \\
8815.91 \\
32069.69 \\
1700.33 \\
2951.10 \\
9088.76 \\
4553.66 \\
2604.72 \\
1264.00 \\
2850.39 \\
6002.42 \\
2767.18 \\
6656.02 \\
8243.72 \\
7799.87 \\
2921.17 \\
4689.06 \\
3416.03 \\
4244.83 \\
3382.57 \\
1369.75 \\
9095.94 \\
4118.31 \\
3906.91 \\
4789.71 \\
3032.11 \\
7130.49 \\
9589.09 \\
3761.78 \\
1951.49 \\
1286.75 \\
1794.68 \\
2149.10 \\
4236.54 \\
1341.59 \\
1320.48 \\
1601.34 \\
136.91 \\
2314.81 \\
11262.07 \\
1701.61 \\
2345.99 \\
30\end{array}$ & $\begin{array}{r}56849.95 \\
75760.19 \\
6482.89 \\
67500.48 \\
5784.67 \\
9006.15 \\
23543.40 \\
2639.01 \\
101893.93 \\
15766.66 \\
51401.16 \\
196100.97 \\
216385.04 \\
22762.06 \\
47458.02 \\
53960.27 \\
15313.28 \\
42654.98 \\
3286.96 \\
16508.87 \\
34866.57 \\
30988.80 \\
101797.33 \\
7434.01 \\
46849.72 \\
25811.82 \\
26441.69 \\
8982.59 \\
10655.81 \\
13665.08 \\
24110.56 \\
8923.43 \\
30623.28 \\
33242.19 \\
28170.90 \\
14195.76 \\
15126.79 \\
20169.56 \\
25729.42 \\
26457.23 \\
858.78 \\
21140.78 \\
20461.10 \\
81348.78 \\
19148.71 \\
192736.00\end{array}$ & 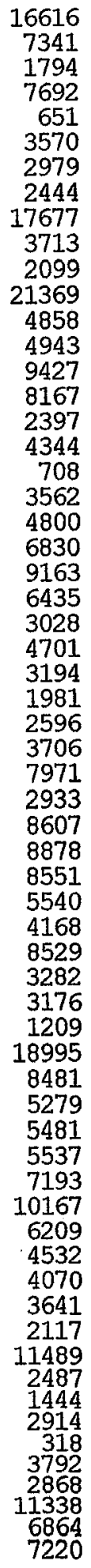 & 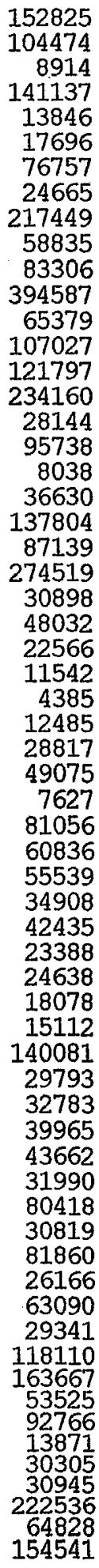 \\
\hline
\end{tabular}


Tabela 1A. Continuação.

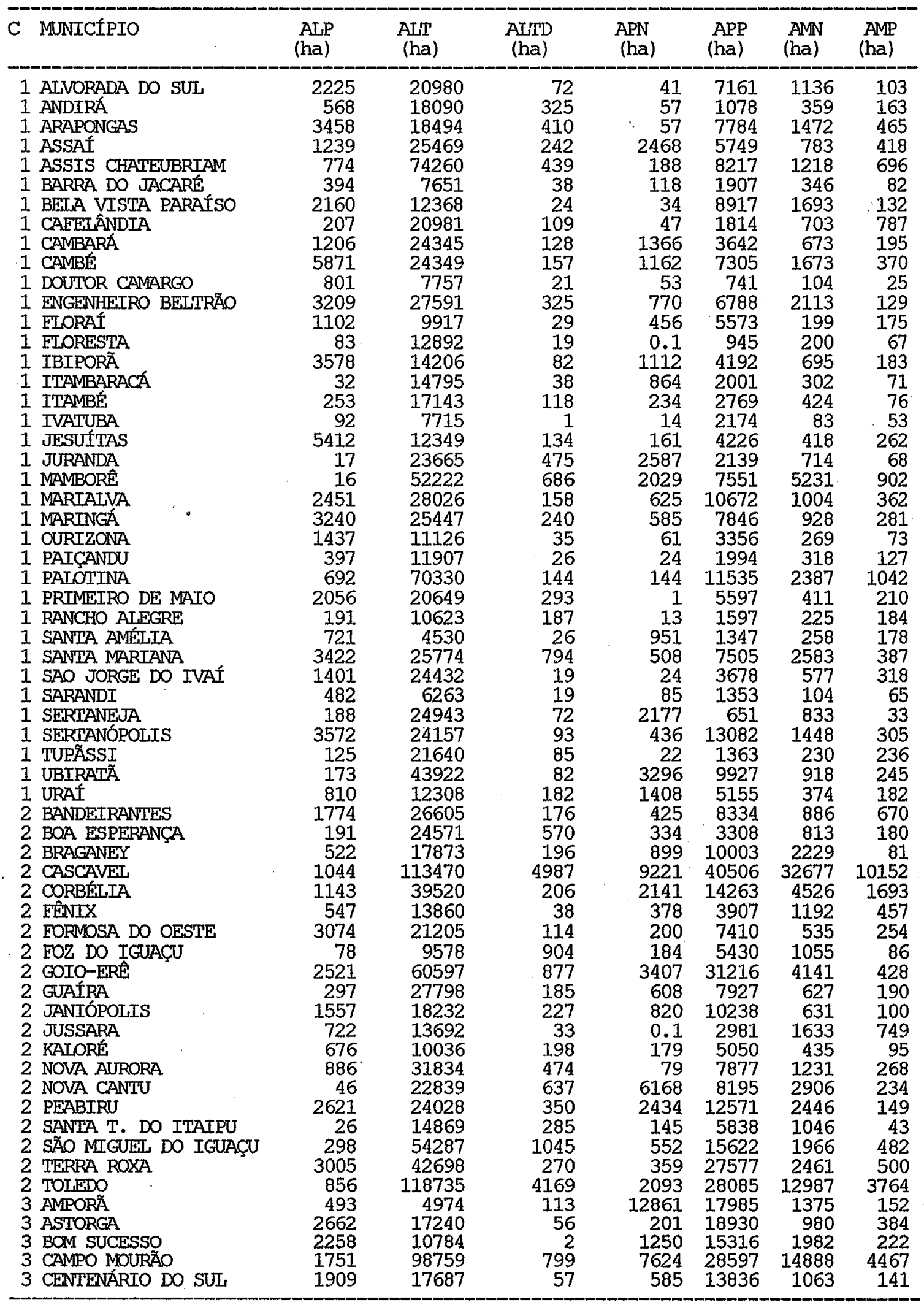


Tabela 1A. Continuação.

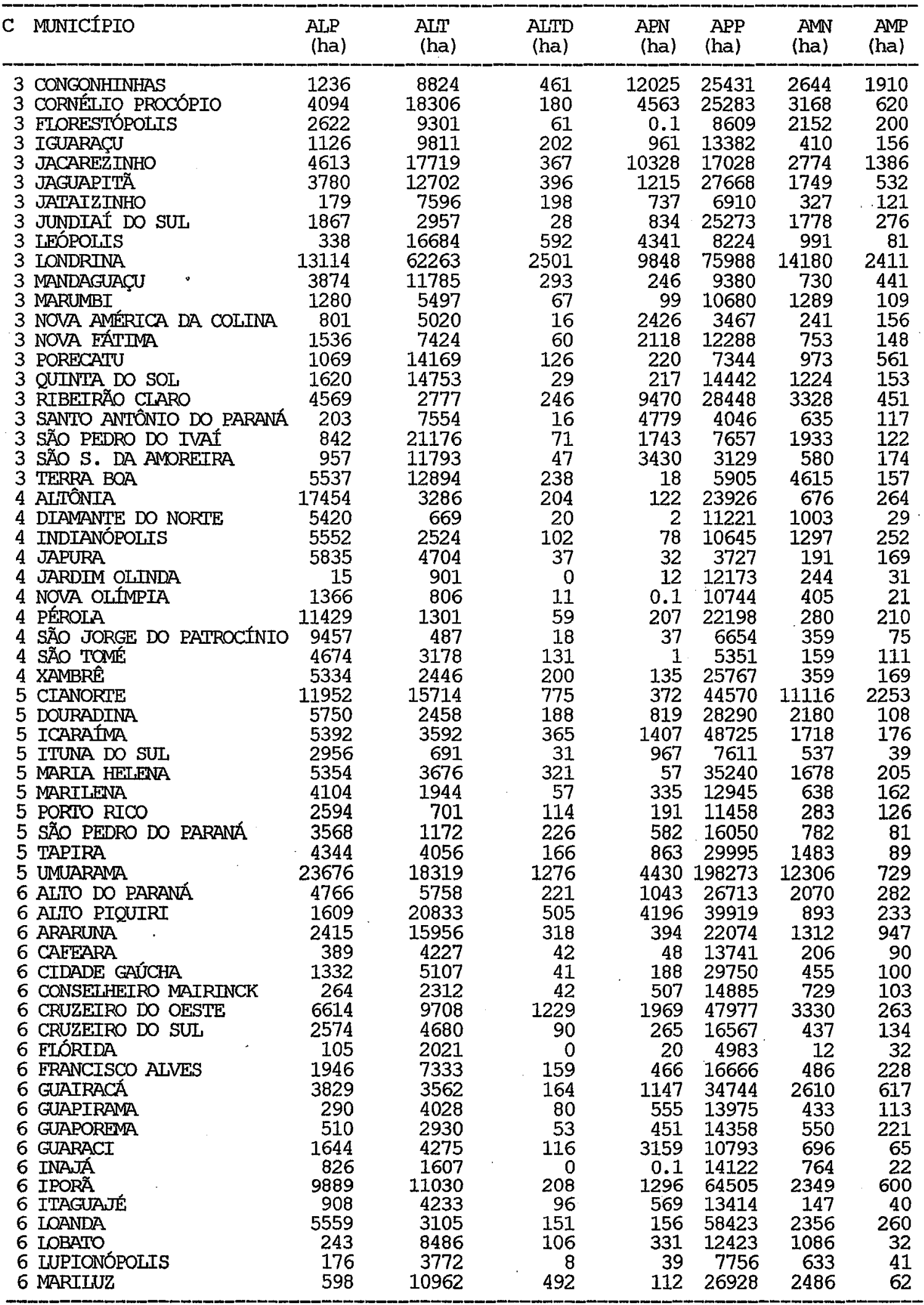


Tabela 1A. Continuação.

\begin{tabular}{|c|c|c|c|c|c|c|c|}
\hline C MNICIPIO & $\begin{array}{l}\text { ALP } \\
\text { (ha) }\end{array}$ & $\begin{array}{l}\text { AIT } \\
\text { (ha) }\end{array}$ & $\begin{array}{l}\text { ALTD } \\
\text { (ha) }\end{array}$ & $\begin{array}{l}\text { APN } \\
\text { (ha) }\end{array}$ & $\begin{array}{l}\text { APP } \\
\text { (ha) }\end{array}$ & $\begin{array}{l}\text { AMN } \\
\text { (ha) }\end{array}$ & $\begin{array}{l}\text { AMP } \\
\text { (ha) }\end{array}$ \\
\hline 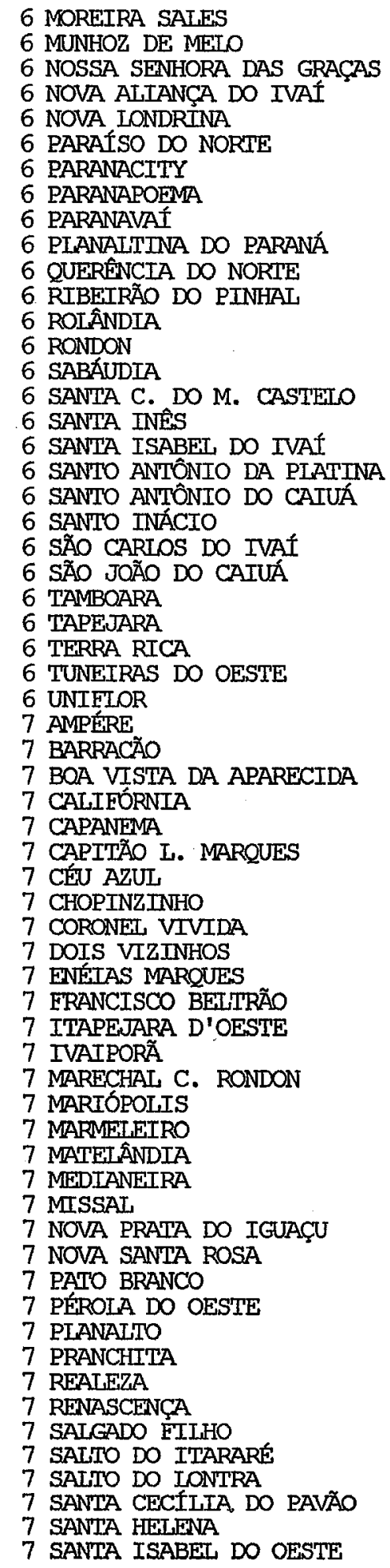 & $\begin{array}{r}5103 \\
1348 \\
770 \\
86 \\
1620 \\
424 \\
2046 \\
251 \\
6768 \\
1230 \\
735 \\
4779 \\
8683 \\
4335 \\
1191 \\
2626 \\
394 \\
6303 \\
4383 \\
978 \\
233 \\
692 \\
1725 \\
1475 \\
4549 \\
7418 \\
2241 \\
1108 \\
718 \\
326 \\
248 \\
1053 \\
350 \\
338 \\
399 \\
448 \\
329 \\
1033 \\
392 \\
857 \\
123 \\
4136 \\
263 \\
224 \\
431 \\
4315 \\
425 \\
1088 \\
233 \\
151 \\
259 \\
128 \\
403 \\
324 \\
328 \\
271 \\
\end{array}$ & $\begin{array}{r}9836 \\
4690 \\
4637 \\
1227 \\
3393 \\
6480 \\
5814 \\
6608 \\
9293 \\
2898 \\
12433 \\
7509 \\
28936 \\
6194 \\
7566 \\
4364 \\
2932 \\
4947 \\
20532 \\
1799 \\
6629 \\
8255 \\
2412 \\
3791 \\
5353 \\
2798 \\
10898 \\
1524 \\
17983 \\
19711 \\
13122 \\
4796 \\
25060 \\
22063 \\
16975 \\
40836 \\
10216 \\
37735 \\
19755 \\
38522 \\
39728 \\
18394 \\
36317 \\
16441 \\
37316 \\
74168 \\
13161 \\
24069 \\
30545 \\
26551 \\
15392 \\
18540 \\
14505 \\
42084 \\
19534 \\
20035 \\
17084 \\
22347 \\
\end{array}$ & 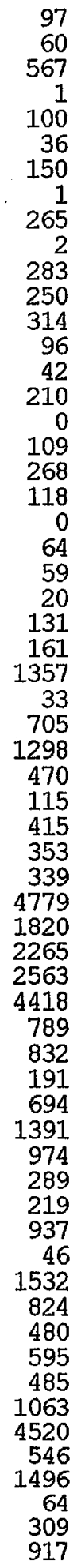 & $\begin{array}{r}703 \\
0.1 \\
241 \\
0.1 \\
3 \\
169 \\
144 \\
669 \\
1100 \\
1195 \\
1867 \\
886 \\
118 \\
891 \\
162 \\
1301 \\
0.1 \\
13 \\
893 \\
209 \\
6 \\
0.1 \\
12 \\
276 \\
396 \\
1496 \\
1225 \\
8 \\
1217 \\
325 \\
1680 \\
197 \\
2915 \\
1068 \\
200 \\
5768 \\
7184 \\
1220 \\
42131 \\
4249 \\
1144 \\
273 \\
1761 \\
920 \\
7906 \\
536 \\
2298 \\
2281 \\
3463 \\
735 \\
581 \\
144 \\
529 \\
3495 \\
173 \\
1814 \\
56\end{array}$ & $\begin{array}{r}11549 \\
6072 \\
12360 \\
10406 \\
22640 \\
12702 \\
23344 \\
9039 \\
85877 \\
26418 \\
57097 \\
20306 \\
10926 \\
36445 \\
7975 \\
32369 \\
9635 \\
44727 \\
40065 \\
17843 \\
16539 \\
12605 \\
22668 \\
10673 \\
47070 \\
48189 \\
37944 \\
6455 \\
3864 \\
10029 \\
5629 \\
6679 \\
3002 \\
9686 \\
9857 \\
17464 \\
4347 \\
16384 \\
7858 \\
11118 \\
2844 \\
15326 \\
3611 \\
26728 \\
16701 \\
2452 \\
4323 \\
36760 \\
12447 \\
6743 \\
9803 \\
1529 \\
9410 \\
4865 \\
6131 \\
9054 \\
576 \\
\end{array}$ & $\begin{array}{r}768 \\
369 \\
347 \\
47 \\
1307 \\
107 \\
981 \\
518 \\
6089 \\
1334 \\
3606 \\
1640 \\
1155 \\
1597 \\
471 \\
886 \\
105 \\
1621 \\
2234 \\
427 \\
238 \\
315 \\
501 \\
111 \\
1673 \\
1288 \\
2443 \\
186 \\
1661 \\
1560 \\
919 \\
365 \\
2978 \\
1841 \\
1529 \\
8575 \\
4675 \\
2919 \\
1372 \\
3923 \\
1028 \\
1636 \\
228 \\
2481 \\
1436\end{array}$ & 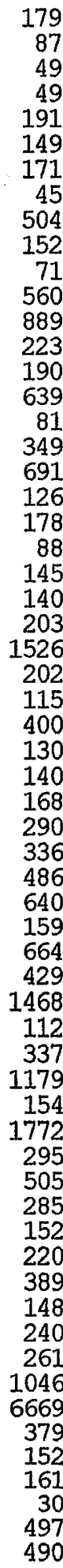 \\
\hline
\end{tabular}


Tabela 1A. Continuação.

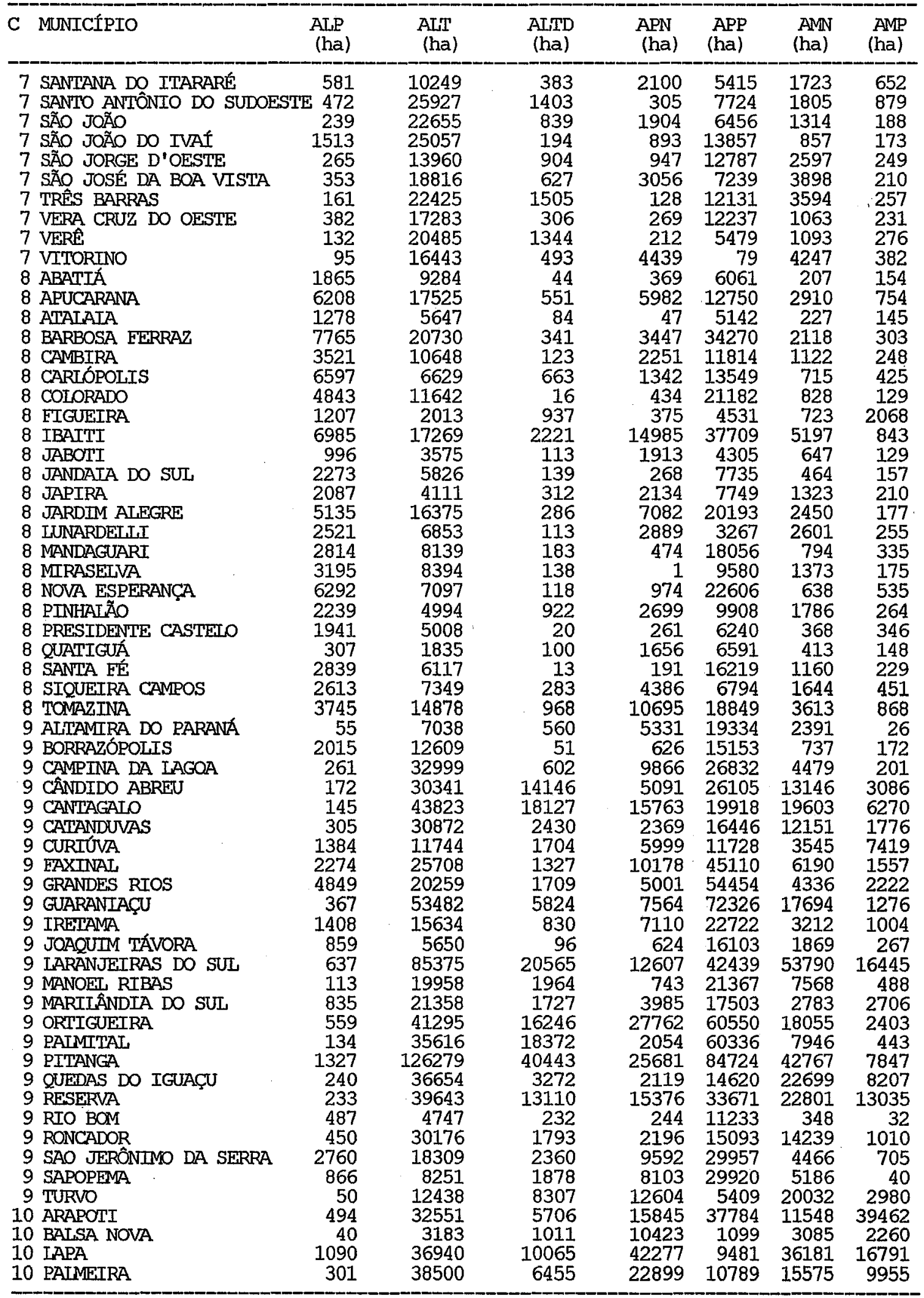


Tabela 1A. Continuação.

\begin{tabular}{|c|c|c|c|c|c|c|c|c|}
\hline $\mathrm{C}$ & MUNICÍPIO & $\begin{array}{l}\text { ALP } \\
\text { (ha) }\end{array}$ & $\begin{array}{l}\text { AIT } \\
\text { (ha) }\end{array}$ & $\begin{array}{l}\text { AITD } \\
\text { (ha) }\end{array}$ & $\begin{array}{l}\text { APN } \\
\text { (ha) }\end{array}$ & $\begin{array}{l}\text { APP } \\
\text { (ha) }\end{array}$ & $\begin{array}{l}\text { AMN } \\
\text { (ha) }\end{array}$ & $\begin{array}{l}\text { AMP } \\
\text { (ha) }\end{array}$ \\
\hline 10 & PIRAQUARA & 136 & 2602 & 526 & 2614 & 666 & 1788 & 582 \\
\hline 10 & PONTA GROSSA & 293 & 47287 & 4635 & 34011 & 24057 & 20956 & 9898 \\
\hline & PORTO AMAZONAS & 290 & 1574 & 215 & 7782 & 1348 & 2227 & 410 \\
\hline & AIMIRANTE TAMANDARÉ & 104 & 5104 & 2260 & 1845 & 404 & 3920 & 4059 \\
\hline 11 & BITURUNA & 646 & 8704 & 5931 & 13562 & 6776 & 31718 & 9420 \\
\hline & CAMPO DO TENENTE & 476 & 3909 & 1726 & 6810 & 1379 & 6167 & 4198 \\
\hline & CASTRO & 1269 & 52870 & 12468 & 62715 & 32731 & 39967 & 15429 \\
\hline 11 & CLEVVEIANDIA & 664 & 19420 & 374 & 16569 & 8342 & 12341 & 1125 \\
\hline & GENERAL CARNEIRO & 156 & 3841 & 2846 & 18073 & 6296 & 39820 & 12274 \\
\hline & GUARAPUAVA & 2129 & 125428 & 27174 & 78201 & 52142 & 76936 & 32577 \\
\hline 11 & IPIRANGA & 282 & 17042 & 4574 & 11149 & 9308 & 13683 & 9341 \\
\hline 11 & JAGUARTAfVA & 131 & 12427 & 3124 & 27710 & 17701 & 15363 & 30571 \\
\hline & MANGUEIRTNHA & 313 & 56905 & 713 & 13592 & 17038 & 30078 & 3158 \\
\hline 11 & PAIMAS & 1713 & 16133 & 4163 & 97589 & 12417 & 94813 & ' 7332 \\
\hline 11 & PAULO FREITAS & 71 & 8335 & 1887 & 5999 & 2406 & 7738 & 1708 \\
\hline & PIRAÍ DO SUL & 35 & 15915 & 2619 & 37412 & 11062 & 18601 & 10094 \\
\hline & QUATRO BARRAS & 166 & 815 & 118 & 1419 & 502 & 3677 & 1341 \\
\hline 11 & RIO NEGRO & 223 & 6278 & 1765 & 7077 & 1123 & 9279 & 10885 \\
\hline 11 & SENGÉSS & 129 & 14470 & 3281 & 13558 & 13815 & 14747 & 77804 \\
\hline & TEIXEIRA SOARES & 627 & 28187 & 3614 & 11444 & 6257 & 28405 & 8605 \\
\hline 11 & TIBAGI & 1765 & 69039 & 3825 & 50629 & 59356 & 49804 & 40101 \\
\hline 11 & TIJUCAS DO SUL & 104 & 4724 & 1344 & 7770 & 379 & 8069 & 8508 \\
\hline 11 & UNIÃO DA VITÓRIA & 516 & 6490 & 3772 & 6895 & 4525 & 23689 & 2145 \\
\hline 12 & ARAUCARIA & 335 & 13303 & 1107 & 3698 & 986 & 2820 & 317 \\
\hline 12 & CONTENDA & 42 & 7890 & 992 & 1559 & 123 & 925 & 11 \\
\hline 12 & CURITIBA & 61 & 2053 & 62 & 903 & 350 & 709 & 247 \\
\hline & AGUDOS DO SUL & 96 & 4614 & 2041 & 2936 & 129 & 1632 & 1037 \\
\hline & ANTONIO OLTNTO & 364 & 8969 & 4498 & 4727 & 473 & 6242 & 3544 \\
\hline 13 & CAMPO LARGO & 421 & 16782 & 3490 & 8534 & 2738 & 10665 & 6445 \\
\hline 13 & COLOMBO & 274 & 2127 & 208 & 1369 & 234 & 1825 & 1590 \\
\hline & CRUZ MACHADO & 162 & 19216 & 25444 & 10646 & 5559 & 15531 & 4498 \\
\hline & IMBITUVA & 597 & 27646 & 4617 & 8084 & 3172 & 15692 & 1028 \\
\hline 13 & IRATI & 201 & 29458 & 9448 & 5928 & 609 & 8633 & 1262 \\
\hline 13 & IVAI & 268 & 11998 & 12182 & 3797 & 1390 & 4978 & 295 \\
\hline 13 & MALLET & 255 & 15279 & 4472 & 6838 & 493 & 12823 & 2275 \\
\hline 13 & MANDIRITUBA & 244 & 9684 & 1561 & 4261 & 976 & 4357 & 2305 \\
\hline 13 & PAULO ERONTIN & 115 & 11038 & 1481 & 3825 & 628 & 6482 & 1069 \\
\hline 13 & PTEN & 176 & 5479 & 1484 & 4445 & 430 & 5006 & 1058 \\
\hline 13 & PORTO VITÓRIA & 83 & 2864 & 1893 & 3828 & 844 & 3864 & 1736 \\
\hline 13 & PRUDENTIÓPOLIS & 1057 & 45007 & 44525 & 12454 & 4930 & 27936 & 4172 \\
\hline 13 & QUTTANDINHA & 106 & 15130 & 3974 & 4079 & 121 & 4965 & 1418 \\
\hline 13 & REBOUÇAS & 102 & 14699 & 1951 & 4086 & 734 & 10021 & 1190 \\
\hline 13 & RTO AZUL & 194 & 15837 & 4172 & 6917 & 751 & 10527 & 1567 \\
\hline & SÃO JOÃO DO TRIUNFO & 60 & 11535 & 8418 & 3197 & 733 & 17091 & 2628 \\
\hline 13 & SÄO JOSÉ DOS PINHAIS & 1697 & 10142 & 128 & 7090 & 702 & 10690 & 387 \\
\hline 13 & SÃO MATEUS DO SUL & 293 & 26713 & 4422 & 13764 & 413 & 29722 & 5091 \\
\hline 13 & WENCESTAW BRAZ & 591 & 16737 & 707 & 5144 & 4254 & 2912 & 474 \\
\hline 14 & ADRIANÓPOLIS & 701 & 5090 & 3579 & 9530 & 13192 & 30362 & 19406 \\
\hline 14 & ANTONTNA & 2695 & 1990 & 1647 & 3818 & 1643 & 14335 & 38 \\
\hline 14 & BOCAIÚVA DO SUL & 163 & 4420 & 5419 & 11199 & 4663 & 14670 & 22556 \\
\hline & CAMPINA GRANDE DO SUL & 2791 & 1919 & 2166 & 5600 & 2059 & 13294 & 1512 \\
\hline & CERRO AZUL & 3489 & 13050 & 12690 & 18089 & 15991 & 13782 & 41019 \\
\hline & GUARAQUEÇABA & 44944 & 1507 & 614 & 5294 & 1961 & 108613 & 734 \\
\hline 14 & GUARATUBA & 16242 & 1248 & 1285 & 1438 & 754 & 28503 & 4055 \\
\hline & INÁCIO MARTINS & 365 & 4660 & 6869 & 11620 & 3280 & 48583 & 17389 \\
\hline & MATTINHOS & 1659 & 214 & 10 & 14 & 159 & 11546 & 269 \\
\hline & MORRETES & 5337 & 2141 & 770 & 2026 & 737 & 16525 & 2769 \\
\hline & PARANAGUA & 5857 & 1250 & 802 & 1931 & 1276 & 19576 & 253 \\
\hline 14 & PINHÃO & 82 & 48288 & 21151 & 55834 & 23245 & 64906 & 9030 \\
\hline & RIO BRANCO DO SUL & 339 & 10859 & 7911 & 13941 & 5569 & 7732 & 18477 \\
\hline & TELAMACO BORBA & 273 & 4703 & 1190 & 2567 & 4700 & 53805 & 87303 \\
\hline
\end{tabular}

Fonte: Dados da pesquisa. 


\section{APÊNDICE 2}

Dados utilizados na determinação das produtividades do trabalho e da terra, por conglomerado e Estado do Paraná, 1985. 
Tabela 2A. Dados utilizados na determinação das produtividades do trabalho e da terra, por conglomerado e Estado do Paraná, 1985.

\begin{tabular}{|c|c|c|c|c|c|c|}
\hline $\begin{array}{l}\text { Cong/ } \\
\text { Estado }\end{array}$ & $\begin{array}{c}\text { VBP } \\
(\mathrm{Cz} \$ 1000)\end{array}$ & $\begin{array}{c}\mathrm{CI} \\
(\mathrm{Cz} \$ 1000)\end{array}$ & $\begin{array}{c}\text { DEP } \\
(\mathrm{Cz} \$ 1000)\end{array}$ & $\begin{array}{c}\text { VA } \\
(\mathrm{Cz} \$ 1000)\end{array}$ & $\begin{array}{c}\mathrm{PO} \\
(\mathrm{EH})\end{array}$ & $\begin{array}{l}A E \\
\text { (ha) }\end{array}$ \\
\hline $\mathrm{C} 01$ & 4595378 & 1454814 & 465498 & 2675067 & 228944 & 1120263 \\
\hline $\mathrm{CO} 2$ & 3262856 & 1188489 & 277599 & 1796768 & 199057 & 1128114 \\
\hline $\mathrm{CO} 3$ & 2348141 & 816085 & 258019 & 1274037 & 144509 & 1111796 \\
\hline $\mathrm{CO4}$ & 750265 & 132715 & 104123 & 577916 & 48553 & 226957 \\
\hline C05 & 1013787 & 256340 & 107349 & 650097 & 65648 & 605403 \\
\hline C06 & 2777758 & 909348 & 295926 & 1507995 & 220252 & 1784142 \\
\hline $\mathrm{CO} 7$ & 3701269 & 1239853 & 332812 & 2128604 & 344048 & 1680209 \\
\hline $\mathrm{CO} 8$ & 1385830 & 337772 & 155242 & 892816 & 134340 & 702516 \\
\hline C09 & 1864379 & 548096 & 177928 & 1138355 & 278010 & 2336009 \\
\hline $\mathrm{C} 10$ & 624413 & 269590 & 71810 & 283014 & 43528 & 585687 \\
\hline C11 & 1860859 & 641266 & 178976 & 1040617 & 122514 & 2148600 \\
\hline $\mathrm{C} 12$ & 133986 & 56503 & 16247 & 61236 & 9876 & 38493 \\
\hline $\mathrm{C} 13$ & 862075 & 205007 & 101031 & 556036 & 136488 & 883505 \\
\hline C14 & 577809 & 96141 & 35080 & 446589 & 65094 & 1145551 \\
\hline Estado & 25758806 & 8152019 & 2577638 & 15029148 & 2040861 & 15497245 \\
\hline
\end{tabular}

Tabela 2A. Continuação.

\begin{tabular}{lrrrrrrr}
\hline $\begin{array}{l}\text { Cong/ } \\
\text { Estado }\end{array}$ & $\begin{array}{c}\text { ALP } \\
\text { (ha) }\end{array}$ & \multicolumn{1}{c}{$\begin{array}{c}\text { ALT } \\
\text { (ha) }\end{array}$} & $\begin{array}{c}\text { ALTD } \\
\text { (ha) }\end{array}$ & $\begin{array}{c}\text { APN } \\
\text { (ha) }\end{array}$ & $\begin{array}{c}\text { APP } \\
\text { (ha) }\end{array}$ & $\begin{array}{r}\text { AMN } \\
\text { (ha) }\end{array}$ & $\begin{array}{r}\text { AMP } \\
\text { (ha) }\end{array}$ \\
\hline C01 & 54055 & 813316 & 6327 & 24178 & 179331 & 33406 & 9650 \\
C02 & 21884 & 706327 & 15941 & 30626 & 256338 & 76423 & 20575 \\
C03 & 64360 & 430450 & 7222 & 92139 & 435246 & 66762 & 15648 \\
C04 & 66536 & 20302 & 782 & 626 & 132407 & 4973 & 1331 \\
C05 & 69690 & 52325 & 3519 & 10023 & 433157 & 32721 & 3968 \\
C06 & 120060 & 333440 & 8915 & 31521 & 1221074 & 56636 & 12496 \\
C07 & 22420 & 1021766 & 46731 & 69305 & 380666 & 115041 & 24280 \\
C08 & 79266 & 201938 & 8688 & 64855 & 305100 & 33321 & 9348 \\
C09 & 22785 & 770258 & 177675 & 198588 & 773053 & 312033 & 81617 \\
C10 & 2644 & 162637 & 28613 & 135851 & 85224 & 91360 & 79358 \\
C11 & 11519 & 476036 & 87578 & 490018 & 263959 & 528815 & 290675 \\
C12 & 438 & 23246 & 2161 & 6160 & 1459 & 4454 & 575 \\
C13 & 7356 & 320954 & 142270 & 125949 & 30313 & 211594 & 45069 \\
C14 & 84937 & 101339 & 66103 & 142901 & 79229 & 446232 & 224810 \\
\hline Estado & $627950 *$ & 5434333 & 602525 & 1422740 & 4576556 & 2013771 & 819400
\end{tabular}

Fonte: dados da pesquisa

Nota: $\mathrm{VBP}=$ valor bruto da produção, $\mathrm{CI}=$ consumo intermediário, $\mathrm{DEP}=$ depreciação, $\mathrm{VA}=$ valor agregado, $\mathrm{PO}=$ pessoal ocupado, $\mathrm{AE}=$ área explorada, ALP = área de lavoura permanente, ALT = área de lavoura temporária, ALTD = área de lavoura temporária em descanso, $\mathrm{APN}=$ área de pastagem natural, $\mathrm{APP}=$ área de pastagem plantada, $\mathrm{AMN}=$ área de mata natural e $\mathrm{AMP}=$ área de mata plantada. 


\section{APÊNDICE 3}

Valores dos indicadores não disponíveis no
Censo Agropecuário, por município e
conglomerado, 1985 .


Tabela 3A. Valores dos indicadores não disponíveis no Censo Agropecuário, por município e conglomerado (C), 1985.

En C2\$ 1000,00

INICADORES

\begin{tabular}{|c|c|c|c|c|c|c|c|c|c|c|c|c|}
\hline Mnicípio & 4 & 5 & 7 & 8 & 9 & 10 & 11 & 12 & 13 & 14 & 15 & 16 \\
\hline SUL & 2.53 & 0.00 & 1178310.27 & 41311.14 & 1043.69 & 14331.37 & 7.95 & 69890.43 & 31190.82 & 33.23 & 6.75 & 379.36 \\
\hline 1 ANDIRÁ & 6.43 & 0.63 & 776945.75 & 15241.73 & 700.73 & 11663.90 & 10134.93 & 47746.55 & 17728.50 & 5262.26 & 58.47 & 32.00 \\
\hline 1 ARAPONGAS & 690.77 & 1.36 & 910207.50 & 97142.10 & 8590.44 & 17827.46 & 59235.50 & 69292.24 & 90069.64 & 7731.73 & 71.30 & 1013.42 \\
\hline 1 ASSAÍ & 228.86 & 0.54 & 857568.65 & 19141.78 & 3728.00 & 30649.60 & 24279.16 & 97931.82 & 28138.90 & 3243.25 & 33.40 & 467.72 \\
\hline 1 ASSIS ARIELABRTAM & 20.32 & 0.801 & 3344975.24 & 9978.91 & 10073.32 & 63216.03 & 53831.19 & 312288.65 & 60987.11 & 10324.23 & 367.80 & 606.31 \\
\hline I BARRA DO JACARÉ & 5.55 & 0.11 & 303791.46 & 6620.43 & 955.68 & 6639.26 & 12295.82 & 28287.73 & 15034.48 & 2116.83 & 12.74 & 3.42 \\
\hline 1 BELA VISIA EARAISOO & 2.36 & 0.18 & 696705.85 & 75814.67 & 1668.84 & 15208.72 & 30051.80 & 49439.39 & 45364.87 & 5071.14 & 147.30 & 1.307 .91 \\
\hline 1 CAFEEAANDIA & 5.17 & 0.28 & 671072.98 & 2441.57 & 18817.82 & 12743.70 & 13215.05 & 71887.62 & 34296.35 & 2634.07 & 12.83 & 34.98 \\
\hline 1 CAMBARA & 6.08 & 0.46 & 992296.92 & 42011.15 & 4905.63 & 28260.25 & 23571.70 & 99680.23 & 37029.43 & 9456.96 & 8.00 & 235.75 \\
\hline 1 CAMPÉ & 19.44 & 2.61 & 1729794.79 & 106358.62 & 8676.82 & 30369.64 & 43293.31 & 97468.97 & 58979.12 & 8804.10 & 205.56 & 8281.34 \\
\hline 1 DAUIOR CAMARGO & 17.11 & 0.02 & 345315.72 & 7547.60 & 451.96 & 2458.70 & 5746.29 & 28029.75 & 6621.63 & 741.02 & 13.51 & 200.87 \\
\hline 1 ENG. BEELTRÃO & 9.83 & 0.03 & 1391910.64 & 53354.64 & 407.02 & 32807.22 & 22699.97 & 90167.14 & 21977.85 & 6518.54 & 337.35 & 197.32 \\
\hline 1 ELORAÍ & 84.47 & 0.12 & 521886.30 & .7021 .82 & 2292.45 & 8388.69 & 20781.40 & 29485.31 & 12783.16 & 2438.78 & 138.22 & 545.29 \\
\hline 1 ELORESTA & 2.92 & 0.00 & 432130.14 & 1070.60 & 660.80 & 9786.60 & 5060.45 & 44101.50 & 8809.90 & 1412.52 & 111.96 & 93.80 \\
\hline 1 IBIPORÄ & 4.75 & 5.65 & 856524.78 & 79481.96 & 1733.92 & 12080.76 & 20865.36 & 42453.98 & 26914.20 & 5356.42 & 25.53 & 790.08 \\
\hline 1 TTPMBARACÁ & 1.05 & 0.00 & 538425.15 & 487.94 & 1745.90 & 16212.40 & 17772.77 & 57984.75 & 9651.85 & 2234.66 & 8.50 & 75.25 \\
\hline 1 ITANES & 4.43 & 0.24 & 502638.34 & 5208.09 & 2286.44 & 14860.60 & 11926.94 & 53762.59 & 15354.08 & 3275.34 & 144.58 & 18.72 \\
\hline 1 IVAIUBA & 0.30 & 0.00 & 324298.89 & 946.15 & 992.44 & 5651.60 & 11967.76 & 35024.22 & 61939.00 & 1122.99 & 241.24 & 102.99 \\
\hline 1 JESUITAS & 9.67 & 1.20 & 676629.43 & 76752.28 & 1816.94 & 17054.17 & 20269.82 & 37240.14 & 38395.68 & 3052.90 & 2.25 & 211.01 \\
\hline 1 JURANDA & 4.64 & 0.00 & 478088.42 & 1.20 & 175.65 & 10461.30 & 9704.53 & 58462.07 & 8342.44 & 1811.32 & 52.47 & 58.96 \\
\hline 1 MAM & 7.76 & 0.001 & 1106586.36 & 80.00 & 5877.40 & 34281.60 & 30780.50 & 154382.38 & 41503.66 & 4080.61 & 98.00 & 276.24 \\
\hline 1 MARTALVA & 15.39 & 0.07 & 1423946.48 & 65312.78 & 4749.85 & 31711.16 & 36717.33 & 109177.89 & 37433.60 & 6517.68 & 688.58 & 268.09 \\
\hline 1 MARTNGÁ & 56.66 & 0.81 & 1650280.73 & 62955.26 & 4230.66 & 175208.10 & 109555.14 & 280682.77 & 155682.70 & 8282.96 & 306.12 & 3152.70 \\
\hline 1 ORIZGNA & 1.12 & 0.00 & 450529.16 & 11861.14 & 1027.15 & 7791.80 & 11088.36 & 28672.53 & 9878.80 & 3096.27 & 87.24 & 1925.88 \\
\hline 1 PAICANDU & 13.66 & 0.00 & 585312.89 & 3512.22 & 8936.85 & 8003.02 & 13114.29 & 35024.76 & 8126.48 & 3551.22 & 9.01 & 10.30 \\
\hline 1 PALOITA & 7.47 & 0.51 & 2817459.32 & 8090.76 & 14198.46 & 75007.26 & 83299.47 & 386194.25 & 170633.52 & 8896.741 & 1200.56 & 999.79 \\
\hline 1 ERIMEIRO LE MAIO & 5.34 & 0.24 & 1206985.54 & 38260.63 & 1569.59 & 27702.42 & 25916.81 & 94091.56 & 38033.77 & 7318.43 & 731.52 & 2682.79 \\
\hline 1 RANCHO ALEGRE & 1.75 & 0.00 & 499833.45 & 7894.97 & 3570.80 & 5502.00 & 5234.43 & 40403.62 & 13189.18 & 3610.60 & 4.00 & 226.72 \\
\hline 1 SANIA AME'I & 3.06 & 0.07 & 164424.31 & 3004.29 & 1011.55 & 5769.28 & 9339.52 & 14386.00 & 4503.01 & 1961.19 & 11.60 & 39.95 \\
\hline 1 SANIA MARTANA & 133.68 & 0.03 & 2480961.46 & 206299.96 & 4457.50 & 30453.97 & 22431.64 & 81990.43 & 57669.38 & 12386.79 & 6.39 & 69.94 \\
\hline 1. SAO JORGE DO IVAT & 4.62 & 0.26 & 962401.33 & 11759.30 & 5964.31 & 22536.10 & 19781.74 & 92828.17 & 28346.23 & 4431.29 & 103.51 & 2007.64 \\
\hline 1 SARANDI & 7.49 & 0.12 & 316493.10 & 9859.80 & 839.90 & 11782.45 & 11549.68 & 39074.70 & 7696.30 & 1316.10 & 7.45 & 132.25 \\
\hline 1 SERTANETA & 35.57 & 0.00 & 812973.51 & 1584.48 & 1281.00 & 39233.72 & 36337.00 & 127463.83 & 36800.22 & 9417.34 & 20.25 & 22.45 \\
\hline NÓPOLIS & 8.61 & 0.00 & 2390988.62 & 81776.48 & 4515.47 & 28388.06 & 66779.63 & 93159.85 & 70599.98 & 8651.94 & 110.85 & 3430.01 \\
\hline 1 TUEÄSST & 7.29 & 0.38 & 718475.18 & 1869.46 & 1509.85 & 10020.90 & 10225.95 & 67787.29 & 10502.91 & 2136.74 & 124.67 & 98.08 \\
\hline 1 UBIRATĨ & 9.60 & 0.54 & 1227887.16 & 1284.78 & 2758.87 & 27320.18 & 50449.38 & 14691 & 4.79 & 6424.77 & 133.60 & 262.43 \\
\hline 1 URAÍ & 7.47 & 0.01 & 574280.30 & 17915.64 & 2958.78 & 21089.66 & 18404.16 & 37298.67 & 12078.21 & 5972.88 & 4.40 & 427.02 \\
\hline 2. BANDEIRANEES & 319.91 & 1.11 & 1057050.94 & 35070.85 & 8032.90 & 28339.91 & 51052.27 & 56860.77 & 42526.65 & 11345.98 & 25.14 & 209.77 \\
\hline 2 BOA ESFERANCA & 17.88 & 1.06 & 537284.40 & 2420.30 & 1952.21 & 20656.76 & 16589.77 & 68152.99 & 13011.62 & 3826.24 & 31.70 & 98.01 \\
\hline 2 BRAGANEY & 6.82 & 0.12 & 483069.17 & 2602.25 & 1460.17 & 15150.20 & 35728.10 & 39489.37 & 15382.30 & 1354.08 & 55.30 & 134.19 \\
\hline 2 CASCAVEN, & 43.69 & 3.08 & 3165052.30 & 13859.05 & 44463.80 & 59189.53 & 203588.15 & 315385.90 & 159705.26 & 22829.29 & 895.40 & 710.46 \\
\hline 2 CCRBETIIA & 5.13 & 0.50 & 1097663.92 & 19595.48 & 15775.26 & 28764.79 & 72107.24 & 133387.34 & 59880.47 & 7254.85 & 88.35 & 463.54 \\
\hline 2 सीNIIX & 2.90 & 0.09 & 514511.83 & 4293.96 & 369.70 & 12736.42 & 8725.47 & 51959.18 & 12905.23 & 1756.07 & 15.04 & 0.00 \\
\hline 2 EORMOSA. DO & 18.16 & 1.40 & 901211.68 & 17949.22 & 2041.06 & 17357.40 & 34486.15 & 4.85 & 7.58 & & 33.31 & 96.80 \\
\hline O IAAQU & 7.93 & 0.14 & 515313.28 & 733.75 & 2103.19 & 4336.48 & 26851.17 & 21436.83 & 9682.05 & 1041.59 & 19.40 & 1.00 \\
\hline 200 & 29.61 & 1.79 & 1901930.38 & 28536.59 & 4665.12 & 40965.04 & 129473.84 & 147769.68 & 49190.32 & 16383.27 & 230.21 & 410.27 \\
\hline $2 \mathrm{GI}$ & 10.60 & 0.73 & 841950.26 & 3265.37 & 1.382 .79 & 19693.80 & 4695 & & & .92 & 173.27 & 998.18 \\
\hline 2 JANIÓPOLIS & 11.33 & 0.81 & 525408.01 & 2840 & 2797.60 & 14405.70 & .96 & .27 & 1484 & 5396.25 & 21.90 & 14.15 \\
\hline & 3.01 & 0.19 & 537686.30 & 15475 & 4127.90 & 16325.71 & 2.32 & 56269.46 & 13956.56 & & 38.53 & 1856.42 \\
\hline $2 \mathrm{kA}$ & 1.78 & 0.27 & 307953,55 & 9301,96 & 1314.02 & 4962.05 & 13354.34 & 20981.05 & 9737.90 & 1666.97 & 7.80 & $411,1.14$ \\
\hline 2 NONA AURCRA & 11.55 & 0.32 & 1117987.61 & 6236.17 & 2805.87 & 21342.56 & 6.28 & 10941 & 44722.25 & 5007.72 & 63.35 & 283.14 \\
\hline 2 NOVA CANIU & 13.91 & 0.17 & 469938.22 & 178.40 & 423.00 & 6529.33 & 36586.96 & 32998.00 & 10951.43 & 1813.27 & 0.00 & 14.73 \\
\hline 2 PEABIRU & 37.43 & 0.09 & 760318.10 & 20180.92 & 1203.79 & 16665.80 & 62698.76 & 62135.28 & 20845.50 & 5374.07 & 70.53 & 652.97 \\
\hline 2 SIA T. DO ITAIPU & 7.38 & 0.00 & 552618.91 & 233.90 & 96.22 & 6230.00 & 30379.11 & 62080.80 & 18312.53 & 918.90 & 52.35 & 9.60 \\
\hline 2 SÖ M. DO IGAAW & 5.57 & 0.21 & 1673197.62 & 5772.43 & 4973.43 & 38838.16 & 125919.65 & 195932.60 & 82197.55 & 4936.45 & 309.87 & 432.66 \\
\hline 2A. ROA & 12.89 & 0.53 & 1875077.85 & 3009 & 2911.20 & 2742 & & & & & & 225.63 \\
\hline 2 TOH & 757.22 & 0.36 & 995.70 & & 2.80 & 9577 & 2204 & 46482 & 3126 & 25875 & 505.22 & 1970.90 \\
\hline 3 AMAEORÃ & 7.33 & 0.00 & 46446 & & 52.00 & & 1110 & 1.30 & 4.97 & 4740.76 & 23.76 & 2.77 \\
\hline & 3.75 & 0.63 & 933550.95 & & & 18677.14 & & & & & 81.29 & 2612.10 \\
\hline $3 \mathrm{BO}$ & 237.03 & 0.16 & 674103.42 & 121929.24 & 3281.70 & 7634.45 & 2.58 & 29896.46 & 54956.41 & 6895.14 & 103.45 & 1336.33 \\
\hline 3 CAMPO MOURÄO & 50.12 & 0.69 & 2572162.03 & 17183.46 & 22177.88 & 82311.79 & 123652.99 & & 146327.44 & 21574.73 & 345.01 & 534.53 \\
\hline 3 CENIENŔRI & 0.78 & 0.00 & 934956.81 & 19412.02 & 1856.92 & 7150.63 & 51826.79 & 21550.03 & 0.94 & 7554.94 & 78.57 & 445.94 \\
\hline 3 CONOONHINHAS & 9.56 & 1.11 & 615457.64 & 11266.67 & 64262.85 & 10141.55 & & 9.03 & 5.60 & & 35.90 & 1.05 \\
\hline DOÓPIO & 4.82 & 0.02 & 1288074.89 & 84792.65 & 9616.00 & 21942.60 & 1.59 & 6.32 & 4.14 & 10418.11 & 41.51 & 785.25 \\
\hline 3 ELORESTḰOLIIS & 13.06 & 0.02 & 581429.07 & 36807.99 & 1121.96 & 6365.59 & & & 6.84 & 6266.05 & 1.53 & 4902.53 \\
\hline 3 IGLARAQU & 5.15 & 0.12 & 685381.78 & 12236.67 & 3350.20 & 7816.79 & 61615.62 & 28773.90 & 42369.01 & 5316.00 & 35.60 & 1274.32 \\
\hline 3 JACAREZINNO & 5.97 & 0.91 & 994933.35 & 67086.78 & 21366.80 & 41681.38 & 78221.08 & 39419.83 & 101006.40 & 22740.33 & 113.65 & 190.75 \\
\hline & 5.66 & 1.02 & 1090148.61 & 46376.50 & 13892.00 & 20441.70 & 73323.27 & 28234.80 & 38355.74 & 7440.14 & 139.67 & 1421.41 \\
\hline 3 JATAIZINHO & 1.72 & 1.08 & 444097.51 & 14902.70 & 1.8676 .08 & 9644.90 & 39000.81 & 36436.58 & 16587.30 & 2662.79 & 9.63 & 11.74 \\
\hline 3 đINDIAf DO SUL & 1.20 & 0.00 & 353616.30 & 32618.84 & 5307.96 & 3636.80 & 1.76 & 6661.57 & 15496 & & 6.00 & 2.50 \\
\hline 3 IEÓPOITS & & 0.00 & 827979.56 & 3512.76 & 443.43 & 15347.20 & 36522.94 & 59148.97 & 9720.57 & 5655.02 & 118.20 & 98.00 \\
\hline & 420.73 & 6.61 & 4581006.79 & 440974.53 & 23148.43 & 68657.05 & 510286.43 & 176293.01 & 188680.40 & 33504.59 & 720.93 & 6724.57 \\
\hline & 411.26 & 0.41 & 958055.36 & 112705.67 & 22553.32 & 12127.06 & 43277.53 & 27763.66 & 36999.16 & 7744.61 & 77.24 & 8711.33 \\
\hline & 1.69 & 1.39 & 264994.01 & 24890.37 & 2475.75 & 12400.51 & 18440.14 & 22111.35 & 13603.27 & 2075.86 & 0.00 & 1917.44 \\
\hline IA A. DA OOTINA & 0.83 & 0.00 & 235173.12 & 11034.10 & 5860.22 & 7861.19 & 12633.58 & 17563.79 & 6991.24 & 3044.05 & 1.00 & 82.22 \\
\hline
\end{tabular}

Nota: Os indicadores estão definidos no final da tabela, p.130. 
INDICADORES

\begin{tabular}{|c|c|c|c|c|c|c|c|c|c|c|c|c|}
\hline & \\
\hline & 4 & 5 & 7 & 8 & 9 & 10 & 11 & 12 & 13 & 14 & 15 & 16 \\
\hline NA EÁTTMA & 0.56 & 0.00 & & & & 12583.57 & 35 & 5351.39 & & & 10.00 & \\
\hline 3 PORECATU & 0.91 & 0.10 & 1018308.46 & 5255.72 & 1436.68 & 5485.52 & 19106.65 & 11486.79 & 11314.30 & & & 115.67 \\
\hline 3 QUINIA DO SOL & 4.25 & 0.06 & 792445.37 & 45283.55 & 3645.29 & 14137.50 & 60216.29 & 52466.52 & 24979.63 & 7969.05 & 288.00 & 144.41 \\
\hline 3 RIBETRÄO CIARO & 13.56 & 0.32 & 887083.60 & 94451.02 & 9584.16 & 14322.79 & 110274.91 & 6247.66 & 49899.28 & 3519.23 & 16.54 & 3.17 \\
\hline 3 SIO A. DO PARAÍSO & 1.57 & 0.00 & 254792.69 & 5495.00 & 425.00 & 2482.49 & 14001.78 & 19437.56 & 1998.19 & 1692.28 & 26.32 & 6.20 \\
\hline 3 SFO PEDRO DO IVAI & 9.43 & 0.20 & 711367.40 & 9117.42 & 1146.84 & 15864.00 & 29797.78 & 60738.36 & 24147.12 & 6006.92 & 169.68 & 1227.46 \\
\hline 3 SAO SEBASTIÄO DA AM & 0.30 & 0.13 & 389991.06 & 11781.40 & 1490.46 & 14583.40 & 19764.87 & 37750.58 & 8905.34 & 3257.47 & 8.57 & 327.50 \\
\hline 3 TERRA BOA & 2.57 & 0.05 & 538513.85 & 133871.93 & 4028.00 & 6151.31 & 24267.62 & 47664.16 & 37914.06 & 11651.50 & 7.97 & 9839.20 \\
\hline 4 AITÔNIA & 76.02 & 1.71 & 1060354.72 & 532214.92 & 3286.93 & 18591.16 & 189521.18 & 7227.72 & 34264.65 & 7139.59 & 29.74 & 57.24 \\
\hline 4 DIAMANIE DO NORTE & 2.83 & 0.04 & 252840.30 & 88157.75 & 640.75 & 6514.60 & 37315.54 & 11589.58 & 27809.77 & 4076.59 & 8.78 & 9137.37 \\
\hline 4 INDIANÓPOLIS & 1.52 & 0.07 & 338472.91 & 112508.70 & 2627.11 & 4546.70 & 26196.68 & 7348.16 & 23020.96 & 2205.11 & 35.06 & 13348.53 \\
\hline 4 JAEURA & 23.70 & 0.25 & 45862 & 171991.85 & 2125.24 & 7953.45 & 13927.47 & 14100.74 & 19717.77 & 2558.49 & 150.00 & 19286.45 \\
\hline OMM OINDA & 1.20 & 0.00 & 13584 & 31.90 & 340.00 & 824.80 & 25441.55 & 2904.78 & 1965.80 & 512.40 & 48.00 & 21.60 \\
\hline OÓMPIA & 0.78 & 0.00 & 27182 & 30562.44 & 429.33 & 2328.50 & 51974.39 & 3006.14 & 11387.53 & 1064.79 & 0.00 & 1079.53 \\
\hline ROLA & 23.28 & 0.99 & 97155 & 242454.41 & 3836.35 & 14957.78 & 750.56 .55 & 4760.24 & 40788.70 & 3887 & 147.96 & 38.00 \\
\hline O J. DO EATROC & 6.46 & 0.58 & 41337 & 205224.55 & 1643.73 & 8470.70 & 22224.98 & 4025.29 & 14184.85 & 3068.14 & 5.21 & 829.35 \\
\hline 4 STO TOMÉ & 1.05 & 0.03 & 36276 & 124529.11 & 2324.63 & 8001.00 & 19127.53 & 14677.99 & 16421.56 & 2773.24 & 18.59 & 14193.19 \\
\hline $4 \mathrm{XAMBR \hat {E }}$ & 6.06 & 0.59 & 964363.72 & 104884.84 & 5506.99 & 8591.50 & 93419.20 & 7922.73 & 41963.11 & 3508.56 & 0.00 & 22.44 \\
\hline ANORIE & 26.43 & 0.91 & 1235414.10 & 294001.45 & 12172.01 & 18582.09 & 92553.00 & 37639.03 & 64713.82 & 13824.67 & 109.57 & 25855.67 \\
\hline JRADINA & 17.61 & 0.02 & 628885.96 & 101283.48 & 1901.68 & 6863.89 & 87811.95 & 7853.52 & 35493.94 & 3929.88 & 197.06 & 227.47 \\
\hline 5 ICARAÍMA & 33.05 & 0.45 & 860035.17 & 76882.65 & 1479.63 & 6811.78 & 145810.60 & 15847.02 & 44333.46 & 4414.57 & 81.42 & 178.30 \\
\hline 5 IIUNA DO SUL & 176.34 & 1.50 & 220434.45 & 70549.24 & 365.98 & 3442.86 & 37353.68 & 3723.96 & 11808.20 & 2483.55 & 20.44 & 1374.27 \\
\hline 5 MARIA HEIENA & 4.35 & 0.63 & 722622.46 & 75774.99 & 6387.04 & 9328.80 & 155825.63 & 8752.10 & 55440.66 & 5077.24 & 49.82 & 71.92 \\
\hline 5 MARTIENA & 7.86 & 0.30 & 328203.43 & 96332.40 & 927.95 & 7804.60 & 42743.47 & 5241.04 & 31061.39 & 3639.88 & 29.76 & 3845.74 \\
\hline 5 PCRTO RTOO & 7.42 & 0.03 & 230876.90 & 45560.66 & 280.43 & 7170.98 & 40499.60 & 4368.23 & 10897.76 & 1154.11 & 117.50 & 1127.13 \\
\hline 5 SÄO P. DO PARANA & 3.54 & 0.00 & 297686.89 & 101232.34 & 612.65 & 6191.25 & 66658.45 & 3964.25 & 26724.16 & 1473.15 & 188.80 & 1718.22 \\
\hline 5 TAPIRA & 11.04 & 0.55 & 561418.14 & 44300.75 & 1129.58 & 11083.75 & 87249.60 & 5911.45 & 27014.16 & 1733.61 & 495.04 & 262.83 \\
\hline 5 UMARAMA & 115.10 & 1.75 & 416477 & 360528.88 & 362.81 & 51181.57 & 652173.17 & 50638.06 & 170719.66 & 22239 & & 439.41 \\
\hline DO PARANÁ & 9.60 & 0.09 & .77 & 52411.73 & .85 & 6.58 & 77324.31 & 17828.98 & 43122.63 & .76 & 358.20 & 455.77 \\
\hline PIQUIRI & 5.49 & 0.80 & .55 & 121 & .78 & 25 & & 55638.84 & & 29 & & 121.28 \\
\hline ARINA & 21.13 & 0.68 & 62188 & 28369 & .85 & 11633.07 & 36.53 & 27652.33 & 15 & & 244 . & 101.79 \\
\hline FEARA & 2.63 & 0.64 & 37271 & .60 & 6.40 & 1.60 & 48352.20 & 9985.93 & .04 & & & 5.60 \\
\hline ADE GAÚCHA & 0.70 & 0.00 & .40 & 16363 & 2.17 & .30 & 78423.21 & 11323.60 & 08.18 & .49 & 90.19 & 270.76 \\
\hline VSEI HETRO MATRTN & 901.43 & 0.00 & 25492 & 7719.92 & 35.15 & 2188.65 & 45319.58 & 3037.41 & 11665.55 & 1193.58 & 0.00 & 0.00 \\
\hline UZEIRO DO OESIE & 4.85 & 0.00 & 1238936.70 & 131651.60 & 4658.69 & 19421.93 & 148289.43 & 30833.28 & 49401.87 & 10873.27 & 271.95 & 3110.56 \\
\hline UZZETRO DO SUL & 1.96 & 0.07 & 406418.81 & 35301.49 & 1306.18 & 7098.17 & 63896.73 & 12520.11 & 46743.40 & 4448 & 0.24 & 1480.69 \\
\hline 6 EIÓRIDA & 0.00 & 0.04 & 113571.50 & 542.40 & 176.00 & 734.00 & 12527.20 & 4272.32 & 6333.85 & 1114 & 0.00 & 261.78 \\
\hline 6 ERAMCISOO ALVES & 27.10 & 0.92 & 418207.80 & 12442.23 & 2090.90 & 11517.76 & 52338.06 & 16922.70 & 36009.11 & 2690.31 & 13.20 & 3.60 \\
\hline 6 GUAIRACÁ & 2.84 & 0.02 & 675806.80 & 103072.82 & 5270.80 & 10464.12 & 107553.82 & 13172.70 & 61025.43 & 5602.31 & 287.91 & 1460.11 \\
\hline 6 GIAPIRAMA & 1320.39 & 0.15 & 296672.99 & 5334.84 & 1154.91 & 7426.52 & 52043.02 & 8420.47 & 33329.38 & 3436.77 & 23.65 & 101.86 \\
\hline 6 QAPPORDMA & 2.68 & 0.02 & 339608.30 & 3155.92 & 918.50 & 7094.02 & 57782.66 & 10287.36 & 9525.65 & .13 & 58.60 & 51.59 \\
\hline ARACI & 0.79 & 3.90 & .92 & 171 & .90 & 5271 & .56 & 10204.27 & 963 & & 0. & 124.00 \\
\hline AIÁ & 0.00 & .00 & 22162 & 24 & .36 & .65 & 274 & .28 & 877 & & 9.90 & 77.85 \\
\hline $\operatorname{CRA}$ & 40.83 & 1.12 & 133029 & 1609 & .66 & 24221.64 & 150 & 23960.99 & 4212 & & 102.76 & 401.03 \\
\hline AGUAJÉ & 0.58 & 0.00 & .63 & .65 & .20 & .40 & & 7245 & .40 & .30 & 29. & 241.31 \\
\hline ANDA & 17.88 & 2.02 & .30 & 8492 & .75 & 1002 & 4943 & 22384.98 & 10140 & 627 & 213.59 & 2284.16 \\
\hline XIO & 0.26 & 0.00 & .29 & & .80 & .70 & 3 & 1131 & & & 29.39 & 105.99 \\
\hline IONÓEOATS & 0.27 & 0.19 & .29 & & 40 & .67 & & .49 & & & & 0.00 \\
\hline IIUZ & 54.03 & 0.00 & .05 & 3051 & .33 & 146 & .23 & 25291.77 & .43 & & 29.44 & 25.00 \\
\hline RADOR & 1.38 & 0.02 & 322765.90 & .89 & 317.50 & 5456.25 & 46820.91 & 5875.71 & 11510.20 & 1259.54 & 30.00 & 0.00 \\
\hline PEIRA SALES & 27.92 & 0.71 & 797361.56 & 89203 & 2420.49 & 20725.14 & 56542.44 & 18511.15 & 21903 & .92 & 75.22 & 618.75 \\
\hline 6 MNHOZ DE MELO & 39.83 & 0.02 & 259910.89 & 31773.75 & 5426.44 & 3146.53 & 30996.34 & 9583.12 & 9367.04 & 2504.16 & 8.05 & 1360.06 \\
\hline 6 NOSSA S. IAS GRACAS & S 1.66 & 0.00 & 463558.46 & 8424.03 & 268.35 & 4535.78 & 42386.25 & 10837.06 & 23098.90 & 2005.16 & 1.30 & 43.70 \\
\hline 6 NONA A. DO TVAI & 109.55 & 0.07 & 150089.70 & 1349.56 & 781.80 & 2270.35 & 38538.35 & 3728.10 & 12369.00 & 698.37 & 0.00 & 0.00 \\
\hline 6 NOVA LONDRINA & 8.93 & 0.04 & 622277.90 & 37691.07 & 2029.61 & 9588.40 & 68307.16 & 10807.26 & 34404.70 & 3132.67 & 77.41 & 378.49 \\
\hline 6 PARAISO DO NORTE & 4.37 & 0.06 & 364394.26 & 6937.25 & 2183.60 & 7544.03 & 37924.17 & 16884.90 & 9387.93 & 2768.30 & 5.75 & 3.00 \\
\hline RANACTIY & 7.57 & 0.02 & 502952.43 & 31156.83 & .76 & 1.80 & .50 & .92 & 328 & & 38.60 & 1155.19 \\
\hline RANAFCEMA & 0.28 & 0.80 & 159147.07 & .49 & 7.98 & 3121.95 & 85.61 & 9125.80 & 7638.05 & 392 & 0.00 & 0.00 \\
\hline 6 PARANAVAI & 91.80 & 0.83 & 1586247.29 & 128764 & 2.53 & 23039.92 & 3.70 & 29339.00 & 220690.38 & 1168 & 95.78 & 3749.14 \\
\hline 6 PLANAITTIA DO PARANÁ & A 0.35 & 0.34 & 316382.48 & 1055 & 4.36 & .13 & 9217 & 8548.62 & .85 & 2101.70 & 80.06 & 608.72 \\
\hline JERGNCIA DO NORIE & 10.22 & 0.91 & 105193 & 31263.77 & 289.01 & 1145 & 183476 & 36524.24 & .51 & .87 & 226.53 & 361.72 \\
\hline ETPÄO DO PTNHAI & 6.12 & 0.16 & 512407.25 & 64278.51 & 4.82 & 9869.95 & 59187.18 & 18585.14 & 3391 & .17 & 13.75 & 15.20 \\
\hline ÂNDIA & 287.15 & & 1620206.33 & 216311.02 & 2.93 & 26274.13 & 57209.81 & 91069.12 & .21 & .89 & & 13205.68 \\
\hline 6 RONDON & 30.79 & 0.32 & 903764.34 & 70021.62 & 3894.41 & 12673.72 & 152112.67 & 18095.96 & 44724.55 & 5889.32 & 516.07 & 3822.82 \\
\hline 6 SABÁUDIA & 1.25 & 0.08 & 359926.16 & 23546.74 & 2552.66 & 5253.70 & 27697.90 & 18781.65 & 36376.86 & 1837.54 & 10.40 & 303.94 \\
\hline 6 SANIA C. M. CASIELO & 7.99 & 0.60 & 561307.36 & 32725.80 & 2193.05 & 6555.60 & 88827.30 & 15657.24 & 37967.09 & 2675.60 & 6.98 & 1111.69 \\
\hline 6 SPNIA INES & 4.63 & 0.00 & 220554.75 & 3061.18 & 311.00 & 1378.60 & 29846.00 & 5268.65 & 8834.65 & 2184.28 & 0.66 & 163.73 \\
\hline 6 SANIA I. DO IVAI & 23.39 & 0.21 & 1026727.49 & 131386.64 & 3355.11 & 8885.03 & 96325.96 & 21121.02 & 50179.34 & 4589.24 & 292.49 & 2169.77 \\
\hline 6 SANIO A. DA PIATTINA & 21.37 & 0.33 & 1338234.97 & 121967.20 & 222547.58 & 23554.17 & 127182.35 & 49969.95 & 72753.26 & 12008.76 & 29.91 & 130.99 \\
\hline 6 SANIO A. DO CAIUA & 0.40 & 0.00 & 243767.69 & 11252.02 & 532.67 & 4237.47 & 58097.59 & 4575.19 & 20684.61 & 2858.36 & 21.80 & 17.69 \\
\hline 6 SANIO INACIO & 3.21 & 0.30 & 359316.95 & 1260.28 & 381.23 & 7442.30 & 39444.00 & 15374.75 & 27890.20 & 4792.00 & 16.70 & 37.54 \\
\hline 6 SAO CARIOS DO IVAI & 10.29 & 0.04 & 421967.10 & 14452.66 & 5801.75 & 7534.60 & 38061.55 & 19364.64 & 26252.63 & 2302.46 & 100.20 & 87.14 \\
\hline DO JOFO DO CATUA & 1.45 & 0.00 & 379483.20 & 22329.10 & 1135.25 & 2861.00 & 65138.76 & 9358.18 & 29916.80 & 2154.85 & 4.50 & 464.27 \\
\hline MBOARA & & 0.05 & 281548.95 & 11909 & 3107.79 & & 34523.79 & & & 2060.65 & 314.07 & 18.63 \\
\hline APEIARA & 333.24 & 0.14 & 826117.56 & 60956.18 & 1577.18 & 12091.78 & 156759.95 & 24878.96 & 40058.21 & 7169.33 & 149.52 & 1227.19 \\
\hline 6 IERRA RICA & 15.58 & 0.05 & 1029107.90 & 134240.30 & 3083.56 & 15768.44 & 165037.45 & 20499.16 & 191183.54 & 8053.35 & 52.91 & 3995.71 \\
\hline 6 TUNETRAS DO OESTE & 10.92 & 3.18 & 835117.01 & 43441.40 & 3497.13 & 10354.14 & 87721.86 & 20111.52 & 29041.75 & 3655.69 & 0.90 & 123.22 \\
\hline NIFIOR & 0.65 & 0.02 & 153716.25 & 7901.70 & 906.10 & 1369.14 & 25197.27 & 3912.13 & & 1264.65 & 5.80 & 77.82 \\
\hline 7 AMEÉRE & 13.48 & 0.39 & 265637.61 & 3878.27 & 7722.31 & 8991.79 & 30466.92 & 31107.85 & 17881.20 & 1455.86 & 100.25 & 7.49 \\
\hline
\end{tabular}


Tabela 3A. Continuação.

\begin{tabular}{|c|c|c|c|c|c|c|c|c|c|c|c|c|}
\hline & \multicolumn{12}{|c|}{ INDTCADORES } \\
\hline & 4 & 5 & 7 & 8 & 9 & 10 & 11 & 12 & 13 & 14 & 15 & 16 \\
\hline 7 BARRACÃO & 21.10 & 0.80 & & & & & & & 21619.76 & & & 17.30 \\
\hline 7 BOA V.DA ADARECIDA & 17.02 & 1.02 & 243613.25 & 2863.91 & 1150.28 & 4983.16 & 26187.14 & 17783.06 & & & & 78.91 \\
\hline 7 CALIEÓPNIA & 4.37 & 0.31 & 251974.52 & 24442.57 & 2084.95 & 5070.91 & 30026.36 & 7503.51 & 8939.29 & 1084.76 & 23.20 & 53.67 \\
\hline 7 CAPANEMA & 15.79 & 0.20 & 583151.15 & 4182.91 & 4410.47 & 23719.79 & 61037.34 & 78735.92 & 42254.41 & 2546.26 & 173.97 & 372.94 \\
\hline 7 CAPITÄO L. MARQUES & 652.50 & 0.21 & 514707.94 & 2932.49 & 1839.92 & 12541.38 & 52654.36 & 42371.10 & 24988.27 & 1198.29 & 34.55 & 98.50 \\
\hline 7 Ć́ AZUL & 5.64 & 0.38 & 537274.48 & 2987.59 & 3840.31 & 13604.03 & 51141.90 & 58954.89 & 37514.98 & 2871.95 & 28.09 & 117.10 \\
\hline 7 AKOETNZINHO & 14.52 & 45.51 & 632018.68 & 3148.58 & 1485.85 & 16143.72 & 108231.68 & 68755.39 & 58301.42 & 3217.34 & 153.43 & 55.53 \\
\hline 7 OORONEL VIVIDA & 14.76 & 1.99 & 472215.63 & 2419.80 & 3042.35 & 18824.65 & 54710.53 & 76483.48 & 38395.34 & 1891.46 & 16.01 & 21.31 \\
\hline 7 DOIS VIZINHOS & 26.19 & 385.40 & 703991.79 & 7718.80 & 4908.53 & 19392.06 & 101186.94 & 72423.31 & 76886.76 & 3051.72 & 153.45 & 548.46 \\
\hline 7 ENÉTIAS MARQUES & 14.22 & 79.02 & 273205.72 & 3444.83 & 5602.23 & 5358.88 & 51210.18 & 22945.84 & 33875.22 & 1159.28 & 25.00 & 90.86 \\
\hline 7 ERANCISOO BENTRÃO & 957.39 & 0.87 & 554103.40 & 9379.12 & 14107.24 . & 19355.69 & 91322.26 & 59800.54 & 79201.26 & 3832.30 & 202.06 & 67.50 \\
\hline 7 ITAPEIIARA D'CESIE & 14.02 & 0.12 & 195118.50 & 999.98 & 1230.31 & 8359.50 & 22120.64 & 33767.46 & 21578.22 & 1043.80 & 25.90 & 136.31 \\
\hline 7 IVATECRẼ & 72.04 & 1.81. & 1075989.17 & 30115.84 & 2497.81 & 24367.53 & 108674.07 & 56378.78 & 35826.23 & 4764.77 & 24.17 & 300.90 \\
\hline 7 MAREOHAL C. RONDON & 11.97 & 0.33 & 2454295.06 & 2487.89 & 7019.30 & 47628.65 & 175563.76 & 311091.92 & 167607.16 & 6845.50 & 272.25 & 361.20 \\
\hline 7 MARTAPÓLTS & 6.97 & 0.05 & 229662.72 & 2120.39 & 1309.80 & 7032.00 & 24035.54 & 38612.85 & 15325.66 & 766.13 & 43.43 & 20.10 \\
\hline 7 MAFYEI FIRO & 14.96 & 3.49 & 295856.02 & 4322.79 & 15640.67 & 9597.33 & 43702.94 & 40828.56 & 22629.61 & 1437.41 & 22.61 & 38.58 \\
\hline 7 MATELÂNDIA & 10.85 & 0.60 & 1107890.10 & 16999.75 & 4237.42 & 18340.27 & 135026.36 & 82400.08 & 88953.83 & 5754.49 & 44.12 & 157.74 \\
\hline 7 MEDIANEITA & 41.03 & 0.24 & 1004074.18 & 6120.16 & 10971.90 & 33859.64 & 89764.03 & 95875.45 & 90501.72 & 2248.74 & 51.45 & 489.15 \\
\hline 7 MISSAL & 7.18 & 0.51 & 537704.61 & 1642.70 & 3765.89 & 14397.44 & 48475.16 & 59353.80 & 41607.68 & 1238.80 & 86.50 & 358.91 \\
\hline P. DO IQIAQU & 17.02 & 0.76 & .30 & .90 & 7.15 & 11309.61 & 54750.00 & 37.67 & 271.57 .17 & 1798.84 & 34.77 & 106.50 \\
\hline 7 NOVA SANIA ROSA & 909.41 & 0.48 & 53663 & 142 & 1514.73 & 12264.62 & 29704.49 & .26 & 38506.25 & 1242.45 & 137.65 & 157.37 \\
\hline 7 PAIO BRANOO & 15.09 & 1.07 & 69266 & 42 & 5638.33 & 32251.27 & 63849.30 & 108865.05 & 51462.87 & 3070.89 & 71.78 & 29.27 \\
\hline LA DO OESIE & 49.88 & 0.50 & .81 & 85 & 7.96 & 11347.19 & 40452.15 & 51501.54 & 34084.23 & 1553.62 & 17.05 & 107.52 \\
\hline 7 PIANALTO & 21.00 & 0.25 & .03 & 5522.47 & .17 & 10932.36 & 11.27 & .41 & 1.67 & 847.68 & 15.85 & 183.57 \\
\hline 7 PRANCHITA & 9.21 & 0.65 & 36 & .92 & 0.55 & 7630 & 20 & .43 & .55 & 186 & 16. & 420.60 \\
\hline 7 REALEZA & 9.84 & 0.44 & .07 & .02 & 68.49 & 11188.56 & & & .76 & .49 & 148. & 93.41 \\
\hline 7 RENASCENCA & 6.92 & 0.30 & 327634.18 & 619.01 & 92230.37 & 17382.55 & 23256 & .21 & .01 & 135 & & 2.50 \\
\hline 7 SALGADO EIIHO & 42.30 & 0.45 & 234897.27 & 3270.64 & 5533.17 & 7052.45 & 51153.30 & 19352.09 & .44 & 152 & 12. & 9.04 \\
\hline 7 SALTO DO ITARARÉ & 32.20 & 0.17 & 169606.56 & 11741.70 & 3353.25 & 3578.00 & 22374.62 & 5579.38 & 7615.25 & 694.21 & 0.0 & 43.54 \\
\hline 7 SALTO DO LONIRA & 14.76 & 0.73 & 320797.33 & 2904.90 & 752.23 & 9913.43 & 33835.87 & 28211.04 & 19568.66 & 1397.33 & 12.70 & 825.52 \\
\hline 7 SANIA C. DO EAVÄO & 4.47 & 0.23 & 255377.42 & 495.70 & 104.20 & 9046.43 & 8525.70 & 22969.32 & 1832.37 & 1945.96 & 2.00 & 11.75 \\
\hline 7 SANIA HEJENA & 10.12 & 0.61 & 1054553.41 & 16830.34 & 6782.85 & 25129.16 & 76480.84 & 146270.87 & 67849.48 & 4071.40 & 190.30 & 278.63 \\
\hline 7 SANTA I. DO OESTE & 22.32 & 0.96 & 340246.13 & 2461.64 & 3812.03 & 11499.97 & 32460.26 & 48154.91 & 24041.10 & 1474.54 & 26.86 & 302.86 \\
\hline 7 SANIANA DO IIARARÉ & 20.22 & 0.46 & 221153.91 & 9321.13 & 4740.54 & 4757.53 & 20818.83 & 13813.00 & 8073.20 & 1256.07 & 0.08 & 8.37 \\
\hline 7 SANIO A. DO SUDOESIE & E 19.93 & 1.29 & 333873.55 & 4941.55 & 3342.63 & 10500.37 & 44821.85 & 36335.87 & 30404.99 & 1759.31 & 36.53 & 112.83 \\
\hline 7 Sस̈O ЈOि̈О & 22.46 & 0.10 & 300784.07 & 2695.60 & 2237.84 & 10326.73 & 42770.71 & 51985.01 & 34896.79 & 1477.37 & 29.00 & 81.54 \\
\hline 7 SĀO JOĀO DO IVAI & 61.89 & 0.55 & 1037773.42 & 13814.24 & 2275.05 & 26629.20 & 58187.53 & 6659 & 43432.21 & 7385.53 & 107.65 & 292.45 \\
\hline 7 SAO JORGE D'OFSIE & 13.68 & 206.56 & 297865.36 & 3446.26 & 4131.33 & 7703.47 & 55452.02 & 32258.57 & 4228 & 1288.00 & 26.45 & 24.00 \\
\hline 7 SÄO J. DA BOA VISTA & 16.90 & 0.78 & 24317 & .17 & .74 & 7218.43 & 24891.37 & 17599.92 & 5.29 & 1084.53 & 24.73 & 229.56 \\
\hline 7 TRES BARRAS & 18.41 & 0.01 & 455915.93 & .73 & 2295.06 & 7301.05 & 60458.04 & 3217 & 0.38 & 1541.23 & 8.00 & 34.73 \\
\hline 7 VERA CRUZ DO CESTE & 334.84 & 0.01 & 456419.66 & .65 & 1751.75 & 13646.74 & 3.28 & & 9.46 & 3.26 & 23.95 & 53.98 \\
\hline$\hat{\mathrm{p}}$ & 14.14 & 24.60 & .21 & 7.54 & .81 & 8824.90 & & & 9.59 & 2.81 & 22.30 & 18.63 \\
\hline RTNO & 3.28 & 0.14 & 3.72 & 891.30 & 3.35 & 5616.45 & & & 7.59 & 5.86 & 48.55 & 62.38 \\
\hline $8 \mathrm{AE}$ & 72.65 & 0.85 & 424801.55 & 1.39 & 1874.82 & 7821.67 & 22158.97 & 22475.06 & 20240.06 & 4387.61 & 9.00 & 51.63 \\
\hline ARANA & 142.74 & 1.26 & 1042010.15 & 223991.20 & 5.41 & 16437.45 & 65043.52 & 51785.91 & 56949.20 & 9215.17 & 122.25 & 4607.74 \\
\hline 8 AIAIAIA & 4.37 & 0.32 & 236907.28 & 10967.92 & 1120.20 & 3746.27 & 16489.92 & 13153.22 & 7.85 & 3.03 & 3.00 & 1269.33 \\
\hline 8 BARBOSA EERRAZ & 29.05 & 0.67 & 1080462.13 & .28 & 34.39 & 16480.60 & 125079.05 & 1.68 & 9.84 & 6507.64 & 71.34 & 8088.11 \\
\hline MBIRA & 17.62 & 0.92 & 591345.14 & 59149.84 & 2698.90 & 10808.75 & 4427 & 3.35 & 7.70 & 2634.31 & 578.37 & 2579.61 \\
\hline 8 CARTÓOOTIS & 233.49 & 0.13 & 720404.12 & 437588.24 & 12946.00 & 13431.94 & 56089.59 & 28144.28 & 76838.93 & 6660.08 & 63.76 & 99.62 \\
\hline 8 OOTORADO & 0.35 & 0.02 & 711304.04 & 50662.68 & 1115.00 & 10572.58 & 72365.70 & 21106.16 & 33148.83 & 1579 & 85.35 & 1667.32 \\
\hline 8 EIGUEIRA & 6.20 & 0.16 & 120955.27 & 5534.36 & 1496.69 & 1595.39 & 9076.88 & 1944.99 & 4713.15 & 1599.48 & 13.02 & 15.22 \\
\hline 8 IRAITI & 20.69 & 0.93 & 929390.42 & 86480.17 & 11419.35 & 17623.88 & 161004.85 & 21283.75 & 34209.80 & 8203.55 & 77.91 & 373.09 \\
\hline 8 JABOTI & 1.54 & 0.70 & 156403.75 & 5299.45 & 2354.15 & 2049.30 & 25249.86 & 3032.56 & 11064.96 & 886.63 & 15.14 & 595.82 \\
\hline 8 JANDATA DO SUL & 28.47 & 1.29 & 335685.16 & 61711.62 & 4363.59 & 6633.82 & 21528.54 & 11884.57 & 17730.09 & 2130.11 & 171.17 & 3554.20 \\
\hline 8 JAPIRA & 6.77 & 0.34 & 196143.97 & 16988.35 & 1674.50 & 3230.33 & 18578.09 & 5193.63 & 8414.72 & 2169.21 & 3.36 & 251.23 \\
\hline 8 JARDM ALECRE & 84.94 & 0.78 & 1033965.89 & 32756.43 & 1192.37 & 21514.31 & 97008.05 & 25328.10 & 23532.41 & 5349.98 & 49.50 & 392.02 \\
\hline 8 IUNARDEIII & 6.52 & 0.41 & 382771.47 & 13110.85 & 764.47 & 8434.42 & 123166.10 & 12285.76 & 7336.64 & 4275.16 & 4.86 & 101.54 \\
\hline RGIARI & 17.32 & 0.20 & .24 & .96 & 4961.30 & 9742.05 & 93203.39 & 19733.25 & 3292 & 2.00 & 49.74 & 432.47 \\
\hline ASELVA & 4.53 & 0.07 & .72 & 389 & 29 & 893 & 26077.30 & .02 & 1971 & 442 & 33.24 & 2571.77 \\
\hline NA ESEERANCA & 8.99 & 0.52 & 733103.19 & 82025.91 & 5.58 & 14720.96 & 104601.30 & 6.15 & 66034.95 & .77 & 41.10 & 124.73 \\
\hline DHALÄO & 7.78 & 0.45 & 219688.71 & 55787.75 & 1709.99 & 3353.30 & 21974.04 & 3916.91 & 10462.82 & 1428.76 & 29.62 & 127.45 \\
\hline SIDENIE CASIELO & 169.75 & 1.63 & 7.92 & 2.25 & 3.70 & 5.75 & 18012.04 & 6.88 & 6.34 & 0.47 & 31.73 & 60.50 \\
\hline 8 QIATIOÁ & 215.91 & 0.03 & 139372.90 & 4266.30 & 1729.35 & 3880.55 & 33290.69 & 1537.26 & 9.50 & 0.84 & 0.00 & 26.20 \\
\hline 8 SANIA EÉ & 19.42 & 0.10 & 545156.00 & 24116.10 & 3463.05 & 10047.72 & 62543.63 & 19474.54 & 7.36 & 7.71 & 69.13 & 3318.97 \\
\hline QUETRA CAMROS & 14.75 & 0.32 & 3.95 & 309 & 5697.58 & 4709.89 & & 2.72 & 15665.07 & 1454.27 & 104.86 & 343.82 \\
\hline ARINA & 30.87 & 0.63 & 5331 & 4935 & 5969.91 & 12743.85 & 81574.06 & 1633 & 20397.33 & 2270.57 & 23.87 & 24.88 \\
\hline AMIRA DO PARANA & 5.59 & 0.0 & 2420 & & 0.00 & 279 & 65191.39 & & 5982.98 & & & 15.71 \\
\hline AEOAOHIS & 7.38 & 0.35 & 563930.26 & 31577.88 & 1334.95 & 969 & 51353.76 & 3386 & 21622.16 & 5.14 & 29.13 & 688.79 \\
\hline TINA DA IACOA & 28.51 & 0.47 & 1057146.15 & 334 & 1406.18 & 20264.85 & 10445 & 90513.02 & .94 & 2.33 & 12.85 & 80.99 \\
\hline NDIDO ABREN & 166.78 & 2.79 & .89 & 69 & 126390.76 & 10094.82 & .82 & 20001.04 & 4345 & 2941.57 & 40.45 & 39.01 \\
\hline NIAGAIO & 39.75 & 1.10 & .12 & .93 & 6.10 & 1610 & 0.06 & .71 & 2600 & 7.52 & 89.78 & 6.00 \\
\hline NDUAS & 24.42 & 0.98 & 508890.77 & .97 & 22201.07 & 886 & 6783 & 44293.21 & 5157 & 2.32 & 54.52 & 17.60 \\
\hline गRÚVA & 10.08 & 0.81 & 254213.34 & 1208 & 71141.79 & 3755.38 & 31279.32 & 9027.20 & 6792.14 & 1937.76 & 6.15 & 128.94 \\
\hline 9 EAXINAL & 60.00 & 4.48 & 1146974.28 & 27052.67 & 10199.61 & 17084.70 & 128894.76 & 51647.98 & 54566.56 & 6576.41 & 16.80 & 116.88 \\
\hline 9 GRANDES RIOS & 47.45 & 1.98 & 935428.28 & 74370.19 & 91186.14 & 11717.54 & 201812.92 & 20280.05 & 37885.06 & 10597.33 & 41.25 & 2807.03 \\
\hline 9 GIARANIAQU & 20.66 & 1.29 & 899647.49 & 4216.08 & 3072.50 & 25474.35 & 188430.27 & 64056.79 & 56602.68 & 7132.49 & 100.46 & 59.37 \\
\hline 9 IRETANA & 20.49 & 1.21 & 461979.29 & 7470.96 & 524.80 & 7044.20 & 99271.75 & 15252.31 & 33413.06 & 2667.45 & 15.87 & 55.57 \\
\hline 9 JOAQUM TAVORA & 1106.02 & 0.37 & 332031.69 & 11954.64 & 4948.38 & 5646.92 & 51887.62 & 7063.94 & 20674.08 & 1984.61 & 8.28 & 208.95 \\
\hline 9 LARANUEIRAS DO & 235.02 & 2.86 & 1289504.57 & 5132.65 & 224318.92 & 35498.67 & 139429.53 & 110299.03 & 76926.55 & 11669.25 & 103.46 & 49.97 \\
\hline
\end{tabular}


Tabela 3A. Continuação.

INDICADORES

\begin{tabular}{|c|c|c|c|c|c|c|c|c|c|c|c|c|}
\hline & & \multirow[b]{2}{*}{16} \\
\hline & 4 & 5 & 7 & 8 & 9 & 10 & 11 & 12 & 13 & 14 & 15 & \\
\hline 9 MANOES, RTBAS & & 1.05 & & & & 15201.85 & 55402.39 & 37170.37 & & & & 61.17 \\
\hline 9 MARTIÂNDIA DO $S$ & & 0.71 & 699745.35 & 5160.70 & 38310.49 & 13383.59 & 76405.25 & 49086.92 & 31975.93 & & 57.22 & 107.02 \\
\hline 9 ORTTUEIRA & 78.14 & 4.16 & 852552.90 & 4625.64 & 4782.72 & 16884.73 & 170792.71 & 38988.40 & 84655.04 & 7840.49 & 70.03 & 90.30 \\
\hline 9 PAIMITAL & 24.49 & 1.39 & 680132.32 & 1364.58 & 1969.99 & 13960.28 & 137429.81 & 16733.13 & 80176.50 & 4281.87 & 189.30 & 19.80 \\
\hline 9 PITANGA & 374.40 & 4.80 & 1966439.65 & 20388.62 & 64602.12 & 42874.19 & 262941.70 & 121726.08 & 104297.50 & 11862.88 & 503.16 & 64.08 \\
\hline 9 QUEDAS DO IGAQU & 59.38 & 2.64 & 595100.71 & 2055.59 & 69574.99 & 12658.30 & 61603.30 & 50489.70 & 30198.37 & 6173.74 & 80.75 & 41.00 \\
\hline 9 RESERVA & 33.48 & 1.04 & 600394.94 & 1433.48 & 234393.45 & 12577.45 & 95924.34 & 32647.60 & 31297.83 & 3715.73 & 27.35 & 3.71 \\
\hline 9 RTO BOM & 10.85 & 0.42 & 224982.31 & 8688.95 & 612.65 & 3867.91 & 40418.13 & 8463.12 & 11004.65 & 1357.53 & 5.00 & 38.15 \\
\hline 9 RONCADOR & 20.75 & 1.07 & 670038.65 & 3082.35 & 7588.87 & 7922.25 & 39289.05 & 44090.96 & 115281.73 & 4935.41 & 30.47 & 152.04 \\
\hline 9 SÄO J. DA SERRA & 15.27 & 0.60 & 666105.64 & 23953.11 & 7154.95 & 11454.90 & 68658.27 & 30963.28 & 28572.36 & 2545.61 & 39.30 & 670.24 \\
\hline 9 SAPOPEMA & 3.28 & 0.57 & 351918.94 & 9930.95 & 293.56 & 4061.08 & 51383.15 & 6840.99 & 20018.62 & 2115.94 & 2.90 & 188.01 \\
\hline 9 TURVO & 20.54 & 0.30 & 289446.98 & 263.23 & 30823.90 & 11192.39 & 32704.48 & 13853.97 & 20382.90 & 1374.03 & 54.05 & 3.18 \\
\hline 10 ARAPOIT & 55.48 & 1.68 & 854363.61 & 6560.75 & 218780.50 & 14322.05 & 118892.95 & 54042.81 & 82629.39 & 5641.37 & 10.50 & 53.13 \\
\hline 10 BALSA NOVA. & 0.17 & 0.03 & 130497.19 & 328.85 & 3849.83 & 3211.14 & 16066.11 & 8361.41 & 6438.38 & 747.09 & 27.23 & 4.54 \\
\hline 10 IAPA. & 28.21 & 1.22 & 649141.53 & 21533.49 & 308937.74 & 42415.90 & 116374.92 & 94098.50 & 72369.63 & 6922.53 & 108.2 & 77.14 \\
\hline 10 PAIMETRA & 7.17 & 0.17 & 703487.83 & 2804.49 & 94288.58 & 32034.30 & 107693.13 & 117044.29 & 89912.21 & 4045.07 & 24.40 & 54.70 \\
\hline 10 PIRAQUARA & 8.76 & 0.06 & 168605.90 & 1300.19 & 12303.39 & 5587.20 & 37328.09 & 10637.77 & 65897.63 & 5878.09 & 9.54 & 5.00 \\
\hline 10 PONIA GROSSA & 595.46 & 3.47 & 1460025.07 & 4098.08 & 113843.91 & 39075.35 & 163004.33 & 157621.46 & 139091.49 & 19765.04 & 195.49 & 372.52 \\
\hline 10 PORTO AMAZONAS & 0.67 & 0.16 & 57804.24 & 5285.74 & 431.64 & 2796.40 & 33219.32 & 7713.66 & 3485.80 & 1129.98 & 3.80 & 5.50 \\
\hline 11 AIMIRANIE TPAMNIXRÉ & 155.39 & 2.78 & 12331 & 433.63 & 9626.27 & 9206.30 & 8503.42 & 6612.35 & 4796.89 & 1495.02 & 31.00 & 12.38 \\
\hline 11 ETIURENA & 11.19 & 0.43 & 170332.14 & 5058.37 & 42851.78 & 6505.08 & 39158.17 & 14571.30 & 26687.43 & & 55.34 & 9.87 \\
\hline 11 CAMPO DO TFNENIE & 5.03 & 0.00 & 99453.63 & 1048.91 & 30372.45 & 7378.55 & 14526.22 & 9398.30 & 9442.48 & 1479.56 & 0.1 & 17.04 \\
\hline 11 CASTRO & 42.28 & 1.09 & 1287651.49 & 11969.48 & 60899.13 & 58669.88 & 316688.61 & 211159.12 & 234015.79 & 17580.80 & 251.88 & 430.23 \\
\hline IANDIA & 18.18 & 0.37 & 361368.80 & .05 & 26859.00 & 9758.25 & 60352.26 & 41610.55 & 28561.54 & 2054.17 & 13. & 104.04 \\
\hline 11 GENERAL CARNEIRO & 1.43 & 0.45 & 220084.73 & 10381.70 & 46204.39 & 4617.69 & 22385.49 & 12.94 & 39161.81 & 5773.00 & 68. & 9.44 \\
\hline 11 GARA & 38.09 & 3.24 & 2807139.42 & 51667.12 & 319754.50 & 63313.81 & 252747.11 & 35.96 & 183108.00 & 20302.96 & 199.10 & 88.54 \\
\hline 11 IPIR? & 41.81 & 0.36 & 238036.95 & 651.20 & 87300.96 & 13549.03 & 50120.24 & 52.53 & & & 7.40 & 1537.03 \\
\hline $11 \mathrm{JAG}$ & 25.37 & 1.24 & 1053817.44 & 1261.13 & 209647.53 & & & 38.65 & & & 59. & 123.91 \\
\hline 11 MANK & 85.59 & 2.32 & 866581.24 & 1267.90 & 5.67 & 21211.93 & 60978.29 & 117059.46 & .86 & 447 & 85. & 13.80 \\
\hline 11 PAIMAS & 24.52 & 5.22 & 1214356.06 & 16312.85 & 28661.00 & 18898.13 & 135812.32 & 39204.25 & 156.81 & 925 & 77. & 32.10 \\
\hline 11 PAUIO ERETIAS & 5.36 & 0.25 & 137679.75 & 91.00 & 6257.19 & 4553.95 & 14703.47 & 24769.30 & 14090.65 & 931.13 & 16. & 7.55 \\
\hline 11 PIRA & 2201.36 & 0.31 & 609827 & 953.60 & 84873.08 & 9652 & 53245 & 29964.74 & 37402.94 & & 119 & 6.83 \\
\hline 11 QUAT & 36.14 & 0.10 & 62426.05 & 2164.30 & $194 \mathrm{C}$ & 3041 . & 4581.08 & 2085.95 & 498 & & & 0.00 \\
\hline 11 RTO I & 22.14 & 0.2 & 139388.30 & 655.50 & 668 & & 19144.07 & 95.20 & & & & 210.05 \\
\hline 11 SENCÉS & 20.08 & 1.24 & 1316777.23 & 1321.68 & 151850.67 & 8335.92 & 42063.41 & & 909 & & 19 & 35.63 \\
\hline 11 TETXEIRA SOARES & 19.25 & 0.00 & 441010.96 & 7144.26 & 6.64 & 1.61 & 272 & & & & & 71.73 \\
\hline 11 TIBA & 26.38 & 1.36 & 1980892.64 & 7422.54 & 242403.07 & 184755.01 & 131636.59 & 4.02 & 82978.40 & 10515 & 95. & 226.89 \\
\hline 11 TI & 2.38 & .08 & 908 & 1.70 & 4.16 & & 14482.77 & & .61 & & & 13.52 \\
\hline VITORIA. & & 0. & 108 & 1442.25 & 4.61 & & 44 & & & & & \\
\hline 12 ARAUCÁRTA & 40.54 & 1.13 & 313231.95 & 15939.90 & 6158.88 & 32433.27 & 32273.04 & & & & & 347.64 \\
\hline $12 \propto$ & & & & & & & & & & & & 87.00 \\
\hline 12 al & 25.62 & 1.37 & 268678.02 & 4327.12 & 8960.45 & 10909.15 & 21627.15 & 10304.36 & 5.48 & 1371 & 18. & 3.00 \\
\hline $137 Q$ & & & & & & & & & & & & 2.51 \\
\hline $13 \mathrm{AN}$ & 5.11 & 0.17 & 72094.83 & 3448.98 & 13768.89 & 8470.75 & 15680.35 & 13786.94 & 974 & 583 & 10. & 19.95 \\
\hline 130 & 16.43 & 0.38 & 2434 & & 122235.62 & & & & & & & \\
\hline $13 \alpha$ & 16.95 & 1.27 & 1169 & 3718.92 & 11985.01 & 161 & 6389.22 & 9072.18 & 10464 & 1372. & 26. & 24.64 \\
\hline $13 a$ & & 1.95 & & & & & & & & & & \\
\hline 13 IMBTIUVA & 30.06 & 0.15 & 328 & 1920.50 & & 207 & 48577.24 & & & & 18. & 97.78 \\
\hline 13 IRAII & 49.27 & 0. & & & & & & & & & & 90.24 \\
\hline $13 \pi$ & 33.85 & 0.22 & 1106 & 339.54 & & & & & & & & 20.10 \\
\hline 13 MAIETT & & & & 13112.30 & & & & & & & & \\
\hline $13 \mathrm{M}$ & 107.26 & 2.99 & & & & & & & & & & 41.86 \\
\hline $13 P F$ & & 0.2 & & 955 & & 105 & & 253 & & & 5. & 4.82 \\
\hline 13 PLEN & 33.0 & 0.0 & & 9865.49 & & & & & & & & 85.61 \\
\hline 13 PORTO VITĆRIA & 2.38 & 0.51 & 42981.20 & 463.00 & 60 & 2717.85 & 12978.07 & 6560.33 & 134 & 503.46 & 3.47 & 0.40 \\
\hline 13 ERULENTÓEOLIS & 42.36 & 0.36 & 445451.49 & 5555.68 & 8310.79 & 24486.10 & 55485.54 & 41127.51 & 42200.03 & 2502.99 & 54.48 & 18.08 \\
\hline 13 QITTANDINHA & & & & & & & & & & & & 147.25 \\
\hline $13 \mathrm{R}$ & 42.55 & 0.85 & & & & 4.65 & 24.68 & & & 1348 & 52.42 & 115.44 \\
\hline $13 \mathrm{RT}$ & 32.57 & & & & & & & & & & & 177.02 \\
\hline 13 SЁO J. DO TRIUNEO & 8.35 & 0.12 & 1239 & 647.12 & $160^{\circ}$ & 8020.17 & 52.69 & & & & & 1.16 \\
\hline 13 SAO J. DOS PINHAIS & 71.53 & & & & & & & & & & & \\
\hline $13 S$ & 100.41 & 0. & & & & & & & & & & \\
\hline $13 \mathrm{WE}$ & 791.95 & 0. & & & & & & & & & 8.47 & 132.25 \\
\hline & & & & & 95140 & & & & & & & \\
\hline 14 ANICNINA & 22.58 & 1.55 & 59454.99 & 8773.72 & 62.00 & 5591.34 & 6024.04 & & & & & 27.50 \\
\hline 14 BOCATÚVA DO SUL & 5.26 & 0.82 & 132320.11 & 740.90 & 144031.87 & & & & & & & 0.00 \\
\hline 140 & 12.6 & 0. & & 15909.31 & & & & & & & & 0.00 \\
\hline $14 \mathrm{a}$ & 29.3 & & 1473 & 26575.06 & 1420 & & & & & & & 18.54 \\
\hline $14 a$ & & & 134920.43 & & & & & & & & & 8.43 \\
\hline $14 \mathrm{G}$ & 8.02 & 1.19 & & 6804.39 & 20.55 & & 5822 . & & & & 3.25 & 15.00 \\
\hline 14 INACIO MARIINS & 2.62 & & 373438.21 & & 126761.31 & & 19576.05 & & & 4228.46 & 31.50 & 0.00 \\
\hline 14 MATINHOS & 0.57 & 0.52 & 11748.25 & 1882.39 & & 272 & 554.35 & & 217.55 & & & \\
\hline & 17.52 & & & & & & & & & & & 31.85 \\
\hline & & & 112572.84 & & & 1938.45 & 8717.20 & 881.95 & 2431.53 & & & 1.01 \\
\hline 14 PINHÄO & 9.76 & 0.12 & 1130250.34 & 559.55 & 82883.32 & 27269.50 & 125404.65 & 70580.51 & 50621.66 & 6085.14 & 87.95 & 1.52 \\
\hline & & 2.54 & & 3075.93 & 46601.36 & & 29542.71 & & 3749.15 & 2002.71 & & 10.16 \\
\hline & 34.13 & 2.89 & 287379.32 & 1979.90 & 2708338.35 & 12018.33 & 14448.92 & 8315.53 & 10632.02 & 33912.64 & 51.81 & 44.35 \\
\hline
\end{tabular}


INDICADORES

\begin{tabular}{|c|c|c|c|c|c|c|c|c|c|c|c|c|c|}
\hline & & \\
\hline & 17 & 18 & 19 & 20 & 21 & 22 & 23 & 24 & 25 & 26 & 27 & 28 & 29 \\
\hline & & & & & & & & & & & & & \\
\hline & & 5070.24 & & & & & & & & & & & \\
\hline 1 ARAPONGAS & 4239.14 & 6334.07 & 4057.04 & 3440.56 & 1906.69 & 181.99 & 18520.91 & 3931.71 & 0.05 & 44.42 & 1645.09 & 2099.86 & 429.02 \\
\hline 1 ASSAI & 8927.57 & 8585.90 & 6334.43 & 8689.23 & 343.08 & 130.36 & 851.22 & 158.16 & & 22.08 & 44.35 & & 265.73 \\
\hline 1 ASSIS CHATEUBRTAM & 17836.52 & 30183.80 & 34067.18 & 24841.50 & 1002.76 & 247.93 & 3144.14 & 830.24 & & 2.16 & 131.13 & 194.15 & 13518.13 \\
\hline 1 BARRA DO JACARE & 2457.01 & 1424.35 & 1580.25 & 1619.82 & 88.79 & 44.27 & & 222.21 & 0.00 & 0.00 & 1.05 & 0.66 & 58.60 \\
\hline LA VISIA PARATSO & 2693.15 & 4804.32 & 3924.51 & 4475.06 & 336.68 & 391.11 & 791.55 & 43.64 & & 0.00 & 50.32 & & 411.58 \\
\hline EEIANDIA & 2249.69 & 7587.99 & 7368.14 & 6877.69 & 260.51 & 66.20 & 7117.32 & 37.95 & 0.00 & 9.98 & 1614.62 & 0.00 & 2292.20 \\
\hline BBARA & 3489.43 & 7586.89 & 4657.50 & 4745.84 & 686.49 & 276.29 & 1029.78 & 852.07 & 0.00 & 0.00 & & & 1896.57 \\
\hline 10 & 6161.14 & 12371.56 & 11150.20 & 6308.80 & 1260.97 & 877.48 & 1547.18 & 290.54 & 3.50 & 12.14 & 289.66 & & 1841.93 \\
\hline XIOR CAMARGO & 2968.08 & 1644.73 & 1667.05 & 1075.96 & 75.98 & 18.60 & 64.44 & 212.23 & 0.40 & & 101.51 & & 35.09 \\
\hline 1 ENG. BETIRÃO & 10964.55 & 8117.43 & 7178.18 & 6221.65 & 316.00 & 121.92 & 319.19 & 13.00 & 0.00 & 2.91 & 5.87 & & 1512.26 \\
\hline 1 ELORAI & 2059.82 & 3038.26 & 2280.79 & 1684.32 & 265.77 & 181.50 & & 12.30 & 0.30 & 0.00 & 202.02 & & 195.74 \\
\hline 1 ELORESTA & 2593.87 & 4397.34 & 4151.61 & 2894.24 & 82.40 & 25.36 & 205.48 & 43.68 & 0.00 & 0.00 & 4.11 & 0.00 & 1445.07 \\
\hline 1 IBIPOR & 7705.89 & 5874.58 & 4555.03 & 4309.40 & 289.47 & 80.50 & 965.78 & 140.65 & 0.00 & 0.00 & 230.82 & 0.00 & 683.02 \\
\hline 1 ITAMBARACÁ & 3013 & 4460.23 & 4243.47 & 469 & 160.75 & 124.68 & & & 0.00 & 0.00 & 0.00 & & 306.45 \\
\hline 1 ITAMEE & 1138.41 & 6782.08 & 9712 & 565 & 375.41 & 156. & 364.99 & 198. & & & 0.75 & & 834.38 \\
\hline $1 \mathrm{I}$ & & 323 & 328 & & 115 & & & & & & 0.02 & & .21 \\
\hline TAS & 134 & 426 & 402 & & 380 & 13 & 167 & & & & 442.22 & & .92 \\
\hline $1 \mathrm{~J}$ & & 669 & 704 & & 221 & & & 105 & & & 4.94 & & .05 \\
\hline $1 \mathrm{M}$ & 07 & 1896 & 1660 & & & & & & & & & & .69 \\
\hline ALVA & 84 & 1109 & 1104 & & .47 & & & & & & 142. & & .70 \\
\hline NGÁ & .59 & 896 & 799 & & 498.60 & 334 & & 1191.15 & & & 49.34 & & 450.42 \\
\hline ZCNA & .09 & 3287 & $264^{\circ}$ & & .50 & & & & & & & & 3.00 \\
\hline ANDU & .87 & 3395.35 & 298 & 12 & 193.29 & 74.33 & .37 & 29.55 & & 0. & 0.08 & & 15.72 \\
\hline IINA & 1054 & 21839.44 & 2671 & 2222 & 1969.20 & 635.60 & 22895.95 & 3399.29 & & 29.99 & 4237.99 & 801.5 & 2383.41 \\
\hline EIRO DE MAIO & 5212.88 & 7670.18 & 1088 & .97 & 286.87 & 147.90 & 377.96 & 128.26 & 4.0 & 0.00 & 10.85 & & 194.83 \\
\hline$D A L E$ & 4075.77 & 3574.18 & 369 & .02 & 148.58 & 21.55 & $171^{\circ}$ & 5.60 & 0. & & 183.09 & & 784.83 \\
\hline$A A M$ & 927.61 & 839.97 & 628.92 & .90 & 128.01 & & & 5.20 & & & 56.93 & & 182.64 \\
\hline $1 \mathrm{~S}$ & 4501.80 & 8281.24 & 993 & .29 & 334.94 & & .50 & 163.23 & & & 4.30 & & 619.00 \\
\hline IVAf & 92 & 10571 & 1060 & & 178.06 & 114 & 1562.77 & 111.66 & & & 67.39 & & 47.15 \\
\hline ANDI & - 271 & 215 & 205 & .02 & 297.96 & & & & & & 99.27 & & 300.35 \\
\hline ANEJA & 7535 & 5394.84 & 1402 & .15 & 205.80 & & 166 & 612.87 & & 2.30 & 83.82 & & 1650.29 \\
\hline IANÓPOTIS & 5731 & 8099 & 839 & 88 & 524.82 & 56 & .57 & & 0. & 64.56 & 444. & & 643.22 \\
\hline ASSI & 4174.62 & 7776.26 & 8301.35 & .24 & 168.31 & 55.52 & 146 & 36 & 0.3 & & 291.61 & 1. & 5374.22 \\
\hline RATÃ & 6134.85 & 15105.41 & 1452 & .24 & .27 & .94 & .76 & 172.67 & 0.00 & 20. & 27.27 & 0.40 & 3957.57 \\
\hline $1 \mathrm{U}$ & 3616.24 & 5800.81 & 0.31 & & & & & & 0.00 & 0.00 & 13.88 & 0.00 & 304.12 \\
\hline DEITPANIES & & & & & & & 134 & 795 & 0.5 & 8.50 & 16.39 & 5.00 & 841.44 \\
\hline SSEER & 340 & 757 & 782 & & 28 & & & & 0.0 & 0.00 & 7.94 & 0.30 & 850.03 \\
\hline $\mathrm{NEY}$ & 248 & & & & & & & & & & 75.41 & 3.60 & 1985.21 \\
\hline VEI & 834 & 3560 & 231 & 194 & 415 & 106 & 243 & 3809.92 & 19.57 & 96.75 & 7064.63 & 16.62 & 4052.80 \\
\hline ETITA & 8227.15 & 1295 & 107 & & .56 & & 4565.83 & 206.59 & 0.00 & 23.75 & 734.92 & 1.95 & 1689.81 \\
\hline IX & 3363.45 & 9.60 & & .32 & 127.60 & & & & 0.52 & 0.08 & 1.55 & 0.00 & 1068.50 \\
\hline OSA DO CESTE & 7175.12 & 505 & 668 & 1.94 & 478.44 & 219.74 & 3322.08 & 74.88 & 0.13 & 0.00 & 483.05 & 58.63 & 438.25 \\
\hline $2 \mathrm{FO}$ & 936.24 & 1177.03 & 1484.33 & & 474.40 & 200.12 & 432.34 & 685.92 & 1.01 & 76.20 & 3.7 & 0.00 & 1047.16 \\
\hline IO-ERE & 17763.06 & 19455.14 & 16833.40 & 21575.41 & 1634.04 & 882.07 & 711.59 & 484.15 & 0.79 & 0.00 & 95.44 & 17.28 & 2721.02 \\
\hline AfRA & 3710.08 & 6801.93 & 783 & & 723.95 & 362.69 & 1037.92 & 2013.20 & 0.72 & 41.52 & 9.23 & 0.02 & 2130.93 \\
\hline IÓPO.TS & 552 & 431 & & & .40 & & 134.33 & 640 & 0.70 & 0.00 & 6.75 & 0.22 & 344.97 \\
\hline & & 480 & & & & & 12 & & & & & & 1604.20 \\
\hline & & 150 & & & & & & 5.92 & 0. & 1.70 & 68.78 & 0. & 30.06 \\
\hline AURORA & & 103 & 115 & & 97 & & 6035 & 306.46 & 0. & 7.7 & 807.25 & 2.85 & 5421.75 \\
\hline CAN & & & & & & & 51.77 & & 0 . & 0. & & & .20 \\
\hline BIIRU & & & & & & & .10 & & 1. & 0. & 97.81 & 135. & 10 \\
\hline T. D & 110 & 38 & & & & & & & 0.71 & 3.65 & 531.48 & & 1.87 \\
\hline M. DO IGAQU & 5086 & 11385 & 12725 & 75 & 1467 & 482 & 1040 & 1139 & 0.50 & 73.47 & 1968.5 & 6. & 5.30 \\
\hline RA ROXA & & & & & & & .71 & & & 71.30 & 97 & 10.60 & 3.92 \\
\hline & .37 & 3356 & 3657 & & & & 1446 & 101. & 5. & 35.52 & 27096 & 15. & 10776.95 \\
\hline ORA & & & & & & & & & 8. & 9.94 & & & .48 \\
\hline RGA & 439 & 635 & 264 & & & & & & 1. & & 820 & & .36 \\
\hline M SUCESSO & 1660.14 & 4779.17 & 2162.38 & .21 & 493.96 & & & & 40. & & & & .19 \\
\hline MPO MOURÄO & 9047.33 & 34501.64 & 22819.25 & 9.18 & 2312.91 & 1084.60 & 1197.03 & 364.14 & 3.8 & 95.90 & 79.67 & & .99 \\
\hline 30 & 2252.11 & 5142.01 & 2115.25 & 5.56 & 452.71 & & 85.64 & & 1.13 & 2.77 & & & .13 \\
\hline 30 & 1568.4 & .42 & & & .97 & & 292.76 & & 0.0 & 5.00 & 82.9 & & 9.76 \\
\hline ÓPIO & 345 & .02 & .31 & & 2398.97 & 35 & 3.58 & & & 1.51 & 12.6 & & 1611.66 \\
\hline RESIOROLES & 150 & .36 & 298 & & .36 & & .56 & & & 0.00 & 0.0 & & 364.68 \\
\hline UARACD & 21 & 35 & 227 & & .08 & & & & & 4.08 & 1.2 & & 72.72 \\
\hline CAREZINHO & 26 & 61 & & & .50 & 1777.06 & & & & 105.24 & 10705.9 & & 378.44 \\
\hline 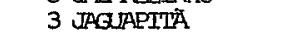 & 215 & & & & .53 & & & & & & & & 374.43 \\
\hline Alanvito & 2386.50 & 1879.93 & 1929.72 & & & & & & & & & & \\
\hline DIAI DO SU & 441.78 & 955.44 & 218.66 & 464.42 & 641.44 & & 38.71 & & & 0.00 & & 0.20 & 237.59 \\
\hline ÓECIS & 4628.10 & 4716.68 & 7837.94 & & & & & & & & 0.99 & & 130.2 \\
\hline ADRTNA & 18719.51 & 19695.61 & 11161.73 & 12455.20 & 3676.90 & 1179.38 & .71 & 4870. & 10 & 82.33 & 3621.75 & & 2641.5 \\
\hline 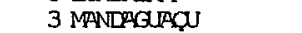 & & 4006.86 & 1814.42 & & & & & & & & 90.05 & 60. & 79.7 \\
\hline UMBI & & & & & & & & & & & 1.42 & & 56.9 \\
\hline A A. DA OOINA & 2071.14 & 2056.97 & 118 & & & & 264.91 & 38.50 & 0.00 & & 16.18 & 0.00 & 267.59 \\
\hline A EÁTTM & 1442.01 & 3334.60 & & & 425.32 & & & 2.47 & & & 0.00 & & 92.19 \\
\hline ECATU & 1068.13 & 2812.18 & & 1747.28 & 293.42 & & 229.28 & 5.71 & & 27 & 11.00 & 0.00 & 3651.70 \\
\hline NIA DO $S$ & 3800.11 & 3590.64 & 3962.79 & 3481.94 & 4564.05 & 543 & 111.44 & 138.73 & & 60 & 6.43 & 0.00 & 394.85 \\
\hline 3 RIBETRÄO CLARO & 5486.52 & 2308.09 & 401.74 & 454.25 & 1468.16 & 509.51 & 52.67 & 19.15 & 0.50 & 1.20 & 25.02 & 0.70 & 56.69 \\
\hline
\end{tabular}


INDICADORES

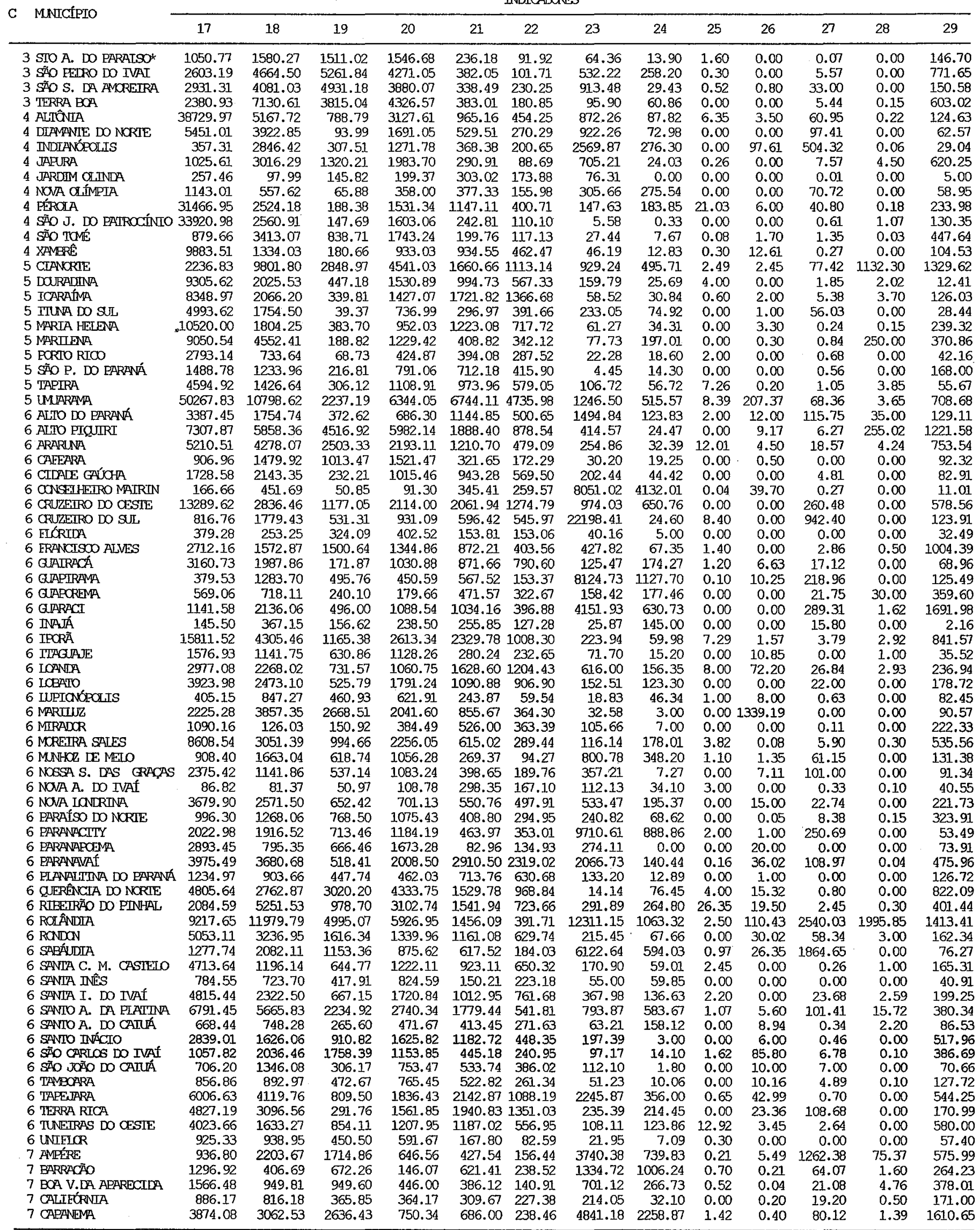


INDICADORES




Tabela 3A. Continuação.

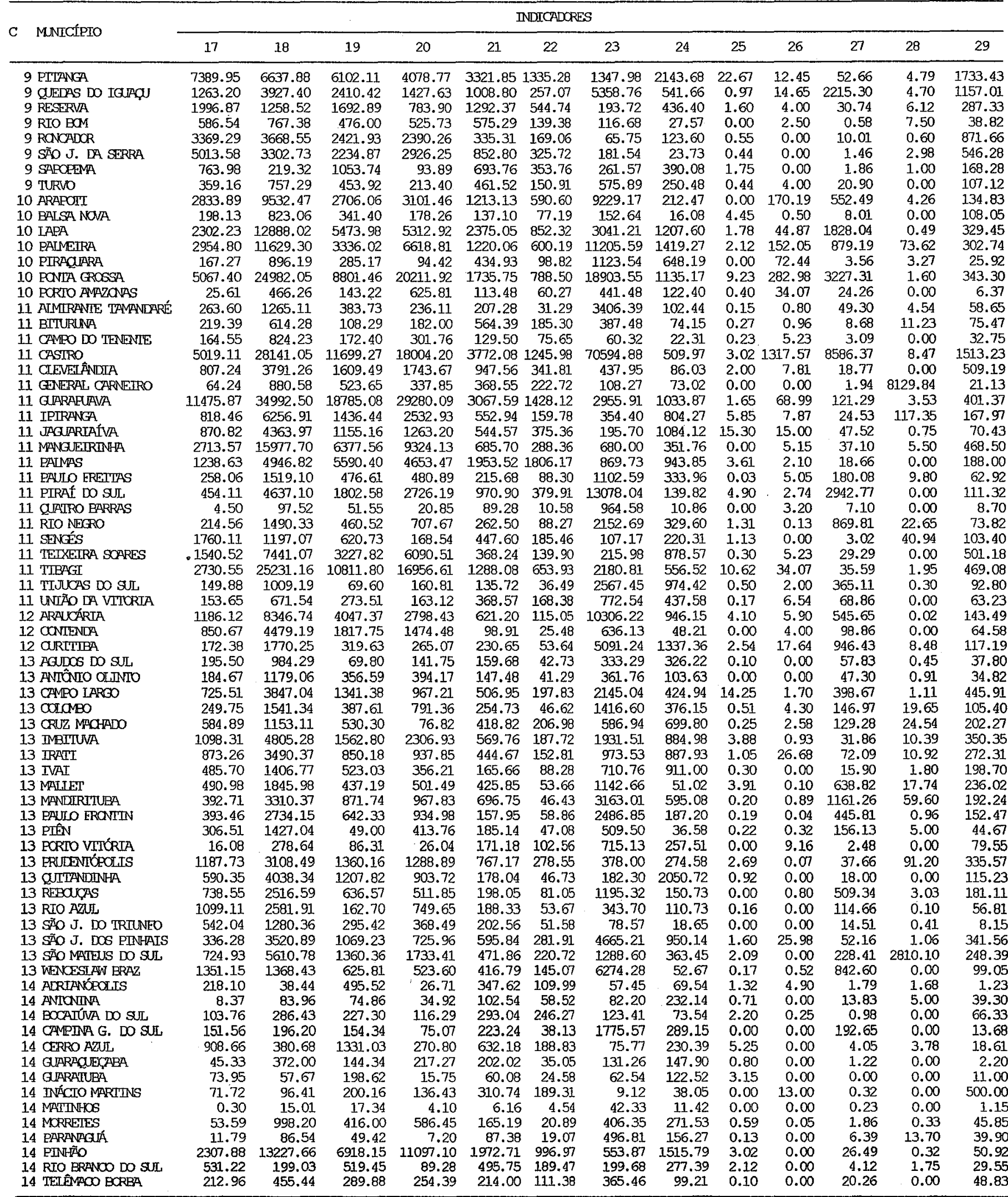




\begin{tabular}{|c|c|c|c|c|c|c|c|c|}
\hline \multirow{2}{*}{ MANIćctPIO } & \multicolumn{8}{|c|}{ INDICADORES } \\
\hline & 30 & 31 & 32 & 33 & 34 & 35 & 36 & 37 \\
\hline 1 ALVORALA DO SUL & 6747.34 & 2587.82 & 14424.27 & 4060.74 & 190.18 & 4823.73 & 355.78 & 3404.77 \\
\hline 1 ANDIRÁ & 4605.37 & 2353.23 & 9789.04 & 1887.00 & 9.43 & 3555.03 & 315.96 & 2584.39 \\
\hline 1 ARAEQNGAS & 1092.91 & 763.52 & 10609.65 & 3093.29 & 292.95 & 3399.28 & 631.82 & 2305.85 \\
\hline 1 ASSAI & 4662.91 & 954.97 & 22716.90 & 3997.87 & 195.96 & 4338.04 & 59.39 & 2179.83 \\
\hline 1 ASSIS CHATEMBRTAM & 3339.34 & 9457.05 & 68675.58 & 12737.07 & 200.64 & 11794.63 & 868.63 & 3388.69 \\
\hline 1 BARRA DO JACARÉ & 987.10 & 672.01 & 4625.22 & 850.04 & 25.56 & 1112.70 & 130.75 & 305.95 \\
\hline 1 BEIA VISTA PARAfSO & 2773.91 & 1471.44 & 11833.25 & 1851.48 & 191.01 & 3561.34 & 377.88 & 2050.81 \\
\hline 1 CAEEI ANDIA & 1717.98 & 1225.56 & 12361.99 & 2442.47 & 9.24 & 2980.91 & 283.33 & 667.79 \\
\hline 1 CAMBARA & 3199.78 & 2042.67 & 16211.84 & 1256.30 & 154.75 & 5093.43 & 486.48 & 1730.05 \\
\hline 1 CAMBÉ & 1403.46 & 6792.42 & 24022.90 & 1923.72 & 83.39 & 4737.37 & 684.09 & 5338.54 \\
\hline 1 DOIOR CAMAFGO & 1326.14 & 408.59 & 3378.79 & 890.10 & 3.96 & 748.55 & 90.69 & 297.33 \\
\hline 1 ENG. BEITRÄO & 4677.44 & 2114.76 & 11387.54 & 2143.92 & 180.05 & 5546.85 & 355.27 & 1592.00 \\
\hline 1 ELCRA & 328.63 & 497.41 & 6127.87 & 1323.39 & 25.92 & 2108.13 & 139.85 & 521.02 \\
\hline 1 ELORESTA & 151.28 & 497.44 & 6013.69 & 1349.61 & 0.14 & 2260.75 & 135.23 & 377.22 \\
\hline 1 IBIECRÃ & 4218.14 & 1022.66 & 12009.42 & 2304.67 & 89.60 & 2743.20 & 383.86 & 1928.77 \\
\hline 1 TIPAMARARAÁ & 6162.80 & 585.80 & 6952.35 & 1668.16 & 8.39 & 3242.59 & 287.56 & 1665.08 \\
\hline 1 TIAMBÉ & 1369.49 & 925.42 & 14045.34 & 3287.51 & 11.82 & 4161.20 & 139.00 & 2176.20 \\
\hline 1 IVATUBA & 357.40 & 536.35 & 5800.36 & 965.41 & 8.87 & 1449.06 & 71.77 & 891.40 \\
\hline 1 JESUTTAS & 422.59 & 945.41 & 7941.63 & 2428.16 & 22.01 & 2222.60 & 267.34 & 541.09 \\
\hline 1 JURANDA & 307.42 & 1996.42 & 20396.53 & 606.49 & 45.89 & 3067.27 & 425.86 & 2113.55 \\
\hline 1 MAMECRE & 1707.46 & 2712.45 & 32614.99 & 3603.36 & 24.64 & 8458.85 & 306.82 & 9536.68 \\
\hline 1 MARTALVA & 3273.97 & 3908.13 & 21304.86 & 3947.33 & 593.33 & 7595.45 & 478.56 & 1454.39 \\
\hline 1 MARINGA & 2846.99 & 1353.85 & 14936.06 & 3465.30 & 193.32 & 4927.29 & 530.38 & 1404.11 \\
\hline 1 ORIZONA & 949.63 & 551.03 & 7489.47 & 1435.73 & 17.93 & 2067.03 & 109.01 & 892.87 \\
\hline 1 EAIÇANU & 995.29 & 801.81 & 7521.28 & 1328.91 & 3.38 & 2127.53 & 115.21 & 643.72 \\
\hline 1 EALOITINA & 6377.04 & 4448.06 & 58329.56 & 3365.00 & 50.72 & 11628.19 & 1291.46 & 6549.80 \\
\hline 1 PRTMEIRO LE MATO & 3954.08 & 2787.08 & 20675.61 & 4310.87 & 81.63 & 5518.05 & 355.24 & 4789.21 \\
\hline 1 RANCHO ALEGRE & 593.03 & 1257.16 & 10004.72 & 1021.94 & 6.73 & 2115.73 & 117.50 & 381.46 \\
\hline 1 SANIA AME:JIA & 712.73 & 294.85 & 1780.75 & 281.72 & 45.65 & 627.43 & 96.11 & 188.00 \\
\hline 1 SANTA MARIANA & 2662.68 & 2613.90 & 13301.29 & 2588.77 & 191.36 & 5559.26 & 463.05 & 3010.46 \\
\hline I SAO JORGE DO TVAÍ & 2635.51 & 916.12 & 24629.76 & 3393.49 & 62.16 & 3749.06 & 227.62 & 2298.09 \\
\hline 1 SARANDI & 1139.86 & 693.28 & 3864.58 & 886.69 & 63.64 & 1403.26 & 191.92 & 664.87 \\
\hline I SERTANETA & 1937.89 & 8563.61 & 22095.58 & 7130.20 & 616.41 & 4263.17 & 460.31 & 16761.13 \\
\hline 1 SERIANÓEOIIS & 18356.85 & 3072.09 & 22500.93 & 3805.68 & 192.72 & 5125.88 & 431.98 & 3701.14 \\
\hline 1 TUPÃSSI & 122.92 & 2758.40 & 13239.60 & 3017.77 & 23.33 & 2572.52 & 149.40 & 757.41 \\
\hline I UBIRATÃ & 1682.92 & 4256.90 & 28574.53 & 2389.12 & 65.75 & 6338.55 & 576.19 & 4680.72 \\
\hline 1 URAI & 3719.89 & 940.67 & 8385.28 & 1198.98 & 204.46 & 2498.43 & 75.49 & 2151.11 \\
\hline 2 BANDEIRANIES & 8857.85 & 2883.96 & 7667.20 & 1813.87 & 333.79 & 3715.01 & 385.80 & 621.97 \\
\hline 2 BOA. ESPERANCA & 1781.39 & 1357.62 & 18236.47 & 2266.75 & 8.07 & 3283.37 & 164.32 & 2034.43 \\
\hline 2 BRAGANEY & 1133.09 & 862.65 & 7134.46 & 1221.61 & 10.10 & 1596.32 & 175.72 & 690.18 \\
\hline 2 CASCAVEL & 6969.55 & 3193.46 & 49106.04 & 19669.55 & 581.50 & 17148.66 & 2173.19 & 9470.80 \\
\hline 2 CORBESTAA & 3454.39 & 1731.08 & 15285.59 & 3856.14 & 45.02 & 5363.30 & 330.57 & 3689.77 \\
\hline 2 FENTX & 812.37 & 782.94 & 6613.47 & 1574.19 & 7.13 & 2488.36 & 85.76 & 420.29 \\
\hline 2 EORMOSA DO CESIE & 3528.59 & 1436.89 & 13617.98 & 2653.15 & 60.05 & 3326.17 & 317.69 & 995.31 \\
\hline 2 FOZ DO IGUAOU & 1551.28 & 358.03 & 3415.97 & 169.08 & 5.43 & 878.03 & 335.71 & 405.70 \\
\hline 2 GOIO-ERE & 7212.27 & 2695.17 & 41927.90 & 7499.08 & 325.49 & 9977.41 & 657.81 & 1930.42 \\
\hline 2 GAfRA & 1607.80 & 993.05 & 19374.64 & 1441.95 & 40.86 & 4040.79 & 145.31 & 2524.86 \\
\hline 2 JANTÓEOCISS & 2405.31 & 842.65 & 12380.25 & 976.63 & 53.78 & 2381.29 & 133.40 & 568.45 \\
\hline 2 JUSSARA & 38.90 & 3012.76 & 12323.01 & 1509.36 & 33.58 & 3021.65 & 115.01 & 3967.92 \\
\hline 2 KALORÉ & 1658.67 & 455.08 & 6525.95 & 832.27 & 7.70 & 1418.74 & 87.55 & 163.94 \\
\hline 2 NONA AURCRA & 883.64 & 2786.07 & 24386.80 & 4983.61 & 31.24 & 5253.04 & 351.01 & 535.52 \\
\hline 2 NONA CANIU & 2027.67 & 739.70 & 9017.99 & 266.75 & 31.36 & 1650.13 & 116.30 & 307.76 \\
\hline 2 PEABIRU & 1791.82 & 1028.56 & 13377.44 & 1448.49 & 57.24 & 4780.44 & 300.88 & 1300.87 \\
\hline 2 STA T. DO ILAIEU & 1550.93 & 286.51 & 6627.17 & 144.06 & 5.48 & 1624.71 & 160.03 & 271.56 \\
\hline 2 SAOM. DO IGAOU & 7773.61 & 1918.56 & 27391.14 & 939.50 & 43.75 & 8380.08 & 1116.23 & 2468.75 \\
\hline 2 TERRA RCKA & 7888.01 & 2507.21 & 32554.61 & 4839.58 & 33.12 & 6869.23 & 438.20 & 4081.89 \\
\hline 2 TOFDO & 6907.83 & 5813.85 & 55785.43 & 11010.16 & 197.32 & 19849.96 & 2225.46 & 5487.71 \\
\hline 3 AMAPCRÄ & 1391.14 & 114.45 & 1257.08 & 285.51 & 17.78 & 1893.13 & 134.24 & 756.11 \\
\hline 3 ASIORGA & 4745.60 & 1979.24 & 8869.59 & 828.64 & 139.26 & 2978.89 & 363.40 & 753.98 \\
\hline 3 BOM SUCESSO & 3184.84 & 1213.97 & 5434.50 & 1224.22 & 47.51 & 1801.75 & 155.41 & 2900.00 \\
\hline 3 GAMO MARÃO & 2341.54 & 4076.23 & 56020.41 & 7930.02 & 433.98 & 14292.20 & 546.79 & 3720.14 \\
\hline 3 OENIENARTO DO SUL & 4461.37 & 4405.87 & 5231.48 & 1594.57 & 86.06 & 3223.19 & 192.24 & 1615.45 \\
\hline 3 CONGONHINHAS & 1448.91 & 590.31 & 1897.53 & 214.75 & 40.39 & 1039.50 & 120.32 & 673.40 \\
\hline 3 CORNÉITO PRCCÓPIO & 3395.91 & 1756.03 & 9337.52 & 2695.36 & 386.14 & 3966.79 & 282.17 & 3286.08 \\
\hline 3 FLCRESTÓEOTIS & 1764.89 & 954.74 & 4587.89 & 954.78 & 181.74 & 3202.70 & 174.10 & 1783.76 \\
\hline 3 IGUARAOU & 1466.45 & 796.50 & 6222.97 & 1652.43 & 36.94 & 2318.63 & 185.79 & 662.03 \\
\hline 3 JACAREZTNHO & 2844.97 & 7709.26 & 13074.14 & 4687.44 & 162.95 & 5271.79 & 698.46 & 6243.31 \\
\hline 3 JAGAPITA & 2477.73 & 739.93 & 3928.41 & 1108.42 & 30.38 & 2864.10 & 380.58 & 2270.76 \\
\hline 3 JAIAIZTNAO & 575.61 & 296.29 & 4528.75 & 728.59 & 67.78 & 1349.69 & 123.87 & 100.12 \\
\hline 3 JUNDIAI DO SUL & 413.59 & 355.31 & 1999.51 & 204.00 & 65.54 & 902.62 & 45.05 & 131.65 \\
\hline 3 IEÓROATS & 1000.45 & 2120.86 & 12548.56 & 2224.64 & 29.89 & 3621.98 & 207.24 & 9326.79 \\
\hline 3 IONLRTMA & 8017.33 & 4051.80 & 29694.48 & 9165.24 & 864.37 & 12833.76 & 2513.55 & 6050.53 \\
\hline 3 MANDAGIAQS & 1598.66 & 403.16 & 6335.76 & 1991.20 & 12.48 & 2941.60 & 260.91 & 405.40 \\
\hline 3 MARIMBI & 958.40 & 299.94 & 2326.22 & 460.98 & 12.88 & 931.65 & 62.51 & 37.00 \\
\hline 3 NONA A, DA COINA & 1767.13 & 438.63 & 1695.57 & 553.38 & 39.55 & 1253.86 & 99.10 & 1120.61 \\
\hline 3 NOVA ER्ATTMA & 1061.53 & 386.36 & 4692.59 & 626.14 & 77.80 & 2080.40 & 161.13 & 749.63 \\
\hline 3 PCRECATU & 1152.97 & 5167.56 & 3480.75 & 1128.83 & 21.01 & 6537.23 & 149.65 & 5245.12 \\
\hline 3 QIINIA DO SOL & 915.22 & 454.53 & 6287.02 & 1702.62 & 40.38 & 2999.88 & 199.00 & 211.36 \\
\hline 3 RIEEIRÄO CIARO & 1839.30 & 184.68 & 1712.87 & 489.16 & 126.78 & 1097.69 & 216.04 & 674.51 \\
\hline
\end{tabular}


INDICADORES

\begin{tabular}{|c|c|c|c|c|c|c|c|c|}
\hline \multirow{2}{*}{ C } & \multicolumn{8}{|c|}{ INDICADORES } \\
\hline & 30 & 31 & 32 & 33 & 34 & 35 & 36 & 37 \\
\hline 3 STO A. DO PARAÍSOt & 957.86 & 402.55 & 4121.66 & 395.34 & 10.98 & 1422.27 & 28.57 & 407.62 \\
\hline 3 SÄO EEIRO DO IVAI & 2777.45 & 2163.92 & 13871.42 & 2761.10 & 3.85 & 4092.03 & 235.80 & 898.20 \\
\hline 3 SAO S. DA AMCREIRA & 2447.76 & 444.69 & 6887.16 & 1543.14 & 316.16 & 2248.69 & 265.30 & 1549.51 \\
\hline 3 TERRA BOA & 923.57 & 6686.19 & 8930.82 & 2132.981 & 1393.96 & 2784.68 & 435.69 & 3362.00 \\
\hline 4 ALIOANIA & 940.33 & 333.11 & 4648.65 & 3584.52 & 449.36 & 888.63 & 273.22 & 369.98 \\
\hline 4 DIAMANIE DO NORIE & 962.16 & 228.63 & 3591.47 & 1561.41 & 294.85 & 544.05 & 56.33 & 558.62 \\
\hline 4 INDIANÓEOL.IS & 758.58 & 639.21 & 2106.50 & 1548.64 & 28.50 & 555.19 & 125.31 & 1060.67 \\
\hline 4 JAPURA & 87.55 & 567.55 & 6946.46 & 1730.35 & 190.19 & 686.90 & 78.66 & 270.89 \\
\hline 4 JARDIM OATIDA & 465.02 & 25.88 & 1111.20 & 114.92 & 0.49 & 285.55 & 40.67 & 37.17 \\
\hline 4 NOVA OU.MPIA & 95.70 & 1.73 & 750.45 & 321.67 & 16.92 & 241.45 & 53.46 & 13.27 \\
\hline 4 EETOLA & 1346.71 & 198.52 & 3184.99 & 1833.32 & 160.29 & 833.11 & 309.00 & 583.97 \\
\hline 4 Sथ̈O J. DO PATROCINIO & 98.08 & 97.50 & 2043.29 & 2323.43 & 254.57 & 266.50 & 127.27 & 186.82 \\
\hline 4 SAO TON & 884.84 & 1048.34 & 4818.55 & 1586.99 & 139.47 & 767.07 & 153.66 & 315,13 \\
\hline 4 XAMBRE & 704.94 & 90.12 & 1543.63 & 1373.68 & 27.72 & 402.78 & 252.23 & 537.05 \\
\hline 5 CIANORIE & 953.93 & 2338.29 & 8882.33 & 2683.23 & 208.53 & 2650.93 & 412.96 & 4556.34 \\
\hline 5 DOURADINA & 1866.51 & 63.33 & 2203.25 & 1286.46 & 152.03 & 777.13 & 123.60 & 739.11 \\
\hline 5 ICARAIMA & 2280.01 & 203.70 & 3939.27 & 3231.55 & 66.44 & 754.44 & 156.97 & 774.45 \\
\hline 5 IIUNA DO SU & 183.04 & 73.92 & 2443.46 & 923.21 & 69.30 & 280.82 & 44.35 & 243.35 \\
\hline 5 MARIA HEIENA & 773.14 & 87.23 & 1559.28 & 1985.26 & 152.31 & 653.00 & 108.70 & 458.08 \\
\hline 5 MARПIDNA & 520.65 & 376.25 & 2037.61 & 1321.39 & 162.67 & 660.70 & 47.68 & 457.94 \\
\hline 5 PORTO RICO & 1526.67 & 64.28 & 2072.49 & 338.99 & 66.11 & 400.20 & 103.10 & 622.67 \\
\hline 5 SÄO P. DO EARANA & 1479.70 & 29.94 & 2689.54 & 234.97 & 29.10 & 2183.39 & 143.26 & 1037.29 \\
\hline 5 TAPIRA & 1726.97 & 117.78 & 2558.44 & 1923.53 & 36.07 & 911.18 & 296.85 & 98.42 \\
\hline 5 UMARAMA & 5814.68 & 820.67 & 11445.41 & 8418.74 & 265.18 & 4561.16 & 997.38 & 3525.14 \\
\hline 6 ALTO DO PARANÁ & 2776.89 & 161.36 & 3267.25 & 437.77 & 76.61 & 1432.60 & 240.83 & 1486.84 \\
\hline 6 ALTO PI风UIRI & 2429.09 & 721.59 & 19385.94 & 1045.51 & 27.61 & 5032.69 & 316.71 & 2348.93 \\
\hline 6 ARARINA & 429.94 & 536.62 & 6374.10 & 960.62 & 29.80 & 2139.88 & 155.36 & 672.69 \\
\hline 6 CAEEARA & 831.43 & 106.95 & 3193.22 & 783.03 & 43.67 & 745.76 & 72.66 & 351.12 \\
\hline 6 CIDADE GAUCHA & 1379.55 & 680.60 & 1024.16 & 546.65 & 27.72 & 1685.64 & 100.62 & 218.78 \\
\hline 6 OCNSETHETIRO MAIRTN & 114.59 & 146.54 & 193.43 & 75.85 & 1699.47 & 417.45 & 89.61 & 1231.59 \\
\hline 6 CRUZETRO DO CESTE & 1435.00 & 310.94 & 4575.69 & 2807.20 & 109.47 & 3015.64 & 317.75 & 765.01 \\
\hline 6 CRUZEIRO DO SUL & 723.83 & 351.08 & 3616.81 & 695.38 & 15.82 & 1017.45 & 187.56 & 714.83 \\
\hline 6 ELÓRTDA & 269.21 & 69.26 & 517.44 & 229.41 & 11.36 & 278.14 & 36.78 & 75.51 \\
\hline 6 ERANCISCO ALVES & 786.63 & 369.94 & 3944.92 & 851.06 & 16.63 & 2033.06 & 275.71 & 443.03 \\
\hline 6 GIIRACÁ & 999.78 & 123.13 & 4571.41 & 799.88 & 71.59 & 1862.84 & 203.27 & 1111.08 \\
\hline 6 GIAPIRAMA & 625.79 & 209.49 & 1922.13 & 136.68 & 31.86 & 1047.02 & 121.48 & 8129.05 \\
\hline 6 GAPCREMA & 396.29 & 356.17 & 1234.61 & 565.68 & 22.28 & 727.36 & 52.45 & 665.21 \\
\hline 6 QUARACI & 660.91 & 1288.81 & 2484.38 & 536.61 & 37.81 & 979.16 & 135.10 & 1028.49 \\
\hline 6 INAIA & 205.27 & 118.71 & 387.37 & 225.72 & 1.37 & 545.73 & 15.11 & 81.65 \\
\hline 6 IPCRA & 2860.87 & 461.78 & 3848.54 & 832.84 & 123.75 & 2187.51 & 405.68 & 1455.38 \\
\hline 6 ITAGUAJE & 469.47 & 149.25 & 1408.92 & 508.79 & 5.97 & 751.40 & 74.15 & 113.93 \\
\hline 6 IOANLA & 3023.98 & 132.13 & 4762.35 & 1365.15 & 103.83 & 1381.76 & 235.85 & 850.35 \\
\hline 6 IOBATO & 835.68 & 362.26 & 1506.41 & 989.77 & 16.40 & 2471.50 & 76.25 & 29.34 \\
\hline 6 IUPIa & 649.80 & 125.63 & 1464.68 & 282.50 & 19.62 & 1002.48 & 73.84 & 184.73 \\
\hline 6 MARTIUZ & 2353.68 & 169.68 & 9126.89 & 1375.87 & 1.35 & 3283.96 & 126.90 & 95.57 \\
\hline 6 MIRADOR & 877.70 & 86.60 & 1234.26 & 196.37 & 1.25 & 1346.54 & 15.78 & 259.10 \\
\hline 6 MORETRA SAIES & 3731.22 & 380.38 & 5753.17 & 5253.17 & 68.85 & 3024.33 & 318.13 & 9871.51 \\
\hline $6 \mathrm{MNHOZ}$ IE MELO & 930.37 & 348.63 & 2118.17 & 430.40 & 3.77 & 546.69 & 95.90 & 117.37 \\
\hline 6 NOSSA S. DAS GRACAS & 1025.02 & 186.54 & 1557.70 & 532.95 & 18.94 & 1362.34 & 100.77 & 377.18 \\
\hline 6 NONA A. DO TVAI & 113.59 & 6.70 & 279.68 & 87.81 & 1.23 & 411.68 & 22.37 & 162.66 \\
\hline 6 NONA IONDRTNA & 1974.99 & 500.62 & 2202.33 & 1129.82 & 79.47 & 815.46 & 148.89 & 419.77 \\
\hline 6 EARATSO DO NORIE & 449.72 & 529.40 & 1673.51 & 496.29 & 27.87 & 1457.80 & 36.47 & 274.91 \\
\hline 6 PARANACITY & 1176.50 & 471.71 & 4377.39 & 814.73 & 50.65 & 1433.32 & 141.12 & 608.60 \\
\hline 6 PARANAPCEMA & 512.93 & 145.59 & 3510.00 & 268.91 & 19.65 & 1068.54 & 53.65 & 735.93 \\
\hline 6 PARANAVAI & 2089.21 & 636.80 & 4861.68 & 1730.38 & 70.98 & 3368.70 & 507.49 & 1302.65 \\
\hline 6 PI ANALTTINA DO PARANÁ & 943.06 & 58.74 & 1183.21 & 1235.54 & 9.46 & 728.83 & 127.00 & 229.31 \\
\hline 6 QUERÊNCIA DO NCRIE & 4005.26 & 599.74 & 6944.36 & 1074.23 & 237.92 & 4087.97 & 95.24 & 1859.87 \\
\hline 6 RIEEIRÄO DO PINHAL & 1700.09 & 318.84 & 4330.37 & 1496.46 & 175.30 & 1550.91 & 630.71 & 918.65 \\
\hline 6 ROA ÂNDIA & 4234.93 & 3180.82 & 17348.29 & 3965.82 & 86.57 & 5565.35 & 962.75 & 4511.90 \\
\hline 6 RONDON & 2416.26 & 931.91 & 2747.03 & 1488.54 & 137.93 & 1611.80 & 143.35 & 860.87 \\
\hline 6 SABAUDIA & 1109.46 & 359.04 & 3097.33 & 1029.82 & 35.90 & 1032.84 & 237.08 & 198.66 \\
\hline 6 SANIA C. M. CASTEIO & 2454.65 & 92.05 & 3266.42 & 655.13 & 55.69 & 1078.20 & 208.92 & 379.39 \\
\hline 6 SANIA INES & 424.84 & 146.43 & 1034.39 & 354.94 & 10.43 & 418.80 & 50.38 & 220.69 \\
\hline 6 SANIA I. DO IVAI & 2493.78 & 792.62 & 4382.79 & 1094.16 & 123.19 & 1203.85 & 612.97 & 847.72 \\
\hline 6 SANIO A. DA PIATINA & 3127.03 & 1866.18 & 7366.28 & 1277.16 & 214.54 & 3246.41 & 412.34 & 604.28 \\
\hline 6 SANTO A. DO CAIUA & 597.86 & 90.33 & 1880.86 & 144.68 & 1.79 & 589.60 & 80.33 & 2329.08 \\
\hline 6 SANIO INÁCTO & 1604.42 & 345.77 & 2044.73 & 1013.03 & 25.35 & 1505.02 & 305.05 & 411.43 \\
\hline 6 SAO CARLOS DO IVAI & 837.70 & 427.84 & 3067.91 & 454.55 & 32.55 & 1969.39 & 66.20 & 799.29 \\
\hline 6 SÄO JCЙO DO CATUÁ & 1315.80 & 101.62 & 1102.52 & 474.52 & 10.30 & 673.65 & 127.98 & 173.02 \\
\hline 6 TAMBOARA & 383.81 & 281.05 & 880.29 & 604.12 & 8.87 & 713.51 & 50.99 & 516.38 \\
\hline 6 TAPE JARA & 1855.42 & 1011.49 & 5524.74 & 616.65 & 76.06 & 1876.51 & 261.19 & 1822.91 \\
\hline 6 TERRA RICA & 1194.69 & 109.99 & 3642.48 & 1698.99 & 157.57 & 1675.30 & 129.63 & 898.87 \\
\hline 6 TUNEIRAS DO CESTE & 2030.83 & 472.58 & 3144.13 & 1629.42 & 19.32 & 2030.24 & 28.19 & 2391.06 \\
\hline 6 UNIELCR & 394.61 & 111.71 & 269.96 & 302.01 & 11.22 & 784.97 & 82.63 & 311.93 \\
\hline 7 AMPARE & 314.82 & 259.07 & 2816.57 & 335.69 & 3.93 & 1116.64 & 136.91 & 561.02 \\
\hline 7 BARPACAO & 3.03 & 35.69 & 1126.84 & 252.92 & 11.46 & 510.90 & 108.11 & 220.08 \\
\hline 7 BOA V.DA AEARECIDA & 822.65 & 116.22 & 1722.23 & 577.35 & 21.17 & 682.33 & 101.02 & 262.44 \\
\hline 7 CAIIFĆRNA & 119.55 & 185.37 & 1277.88 & 220.98 & 11.73 & 622.94 & 99.23 & 241.50 \\
\hline 7 CADANEMA & 2081.21 & 485.00 & 4684.08 & 1414.47 & 26.18 & 1909.19 & 523.79 & 571.77 \\
\hline
\end{tabular}


Tabela 3A. Continuação.

\begin{tabular}{|c|c|c|c|c|c|c|c|c|}
\hline \multirow{2}{*}{ MNICÍPIO } & \multicolumn{8}{|c|}{ INDICADORES } \\
\hline & 30 & 31 & 32 & 33 & 34 & 35 & 36 & 37 \\
\hline 7 CAPITÄO L. MARQES & 2040.50 & 379.19 & 3243.58 & 1161.91 & 23.45 & 1792.27 & 305.39 & 442.37 \\
\hline 7 Ć́N AZUL & 310.77 & 665.17 & 7353.36 & 2039.15 & 12.65 & 2469.66 & 796.16 & 679.16 \\
\hline 7 C-APPINZINHO & 2267.96 & 971.86 & 8687.33 & 2695.07 & 15.45 & 3859.76 & 428.24 & 2408.08 \\
\hline 7 CORONET VIVIDA & 1886.40 & 759.59 & 9825.90 & 597.99 & 19.03 & 2681.39 & 374.60 & 882.09 \\
\hline 7 DOIS VIZINHOG & 2324.59 & 345.62 & 5515.29 & 1021.59 & 40.26 & 2796.63 & 861.47 & 1032.25 \\
\hline 7 ENÉIAS MAROUES & 460.38 & 106.58 & 2391.05 & 573.84 & 12.00 & 524.40 & 305.87 & 263.92 \\
\hline 7 FRANCTSOO BEITTRÄO & 611.50 & 458.53 & 5237.02 & 689.37 & 31.69 & 2372.28 & 917.88 & 1188.96 \\
\hline 7 IIAPEJARA D'OESTE & 1170.56 & 414.66 & 6029.61 & 315.80 & 3.47 & 1643.30 & 292.06 & 906.66 \\
\hline 7 TVAIPORÃ & 1753.69 & 467.22 & 5850.61 & 1197.23 & 92.02 & 3470.76 & 196.28 & 1147.67 \\
\hline 7 MAREOARL C. RONDON & 2598.59 & 3728.00 & 25129.52 & 2979.07 & 50.70 & 9309.681 & 1698.14 & 2429.26 \\
\hline 7 MARTó́POLIS & 885.23 & 402.31 & 4066.11 & 739.91 & 27.74 & 1326.49 & 147.99 & 469.22 \\
\hline 7 MARMEI FIRO & 256.53 & 252.50 & 4323.62 & 328.86 & 13.26 & 1411.36 & 234.54 & 429.64 \\
\hline 7 MATEI ÂNDIA & 273.48 & 1614.61 & 9658.77 & 1881.91 & 39.95 & 2646.16 & 579.17 & 1387.00 \\
\hline 7 MEDIANEIRA & 456.46 & 1151.95 & 11745.04 & 942.98 & 14.78 & 4440.11 & 812.06 & 1246.64 \\
\hline 7 MESSAL & 2471.86 & 552.94 & 4694.74 & 1304.07 & 19.25 & 1835.31 & 633.37 & 587.36 \\
\hline 7 NONA P. DO IQADU & 1765.68 & 119.70 & 4782.81 & 580.57 & 20.42 & 1410.25 & 198.26 & 1517.22 \\
\hline 7 NONA SANIA RCSA & 1891.67 & 517.48 & 4446.97 & 1118.98 & 5.65 & 1995.54 & 474.90 & 316.25 \\
\hline 7 PATO ERANCO & 2850.52 & 891.93 & 14311.18 & 1603.01 & 30.93 & 3281.30 & 728.29 & 1544.75 \\
\hline 7 DERA DO CESTE & 485.12 & 309.94 & 6418.23 & 739.02 & 9.89 & 1772.28 & 202.43 & 868.87 \\
\hline 7 PLANALTO & 1447.35 & 399.43 & $3781: 08$ & 811.93 & 12.41 & 1319.82 & 403.88 & 1966.80 \\
\hline 7 ERANOHITA & 166.95 & 258.20 & 6242.84 & 901.70 & 0.32 & 1493.09 & 160.07 & 275.44 \\
\hline 7 REALEZA & 2364.69 & 605.09 & 3752.09 & 740.12 & 24.99 & 2016.71 & 823.79 & 1476.76 \\
\hline 7 RENASCENCA & 364.99 & 288.63 & 7303.69 & 734.08 & 8.14 & 1748.37 & 189.44 & 493.78 \\
\hline 7 SALGADO ETHHO & 138.56 & 26.83 & 1400.20 & 840.27 & 4.66 & 541.28 & 200.57 & 628.88 \\
\hline 7 SALTO DO ITARARE & 222.85 & 42.20 & 611.16 & 184.60 & 9.74 & 275.15 & 13.02 & 160.26 \\
\hline 7 SALTO DO IONIRA & 1122.55 & 117.15 & 2891.00 & 365.35 & 20.43 & 1266.26 & 233.08 & 893.31 \\
\hline 7 SANIA C. DO PAVÃO & 882.68 & 677.92 & 4358.09 & 409.88 & 2.96 & 1215.37 & 16.21 & 152.86 \\
\hline 7 SANIA HEIENA & 5254.56 & 1621.90 & 15672.30 & 2440.40 & 19.60 & 5135.441 & 1068.18 & 2845.67 \\
\hline 7 SANIA I. DO OESTE & 1356.65 & 451.62 & 4403.66 & 362.22 & 18.13 & 1681.51 & 262.13 & 407.54 \\
\hline 7 SANIJANA DO IIAARARÉ & 487.60 & 37.87 & 1820.56 & 225.24 & 36.84 & 1053.41 & 4.79 & 357.37 \\
\hline 7 SANIO A. DO SUDOESIE & 98.31 & 324.55 & 3352.11 & 377.79 & 24.62 & 1309.98 & 407.18 & 3579.20 \\
\hline 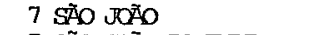 & 1191.69 & 692.30 & 6234.74 & 525.54 & 10.88 & 2146.03 & 299.28 & 1014.23 \\
\hline 7 SÃO JÖ̈O DO IVAI & 161.72 & 1671.85 & 12783.21 & 2191.04 & 95.72 & 3468.24 & 319.94 & 869.52 \\
\hline 7 SÃO JOREE D'OESTE & 788.71 & 357.68 & 1204.75 & 531.62 & 9.16 & 963.65 & 300.12 & 359.87 \\
\hline 7 SĀO J. DA BOA VISIA & 895.05 & 52.95 & 2886.91 & 166.30 & 53.69 & 940.65 & 54.86 & 306.76 \\
\hline 7 TRESS BARRAS & 2216.33 & 147.23 & 3295.82 & 945.65 & 27.20 & 1391.40 & 150.90 & 108.01 \\
\hline 7 VERA CAJZ DO OESIE & 921.51 & 496.19 & 8660.61 & 996.86 & 47.03 & 2391.00 & 226.80 & 498.18 \\
\hline $7 \mathrm{VERE}$ & 1600.37 & 367.48 & 6491.35 & 1277.03 & 4.09 & 1643.45 & 290.61 & 1229.25 \\
\hline 7 VIITRTINO & 1395.68 & 194.18 & 4175.24 & 766.90 & 3.86 & 1328.57 & 283.83 & 367.76 \\
\hline 8 ABATIÁ & 1025.72 & 344.65 & 4468.91 & 486.66 & 57.12 & 1542.00 & 570.55 & 487.50 \\
\hline 8 APUCARANA & 1471.70 & 890.57 & 9629.34 & 1751.50 & 167.45 & 2970.32 & 554.85 & 1954.42 \\
\hline 8 ATALATA & 1136.76 & 869.23 & 2359.01 & 746.78 & 24.13 & 841.89 & 26.65 & 520.84 \\
\hline 8 BARBOSA EERRAZ & 2526.03 & 717.60 & 4786.32 & 2677.20 & 149.48 & 2803.11 & 280.06 & 935.04 \\
\hline 8 CAMBIRA & 1406.84 & 346.58 & 3117.60 & 1352.17 & 84.12 & 1800.48 & 247.34 & 433.59 \\
\hline 8 CARLÓPOTS & 4693.88 & 242.51 & 4848.16 & 207.11 & 468.84 & 1759.90 & 459.08 & 1215.66 \\
\hline 8 COLORADO & 1385.16 & 210.51 & 5025.17 & 1601.96 & 19.19 & 4602.97 & 241.99 & 3716.63 \\
\hline 8 FIGUEIRA & 254.95 & 217.95 & 320.94 & 92.18 & 49.27 & 419.55 & 35.02 & 165.53 \\
\hline 8 IPAITI & 2517.29 & 364.66 & 1481.74 & 576.69 & 89.69 & 4212.25 & 93.56 & 1260.03 \\
\hline 8 JABOII & 1.60 & 24.33 & 573.01 & 142.72 & 15.66 & 216.05 & 13.98 & 116.87 \\
\hline 8 JANDAIA DO SUL & 1395.11 & 386.79 & 2583.68 & 771.25 & 50.82 & 793.19 & 123.43 & 305.27 \\
\hline 8 JAPIRA & 523.06 & 114.04 & 713.60 & 153.53 & 30.97 & 535.00 & 54.16 & 213.98 \\
\hline 8 JARDIM AIEGRE & 1024.92 & 320.92 & 5175.86 & 973.69 & 125.55 & 1950.51 & 209.24 & 827.47 \\
\hline 8 ILNARDELLI & 782.64 & 116.89 & 2098.11 & 883.81 & 97.59 & 1005.77 & 181.30 & 69.89 \\
\hline 8 MANDPGART & 784.47 & 1163.57 & 2714.74 & 1561.04 & 69.81 & 1752.99 & 285.75 & 668.68 \\
\hline 8 MIRASEIVA & 1287.64 & 1128.92 & 4359.95 & 1020.74 & 107.28 & 2578.58 & 215.64 & 3187.86 \\
\hline 8 NOVA ESEERANCA & 615.26 & 516.34 & 3538.52 & 1950.61 & 39.42 & 2299.25 & 404.79 & 2341.43 \\
\hline 8 PINHALAO & 240.44 & 71.75 & 539.23 & 142.58 & 63.28 & 352.97 & 7.06 & 242.71 \\
\hline 8 PRESTDENIE CASTEIO & 3825.99 & 3562.69 & 856.48 & 1159.85 & 44.57 & 361.61 & 162.84 & 1930.17 \\
\hline 8 QUATTOÁ & 192.67 & 2.72 & 109.34 & 91.86 & 6.05 & 185.67 & 109.32 & 34.53 \\
\hline 8 SANIA 色 & 879.82 & 685.54 & 3806.25 & 2084.70 & 22.99 & 1726.94 & 200.48 & 570.05 \\
\hline 8 SIQUEIRA CAMPCS & 623.41 & 32.58 & 1151.98 & 426.62 & 37.20 & 441.46 & 46.95 & 238.01 \\
\hline 8 TAMAZINA & 610.39 & 111.62 & 1415.37 & 930.08 & 118.34 & 954.94 & 124.98 & .177 .01 \\
\hline 9 ALITAMIRA DO EARANÁ & 1751.65 & 409.92 & 532.56 & 471.71 & 5.31 & 397.13 & 34.85 & 1290.03 \\
\hline 9 BORRAZÓEOATS & 1712.00 & 763.48 & 5516.45 & 1015.60 & 54.80 & 1610.49 & 184.34 & 485.81 \\
\hline 9 CAMPINA DA LAGOA & 2694.71 & 1924.34 & 19367.70 & 880.46 & 29.12 & 4681.55 & 265.90 & 3938.03 \\
\hline 9 CANDIDO ABREU & 1768.58 & 160.08 & 2309.74 & 956.87 & 108.26 & 1370.78 & 12.07 & 1546.72 \\
\hline 9 CANIAGALO & 2755.92 & 1115.07 & 2307.66 & 1150.11 & 351.65 & 1615.46 & 75.34 & 423.91 \\
\hline 9 CATANDDNAS & 1751.06 & 1134.97 & 7034.60 & 738.30 & 16.51 & 2643.78 & 119.40 & 1076.19 \\
\hline 9 वRTÚVA & 871.97 & 1519.70 & 1547.84 & 289.74 & 120.29 & 734.84 & 5.66 & 398.06 \\
\hline 9 EAXINAL & 2729.42 & 790.18 & 8640.61 & 1536.21 & 89.44 & 2896.43 & 150.05 & 1947.51 \\
\hline 9 GRANDES RTOS & 3457.95 & 295.86 & 5212.96 & 1430.54 & 940.14 & 2153.51 & 180.33 & 911.09 \\
\hline 9 GARANTACU & 3276.96 & 1820.75 & 8958.84 & 1463.61 & 33.78 & 4100.30 & 231.27 & 821.72 \\
\hline 9 IREIPAMA & 814.63 & 559.22 & 2361.21 & 793.49 & 14.55 & 941.30 & 69.44 & 226.17 \\
\hline 9 JAAQTM TAVORA & 995.46 & 92.33 & 487.32 & 152.60 & 662.89 & 705.30 & 94.20 & 6731.15 \\
\hline 9 IARANUEIRAS DO SUL & 1874.62 & 1768.89 & 7685.49 & 2476.18 & 48.87 & 5524.21 & 642.11 & 712.02 \\
\hline 9 MANOEL RTBAS & 1166.46 & 254.62 & 6969.15 & 496.59 & 6.12 & 2506.58 & 27.59 & 612.75 \\
\hline 9 MARTASNDIA DO SUL & 1022.99 & 856.14 & 13341.51 & 971.68 & 222.74 & 2791.61 & 280.10 & 2185.06 \\
\hline 9 ORTTQUETRA & 3385.41 & 224.02 & 5150.26 & 1072.12 & 98.62 & 2928.25 & 278.31 & 2328.02 \\
\hline 9 DAIMLTAL & 3426.03 & 1381.65 & 2219.41 & 693.72 & 61.26 & 2008.91 & 58.16 & 1744.30 \\
\hline
\end{tabular}


Tabeia 3A. Continuação.

INDICADORES

C MNICÍPIO

$$
30
$$

$$
30
$$$$
31
$$

32

33

34

35

36

9 PITANGA

9 QUEDAS DO IGACU

$\begin{array}{lll}4966.13 & 3204.47 & 10494.32\end{array}$

$\begin{array}{lll}2308.44 & 653.20 & 3398.59 \\ 1612.45 & 21.4 .60 & 2507.21\end{array}$

9 RIO BOM

9 RONCADOR

9 SÃO J. DA SERRA

9 SAPOPEMA

9 TURVO

10 ARAPOIT

10 BALSA NOVA

10 LAPA

10 PAIMEIRA

10 PIRAQUARA

10 PANIA GROSSA

10 RORTO AMAZONAS

11 AIMIRANIE TAMANIARÉ

11 BTTURNA

11 CAMPO DO TENENIE

11 CASIRO

11 CIEVEI ÂNDTA

11 GENERAL CARNEIRO

11 GUARAFUAVA

11 IPTRANGA

11 JAGUARTAIVA

11 MANGUETRTNHA

11 PAIMAS

11 PALLO FREITIAS

11 PIRAf DO SUL

11 QIATRO BARRAS

11 RIO NEGRO

11 SENGÉS

11 TETXXETRA SOARES

11 TIRAGI

11 TIJUCAS DO SUL

11 UNIÃO DA VITORTA

12 ARAUCÁRTA.

12 OONTENDA

12 ORIITBA

13 AGUDOS DO SUL

13 ANIÔNTO OLINTO

13 CAMPO LARGO

13 OCLOMBO

13 CRIZ MACHADO

13 IMBITUVA

13 IRATI

13 IVAI

13 MALIET

13 MANDIRTTUBA

13 PAULO ERONIIN

13 PIÊN

13 PORTO VITIRIA

13 ERULENIÓPOTIS

13 QULTANDINHA

13 REBOUCAS

13 RTO AZUL

13 Sก̃O J. DO TRTINFO

13 SÃO J. DOS PINIAIS

13 STOO MATEUS DO SUL

13 WENCESLAW BRAZ

14 ALRTANÓPOM.IS

14 ANIONINA

14 BOCATÚNA DO SUL

14 CAMPINA G. DO SUL

14 CERRO AZUL.

14 GUARAQUECABA

14 GIARATUBA

14 INÁCTO MARTTIS

14 MATINHAOS

14 MORRETES

14 PARANAGUA

14 PINIÄO

14 RTO BRANCO Do SUL

42.98

2507.21
1287.05

$2889.81 \quad 209.32$

$\begin{array}{lll}6216.07 & 198.32 & 3709.54\end{array}$

$\begin{array}{lll}158.99 & 1196.81 & 6202.50\end{array}$

$\begin{array}{lll}4162.79 & 379.18 & 5766.37\end{array}$

$\begin{array}{lrr}730.43 & 44.12 & 1481.25\end{array}$

$1380.22 \quad 91.57$

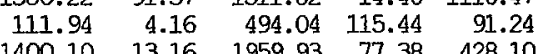

$\begin{array}{rrrrr}1380.22 & 91.57 & 1511.82 & 14.40 & 1110.47 \\ 111.94 & 4.16 & 494.04 & 115.44 & 91.24\end{array}$

$\begin{array}{lll}2497.50 & 119.35 \quad 767.93\end{array}$

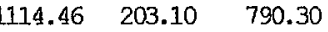

$1102.83 \quad 29.46$

$296.50 \quad 8.78$

$2385.19 \quad 101.91 \quad 811.23$

$\begin{array}{lll}3334.81 & 629.04 & 7590.70\end{array}$

$303.91 \quad 20.35$

$1946.90 \quad 230.17$

$191.15 \quad 33.02$

$1386.49 \quad 187.40$

$\begin{array}{lll}1082.41 & 1102.85 & 7793.44\end{array}$

$804.41 \quad 1449.11 \quad 11862.74$

$202.48 \quad 53.78 \quad 25.72$

$2603.31 \quad 2617.33 \quad 25142.92$

65.66

$129.10 \quad 15.40$

$3165.16 \quad 573.18$

$46.19 \quad 322.40$

$181.71 \quad 119.8$

$\begin{array}{lll}91.31 & 23.16 & 61.11\end{array}$

$\begin{array}{llr}511.30 & 71.73 & 1026.59\end{array}$

$\begin{array}{lll}5235.67 & 21.31 \quad 188.95\end{array}$

$7551.51 \quad 2906.51 \quad 31556.64$

$271.47 \quad 8.42$

$182.08 \quad 15.60$

$4991.20 \quad 710.95$

$490.82 \quad 54.09$

$\begin{array}{rrr}573.52 & 38.06 & 842.85\end{array}$

$\begin{array}{lll}4936.27 & 2016.74 & 47571.69\end{array}$

$\begin{array}{lll}766.80 & 177.06 & 7373.57\end{array}$

$\begin{array}{lll}3974.84 & 2162.05 & 4389.58\end{array}$

$\begin{array}{lll}1989.55 & 1078.96 \quad 15358.44\end{array}$

$\begin{array}{lll}3943.23 & 345.11 & 5329.50\end{array}$

$\begin{array}{lll}401.15 & 146.28 & 1577.81\end{array}$

$\begin{array}{lrl}748.30 & 1048.47 & 6253.27\end{array}$

$\begin{array}{rrr}75.45 & 153.79 & 95.27\end{array}$

$\begin{array}{lll}290.05 & 144.45 & 1277.01\end{array}$

$2578.90 \quad 545.82 \quad 1965.04$

$\begin{array}{lll}735.97 & 1140.45 & 10809.73\end{array}$

$\begin{array}{lll}1946.04 & 1730.35 \quad 17663.41\end{array}$

$\begin{array}{lll}643.77 & 919.78 & 211.22\end{array}$

$\begin{array}{lll}1680.89 & 113.30 \quad 202.99\end{array}$

$\begin{array}{lll}997.97 & 36.11 & 3135.68\end{array}$

$\begin{array}{lll}778.55 & 33.74 & 969.34\end{array}$

$214.77 \quad 57.15 \quad 335.33$

$\begin{array}{lll}87.60 & 17.18 & 838.99\end{array}$

$\begin{array}{lll}228.01 & 11.78 \quad 1069.86\end{array}$

$\begin{array}{lll}817.09 & 35.05 & 414.00\end{array}$

$\begin{array}{lll}290.54 & 204.06 & 99.07\end{array}$

$\begin{array}{llr}655.50 & 105.01 & 666.47\end{array}$

$1063.56 \quad 509.73 \quad 5396.53$

$\begin{array}{lll}120.89 & 184.96 & 2897.06\end{array}$

$\begin{array}{lrr}252.88 & 84.99 & 1910.00\end{array}$

$611.07 \quad 140.40 \quad 1141.42$

$\begin{array}{lll}197.48 & 131.17 & 1117.61\end{array}$

$\begin{array}{rrr}331.33 & 153.83 & 3158.25 \\ 68.39 & 31.86 & 2483.80\end{array}$

$\begin{array}{rrr}68.39 & 31.86 & 2483.80\end{array}$

$\begin{array}{rrr}253.40 & 94.47 & 195.24 \\ 1273.67 & 449.11 & 3089.59\end{array}$

$\begin{array}{lll}298.06 & 25.87 & 1550.07\end{array}$

$\begin{array}{lll}85.15 & 102.94 & 2795.85\end{array}$

$\begin{array}{lll}165.45 & 78.09 & 2083.95\end{array}$

$\begin{array}{lll}448.97 & 45.47 & 1541.29\end{array}$

$\begin{array}{lll}565.27 & 285.58 & 195.18\end{array}$

$712.22 \quad 498.76 \quad 4808.43$

$\begin{array}{lll}451.45 & 82.34 \quad 1852.23\end{array}$

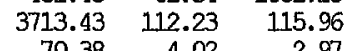

$\begin{array}{lll}70.38 & 4.02 & 2.97\end{array}$

$\begin{array}{rrr}1454.32 & 46.92 & 46.11 \\ 540.41 & 10.65 & 23.26\end{array}$

$\begin{array}{rrr}540.41 & 10.65 & 23.26 \\ 12394.50 & 176.61 & 182.39\end{array}$

$\begin{array}{lll}506.09 & 157.00 \quad 21.54\end{array}$

$\begin{array}{lrr}303.38 & 21.17 & 12.87\end{array}$

$1023.05 \quad 119.76 \quad 151.44$

$\begin{array}{rrr}42.03 & 8.40 & 10.00\end{array}$

$\begin{array}{rrr}335.12 & 613.25 & 157.62\end{array}$

$1006.67 \quad 650.97 \quad 17583.05$

$\begin{array}{rrr}240.15 & 107.79 \quad 351.77\end{array}$

$\begin{array}{rr}1255.19 & 4.05 \\ 4022.87 & 237.01\end{array}$

$\begin{array}{lr}313.90 & 21.59\end{array}$

$525.07 \quad 144.58$

$601.57 \quad 82.91$

$1815.77 \quad 141.46$

$210.32 \quad 13.51$

$617.72 \quad 369.08$

$59.05 \quad 39.78$

$236.48 \quad 15.32$

$336.40 \quad 174.40$

$723.37 \quad 37.12$

4456.501080 .42

$60.67 \quad 1.35$

$231.47 \quad 11.42$

$507.34 \quad 389.88$

$167.12 \quad 64.48$

$186.19 \quad 51.86$

$124.76 \quad 1.92$

$158.67 \quad 14.93$

$350.40 \quad 179.42$

$183.17 \quad 605.15$

$430.78 \quad 176.23$

$673.41 \quad 144.06$

$310.34 \quad 67.32$

$225.48 \quad 36.25$

$163.60 \quad 38.88$

$156.44 \quad 224.03$

$147.34 \quad 14.84$

$231.96 \quad 5.05$

$\begin{array}{ll}79.01 & 2.70\end{array}$

$777.49 \quad 95.19$

$197.56 \quad 92.40$

$135.18 \quad 23.74$

$355.93 \quad 11.60$

$402.01 \quad 5.19$

$490.89 \quad 543.18$

$530.18 \quad 536.71$

$389.80 \quad 176.06$

$145.19 \quad 55.89$

$67.76 \quad 62.21$

$179.47 \quad 74.11$

$80.67 \quad 59.09$

$367.17 \quad 357.62$

$440.64 \quad 33.26$

$107.68 \quad 17.46$

$214.80 \quad 37.71$

$\begin{array}{rr}25.57 & 0.89\end{array}$

$147.79 \quad 625.53$

$114.78 \quad 83.67$

$1187.10 \quad 181.06$

$258.02 \quad 159.37$

$340.60 \quad 19.59$

$\begin{array}{rrr}2385.19 & 101.91 & 811.23 \\ 496.31 & 8.69 & 265.99\end{array}$

$\begin{array}{lll}842.85 & 13.35 & 260.17\end{array}$

$\begin{array}{lll}3361.64 & 436.37 \quad 2134.52\end{array}$

$\begin{array}{lll}364.04 & 38.84 & 70.89\end{array}$

$\begin{array}{lll}4696.61 & 610.54 \quad 5017.91\end{array}$

$5129.13 \quad 538.49 \quad 2746.75$

$\begin{array}{llll}501.94 & 438.72 & 154.41\end{array}$

$8834.77 \quad 766.94 \quad 5814.90$

$\begin{array}{lll}476.14 & 51.30 & 639.95\end{array}$

$\begin{array}{lll}674.26 & 59.59 & 116.08\end{array}$

$\begin{array}{llll}553.00 & 75.06 & 62.38\end{array}$

$\begin{array}{llll}656.60 & 41.46 \quad 632.84\end{array}$

696.22 1569.1513742 .30

$\begin{array}{lll}48.02 & 162.59 & 1315.98\end{array}$

$\begin{array}{lll}702.15 & 303.12 & 441.80\end{array}$

$\begin{array}{lll}398.54 & 199.15 & 1992.56\end{array}$

$\begin{array}{llll}2334.06 & 66.10 & 786.59\end{array}$

$\begin{array}{lll}1324.27 & 97.85 & 590.93\end{array}$

$\begin{array}{llr}5756.72 & 210.18 \quad 1600.86\end{array}$

$\begin{array}{lll}3291.15 & 236.23 & 857.11\end{array}$

$\begin{array}{lll}782.15 & 69.07 \quad 352.14\end{array}$

$2236.65 \quad 206.35 \quad 843.44$

$226.15 \quad 59.00 \quad 52.07$

$\begin{array}{lll}96.63 & 40.09 & 142.67\end{array}$

$\begin{array}{lll}1557.41 & 36.18 & 111.05\end{array}$

$\begin{array}{lll}3658.51 & 116.25 & 1759.24\end{array}$

$\begin{array}{llll}8131.73 & 338.45 \quad 6909.22\end{array}$

$\begin{array}{lll}323.13 & 26.57 & 141.17\end{array}$

$\begin{array}{lll}537.66 & 73.66 & 137.37\end{array}$

$\begin{array}{lll}3242.26 & 248.73 \quad 263.22\end{array}$

$\begin{array}{lll}1208.25 & 98.54 & 88.02\end{array}$

$\begin{array}{lll}1155.53 & 76.69 & 537.58\end{array}$

$\begin{array}{rrr}286.90 & 195.56 \quad 22.48\end{array}$

$\begin{array}{lll}657.97 & 14.74 & 970.38\end{array}$

$\begin{array}{lll}1204.56 & 218.91 & 245.73\end{array}$

$\begin{array}{lll}1555.58 & 74.80 & 350.93\end{array}$

$\begin{array}{lll}1200.70 & 87.20 & 481.57\end{array}$

$2490.51 \quad 101.83 \quad 912.42$

$\begin{array}{lll}1730.40 & 176.76 & 904.53\end{array}$

$\begin{array}{lll}680.93 & 73.76 \quad 441.78\end{array}$

$\begin{array}{lll}873.19 & 19.35 & 499.01\end{array}$

$\begin{array}{lll}1046.07 & 177.81 \quad 625.01\end{array}$

$\begin{array}{lll}685.83 & 51.48 & 96.65\end{array}$

$\begin{array}{lll}383.28 & 49.27 & 24.71\end{array}$

$\begin{array}{lll}171.72 & 68.63 & 52.44\end{array}$

$\begin{array}{lll}1207.79 & 24.47 \quad 533.65\end{array}$

$1181.41 .135 .49 \quad 621.69$

$\begin{array}{lll}907.12 & 45.86 & 144.96\end{array}$

$\begin{array}{lll}780.70 & 62.17 & 253.40\end{array}$

$403.87 \quad 8.57 \quad 75.75$

$\begin{array}{lll}2968.24 & 534.68 \quad 396.43\end{array}$

$\begin{array}{lll}1981.25 & 131.00 \quad 1342.59\end{array}$

$\begin{array}{lll}1025.02 & 79.77 & 409.81\end{array}$

$\begin{array}{rrr}800.86 & 28.19 \quad 47.26\end{array}$

$\begin{array}{lll}215.83 & 16.15 & 483.34\end{array}$

$432.83 \quad 7.70 \quad 73.11$

$\begin{array}{lll}260.47 & 130.73 & 81.73\end{array}$

$\begin{array}{llll}1251.76 & 30.27 & 134.54\end{array}$

$\begin{array}{lll}406.98 & 30.25 & 176.58\end{array}$

$\begin{array}{lll}234.26 & 14.83 \quad 36.08\end{array}$

$\begin{array}{rrr}1131.25 & 6.14 & 487.68\end{array}$

$\begin{array}{lll}25.40 & 11.64 \quad 32.87\end{array}$

$\begin{array}{lll}25.68 & 47.32 & 246.81\end{array}$

$\begin{array}{lll}230.31 & 79.64 & 156.74\end{array}$

$\begin{array}{lll}4860.27 & 74.95 & 785.52\end{array}$

$\begin{array}{lll}566.60 & 13.99 & 574.08\end{array}$

$\begin{array}{lll}6127.59 & 39.55 & 236.71\end{array}$

Nota: 4-Frangas e frangos; 5-Outras aves compradas; 7-Terras próprias); 8-culturas permanentes; 9-Matas plantadas; 10-Veículos e outros meios de transporte; 11-Animais (reproduçăo, criação e trabalho); 12-Máquinas e instrumentos agrários; 13- Instalaçóes e outras benfétorias; 14-Salários 


\title{
APÊNDICE 4
}

\author{
Resultados das regressões sobre as \\ produtividades do trabalho e da terra, \\ por conglomerado e Estado do Paraná, \\ 1985 .
}


Tabela 4A. Resultados das regressões sobre a produtividade do trabalho, por conglomerado e Estado do Paraná, 1985.

\begin{tabular}{|c|c|c|c|c|c|c|c|c|c|c|c|}
\hline \multirow[b]{2}{*}{ C/EST. } & \multirow[b]{2}{*}{$\mathbf{N}$} & \multirow[b]{2}{*}{$\mathbf{R}^{2}$} & \multirow[b]{2}{*}{ Teste F } & \multicolumn{8}{|c|}{ Coeficientes estimados das variáveis independentes e respectivo teste t } \\
\hline & & & & Intercep & BEEH & MEEH & CPEH & REEH & IAEH & AEEH & QT \\
\hline Est. & 305 & 0,590 & $61,124^{*}$ & $\begin{array}{l}-0,170 \\
-1,098\end{array}$ & $\begin{array}{l}0,084 \\
2,035^{b}\end{array}$ & $\begin{array}{l}0,096 \\
1,879^{c}\end{array}$ & $\begin{array}{l}0,032 \\
1,979^{\mathrm{b}}\end{array}$ & $\begin{array}{l}-0,132 \\
-3,101^{\prime}\end{array}$ & $\begin{array}{l}0,090 \\
2,229^{\mathrm{b}}\end{array}$ & $\begin{array}{l}0,386 \\
5,878^{2}\end{array}$ & $\begin{array}{r}0,451 \\
10,134^{\mathrm{a}}\end{array}$ \\
\hline $\mathrm{C} 01$ & 37 & 0,649 & $7,669^{a}$ & $\begin{array}{l}-0,177 \\
-0,259\end{array}$ & $\begin{array}{l}0,033 \\
0,326\end{array}$ & $\begin{array}{l}-0,171 \\
-1,145\end{array}$ & $\begin{array}{l}-0,023 \\
-0,540\end{array}$ & $\begin{array}{l}-0,164 \\
-1,402\end{array}$ & $\begin{array}{l}0,209 \\
1,389\end{array}$ & $\begin{array}{l}0,831 \\
3,601^{2}\end{array}$ & $\begin{array}{l}0,485 \\
2,615^{\text {\& }}\end{array}$ \\
\hline $\mathrm{C02}$ & 20 & 0,928 & $21,984^{2}$ & $\begin{array}{l}-0,600 \\
-0,783\end{array}$ & $\begin{array}{l}-0,164 \\
-1,236\end{array}$ & $\begin{array}{l}0,372 \\
1,943^{c}\end{array}$ & $\begin{array}{l}-0,011 \\
-0,398\end{array}$ & $\begin{array}{l}-0,141 \\
-1,316\end{array}$ & $\begin{array}{l}0,358 \\
2,364^{b}\end{array}$ & $\begin{array}{l}0,097 \\
0,285\end{array}$ & $\begin{array}{l}0,555 \\
2,646^{b}\end{array}$ \\
\hline $\mathrm{C03}$ & 26 & 0,585 & $3,618^{\bullet}$ & $\begin{array}{l}1,061 \\
0,920\end{array}$ & $\begin{array}{l}0,231 \\
1,710^{\circ}\end{array}$ & $\begin{array}{l}-0,061 \\
-0,234\end{array}$ & $\begin{array}{l}0,106 \\
1,142\end{array}$ & $\begin{array}{l}-0,428 \\
-2,281^{b}\end{array}$ & $\begin{array}{l}0,297 \\
1,206\end{array}$ & $\begin{array}{l}0,461 \\
1,5355^{d}\end{array}$ & $\begin{array}{l}0,132 \\
0,530\end{array}$ \\
\hline $\mathrm{C04}$ & 10 & 0,887 & 2,241 & $\begin{array}{l}1,781 \\
1,317\end{array}$ & $\begin{array}{l}-0,884 \\
-3,221^{\mathrm{c}}\end{array}$ & $\begin{array}{l}0,446 \\
1,674\end{array}$ & $\begin{array}{l}0,418 \\
3,812^{c}\end{array}$ & $\begin{array}{l}0,572 d \\
2,653\end{array}$ & $\begin{array}{l}0,033 \\
0,093\end{array}$ & $\begin{array}{l}-0,272 \\
-1,257\end{array}$ & $\begin{array}{l}-0,179 \\
-0,437\end{array}$ \\
\hline $\cos$ & 10 & 0,938 & 4,317 & $\begin{array}{l}-2,357 \\
-1,207\end{array}$ & $\begin{array}{l}0,297 \\
1,692\end{array}$ & $\begin{array}{l}-0,019 \\
-0,063\end{array}$ & $\begin{array}{l}-0,214 \\
-1,293\end{array}$ & $\begin{array}{l}-0,176 \\
-1,079\end{array}$ & $\begin{array}{l}0,406 \\
1,513\end{array}$ & $\begin{array}{l}0,587 \\
1,646\end{array}$ & $\begin{array}{l}1,392 \\
2,087\end{array}$ \\
\hline $\mathrm{C} 06$ & 50 & 0,503 & $6,072^{2}$ & $\begin{array}{l}-2,097 \\
-2,644^{a}\end{array}$ & $\begin{array}{l}-0,036 \\
-0,402\end{array}$ & $\begin{array}{l}0,129 \\
0,625\end{array}$ & $\begin{array}{l}0,059 \\
1,297\end{array}$ & $\begin{array}{l}-0,018 \\
-0,109\end{array}$ & $\begin{array}{l}0,025 \\
0,339\end{array}$ & $\begin{array}{l}0,625 \\
2,100^{b}\end{array}$ & $\begin{array}{l}0,867 \\
3,218^{\mathrm{a}}\end{array}$ \\
\hline $\mathrm{CO}$ & 44 & 0,797 & $20,204^{n}$ & $\begin{array}{l}1,144 \\
3,365^{n}\end{array}$ & $\begin{array}{l}-0,019 \\
-0,172\end{array}$ & $\begin{array}{l}0,427 \\
3,540^{2}\end{array}$ & $\begin{array}{r}0,055 \\
1,654^{d}\end{array}$ & $\begin{array}{l}0,215 \\
1,174\end{array}$ & $\begin{array}{l}0,100 \\
1,605^{d}\end{array}$ & $\begin{array}{l}-0,343 \\
-1,417\end{array}$ & $\begin{array}{l}-0,064 \\
-0,476\end{array}$ \\
\hline $\mathrm{C} 08$ & 23 & 0,562 & $2,751^{b}$ & $\begin{array}{l}2,496 \\
1,152\end{array}$ & $\begin{array}{l}0,140 \\
0,555\end{array}$ & $\begin{array}{l}0,635 \\
1,807^{\circ}\end{array}$ & $\begin{array}{l}0,090 \\
0,645\end{array}$ & $\begin{array}{l}0,256 \\
1,408\end{array}$ & $\begin{array}{l}0,128 \\
0,570\end{array}$ & $\begin{array}{l}-0,409 \\
-0,681\end{array}$ & $\begin{array}{l}-0,687 \\
-1,065\end{array}$ \\
\hline C09 & 25 & 0,737 & $6,800^{\circ}$ & $\begin{array}{l}-0,839 \\
-1,053\end{array}$ & $\begin{array}{l}-0,085 \\
-1,159\end{array}$ & $\begin{array}{l}0,340 \\
2,997^{1}\end{array}$ & $\begin{array}{l}0,025 \\
1,069\end{array}$ & $\begin{array}{l}0,256 \\
1,894^{\mathrm{c}}\end{array}$ & $\begin{array}{l}-0,120 \\
-1,210\end{array}$ & $\begin{array}{l}0,322 \\
1,273\end{array}$ & $\begin{array}{l}0,286 \\
1,386\end{array}$ \\
\hline $\mathrm{C} 10$ & - & - & - & - & - & - & - & - & - & - & - \\
\hline C11 & 19 & 0,753 & $4,798^{b}$ & $\begin{array}{l}-0,748 \\
-0,991\end{array}$ & $\begin{array}{l}0,360 \\
1,105\end{array}$ & $\begin{array}{l}-0,118 \\
-0,346\end{array}$ & $\begin{array}{l}-0,166 \\
-1,306\end{array}$ & $\begin{array}{l}-0,471 \\
-1,256\end{array}$ & $\begin{array}{l}0,189 \\
0,680\end{array}$ & $\begin{array}{l}1,262 \\
3,432^{*}\end{array}$ & $\begin{array}{l}-0,071 \\
-0,224\end{array}$ \\
\hline $\mathrm{Cl2}$ & - & - & - & - & - & - & * & - & - & - & - \\
\hline C13 & 20 & 0,695 & $3,917^{b}$ & $\begin{array}{l}0,633 \\
1,321\end{array}$ & $\begin{array}{l}0,260 \\
1,741^{d}\end{array}$ & $\begin{array}{l}0,141 \\
0,663\end{array}$ & $\begin{array}{l}-0,026 \\
-0,580\end{array}$ & $\begin{array}{l}0,172 \\
0,950\end{array}$ & $\begin{array}{l}0,176 \\
1,574^{d}\end{array}$ & $\begin{array}{l}0,016 \\
0,061\end{array}$ & $\begin{array}{l}-0,148 \\
-0,677\end{array}$ \\
\hline C14 & 14 & 0,919 & $9,713^{n}$ & $\begin{array}{l}-0,844 \\
-1,184\end{array}$ & $\begin{array}{l}-0,588 \\
-2,552^{b}\end{array}$ & $\begin{array}{l}0,428 \\
1,360\end{array}$ & $\begin{array}{l}0,564 \\
5,792^{*}\end{array}$ & $\begin{array}{l}-0,345 \\
-1,555\end{array}$ & $\begin{array}{l}0,332 \\
1,949^{\circ}\end{array}$ & $\begin{array}{l}0,155 \\
0,690\end{array}$ & $\begin{array}{l}0,936 \\
3,919^{\prime}\end{array}$ \\
\hline
\end{tabular}

Fonte: Dados da pesquisa

$\mathrm{a}=$ significativo a $1 \% ;{ }^{\mathrm{b}}=$ significativo a $5 \% ;^{c}=$ significativo a $10 \% ; \mathrm{e}^{\mathrm{d}}=$ significativo a $15 \%$. 
Tabela 4B. Resultados das regressões sobre a produtividade da terra, por conglomerado e Estado do Paraná, 1985.

\begin{tabular}{|c|c|c|c|c|c|c|c|c|c|c|c|}
\hline \multirow[b]{2}{*}{ C/EST. } & \multirow[b]{2}{*}{$\mathbf{N}$} & \multirow[b]{2}{*}{$\mathbf{R}^{2}$} & \multirow[b]{2}{*}{ Teste F } & \multicolumn{8}{|c|}{ Coeficientes estimados das variáveis independentes e respectivo teste $t$} \\
\hline & & & & Intercep & BEAE & MEAE & CPAE & REAE & IAAE & EHAE & QT \\
\hline Est. & 305 & 0,857 & $253,450^{\prime}$ & $\begin{array}{l}-0,170 \\
-1,098\end{array}$ & $\begin{array}{l}0,084 \\
2,035^{b}\end{array}$ & $\begin{array}{l}0,096 \\
1,879^{\mathrm{c}}\end{array}$ & $\begin{array}{l}0,032 \\
1,979^{\mathrm{b}}\end{array}$ & $\begin{array}{l}-0,132 \\
-3,101\end{array}$ & $\begin{array}{l}0,090 \\
2,229^{\mathrm{b}}\end{array}$ & $\begin{array}{l}0,443 \\
9,800^{\wedge}\end{array}$ & $\begin{array}{c}0,451 \\
10,134^{\mathrm{a}}\end{array}$ \\
\hline $\mathrm{Co1}$ & 37 & 0,916 & $44,888^{2}$ & $\begin{array}{l}-0,177 \\
-0,259\end{array}$ & $\begin{array}{l}0,033 \\
0,326\end{array}$ & $\begin{array}{l}-0,171 \\
-1,145\end{array}$ & $\begin{array}{l}-0,023 \\
-0,540\end{array}$ & $\begin{array}{l}-0,164 \\
-1,402\end{array}$ & $\begin{array}{l}0,209 \\
1,389\end{array}$ & $\begin{array}{l}0,285 \\
1,806^{\mathfrak{c}}\end{array}$ & $\begin{array}{l}0,485 \\
2,615^{*}\end{array}$ \\
\hline $\mathrm{CO2}$ & 20 & 0,981 & $87,281^{\circ}$ & $\begin{array}{l}-0,600 \\
-0,783\end{array}$ & $\begin{array}{l}-0,164 \\
-1,236\end{array}$ & $\begin{array}{l}0,372 \\
1,943^{\circ}\end{array}$ & $\begin{array}{l}-0,011 \\
-0,398\end{array}$ & $\begin{array}{l}-0,141 \\
-1,316\end{array}$ & $\begin{array}{l}0,358 \\
2,364^{b}\end{array}$ & $\begin{array}{l}0,489 \\
2,812^{b}\end{array}$ & $\begin{array}{l}0,555 \\
2,646^{b}\end{array}$ \\
\hline $\mathrm{C03}$ & 26 & 0,867 & $16,723^{2}$ & $\begin{array}{l}1,061 \\
0,920\end{array}$ & $\begin{array}{l}0,231 \\
1,710^{\mathrm{c}}\end{array}$ & $\begin{array}{l}-0,061 \\
-0,234\end{array}$ & $\begin{array}{l}0,106 \\
1,142\end{array}$ & $\begin{array}{l}-0,428 \\
-2,281^{b}\end{array}$ & $\begin{array}{l}0,297 \\
1,206\end{array}$ & $\begin{array}{l}0,393 \\
1,816^{c}\end{array}$ & $\begin{array}{l}0,132 \\
0,530\end{array}$ \\
\hline $\mathrm{C04}$ & 10 & 0,995 & $54,398^{\circ}$ & $\begin{array}{l}1,781 \\
1,317\end{array}$ & $\begin{array}{l}-0,884 \\
-3,221^{c}\end{array}$ & $\begin{array}{l}0,446 \\
1,674\end{array}$ & $\begin{array}{l}0,418 \\
3,812^{\mathrm{c}}\end{array}$ & $\begin{array}{l}0,572 \\
2,653^{\mathrm{d}}\end{array}$ & $\begin{array}{l}0,033 \\
0,093\end{array}$ & $\begin{array}{l}0,687 \\
2,180\end{array}$ & $\begin{array}{r}-0,179 \\
-0,437\end{array}$ \\
\hline $\cos$ & 10 & 0,997 & $82,961^{*}$ & $\begin{array}{l}-2,359 \\
-1,207\end{array}$ & $\begin{array}{l}0,297 \\
1,692\end{array}$ & $\begin{array}{l}-0,019 \\
-0,063\end{array}$ & $\begin{array}{l}-0,214 \\
-1,293\end{array}$ & $\begin{array}{l}-0,176 \\
-1,079\end{array}$ & $\begin{array}{l}0,406 \\
1,513\end{array}$ & $\begin{array}{l}0,120 \\
0,487\end{array}$ & $\begin{array}{l}1,392 \\
2,087\end{array}$ \\
\hline $\mathrm{CO6}$ & 50 & 0,877 & $42,705^{a}$ & $\begin{array}{l}-2,099 \\
-2,644^{\mathrm{a}}\end{array}$ & $\begin{array}{l}-0,036 \\
-0,402\end{array}$ & $\begin{array}{l}0,129 \\
0,625\end{array}$ & $\begin{array}{l}0,059 \\
1,297\end{array}$ & $\begin{array}{l}-0,018 \\
-0,109\end{array}$ & $\begin{array}{l}0,025 \\
0,339\end{array}$ & $\begin{array}{l}0,216 \\
1,473^{d}\end{array}$ & $\begin{array}{l}0,867 \\
3,218^{a}\end{array}$ \\
\hline $\mathrm{C} 07$ & 44 & 0,945 & $88,226^{a}$ & $\begin{array}{l}1,144 \\
3,365^{\star}\end{array}$ & $\begin{array}{l}-0,019 \\
-0,172\end{array}$ & $\begin{array}{l}0,427 \\
3,540^{\prime \prime}\end{array}$ & $\begin{array}{l}0,055 \\
1,654^{d}\end{array}$ & $\begin{array}{l}0,215 \\
1,174\end{array}$ & $\begin{array}{l}0,100 \\
1,605^{d}\end{array}$ & $\begin{array}{l}0,545 \\
6,803^{\wedge}\end{array}$ & $\begin{array}{l}-0,064 \\
-0,476\end{array}$ \\
\hline $\mathrm{C} 08$ & 23 & 0,863 & $13,440^{\mathrm{a}}$ & $\begin{array}{l}2,496 \\
1,152\end{array}$ & $\begin{array}{l}0,140 \\
0,555\end{array}$ & $\begin{array}{l}0,635 \\
1,807^{c}\end{array}$ & $\begin{array}{l}0,090 \\
0,645\end{array}$ & $\begin{array}{l}0,256 \\
1,408\end{array}$ & $\begin{array}{l}0,128 \\
0,570\end{array}$ & $\begin{array}{l}0,159 \\
0,517\end{array}$ & $\begin{array}{l}-0,687 \\
-1,065\end{array}$ \\
\hline $\mathrm{COS}$ & 25 & 0,963 & $63,010^{*}$ & $\begin{array}{l}-0,839 \\
-1,053\end{array}$ & $\begin{array}{l}-0,085 \\
-1,159\end{array}$ & $\begin{array}{l}0,340 \\
2,997^{\mathrm{a}}\end{array}$ & $\begin{array}{l}0,025 \\
1,069\end{array}$ & $\begin{array}{l}0,256 \\
1,894^{c}\end{array}$ & $\begin{array}{l}-0,120 \\
-1,210\end{array}$ & $\begin{array}{l}0,261 \\
1,535^{d}\end{array}$ & $\begin{array}{l}0,286 \\
1,386\end{array}$ \\
\hline $\mathrm{Cl} 0$ & - & - & - & - & - & - & - & - & - & - & - \\
\hline $\mathrm{Cl1}$ & 19 & 0,886 & $12,224^{\prime \prime}$ & $\begin{array}{l}-0,748 \\
-0,991\end{array}$ & $\begin{array}{l}0,360 \\
1,105\end{array}$ & $\begin{array}{l}-0,118 \\
-0,346\end{array}$ & $\begin{array}{r}-0,166 \\
-1,306\end{array}$ & $\begin{array}{l}-0,471 \\
-1,256\end{array}$ & $\begin{array}{l}0,189 \\
0,680\end{array}$ & $\begin{array}{l}-0,056 \\
-0,179\end{array}$ & $\begin{array}{l}-0,071 \\
-0,224\end{array}$ \\
\hline $\mathrm{Cl} 2$ & - & - & - & - & - & - & - & - & - & - & - \\
\hline $\mathrm{Cl3}$ & 20 & 0,911 & $17,541^{\star}$ & $\begin{array}{l}0,633 \\
1,321\end{array}$ & $\begin{array}{l}0,260 \\
1,741^{d}\end{array}$ & $\begin{array}{l}0,141 \\
0,663\end{array}$ & $\begin{array}{l}-0,026 \\
-0,580\end{array}$ & $\begin{array}{l}0,172 \\
0,950\end{array}$ & $\begin{array}{l}0,176 \\
1,574^{d}\end{array}$ & $\begin{array}{l}0,261 \\
1,468\end{array}$ & $\begin{array}{l}-0,148 \\
-0,677\end{array}$ \\
\hline C14 & 14 & 0,971 & $28,243^{2}$ & $\begin{array}{l}-0,844 \\
-1,184\end{array}$ & $\begin{array}{l}-0,588 \\
-2,552^{b}\end{array}$ & $\begin{array}{l}0,428 \\
1,360\end{array}$ & $\begin{array}{l}0,564 \\
5,792^{\mathrm{a}}\end{array}$ & $\begin{array}{l}-0,345 \\
-1,555\end{array}$ & $\begin{array}{l}0,332 \\
1,949^{c}\end{array}$ & $\begin{array}{l}0,455 \\
1,868^{d}\end{array}$ & $\begin{array}{l}0,936 \\
3,919^{\star}\end{array}$ \\
\hline
\end{tabular}

Fonte: Dados da pesquisa

${ }^{a}=$ significativo a $1 \% ;{ }^{b}=$ significativo a $5 \% ;^{\circ}=$ significativo a $10 \% ; e^{d}=$ significativo a $15 \%$. 
Tabeja 5A. Coefictentes de correlação de Pearson das varḱveis, referentes ao valor agregado, por conglomerado e Estudo do Paraná, 1985

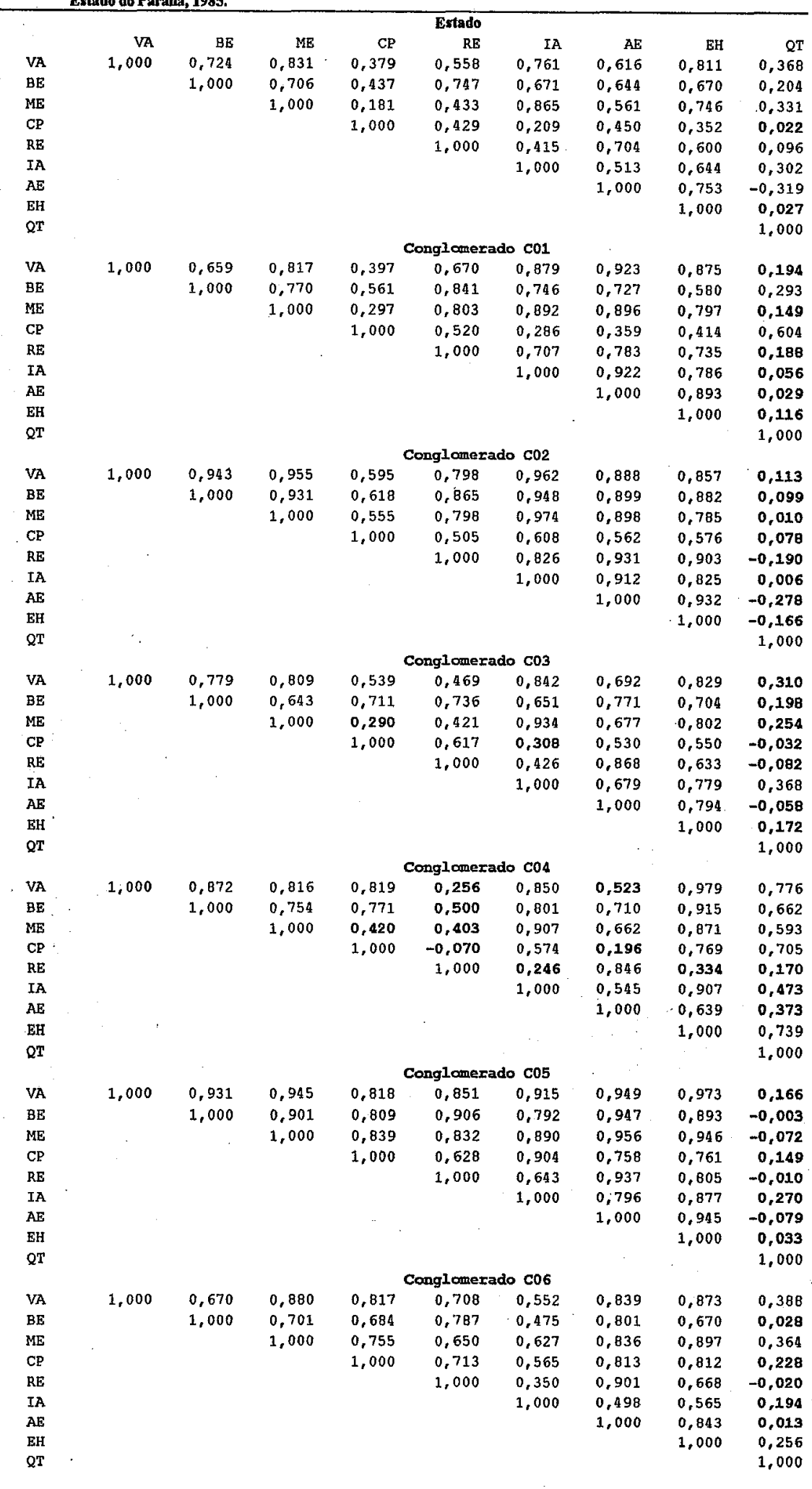


Tabela 5A. Contlnuagão

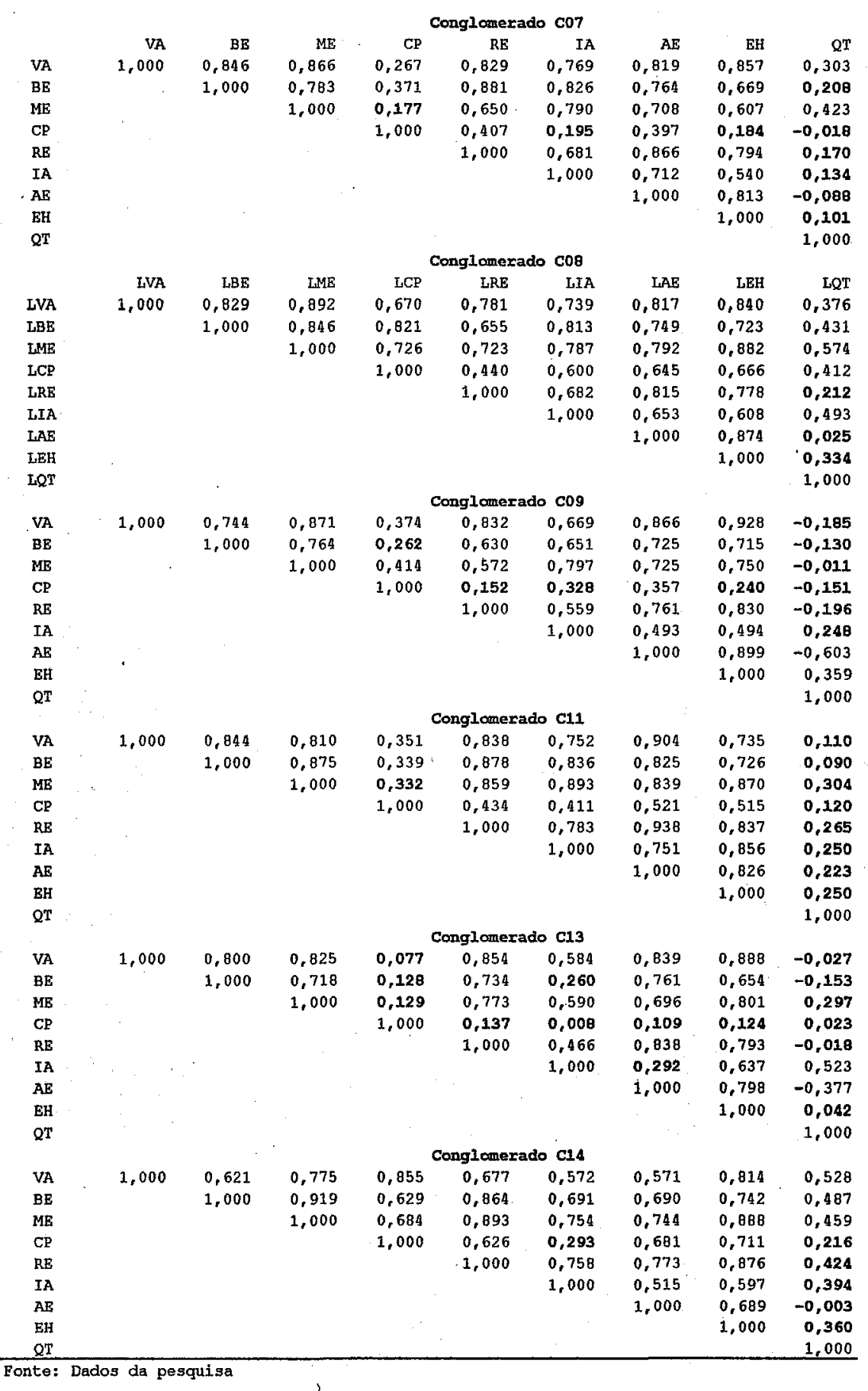

